\title{
Molecular details of membrane deformation by ENTH domains
}

\author{
Dissertation \\ for the award of the degree \\ "Doctor rerum naturalium" (Dr. rer. nat.) \\ Division of Mathematics and Natural Sciences \\ of the Georg-August-Universität Göttingen
}

submitted by

Benjamin Kroppen

from

Korbach, Germany

Göttingen, 2017 



\section{Members of the Thesis Committee:}

Prof. Dr. Michael Meinecke (first reviewer)

Department of Cellular Biochemistry, University Medical Center Göttingen

Prof. Dr. Andreas Janshoff (second reviewer)

Institute of Physical Chemistry, University of Göttingen

Dr. Achim Dickmanns

Department of Molecular Structural Biology, University of Göttingen

\section{Additional Reviewers:}

Prof. Dr. Kai Tittmann

Department of Molecular Enzymology, University of Göttingen

Prof. Dr. Silvio Rizzoli

Department of Neuro- and sensory physiology, University Medical Center Göttingen

Prof. Dr. Markus Bohnsack

Department of Molecular Biology, University Medical Center Göttingen

Date of the oral examination: 22.11.2017 


\section{Affidavit}

I hereby declare that this thesis has been written independently and with no other sources and aids than quoted.

\section{Benjamin Kroppen}

Göttingen, 30 September 2017 
- to my parents -

- to my grandmother - 


\section{List of Publications}

Barbot, Mariam, Daniel C. Jans, Christian Schulz, Niels Denkert, Benjamin Kroppen, Michael Hoppert, Stefan Jakobs, and Michael Meinecke. 2015. "Mic10 Oligomerizes to Bend Mitochondrial Inner Membranes at Cristae Junctions." Cell Metabolism.

Gleisner, Martin, Benjamin Kroppen, Christian Fricke, Nelli Teske, Torben-Tobias Kliesch, Andreas Janshoff, Michael Meinecke, and Claudia Steinem. 2016. "Epsin N-Terminal Homology Domain (ENTH) Activity as a Function of Membrane Tension." Journal of Biological Chemistry, no. 5

Tarasenko, Daryna, Mariam Barbot, Daniel C Jans, Benjamin Kroppen, Boguslawa Sadowski, Gudrun Heim, Wiebke Möbius, Stefan Jakobs, and Michael Meinecke. 2017. "The MICOS Component Mic60 Displays a Conserved Membrane-Bending Activity That Is Necessary for Normal Cristae Morphology." The Journal of Cell Biology 216 (4). 


\section{Abstract}

During clathrin mediated endocytosis (CME) cargo molecules are transported across the plasma membrane from the outer cell surface into the cytosol. In this process, the plasma membrane undergoes massive local remodeling events as well as local changes in lipid composition mediated and regulated by the interplay of over 40 proteins that bind at specific time points at the membrane.

One of these proteins is Epsin1. It is highly conserved across eukaryotic evolution and its structure reveals a tightly folded N-terminal ENTH (Epsin N-terminal homology) domain and an unstructured C-terminus. The ENTH domain has a compact globular structure mainly composed of helices. It is the membrane binding module and specifically binds to phosphatidylinositol 4,5-bisphosphate $\left(\operatorname{Ptd} \operatorname{lns}(4,5) \mathrm{P}_{2}\right)$. The binding to $\operatorname{Ptdlns}(4,5) \mathrm{P}_{2}$ causes the formation of an amphipathic helix, which is associated with membrane deformation.

In this thesis, the roles of additional phospholipids beside Ptdlns $(4,5) \mathrm{P}_{2}$ in ENTH domain induced membrane deformation were investigated. Especially, phosphatidylserine (PtdSer) was identified to promote ENTH domain induced membrane tubulation by analysis of liposome morphology. Solid-state NMR studies revealed that the ENTH domain undergoes conformational changes in presence of PtdSer in the membrane.

The generation of membrane tubules was accompanied by the formation of ENTH domain homo-oligomers. By mutating an arginine within the loop between helix 6 and helix 7 to an alanine (R114A) oligomerization as well as membrane deformation was inhibited. The ENTH domain was demonstrated to form homo-oligomers in presence of PtdSer by FRET studies and this particular loop was identified as the location for ENTH domain interprotein interaction site by MS/MS. 
Index

\section{Index}

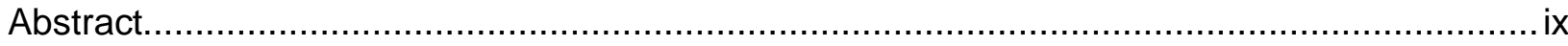

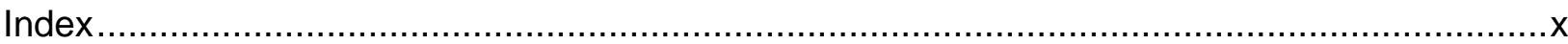

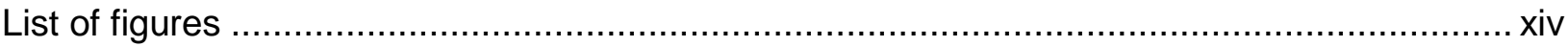

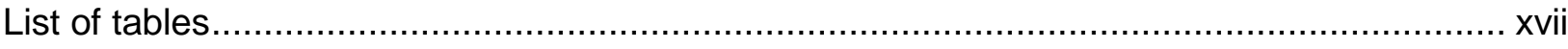

List of abbreviations ......................................................................................................

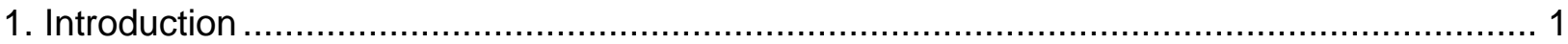

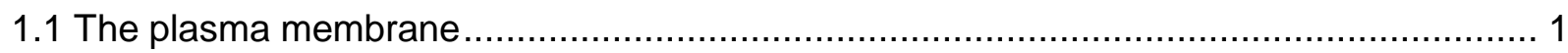

1.2 General view on the endocytic process ….............................................................. 3

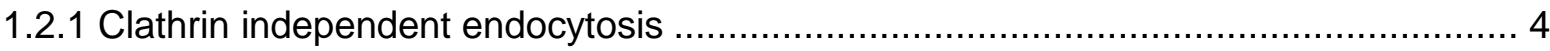

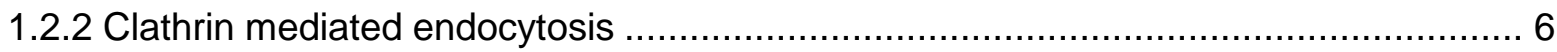

1.2.3 Cargo and tissue modulation of clathrin mediated endocytosis ............................. 8

1.2.4 Clathrin mediated endocytosis in yeast .......................................................... 9

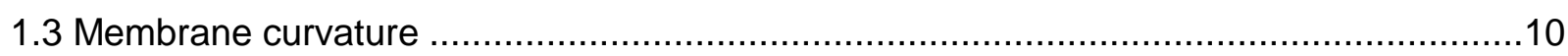

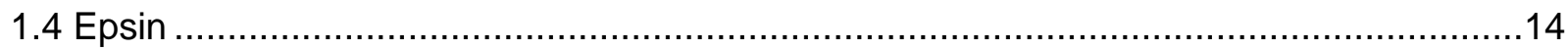

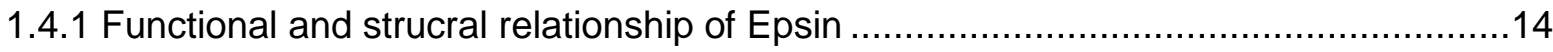

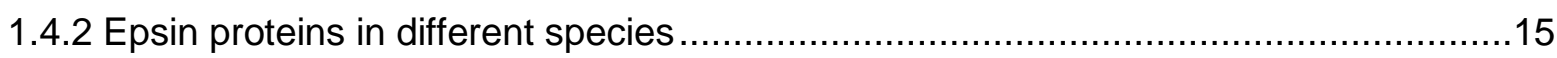

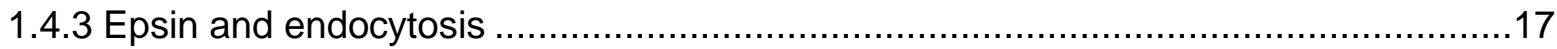

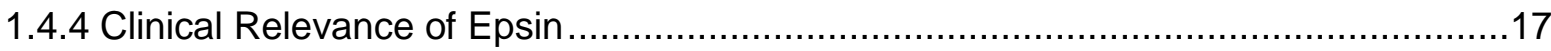

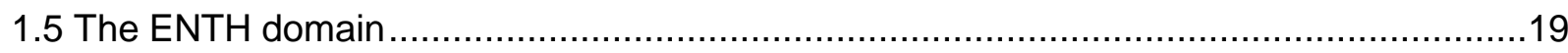

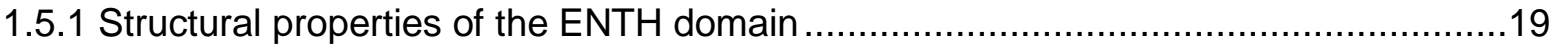

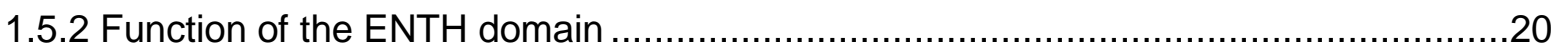

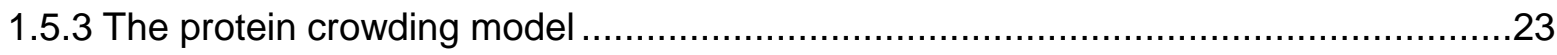

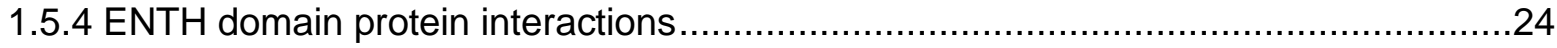

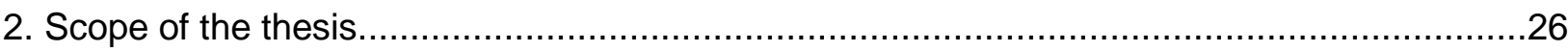

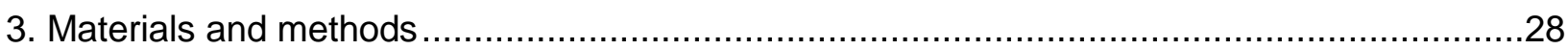

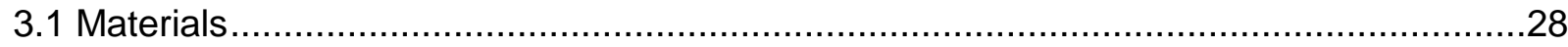

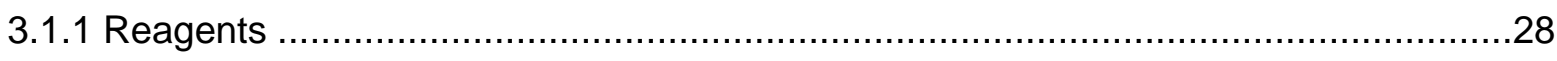




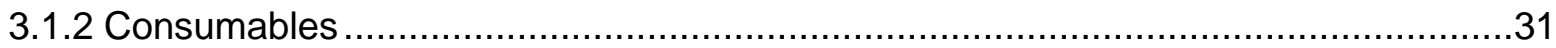

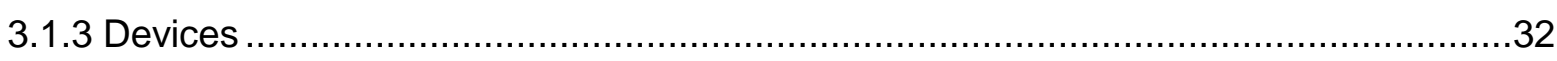

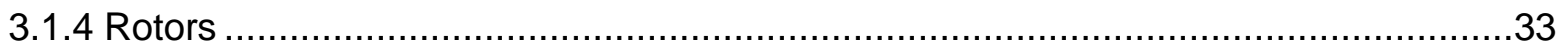

3.1.5 Buffers, mediums and solutions ……..................................................................

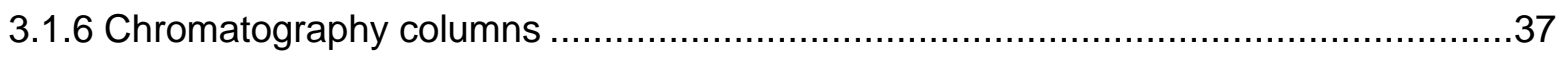

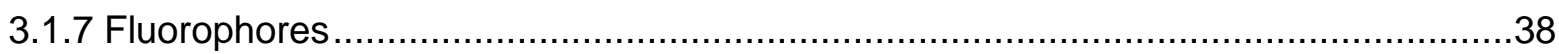

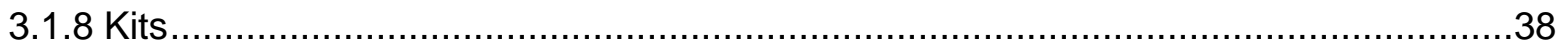

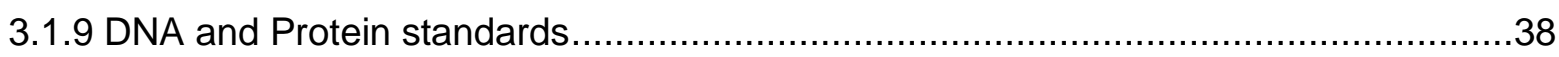

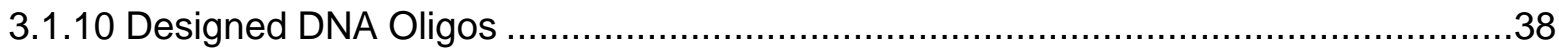

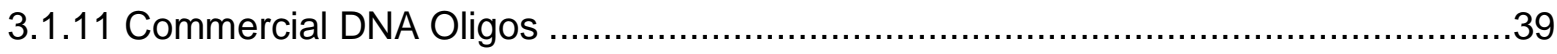

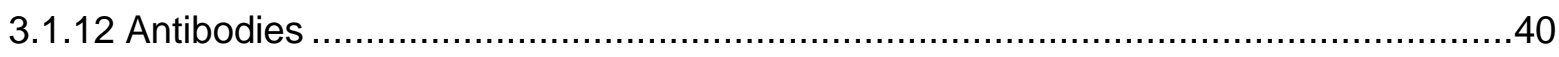

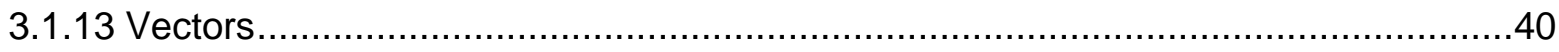

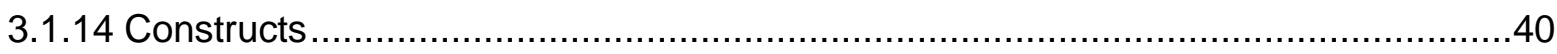

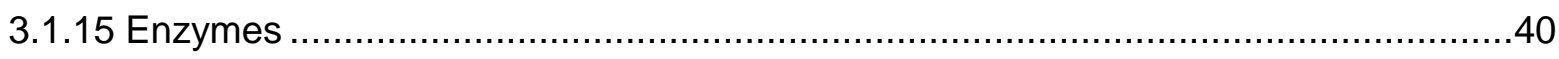

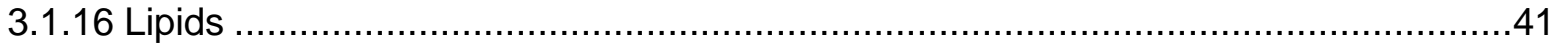

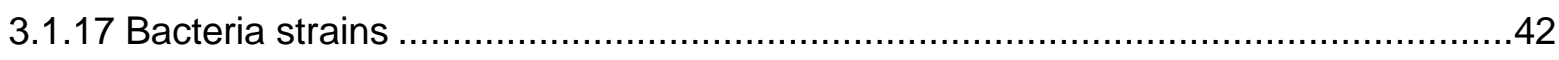

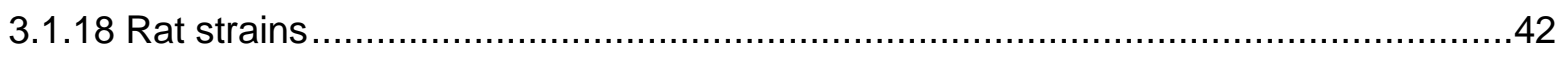

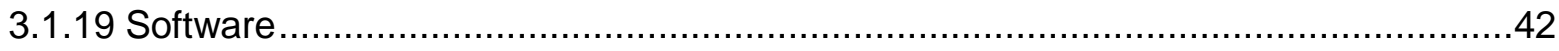

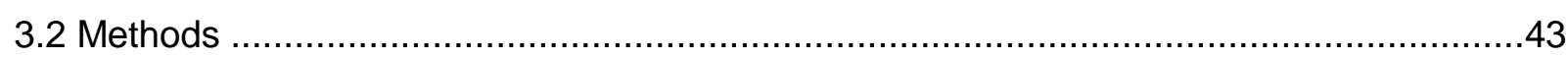

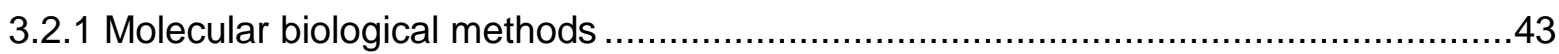

3.2.1.1 Determination of DNA concentration..............................................................43

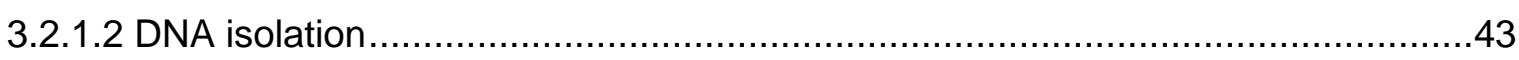

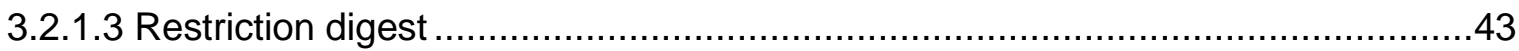

3.2.1.4 Ligation of DNA ......................................................................................

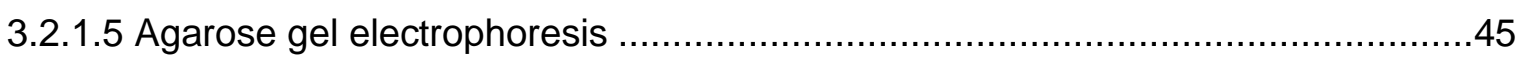

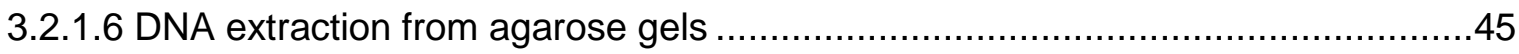

3.2.1.7 Polymerase chain reaction.............................................................................45

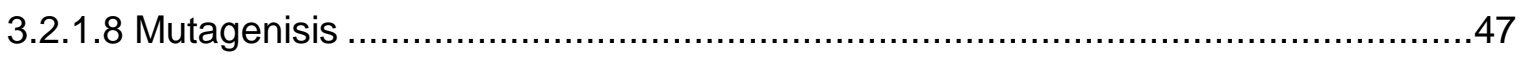

3.2.1.9 General cloning strategy ........................................................................... 


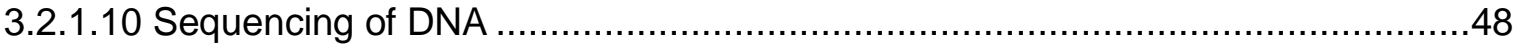

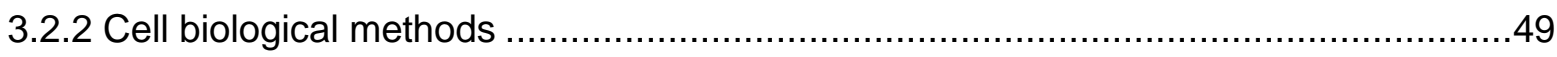

3.2.2.1 Transformation of chemically competent cells ..............................................49

3.2.2.2 Expression of recombinant proteins by IPTG induction ...................................49

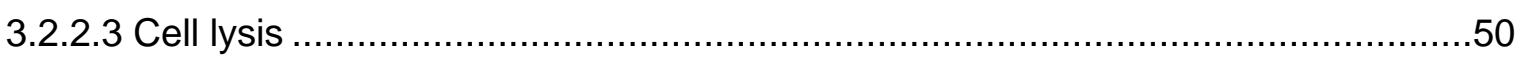

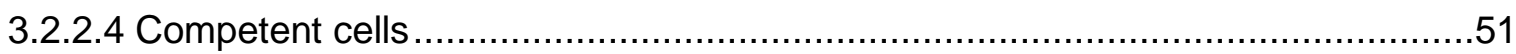

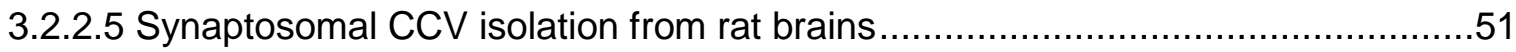

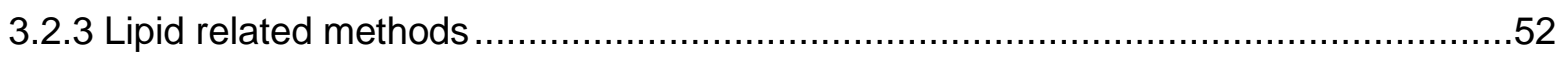

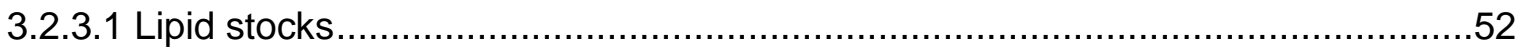

3.2.3.2 Preparation of small and large unilamellar vesicles.......................................52

3.2.3.3 Preparation of giant unilamellar vesicles ................................................. 53

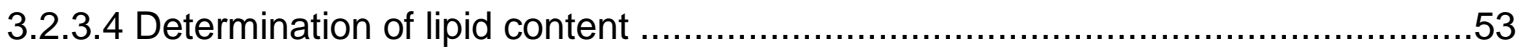

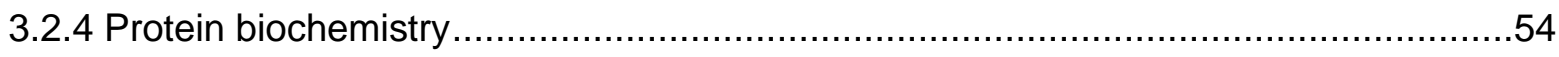

3.2.4.1 Sodium dodecyl sulfate polyacrylamide gel electrophoresis (SDS-PAGE) ..........54

3.2.4.2 Visualization of proteins by Coomassie Brilliant Blue ......................................54

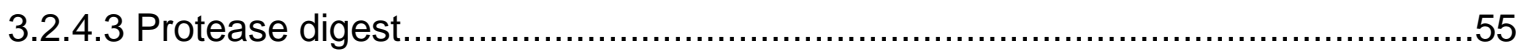

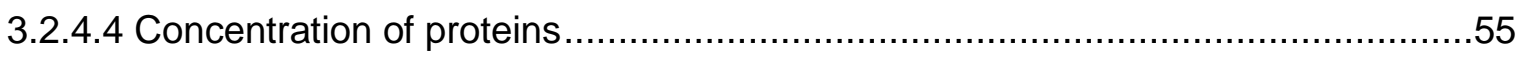

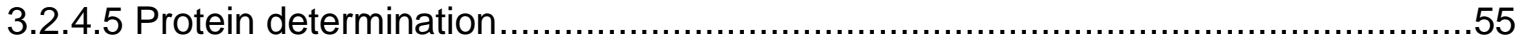

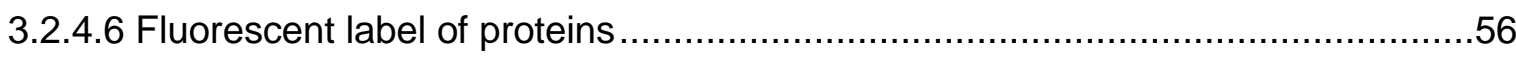

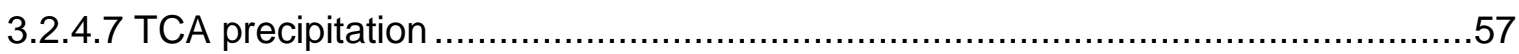

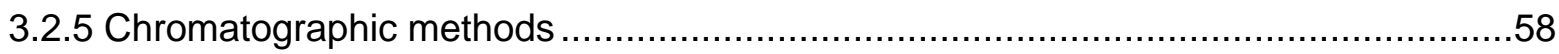

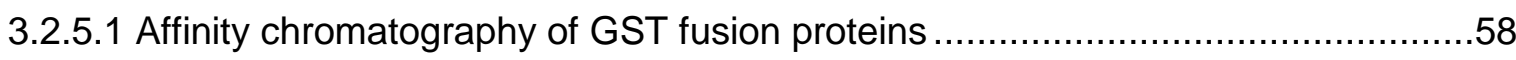

3.2.5.2 Affinity chromatography of polyhistidine fusion proteins ..................................58

3.2.5.3 Buffer exchange of protein solutions with the ÄKTAPrime Plus ........................59

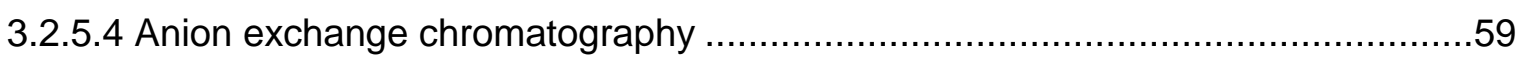

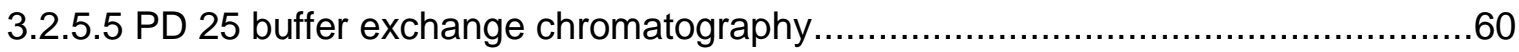

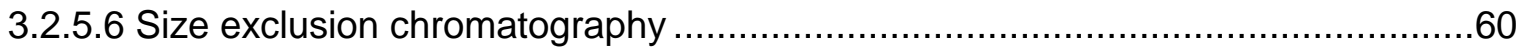

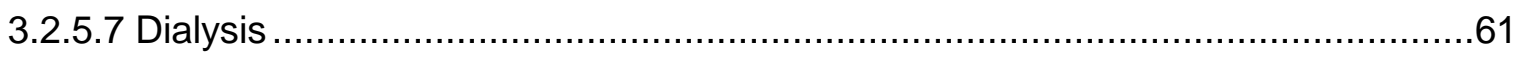

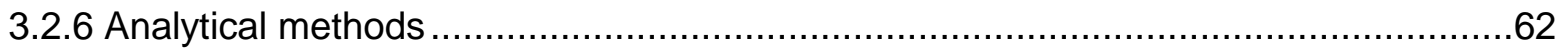




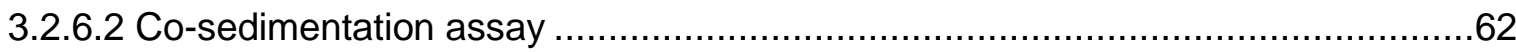

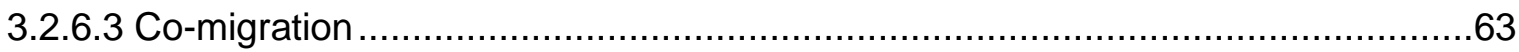

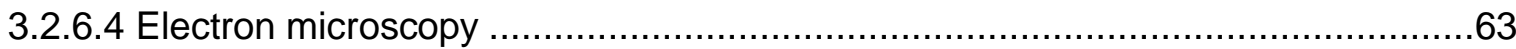

3.2.6.5 Binding and membrane deformation dynamics on GUVs ...............................63

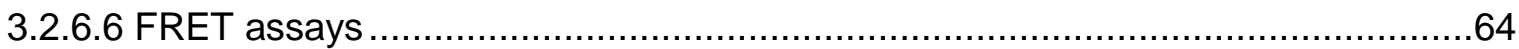

3.2.6.7 Secondary structure analysis by CD spectroscopy .......................................65

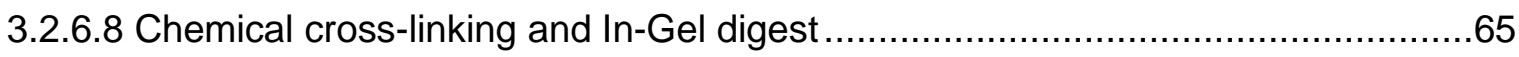

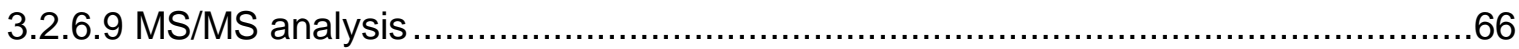

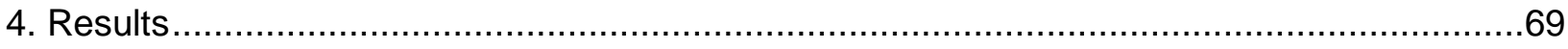

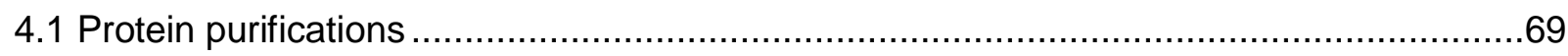

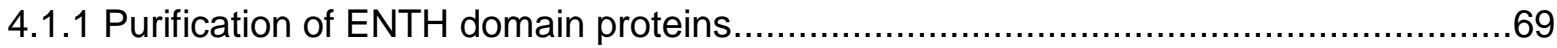

4.1.2 Purification of the BAR domain and ANTH domain.............................................

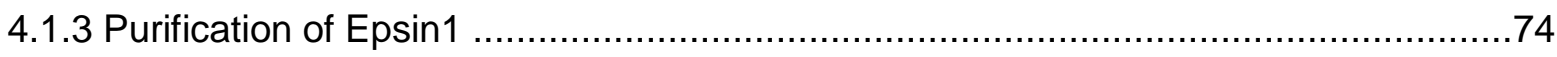

4.1.4 Purification of clathrin triskelia from native tissue …...........................................

4.2 PtdSer promotes ENTH domain dependent membrane deformation ............................78

4.3 ENTH domain oligomerization is dependent on PtdSer and the arginine $114 \ldots \ldots \ldots \ldots . . . .94$

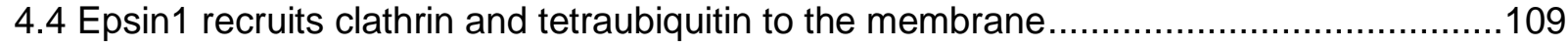

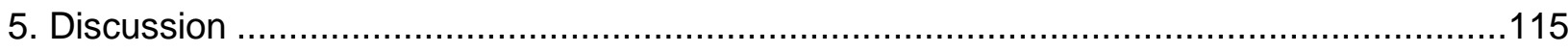

5.1 PtdSer promotes ENTH domain induced membrane tubulation ..................................115

5.2 The ENTH domain induced membrane deformation is associated with the formation of

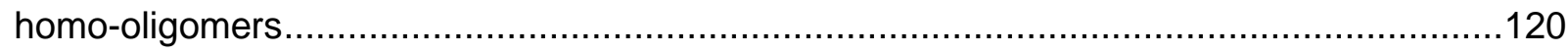

5.3 Epsin1 interacts with clathrin and tetraubiquitin on the membrane ............................123

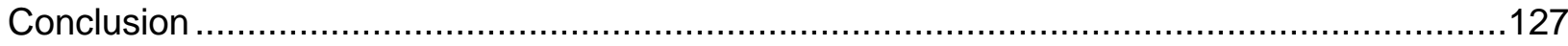

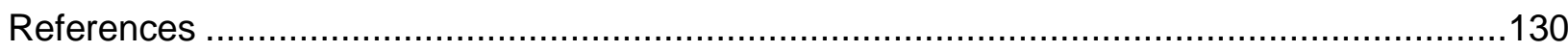

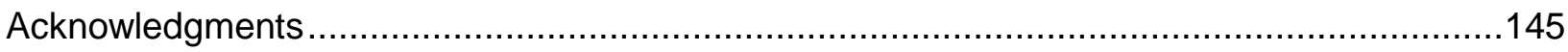

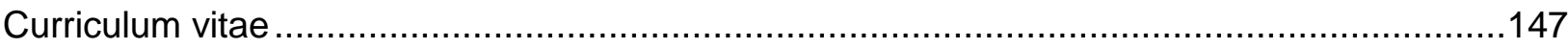




\section{List of figures}

Figure 1: Schematic illustration of a eukaryotic cell. 1

Figure 2: Schematic illustration of the endosomal trafficking. ......................................... 4

Figure 3: The diversity of endocytic pathways in metazoan cells................................... 5

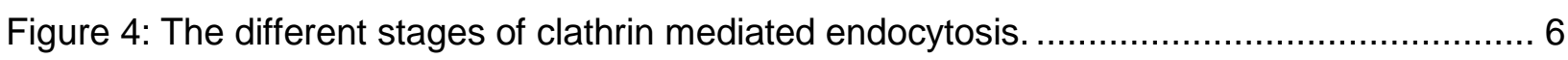

Figure 5: Schematic illustration of various bilayer phases. ..........................................10

Figure 6: Schematic illustration of the different mechanisms of bending membranes..............13

Figure 7: The linear architecture of Epsins across different species. ..............................15

Figure 8: Structural properties of the ENTH domain and related domains. ..........................20

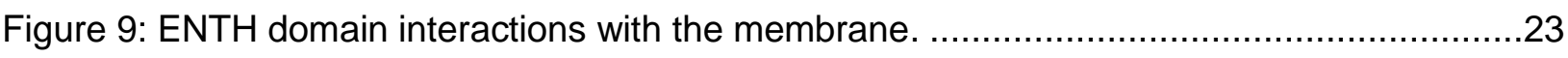

Figure 10: Schematic illustration of the purification strategy of ENTH domain constructs.........69

Figure 11: Recombinant expression and purification of rat ENTH domain.............................70

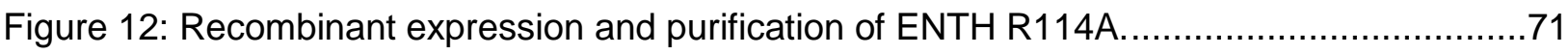

Figure 13: Recombinant expression and purification of ENTH V50,51A ..............................72

Figure 14: Schematic illustration of the purification strategy of BAR domain and ANTH

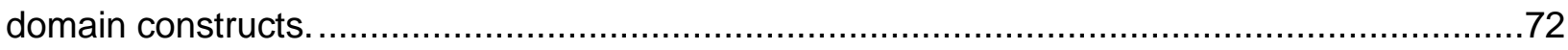

Figure 15: Recombinant expression and purification of the BAR domain. .............................73

Figure 16: Recombinant expression and purification of the ANTH domain. ...........................74

Figure 17: Schematic illustration of the purification strategy of Epsin1 constructs. .................74

Figure 18: Recombinant expression and purification of the rat Epsin1. ..............................75

Figure 19: Schematic illustration of the purification strategy of clathrin triskelia from rat

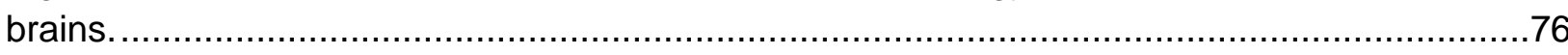

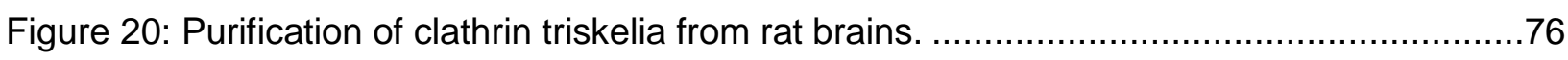

Figure 21: The ENTH domain deforms LUVs composed of brain lipid extract in $\operatorname{Ptdlns}(4,5) \mathrm{P}_{2}$

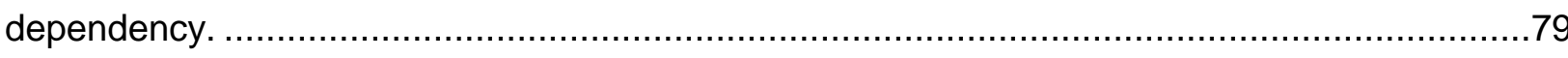

Figure 22: Comparison of endocytic, membrane interacting domains. ............................... 81 
Figure 23: PtdSer promotes ENTH domain induced membrane deformation and the formation of ENTH domain homo-oligomers.

Figure 24: Quantitative evaluation of PtdSer dependent membrane deformation by the ENTH domain.

Figure 25: PtdEtn is not able to promote ENTH domain induced membrane deformation and the formation of ENTH domain homo-oligomers.

Figure 26: The GUV assay.

Figure 27: The ENTH domain binds to and deforms PtdSer containing GUVs.

Figure 28: The ENTH domain does not deform GUVs without PtdSer.

Figure 29: The ENTH domain does not deform GUVs without PtdSer.

Figure 30: O-phosphoserine is partially able to rescue ENTH domain induced membrane deformation and homo-oligomer formation.

Figure 31: The presence of cholesterol within LUVs promotes the ENTH domain dependent generation of segmented membrane tubules.

Figure 32: Positions of amino acids V50,51 and R114 within the crystal structure of the ENTH domain.

Figure 33: ENTH V50,51A is a loss of function mutant. .96

Figure 34: Co-sedimentation of ENTH R114A in comparison to the ENTH domain WT.

Figure 35: Analysis of membrane deformation by ENTH R114A in comparison to the ENTH domain WT.

Figure 36: Statistical analysis of membrane deformation by ENTH R114A in comparison to the ENTH domain WT.

Figure 37: Co-migration assay of ENTHR114A in comparison to the ENTH domain WT. 100

Figure 38: Controls of the co-migration assay of ENTHR114A in comparison to the ENTH domain WT.

Figure 39: CD spectroscopic analysis of ENTH R114A in comparison to the ENTH domain WT.

Figure 40: Choice of fluorophores for the FRET assay.

Figure 41: Protein-protein FRET assay of ENTH R114A in comparison to the ENTH domain WT.

Figure 42: Lipid-protein FRET assay of ENTH R114A in comparison to the ENTH domain WT. 
List of figures

Figure 43: Cross-linking and MS/MS analysis of ENTH domain oligomerization in comparison to ENTH R114A.

Figure 44: Epsin1 displays the same phenotype as the ENTH domain in membrane binding and deformation.

Figure 45: Epsin1 binds to Ptdlns $(4,5) \mathrm{P}_{2}$ containing membranes in the GUV assay

Figure 46: Epsin1 is able to recruit clathrin to LUVs.

Figure 47: Clathrin co-localizes with Epsin1 on GUVs

Figure 48: Tetraubiquitin is recuitied by Epsin1 to GUVs

Figure 49: Schematic illustration of the in vitro cargo sorting of ubiquitin into clathrin baskets by Epsin 1 


\section{List of tables}

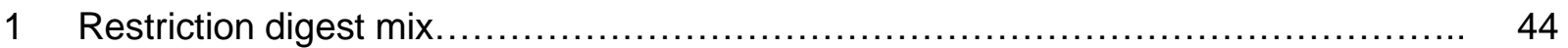

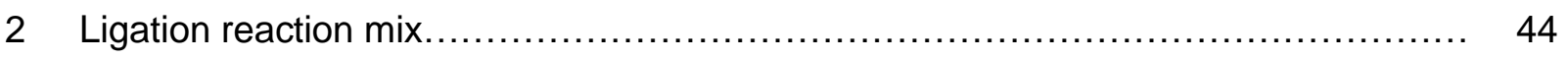

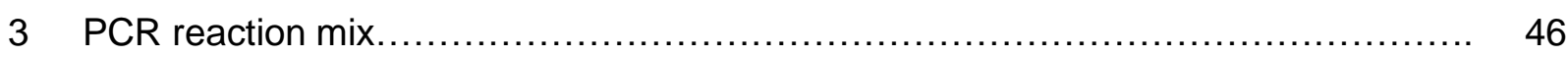

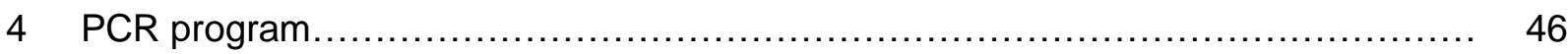

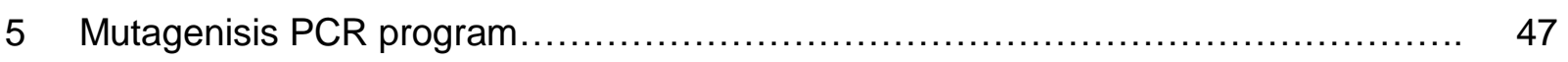

6 Phospholipid profile of the Avanti polar brain lipid extract........................ 82

7 Relative peptide fragment abundancy of inter-protein cross-links between $\mathrm{K} 117 \ldots \ldots \quad 106$ 


\section{List of abbreviations}

\begin{tabular}{|c|c|}
\hline${ }^{\circ} \mathrm{C}$ & Degree Celsius \\
\hline$\mu$ & Micro (prefix) \\
\hline ANTH & AP180 N-terminal homology \\
\hline AP-1 & Activator protein 1 \\
\hline AP180 & Adaptor protein 180 \\
\hline AP2 & Adaptor protein complex 2 \\
\hline APP & Amyloid precursor protein \\
\hline $\mathrm{ARH}$ & Autosomal recessive hypercholesterolemia \\
\hline Arp2/3 & Actin-related protein $2 / 3$ complex subunit 2 \\
\hline BAR & Bin/Amphiphysin/Rvs \\
\hline BAS & Burst analysis spectroscopy \\
\hline CALM & Clathrin assembly lymphoid myeloid leukemia protein \\
\hline CCPs & Clathrin coated pits \\
\hline CCV & Clathrin coated vesicles \\
\hline $\mathrm{CHCl}_{3}$ & Chloroform \\
\hline ClEs & Clathrin-independent endocytic pathways \\
\hline CLAP & Clathrin interaction region with AP-2 \\
\hline CME & Clathrin-mediated endocytosis \\
\hline CTV & Cytoplasm-to-vacuole \\
\hline D. melanogaster & Drosophila melanogaster \\
\hline Dab2 & Disabled homolog 2 \\
\hline DNA & Deoxyribonucleic acid \\
\hline DPW & Aspartic acid - proline - tryptophan motifs \\
\hline DRM & Detergent-resistant membrane \\
\hline EDE1 & EH domain-containing and endocytosis 1 \\
\hline
\end{tabular}




\begin{tabular}{|c|c|}
\hline Ede1p & EH domain-containing and endocytosis protein 1 \\
\hline EGFR & Epidermal Growth Factor Receptor \\
\hline $\mathrm{EH}$ & Eps15 homology \\
\hline $\mathrm{ENaC}$ & Epithelial sodium channel \\
\hline ENT1 & Equilibrative Nucleotide Transporter 1 \\
\hline Ent1p & Equilibrative Nucleotide Transporter 1 protein \\
\hline ENT2 & Equilibrative Nucleotide Transporter 2 \\
\hline ENT3 & Equilibrative Nucleotide Transporter 3 \\
\hline Ent3p & Equilibrative Nucleotide Transporter 3 protein \\
\hline ENT4 & Equilibrative Nucleotide Transporter 4 \\
\hline ENTH & Epsin N-terminal Homology \\
\hline EPEC & Enteropathogenic Escherichia coli \\
\hline EPR & Electron paramagnetic resonance \\
\hline Eps15 & Epidermal growth factor receptor substrate 15 \\
\hline EpsinR & Epsin related protein \\
\hline ER & Endoplasmic reticulum \\
\hline $\mathrm{FCHo}$ & FCHo domain only \\
\hline g & Gram \\
\hline GAPs & GTPase activating proteins \\
\hline GEEC & GPI-enriched endosomal compartments \\
\hline GTP & Guanosine triphosphate \\
\hline GTPase & Guanosin triphosphate hydrolase \\
\hline Gts $1 p$ & Protein GTS1 \\
\hline GUVs & Giant unilamellar vesicles \\
\hline $\mathrm{h}$ & Hour \\
\hline Hrs & Hepatocyte growth factor-regulated tyrosine kinase substrate \\
\hline HSC70 & Heat Shock Cognate 70 \\
\hline
\end{tabular}


Abbrevations

\begin{tabular}{|c|c|}
\hline IL & Interleukin \\
\hline $\operatorname{lnsPtd}(4) P$ & Phosphatidylinositol-4-phosphate \\
\hline ITC & Isothermal titration calometry \\
\hline KD & Knock-down \\
\hline $\mathrm{KO}$ & Knock-out \\
\hline | & Liter \\
\hline LDLR & Low density lipoprotein receptor \\
\hline LDLs & Low density lipoproteins \\
\hline LMDLADV & $\begin{array}{l}\text { Leucine - methionine - aspartic acid - leucine - alanine - aspartic acid - } \\
\text { valine }\end{array}$ \\
\hline LPA & Lysophosphatidic acid \\
\hline Lqf & Liquid facets \\
\hline Lsb3p & LAS seventeen-binding protein 3 \\
\hline Lsb4p/Ysc84p & LAS seventeen-binding protein 4 \\
\hline Lsb5p & LAS seventeen-binding protein 5 \\
\hline LUVs & Large unilamellar vesicles \\
\hline LVDLD & Leucine - valine - aspartic acid - leucine - aspartic acid \\
\hline M & Molar (substance concentration) \\
\hline $\mathrm{m}$ & Meter \\
\hline $\mathrm{m}$ & Milli (prefix) \\
\hline M6P & Mannose-6-phosphate \\
\hline M6PR & Mannose-6-phosphate receptor \\
\hline $\mathrm{MeOH}$ & Methanol \\
\hline MICOS & Mitochondrial contact site and cristae organizing system \\
\hline $\min$ & Minute \\
\hline mol & Mole (Amount of substance) \\
\hline mtDNA & Mitochondrial DNA \\
\hline
\end{tabular}


$\mathrm{n}$

NICD

Notch1

NPF

NTA

PA

PIP2

PM

POB1

PtdCho

PtdEtn

Ptdlns

Ptdlns $(4,5) \mathrm{P}_{2}$

PtdSer

RER

Rhod

RNA

rRNA

$\sec$

SER

SH3

SHIP2

shRNAs

siRNA

Sla1p

Sla2

Sla2p
Nano (prefix)

Notch intracellular domain

Notch homolog 1

Asparagine - proline - phenylalanine motifs

Nitrilotriacetic acid

Phosphatidic acid

Phosphatidylinositol 4,5-bisphosphate

Plasma membrane

BTZ/POZ domain-containing protein POB1

Phosphatidylcholine

Phosphatidylethanolamine

Phosphatidylinositides

Phosphatidylinositol $(4,5)$ bisphosphate

Phosphatidylserine

Rough endoplasmic reticulum

lissamine rhodamine B sulfonyl

Ribonucleic acid

Ribosomal RNA

Second

Smooth endoplasmic reticulum

Src-homology 3

SH2 domain-containing inositol phosphatase 2

Short harpin RNA

Small interfering RNA

Actin cytoskeleton-regulatory complex protein SLA1

Actin cytoskeleton-regulatory complex SLA2

Actin cytoskeleton-regulatory complex protein SLA2 
Abbrevations

\begin{tabular}{|c|c|}
\hline SNARES & Soluble N-ethylmaleimide-sensitive-factor attachment receptor \\
\hline SPFH & Stomatin/Prohibitin/Flotillin/HflK/C \\
\hline STAM & Signal transducing adaptor molecule \\
\hline SUV & Small unilamellar vesicle \\
\hline Syp1p & Septin-associated protein 1 protein \\
\hline T. brucei & Trypanosoma brucei \\
\hline TfR & Transferrin receptor \\
\hline TIRFM & Total internal reflection fluorescence microscopy \\
\hline UIMs & Ubiquitin interacting motifs \\
\hline VEGF & Vascular epithelial growth factor \\
\hline VEGFR2 & Vascular epithelial growth factor receptor 2 \\
\hline VHS & Vps27, Hrs and STAM \\
\hline Vps27 & Vacuolar sorting protein 27 \\
\hline Vpsp1p & Vacuolar protein sorting 1 protein \\
\hline Vti1 & v-SNARE (Vti1p) \\
\hline WASP/Myo & Wiskott-Aldrich syndrome protein/myosin \\
\hline$x g$ & Times gravity, unit of relative centrifugal force \\
\hline
\end{tabular}





\section{Introduction}

\subsection{The plasma membrane}

Cells are enclosed and defined by the plasma membrane (PM), composed of lipids and membrane proteins. This membrane maintains the physical integrity of the cell and serves as barrier between the cytosol and the outer environment. The cell membrane is selectively permeable for certain particles and protects the cytosol from intrusion of nanoparticles. It is also a place for signal transduction, nutrient uptake, sensing environmental changes and cell to cell communication. To adapt to all these functions the cell membrane is highly dynamic and changes the shape either globally, or locally to respond to cellular demands. The cell membrane undergoes permanently local remodeling events (Figure 1). Molecules are transported across the membrane by vesiculation. Therefore, the membrane must invaginate deeply and form areas of high curvature. But what is the physical behavior of a cell membrane? And what are the energetic barriers that keep the integrity and must be overcome to bend the membrane?

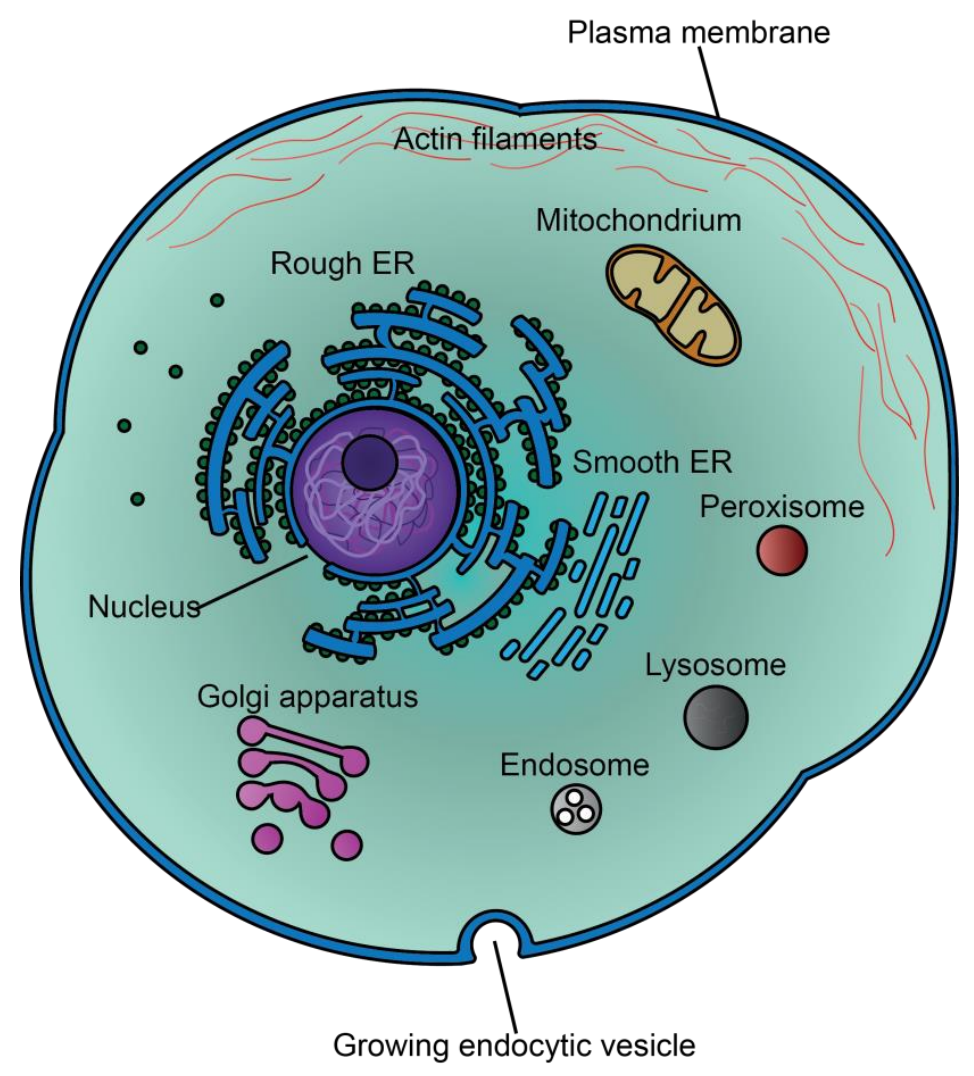

Figure 1: Schematic illustration of a eukaryotic cell. The cell and several organelles are enclosed by lipid bilayers. Communication between membranous organelles and environmental sensing are established by vesicular transport. 
The matrix of cellular membranes is formed by phospholipids. These molecules are amphipathic and possess a hydrophilic headgroup and hydrophobic fatty acid residues. They spontaneously self-assemble into bilayers in an aqueous solution due to their physical characteristics. The lipid composition of mammalian plasma membranes is highly diverse and tissue dependent. However, there is a distinct tendency of lipid species that are enriched in plasma membranes. The most abundant lipids are phosphatidylcholine (PtdCho) with nearly $50 \%$ and phosphatidylethanolamine (PtdEtn) with up to $30 \%$ in different tissues ${ }^{1}$, 2, 3 . PtdCho has a cylindrical shape and tends to self-organize into planar bilayers. PtdEtn induces negative membrane curvature due to its intrinsic inverse conical shape and thus classified as a non-bilayer lipid. A certain lipid portion is represented by phosphatidylserine (PtdSer) and phosphatidylinositides (Ptdlns). Both lipid species are negatively charged and phosphatidylinositides are critical lipids for signaling due to their property of being multiple phosphorylated. Phosphatidylinositol(4,5)bisphosphate $\left(\operatorname{Ptdlns}(4,5) \mathrm{P}_{2}\right)$ for example is a key player in endocytic pathways. Additionally, mammalian plasma membranes are enriched in sterols and sphingolipids which are densely packed and resist to mechanical stress ${ }^{4}$. The lipids of two bilayer leaflets of the plasma membrane are asymmetrically distributed. The outer leaflet is enriched in PtdCho as well as sphingolipids and the inner leaflet contains higher portions of PtdSer, PtdEtn and different species of phosphatidylinositides ${ }^{5}$. 


\subsection{General view on the endocytic process}

In mammalian cells, endocytic membrane trafficking has a pivotal role in the delivery of membrane components, solute molecules and receptor associated ligands to several intracellular destinations (Figure 2). Endocytosis is also used by toxins, viruses, and symbiotic microorganisms to enter the cell ${ }^{6}$. Earlier models described endocytosis as a simple route, with the main pathways thought to lead to degradation in lysosomes or recycling back to the plasma membrane. However, more recent models present this process as more complex and multifunctional.

It has been now almost 20 years since the publication of the first report characterizing the recycling of receptors back to the plasma membrane, which demonstrated the crucial role of clathrin mediated endocytosis (CME) on the control of the signal cascade of Epidermal Growth Factor Receptor (EGFR) ${ }^{7}$. Receptor mediated endocytosis is the best characterized endocytic process and it is known to be involved in the internalization of receptors and their ligands by clathrin coated pits (CCPs) ${ }^{6}$. Several ligands are then degraded in late endosomes or lysosomes, while receptors are re-used several times.

Such clathrin-dependent regulatory and trafficking pathways not only occur at the plasma membrane, but also between intracellular organelles. In general, they are essential for the maintenance of the right composition of organelles as well as for returning crucial molecules to the appropriate compartments. Moreover, endocytic recycling is also essential for keeping the distinction between apical and basolateral membranes in polarized cells ${ }^{8}$.

Different types of sealed endocytic compartments originate from the plasma membrane, and the better characterized of these starts with the formation of a $\mathrm{CCP}^{6}$. Commonly, endocytosed molecules are then delivered to early endosomes, where sorting takes place ${ }^{9}$. Sorting endosomes are tubular-vesicular structures that have a luminal $\mathrm{pH}$ of $\sim 6.0^{10,11}$ and accept material only for 5-10 minutes ${ }^{12}$. After this, they translocate onward microtubules, stop fusing with freshly endocytosed vesicles and its lumen becomes more acidic. At this time point, endosomes start to gain hydrolases and acquire the characteristics of late endosomes. This process is called endosomal maturation. After the sorting endosome, there are three destinations for cargo, which are the plasma membrane, late endosomes and the endocytic recycling compartment.

$\mathrm{CME}$ is a major endocytic pathway of the plasma membrane however, several studies demonstrated that other endocytic pathways can also take place in mammalian cells. 


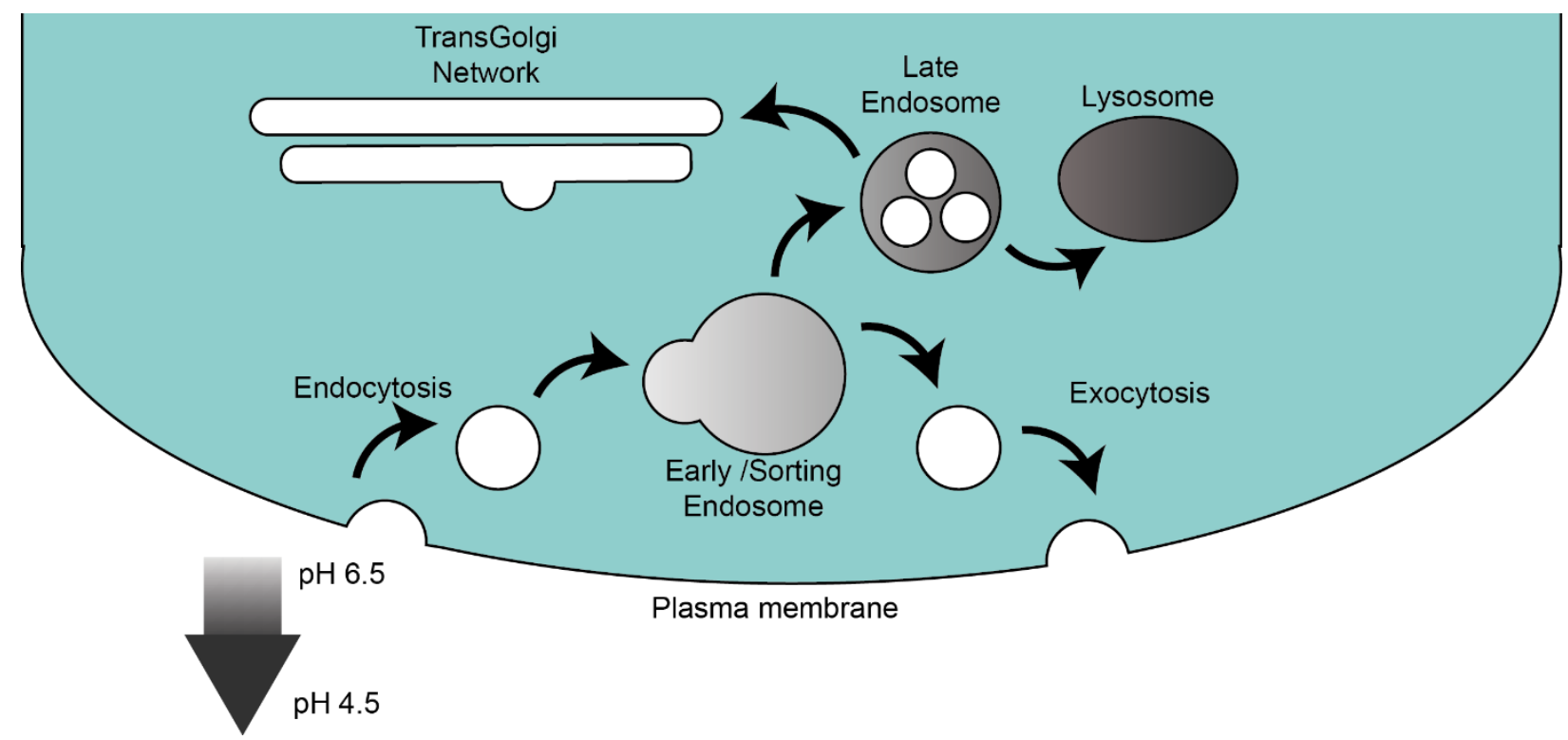

Figure 2: Schematic illustration of the endosomal trafficking (adapted from Elkin S. R. et al. 13). Vesicles are internalized into the cytosol and fuse with the early endosome. The cargo is sorted to be transferred back to the cell surface by exocytosis or to the late endosome. The cargo is then transferred to the TransGolgi network or degraded in lysosomes. The endosome undergoes continuous acidification which is indicated by the darker color of the compartments.

\subsubsection{Clathrin independent endocytosis}

Endocytosis is a basic process which is used by cells to incorporate an assortment of molecules. Since these molecules can be quite diverse, it is important to understand the different pathways that mediate their internalization and how these pathways are regulated. The discovery of clathrin mediated endocytosis and of the main players involved in this complex process provides a fundamental model for the investigation of membrane trafficking in cells ${ }^{13,14}$. Some of these pathways are fundamental, although others are triggered by specific stimuli or even used by pathogens to infect cells ${ }^{15}$. Moreover, they differ in the composition of the molecular machinery, the associated cargo destination, as well as in mechanism and kinetics of formation ${ }^{16}$.

Several endocytic pathways that do not require clathrin begun to be recognized as distinct clathrin independent endocytic pathways (CIEs). These pathways can be divided into those which require dynamin and those that are dynamin-independent. Another way to distinguish is related to the presence or absence of a proteinatious coat ${ }^{16}$.

The plasma membrane, in different cell types (excluding neurons and leukocytes) contains small flask-shaped invaginations of 60 to $80 \mathrm{~nm}{ }^{17}$ and depending on the cell type, these so called caveolae play different roles. It has been observed that these structures internalize glycosphingolipids as well as integrins ${ }^{18}$. In addition, caveolae play a role in lipid and cholesterol regulation in adipocytes ${ }^{19}$. Finally, they participate in mechanosensing by 
counteracting cell membrane swelling, working as a membrane reservoir ${ }^{20}$. The formation of caveolae strongly depends on the presence of Caveolin1, or Caveolin3 in skeletal muscle cells ${ }^{21,22}$. They bind or form special lipid rafts at the plasma membrane composed of sphingomyelin and glycosphingolipids as well as cholesterol ${ }^{23,24}$. Caveolins possess an intramembrane domain, a scaffolding domain and a domain that undergoes palmitylation during protein maturation ${ }^{25}$

The GEEC pathway (Figure 3) is a novel coat and dynamin independent endocytic pathway ${ }^{26},{ }^{27}$. Originally, GPI-anchored proteins were thought to be internalized via the caveolae dependent pathway. However, this idea was changed by data collected in several studies, which demonstrated that GPI-anchored proteins are not actively enriched in caveolae ${ }^{27,28,29}$. In the absence of cross-linking, GPI-anchored proteins form nanoscale clusters on the plasma membrane, and are internalized through the GEEC pathway.

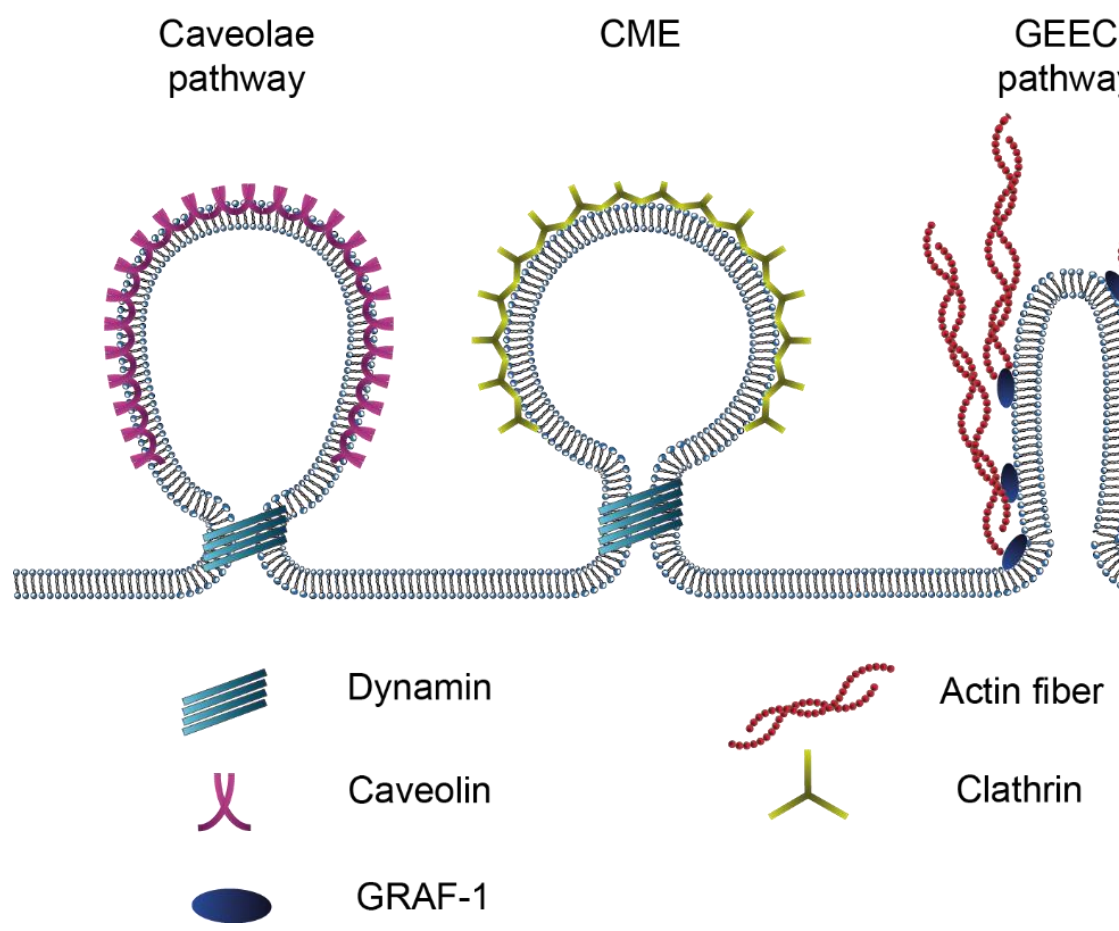

Figure 3: The diversity of endocytic pathways in metazoan cells (adapted from Mayor S. et al. 31). The caveolae endocytic pathway and clathrin mediated endocytosis are associated with a characteristic protein coat and depend on dynamin. The GEEC pathway is dependent on the actin cytoskeleton. 


\subsubsection{Clathrin mediated endocytosis}

So far, clathrin mediated endocytosis is the best described endocytic pathway and since the discovery of clathrin as the lattice forming coat molecule in CME by Pearse B. M. F. in $1976{ }^{30}$, extensive studies were performed to elucidate the mechanisms of this process. The plasma membrane locally invaginates, encloses the cargo and is released into the cytosol as a clathrin coated vesicle (CCV) (Figure 4). Clathrin dissociates from the CCV and finally fuses with the endosome. The plasma membrane undergoes massive local remodeling events as well as drastic changes of the local lipid composition during the events of $\mathrm{CME}$. These processes are mediated and regulated by over forty proteins that bind at specific time points to the membrane.

Nucleation Cargo selection Coat assembly Scission Uncoating

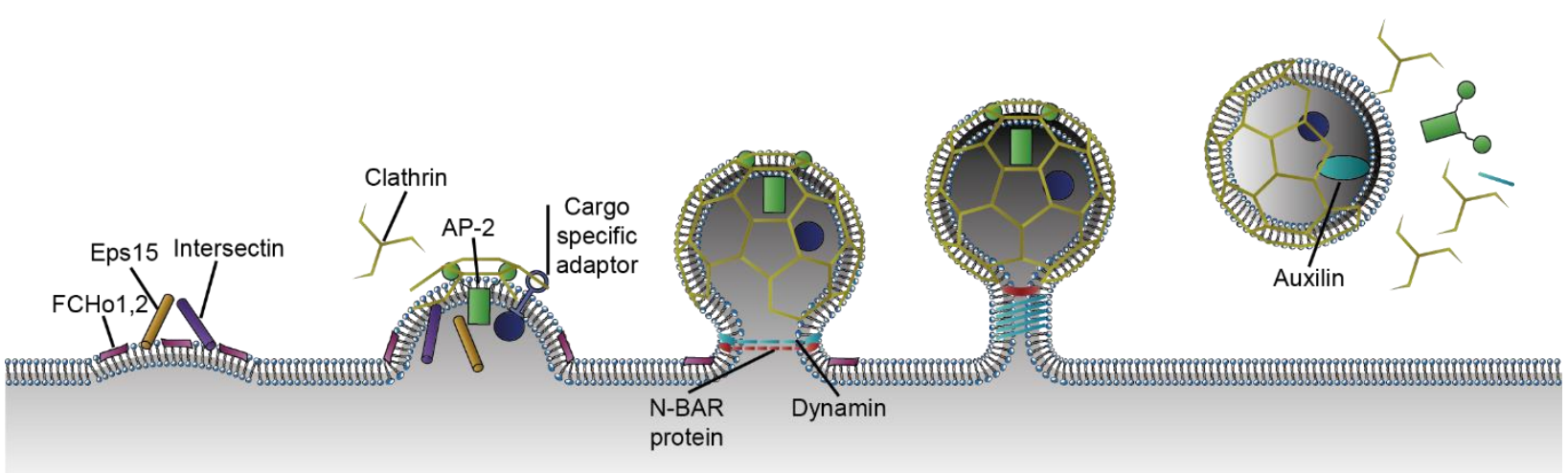

Figure 4: The different stages of clathrin mediated endocytosis (adapted from McMahon H. T. et al. ${ }^{31}$ ). The nucleation is initiated by a complex of FCHo, Eps15 and intersectin. Cargo selection is characterized by the recruitment of cargo specific adaptors, AP-2 and clathrin. The pit gets a more defined vesicular shape, and the complete clathrin lattice is formed in the coat assembly step. The neck region still connects the CCV and the plasma membrane. Dynamin is then recruited by BAR domain proteins to the neck. Finally, the clathrin coated vesicle is released off the membrane by dynamin activity and clathrin starts to disassemble.

Clathrin mediated endocytosis is classically subdivided into several stages that were determined by morphological studies. However, the key proteins and the processes within the stages remain controverse. The nucleation is the initial step, in which the membrane pit starts to get a defined shape by local invagination of the plasma membrane. Three components play a key role in the nucleation of the plasma membrane by assembling to a nucleation module ${ }^{31}$. $\mathrm{FCH}$ domain only $(\mathrm{FCHo})$ proteins, Eps15 (Epidermal growth factor receptor substrate 15) and intersectins define this nucleation module, thus the depletion of one of these proteins inhibits the formation of the clathrin coat ${ }^{32,33}$. Especially FCHo 1,2 are believed to be key proteins in this model. They initially bind to Ptdlns $(4,5) \mathrm{P}_{2}$ containing membranes with a low curvature and recruit intersectin and Eps15 that in turn recruits AP-2 
(Adaptor protein complex 2) ${ }^{33}$. In contrast, another model was proposed, in which nucleation is mediated by AP-2 ${ }^{34}$ which is the main adaptor protein in CME. This protein binds to Ptdlns $(4,5) \mathrm{P}_{2}{ }^{35}$ and recruits clathrin to the membrane ${ }^{36,37}$. In addition, AP-2 interacts with nearly all proteins involved in clathrin mediated endocytosis. The interactions are mediated by the $\alpha$-Ear of AP-2 and DPW/F motives ${ }^{38}$. In 2012 it was demonstrated, by total internal reflection fluorescence microscopy (TIRFM) that AP-2 initiates the nucleation in BSC1 cells followed by the recruitment of $\mathrm{FCHo}$ proteins ${ }^{39}$.

Subsequent to nucleation, cargo selection is the next stage of CME and is defined by the interactions of AP-2. AP-2 interacts directly with cargo, but also indirectly through its binding to the corresponding adaptor proteins. One example is stonin2 that binds AP-2 and the cargo molecule synaptogamin ${ }^{40}$. It was shown that the nucleation complex still assembles in AP-2 depleted cells, but clathrin was not recruited to the membrane and the CCVs did not mature ${ }^{41,42}$.

In the next stage, the membrane gets a more pronounced invaginated shape as more clathrin triskelia are recruited by AP-2 and other adaptor proteins. As clathrin triskelia assemble into a scaffold, membrane curvature is stabilized. In cells without clathrin, AP-2 is recruited to the nucleation complex, but invagination of these patches is depleted ${ }^{43}$. It still remains controversial if clathrin polymerization induces membrane curvature, as the budding of clathrin coated pits was induced by using clathrin triskelia together with truncated adaptor proteins that were not able to induce membrane deformation by themselves ${ }^{44}$. However, clathrin binds to the flexible parts of the adaptor proteins which is thought to transmit the potential polymerization force in an inefficient way to the membrane ${ }^{31}$. Clathrin, if bound by adaptor proteins to flat membranes, does not form the characteristic alternating pentagonal and hexagonal lattices with an intrinsic curvature of a CCP. Instead, it assembles only in hexagons forming flat lattices ${ }^{45}$. The stage of clathrin coat assembly is accompanied by the displacement of adaptor proteins like Eps 15 and curvature generating adaptors like Epsin proteins $^{46,47}$.

Later, when the clathrin coated pit gets the characteristic shape and size of a vesicle, a neck region is formed, which connects the CCV with the plasma membrane. This stage of CME is characterized by two types of key proteins. The N-BAR domain proteins amphiphysin and endophilin have intrinsically highly curved shapes ${ }^{48}$. These proteins are able to sense and induce high degree membrane curvature ${ }^{49}$. Ultimately, it was demonstrated, by the use of GUVs (Giant unilamellar vesicles) coupled to optical tweezers, that amphiphysin 1 preferentially binds to curved membranes than to flat membranes ${ }^{50}$. As they bind to the neck region of the CCP in late stages of endocytosis ${ }^{51}$, BAR domain proteins assemble into a neck-surrounding helical ultrastructure generating and stabilizing high membrane curvature ${ }^{52}$. The second key protein is dynamin that promotes the fission of 
the CCV from the plasma membrane. Dynamin is recruited by BAR domain proteins of CME. Meinecke M. et al. showed that dynamin is not efficiently recruited to CCPs in endophilin and amphiphysin knocked down SK-MEL-2 cells ${ }^{53}$. In addition, they showed that amphiphysin recruits dynamin to GUVs which ultimately induces membrane vesiculation in the presence of GTP. The binding between both proteins is established by the SH3 (Src-homology 3) domain and the proline-rich domain of dynamin ${ }^{54}$. The actual mechanism of how dynamin promotes fission is not completely elucidated. After its recruitment to the neck and selfassembly to a ring ${ }^{55}$, dynamin promotes the hydrolysis of GTP (Guanosine triphosphate) leading to a conformational change of this protein ${ }^{56,57}$. It is implicated that dynamin then constricts the neck which leads to the release of the CCV ${ }^{58}$. Dynamin activity plays a crucial role in membrane fission because inhibiting its GTPase activity or knocking it down arrests CCVs on the plasma membrane ${ }^{59,60 .}$

After the release of the CCV from the plasma membrane, clathrin rapidly dissociates into triskelia. This process is induced by the ATPase activity of the Heat Shock Cognate 70 (HSC70) ${ }^{61}$ in cooperation with its cofactor ${ }^{62}$. The uncoated vesicle travels through the cytosol to fuse with the endosome.

\subsubsection{Cargo and tissue modulation of clathrin mediated endocytosis}

The cellular function of clathrin mediated endocytosis strongly depends on the tissue where it takes place. The ubiquitous function is the internalization of plasma membrane bound receptors. The Transferrin receptor (TfR) and Low Density Lipoprotein receptor (LDLR) are both internalized constitutively by $\mathrm{CME}^{30,63}$, whether their ligands are bound or not. The TfR binds transferrin-iron complexes, thus it is crucial for cellular iron internalization ${ }^{64}$ and binds AP-2 directly ${ }^{65,66}$. The LDLR plays a crucial role in the uptake of cholesterol by Low Density Lipoproteins (LDLs) ${ }^{67}$. This receptor binds CME adaptor proteins ARH (Autosomal Recessive Hypercholesterolemia) or Dab2 (Disabled homolog 2) ${ }^{66}$.

Several receptors that are CME cargoes are only internalized after their stimulation by the corresponding ligands. So far, two receptor families are well characterized for CME after stimulation: the $G$ protein-coupled receptor family (for example the adrenergic receptor ${ }^{68}$ ) and the receptor tyrosine kinase family (Insulin receptor ${ }^{69}$, Epidermal Growth Factor receptor ${ }^{70}$ ).

The binding of the EGFR to its ligand leads to the dimerization, ubiquitination and autophosphorylation of the receptor. These events induce a signal cascade associated with cell growth and inhibition of apoptosis ${ }^{71,72}$. In several tissues CME function is extended to regulate signaling pathways, like the Wingless pathway. This pathway was studied in Drosophila melanogaster and plays a role in embryonic development of the body axis, cell fate, cell proliferation and migration ${ }^{73}$. The Wingless ligands bind to the membrane receptor 
Frizzled. Activated Frizzled is the cargo protein for Dishevelled, an endocytic adaptor protein, and finally internalized ${ }^{74}$. By this process, CME regulates signal transduction pathways only by physically removing used receptors from the cell surface ${ }^{75}$.

The main role of CME in the brain is the recycling of synaptic vesicles proteins and lipids after the release of the neuro transmitter into the synaptic cleft ${ }^{40,76}$. The composition of associated adaptor proteins of synaptic CCVs also differs from the composition of CCVs in other tissues. For example, AP180 replaces CALM in synaptic vesicles ${ }^{31}$.

\subsubsection{Clathrin mediated endocytosis in yeast}

Yeast endocytosis takes place at plasma membrane subdomains which are called actin patches ${ }^{77,78}$. At yeast endocytic sites, the proteins that are first detected are the ubiquitin binding protein Ede1p (EH domain-containing and endocytosis 1) and the F-BAR protein Syp1p ${ }^{79,32}$. Syp1p (Septin-associated protein 1) induces the formation of endocytic sites at the bud neck, in a polarized way, however its deletion does not inhibit patch formation in buds. After the arrival of early proteins, accumulation of cargo molecules at the nascent actin patch takes place. At this point, several other proteins are recruited to the endocytic site. Among them are Sla2p (actin cytoskeleton-regulatory complex protein SLA2) and Ent $1 / 2 p$ (extended version), which have domains that specifically bind to $\operatorname{Ptd} \operatorname{lns}(4,5) \mathrm{P}_{2}$ 80, 81 . Later, coat proteins arrive, together with members of the WASP/Myo (Wiskott-Aldrich syndrome protein/myosin) module. Lsb5p (LAS seventeen-binding protein 5) and Gts $1 p$ (protein GTS1) promote the uncoating, whereas Lsb3p (LAS seventeen-binding protein 3) and Lsb4p/Ysc84p (LAS seventeen-binding protein 4 ) are involved in actin polymerization and bundling ${ }^{82,83}$. The proteins that arrive at later time-points are probably involved in the link between the early coat, actin and the scission machinery. At the end of the endocytic process, the vesicle pinches off from the plasma membrane and moves towards the center of the cell, where the endocytic coat disassembles.

Among the 60 yeast proteins that are known to localize at endocytosis sites, approximately $85 \%$ are homolog to mammalian proteins involved in the endocytic process. As an example, intersectin in mammals possesses two Eps 15 homology domains and five $\mathrm{SH} 3$ domains and it is believed that it plays a role similar to the one of the yeast proteins Pan $1 p$ and Sla1p ${ }^{51}$. 


\subsection{Membrane curvature}

To understand the mechanisms of membrane curvature it is necessary to understand the mechanics and thermodynamics of lipid membranes. One measure to predict the behavior of lipids in a membrane is the packing parameter introduced by Israelachvili J. et al. in $1977^{84}$. It defines, in a simplified way, the intrinsic geometry of a lipid depending on the headgroup, the volume of the lipid and the fatty acid chain length. The packing parameter determines the shape of the membrane. Cylindrical shaped lipids tend to form bilayers, while inverted conical shaped lipids govern micelles. Conical shaped lipids tend to form reverse micelles (splayed chain confirmation) in which the headgroups form the core and the acyl chains form the continuous phase ${ }^{85}$.

The motion of lipids within a bilayer is explained by the bilayer phase behavior ${ }^{86}$ (Figure 5). At low temperatures bilayers are in the liquid ordered phase $\left(L_{0}\right)$ that is displayed by a highly ordered lipid fatty acid chains ${ }^{87}$. At higher temperatures the bilayer phase transits into the lamellar gel phase $\left(L_{\beta}\right.$ for lipids similar to PtdEtn, or $L_{\beta}$, for lipids similar to PtdCho). The lipids are still highly ordered, but their fatty acid residues are slightly tilted organized. The next phase is the fluid phase (liquid disordered, $L_{\alpha}$ ) ${ }^{87}$, which is physiologically the most relevant ${ }^{86}$. The transitions between the phases are known as the melting temperature. The length of the fatty acid chains has a great impact on the melting temperatures because of the Van der Waals interactions between them ${ }^{88}$. The degree of fatty acid chain saturation also impacts the melting temperature.

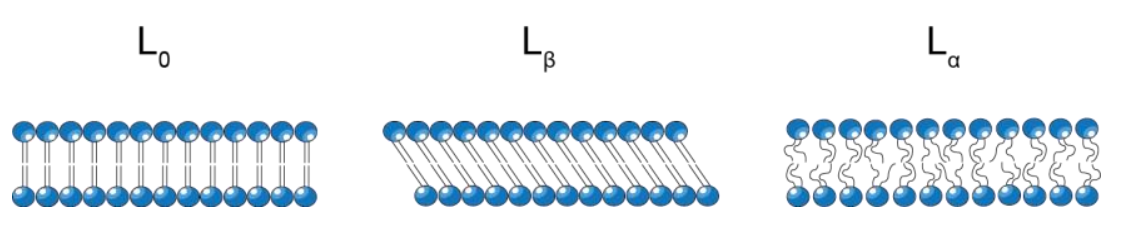

Figure 5: Schematic illustration of various bilayer phases (adapted from Kranenburg M. et al. ${ }^{86}$ ). Lipids are highly ordered in liquid ordered phase $\left(L_{0}\right)$. The fatty acid tails are oriented in a tilted manner in the lamellar gel phase $\left(L_{\beta}\right)$ and unordered in the fluide phase $\left(L_{\alpha}\right)$.

In 1972 Singer S. J. et al. introduced the fluid mosaic model to describe the properties of the bilayer components in cellular membranes ${ }^{89}$. Although, the classic fluid mosaic model became obsolete and has been replaced by different complex models, it can still be used to understand the basic properties of the membrane. Lipids and integral membrane proteins are free in lateral diffusion within the membranous matrix, so they behave like a two-dimensional fluid in the liquid disordered phase. Lipids are also able to perform transversal diffusion (flip-flop) although Singer S. J. assumed this as a rare event. Furthermore, the membrane viscosity is increased as a consequence of high cholesterol 
concentrations. The restriction of the fluid mosaic model is that it does not explain the formation of subdomains within the lipid bilayer, since the single components of a membrane are assumed to behave independently ${ }^{90}$. One example for these subdomains are lipid rafts 91. They are described as regions within the membrane that are enriched in cholesterol and glycosphingolipids. Lipid rafts have a distinct behavior in lateral motion, if compared to the surrounding lipids. Considering the differences in the packing parameters, lipid rafts are in the lamellar gel phase while the surrounding lipids are in the liquid disordered phase. These membrane subdomains are of biological relevance since they play a role in different endocytic pathways ${ }^{92}$ and in the recruitment of several proteins for example. ${ }^{93}$

Membrane deformation against the intrinsic shape of a lipid membrane is an energy consuming process and must exceed resistance to bending ${ }^{94}$. By using the classical Canhman ${ }^{95}$ and Helfrich ${ }^{96}$ theory, Stachowiak J. C. et al. estimated the energy cost for creating a curved sphere from a plain membrane as follows:

$$
\mathrm{G}_{\text {bending }}=(8 \pi \mathrm{K}) /\left(4 \pi \mathrm{r}^{2}\right)
$$

Where $\mathrm{K}$ is the bending rigidity of the membrane and $\mathrm{r}$ is the vesicle radius. Usual values for $\mathrm{k}$ are $\mathrm{k} \sim 10 \mathrm{k}_{\mathrm{B}} T$ for a fluid membrane and $\mathrm{k} \sim 50 \mathrm{k}_{\mathrm{B}} T$ for a typical mammalian plasma membrane containing $50 \%$ cholesterol ${ }^{97}$.

Several mechanisms have been identified regarding how local membrane deformation is generated in cells. One mechanism is the generation of lipid asymmetry between the opposing membrane leaflets (Figure 6A). Here, the geometries of the different lipid species are the driving force for membrane curvature and the headgroups as well as the structure of the fatty acid chain contribute to deformation processes ${ }^{98}$. To avoid lipid packing defects that result exposure of the hydrophobic acyl moieties to the aqueous solution, the membrane compensates by adopting to the intrinsic shape of the lipid geometry ${ }^{99,100}$. One example for the influence of lipid modification on membrane asymmetry is the conversion of lysophosphatidic acid (LPA) to PA mediated by LPA acyl transferase or the reverse conversion of PA to LPA by phospholipase $A_{2}{ }^{101}, 102$. PA induces negative membrane curvature due to the small headgroup in respect to the fatty acid chains. The loss of an acyl moiety inverses the conical structure resulting in an induction of positive curvature by LPA 101. Another example is the asymmetry of the plasma membrane itself. The exterior leaflet is enriched in sphingolipids and PtdCho. Both lipid species are cylindrically shaped but sphingolipids neighboring cylindrical lipids pack more tightly and increase the mechanical stability of this leaflet ${ }^{103}$. The interior leaflet is enriched in PtdEtn that creates negative curvature due to its strong conical shape ${ }^{104}$. This asymmetry is assumed to be involved in membrane curvature generation at the membrane ${ }^{94}$. 
Integral membrane proteins can have an impact on membrane deformation as well (Figure 6B). If the intrinsic shape of these proteins is conical, the membrane adapts to the shape to avoid packing defects and local membrane curvature is generated ${ }^{105,98}$. Integral membrane proteins often cluster and enhance the deformation induction by their selfassembly. Barbot M. et al. demonstrated that Mic10, a protein of the mitochondrial contact site and cristae organizing system (MICOS), is able to induce membrane hairpin formation via its self-assembly ${ }^{106}$. Mic10 consists of 2 transmembrane helices, one expands vertical through the hydrophobic area of the membrane, the other is assumed to expand in a slightly tilted way due to its length. Membrane deformation induced by this protein, is due to its ability to homo-oligomerize, since mutants without this ability did not induce curvature.

The cytoskeleton can induce membrane curvature in several ways (Figure 6C). Bursts of actin polymerization can induce stress on the membrane by pushing force, for instance in the generation of filopodia ${ }^{107,108}$. Microtubules together with motor proteins can also exert pulling force on the membrane. This was demonstrated for membrane remodeling in the mammalian ER ${ }^{109}$ as well as in Saccharomyces cerevisiae ${ }^{110}$.

The scaffolding mechanism was extensively studied in BAR (Bin/Amphiphysin/Rvs) domain proteins (Figure 6D). These soluble proteins dimerize ${ }^{111}$ resulting in an intrinsic concave shape ${ }^{112}$. The concave region is enriched in positively charged amino acids that interact with negatively charged phospholipids ${ }^{113}$. They preferentially bind to membrane curvatures corresponding to their own intrinsic shape ${ }^{49}$. A subgroup of this protein family, like amphiphysin and endophilin, contain the N-BAR domains that have amphipathic helices in addition to the protein scaffold ${ }^{114,48,}{ }^{113}$. The insertion of the amphipathic helices destabilizes the membrane tension and then it can be forced into the intrinsic BAR domain shape with lower energy costs.

The insertion of an amphipathic helix into one leaflet of the membrane is another mechanism to deform membranes (Figure 6E), called the hydrophobic insertion mechanism 115,105 . Proteins that use this mechanism have domains that act as a molecular wedge by the insertion into one leaflet of the membrane. This asymmetrically increases the surface of the membrane leading to packing defects and generation of positive curvature ${ }^{115}$. This mechanism was demonstrated for N-BAR proteins ${ }^{48}$, as mentioned before, but especially proteins of the Epsin family are known to induce membrane curvature by hydrophobic insertion ${ }^{115,116 .}$

Finally, a more recent mechanism to induce membrane curvature was introduced by Stachowiak J. C. et al., designated the protein crowding mechanism ${ }^{117}$ (Figure 6F). In this mechanism, peripheral membrane proteins bind with high density at the membrane. The resulting protein collisions induce membrane stress by lateral pressure ${ }^{118}$. The membrane 
then compensates by curvature generation. This principle was demonstrated by attaching globular domains to membranes ${ }^{119}$.

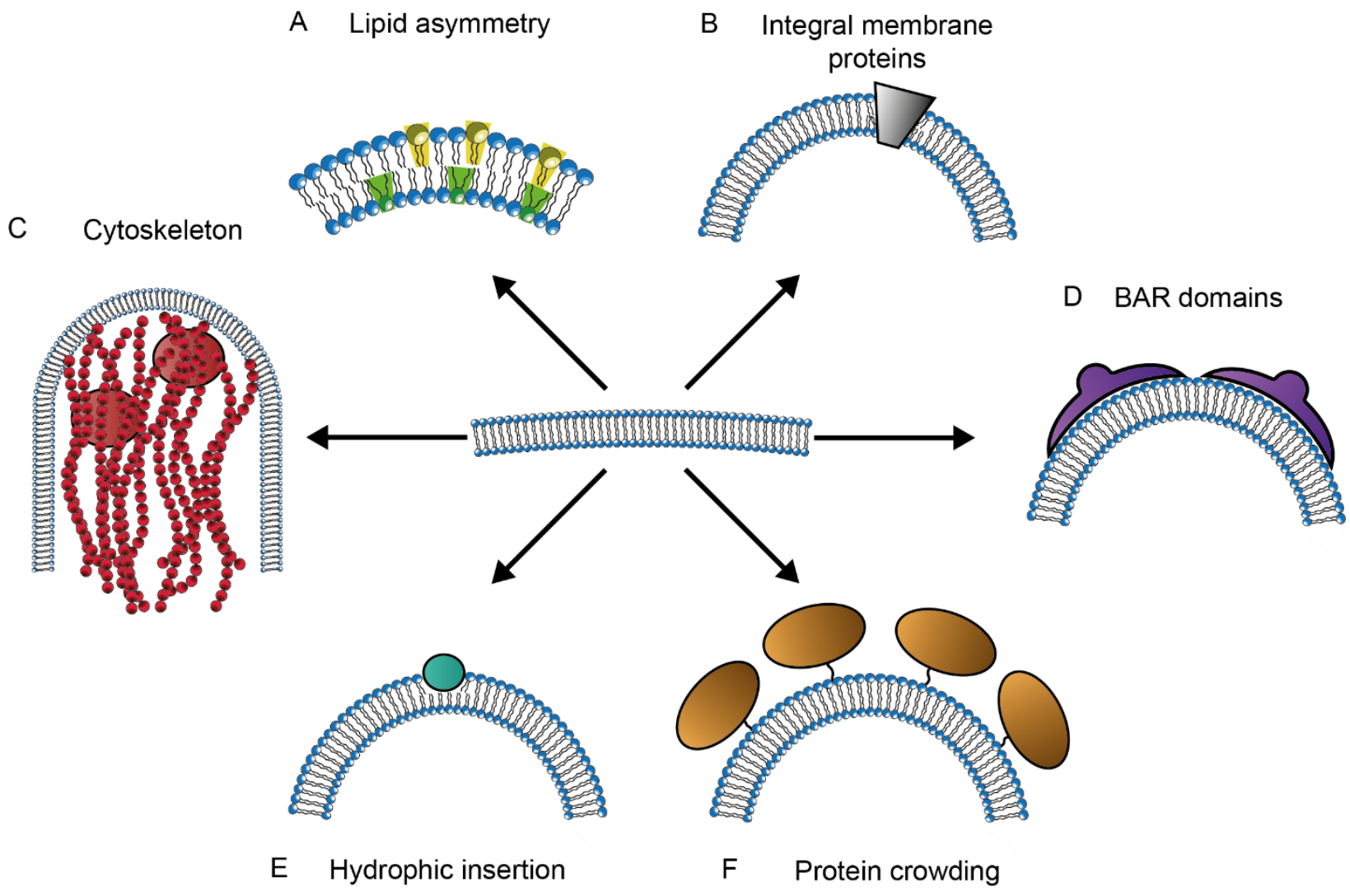

Figure 6: Schematic illustration of the different mechanisms of bending membranes. A Lipid asymmetry of conical shaped, or inverse conical shaped lipids induce membrane curvature. B The membrane adapts to the intrinsic shape of integral membrane proteins. C Cytoskeleton proteins can induce membrane curvature by pushing (or pulling). D The scaffolding mechanism is predominately used by BAR-domain proteins. E Insertion of an amphipathic molecule into one leaflet of the membrane induces lipid packing defects. $\mathbf{F}$ Protein crowding induces lateral pressure on the membrane, resulting in membrane deformation (adapted from McMahon et al. $2005^{98}$ and Stachowiak et al. $2013^{94}$ ). 
Introduction: Epsin

\subsection{Epsin}

Epsins are a family of membrane binding adaptor proteins, which are highly conserved across eukaryotic evolution and are expressed in all vertebrates. Epsin1, the eponym of this protein family, was originally identified as a binding partner of Eps15, one of the clathrin mediated endocytosis initiation proteins ${ }^{120}$. In the same study, it was revealed that the perturbation of Epsin1 function in $\mathrm{CHO}$ cells inhibited cellular uptake of clathrin mediated endocytosis cargoes.

\subsubsection{Functional and strucral relationship of Epsin}

The different Epsins have a similar architecture to Epsin1. This protein contains a characteristic 150 amino acid long ENTH (Epsin N-Terminal Homology) domain, which is in contrast to the rest of the protein tightly folded, and the main lipid binding module of the whole protein. The ENTH domains of Epsin1, 2 and 3 bind specifically phosphatidylinositol $(4,5)$ bisphosphate (Ptdlns $(4,5) \mathrm{P}_{2}$ ) (Figure 7 ), a lipid highly enriched at the plasma membrane at endocytic sites.

It is generally believed that Epsins play a role in cargo sorting for endocytic internalization. C-terminal to the ENTH domain Epsin1 possesses two to three ubiquitin interacting motifs (UIMs), depending on the spliced isoform ${ }^{121}$. In vitro, the UIMs interact tandemly to recruit purified tetraubiquitin and higher ubiquitinated proteins from cell extracts 122. The same study showed that the a subunit of the interleukin receptor is internalized into HeLa cells by endocytosis if it carries a tetraubiquitin. In contrast, the monoubiquitinated receptor was not internalized. The unstructured $C$ terminus of Epsin1 also contains several repeats of DPW (aspartic acid - proline - tryptophan) motifs, which are demonstrated to interact with the $\alpha$-appendage of the endocytic AP-2. The position and number of DPW motifs within the different Epsins is not conserved. This region is flanked by two clathrin binding motifs, LMDLADV (leucine - methionine - aspartic acid - leucine - alanine - aspartic acid - valine) and LVDLD (leucine - valine - aspartic acid - leucine - aspartic acid), that cooperatively bind one clathrin triskelion ${ }^{123}$. The clathrin interaction region together with the AP-2 binding motifs is often referred to as CLAP (clathrin and AP-2).

Several copies of NPF (asparagine - proline - phenylalanine) motifs are located at the C-terminal end of Epsin1, which mediate binding to EH (Eps15 homology) domain containing proteins like the CME initiation protein Eps15 ${ }^{120}$, POB1 ( BTZ/POZ domain-containing protein $\mathrm{POB} 1$ ) and intersectin. POB1 is involved in the regulation of DNA duplication during mitosis ${ }^{124}$ and intersectin is involved in the coordination of CME with the actin assembly machinery ${ }^{125}$. 


\subsubsection{Epsin proteins in different species}

Epsins are crucial for cell homeostasis and yeast cells are not viable if their Epsinlike proteins are knocked down ${ }^{126}$. Mammals have in general three Epsins (Figure 7). Epsin1 and Epsin2 are enriched in the brain and have crucial function in CME as they interact with AP-2 and clathrin ${ }^{127}$. Epsin3 is upregulated in wounded epithelia ${ }^{128}$. In addition, EpsinR (Epsin related protein) was identified as another ENTH domain containing protein ${ }^{129}$, 130. This protein is involved in membrane trafficking from the Trans-Golgi to endosomes. EpsinR rather binds to phosphatidylinositol(4)phosphate $(\operatorname{InsPtd}(4) \mathrm{P})$ than $\operatorname{Ptdlns}(4,5) \mathrm{P}_{2}$ and has a high affinity to AP-1 (Adaptor protein complex1). Other names for this protein are CLINT ${ }^{129}$ and Enthoprotin ${ }^{131}$. Embryonic fibroblasts from conditional Epsin triple KO (knock out) mice were used to demonstrate that endocytosis is impaired if all Epsin genes are knocked out ${ }^{132}$.

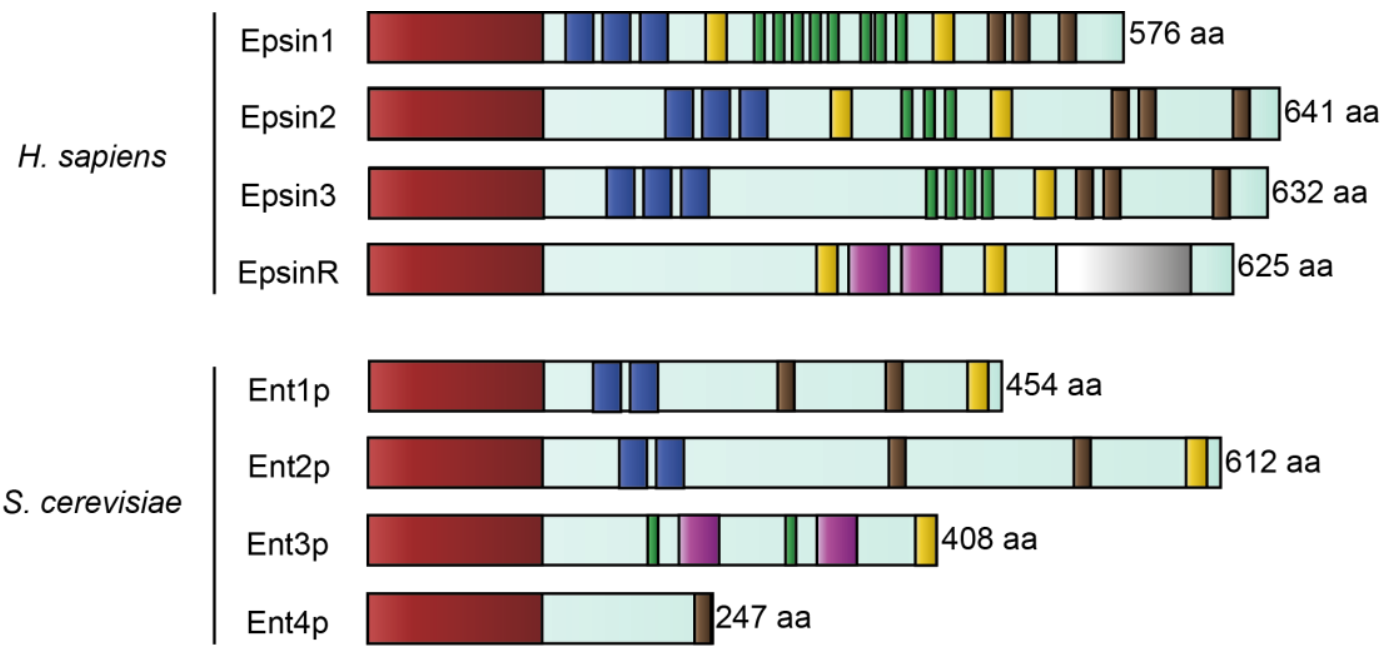

T. brucei $\mid \mathrm{TbEpsinR}$ 505 aa
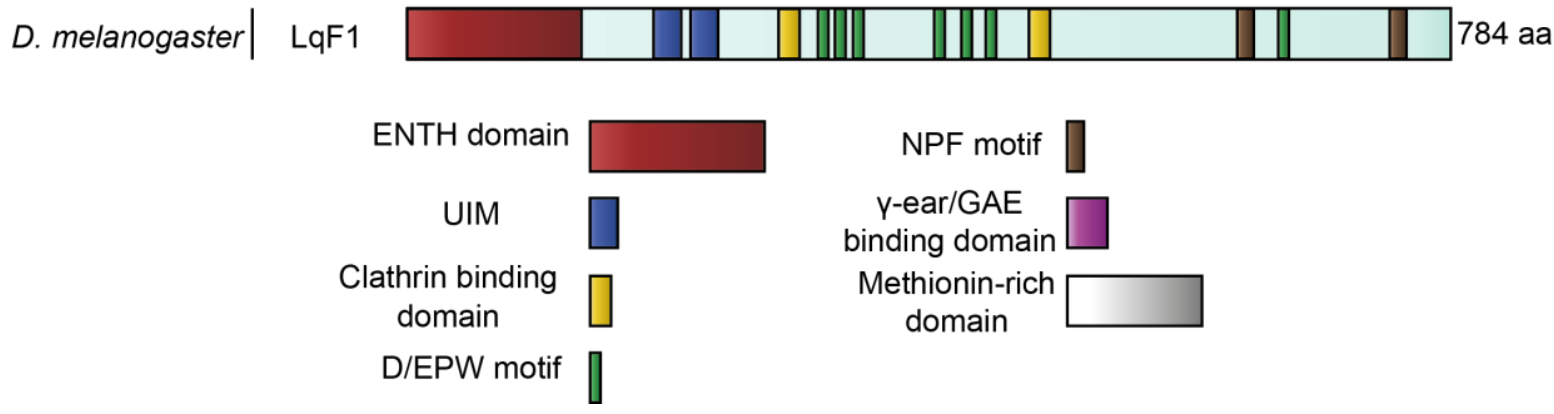

Figure 7: The linear architecture of Epsins across different species. The structures of human Epsins were taken and modified from Horvath et al., $2006{ }^{133}$ and the modified structures of yeast, D. melanogaster and $T$. brucei Epsins derived from De Camilli et al., $2002^{134}$. 
Proteins containing the ENTH domain have in common the fact that they bind to Ptdlns $(4,5) \mathrm{P}_{2}$ membranes. Saccharomyces cerevisiae possesses 4 proteins containing this characteristic motif (Figure 7). Ent1p and Ent2p (Equilibrative Nucleotide Transporter 2) are paralogues which can compensate each other in single KO mutants ${ }^{126}$. They are involved in endocytosis by clathrin recruitment to the cell membrane and are involved in actin patch assembly. Ent3p (Equilibrative Nucleotide Transporter 3) has the highest similarity to EpsinR 135. It is involved in the traffic between the Golgi and endosomes. Ent4p (Equilibrative Nucleotide Transporter 4) is not completely described so far and it is thought to be involved in Arn $1 p$ trafficking in absence of ferrichrome ${ }^{136}$.

Drosophila melanogaster (D. melanogaster) possesses one Epsin protein (Figure 7), which is called Lqf (liquid facets) ${ }^{137}$. This protein plays a critical role in the Notch signaling pathway ${ }^{138}$ but it is not required for synaptic vesicle recycling, which is classically regulated by clathrin mediated endocytosis ${ }^{139}$. Electrophysiological examination on third instar larval body walls did not show any defects in synaptic vesicle endocytosis when lqf mutants were analyzed in comparison to the wild type. In contrast, it was shown that the Notch pathway strongly depends on three motifs of Lqf: its ENTH domain, the ubiquitin interaction motifs and the C-terminal binding motifs ${ }^{140}$. The Notch pathway enables cells to communicate with each other by integral membrane proteins. The ligand cell carries the delta ligands that bind to the Notch receptor of the signal receiving cell. The Notch receptor then undergoes a series of proteolysis steps and a part of it, NICD (Notch intracellular domain), is transported to the nucleus where it activates Notch target genes. The extracellular part of the Notch receptor remains at the delta ligand and is internalized by endocytosis. Meloty-Kapella L. et al. demonstrated that in $D$. melanogaster Epsin and actin are responsible for the initiation of the signal cascade, once they pull the Notch receptor, making it available for the first proteolysis ${ }^{141}$. Lqf binds the ubiquitinated delta ligand Notch extracellular domain complex and induces pulling force. The complex is then internalized by transendocytosis into the ligand cell. The pulling force of Epsin was demonstrated by using the Notch1 (Notch homolog 1) soluble part of the receptor attached to laser trapped beads. The displacement of the Notch1 beads, as a measure for pulling force, was then detected in presence of ligand cells. The pulling force decreased if the cells used were silenced by Epsin siRNAs (small interfering RNA).

Evolutionary studies about Epsins were also carried out in Trypanosoma brucei ( $T$. brucei), which is a protozoan parasite. Remarkably, this organisms possess a reduced clathrin adaptor gene cohort, consisting of one Epsin protein (TbEpsinR) (Figure 7), a CALM (Clathrin assembly lymphoid myeloid leukemia protein) protein and the clathrin heavy and light chain, but not AP-2 ${ }^{142}$. The Epsin protein is most related to the mammalian EpsinR. TbEpsinR has a double function: it is localized at endosomal membranes and surprisingly it 
Introduction: Epsin

also accumulates, unlike mammalian EpsinR, at the flagellar pocket, where clathrin mediated endocytosis in T.brucei takes place ${ }^{143}$.

\subsubsection{Epsin and endocytosis}

Epsin1 plays a crucial role in endocytosis of synaptic vesicles ${ }^{144}$. It was shown that Epsin1 concentrates at nerve terminals in primary cultures of hippocampal cells. Endocytosis was impaired and arrested at the cell surface if Epsin1 was silenced by shRNAs (short hairpin RNA). It is remarkable that synaptic vesicle internalization could be rescued by introducing an Epsin1 construct that at least possessed the ENTH domain, the CLAP region and the NPF motifs. The interaction between clathrin and Epsin1 was elucidated in a model membrane system with different degrees of curvature ${ }^{145}$. Clathrin alone was not able to bind to the membrane system, but Epsin1 was sufficient to recruit clathrin to highly curved membranes. In 2012 Boucrot E. et al. demonstrated the significance of Epsins during endocytosis in different cell types ${ }^{115}$. In triple silenced cells (Epsin1, 2,3 siRNAs) endocytic cargo uptake was impaired and clathrin remained as flat lattices on the plasma membrane. In addition, they showed that Epsins are sufficient to mediate clathrin coated vesicle fission from the plasma membrane if dynamin expression in such cells was reduced.

Although AP-2 is the main adaptor protein for cargo recognition in CME, there are a few cargo proteins, which are Epsin specific. One example is the epithelial sodium channel $(\mathrm{ENaC})$ which is predominantly localized in polarized epithelial cells in kidneys, lung and colon ${ }^{146}$. These channels are involved in maintaining the $\mathrm{Na}^{+}$and $\mathrm{K}^{+}$concentration in blood, epithelial and extra epithelial fluids. In 2009 it was shown that ENaC is a cargo for CME ${ }^{147}$. They demonstrated by immunoprecipitation and in a Xenopus oocytes expression system that the UIMs of Epsin specifically bind to ubiquitinated ENaC. Another CME cargo that is internalized upon the interaction with Epsin is the EGFR. Its activation leads to receptor dimerization, autophosphorylation and cascadial phosphorylation of cytosolic signaling proteins. The cell can respond in different ways to the signaling, for instance with proliferation or migration. The activated receptor is internalized by CME into the cytosol ${ }^{148}$ after ubiquitination, where it is degraded or recycled back to the cell membrane. EGFR uptake is dependent on its ubiquitination and the interaction with Epsin. Internalization was significantly decreased if Epsin in HeLa cells was silenced by siRNA ${ }^{149}$.

\subsubsection{Clinical Relevance of Epsin}

Besides its classical role as an endocytic adaptor, several research works suggest that these proteins have a role in the regulation of the activation of GTPases ${ }^{150,151}$. Epsins were reported to interact and inhibit several GTPase activating proteins (GAPs) which are recruited or localized at the plasma membrane, promoting the accumulation of GTP-loaded 
GTPases and the development of polarized edges. These studies suggest that Epsins may be able to regulate cell polarity and migration through an unknown alternative mechanism.

Since Epsins are involved in cell proliferation, a growing interest has arisen on the potential of migration and differentiation to regulate carcinogenesis. In fact, several transcriptomic and proteomic studies reported elevated expression of Epsins in tumor tissues and tumor cell lines ${ }^{128,152,153}$. By using mouse models, in which Epsin1 and 2 were indelibly deleted, it was shown that adult mice lacking these proteins presented highly disorganized vascular structures and markedly increased vascular permeability in tumors, which resulted in increased nonproductive tumor angiogenesis and retarded tumor growth. The Epsins interact with the activated vascular epithelial growth factor receptor 2 (VEGFR2) and the authors propose a model, in which Epsin attenuates the VEGF (vascular epithelial growth factor) signal for a controlled angiogenesis ${ }^{154}$. Another study showed that expression of Epsins is upregulated in both human and mouse prostate cancer cells, as well as in prostate cancer tissues ${ }^{155}$. Taken together, these data highlight Epsins as potential targets for antitumoral strategies.

Another pathological condition to which Epsins seem to be related to is schizophrenia. This disease is a highly heritable psychosis that affects $1 \%$ of the world's population, but the genes that contribute to its development remain elusive ${ }^{156}$. An association study performed by Pimm J. et al, in which blood samples from 450 volunteers with schizophrenia and 450 controls from London and Southern England were used, marked the Epsin 4 gene (which encodes Enthoprotin, a protein involved in vesicular transport) on chromosome $5 q$ as a robust candidate for schizophrenia susceptibility ${ }^{157}$. Two other studies, conducted in the Han Chinese population, provided contradictory evidence for this population ${ }^{158,159}$.

Epsins might also play a role in pathogenic bacteria entry into the cell. For example, the extracellular pathogens EPEC (enteropathogenic Escherichia coli) adhere to intestinal cells causing the formation of pedestals (actin-rich structures). This process is dependent on Epsin1, which co-localizes with pedestals in infected HeLa cells ${ }^{160}$.

Finally, Epsins seem also to be involved in the clathrin mediated endocytosis of the influenza virus independent of the AP-2 adaptor ${ }^{161}$. The contemporaneous recruitment of Epsin1 to the binding sites of influenza viruses with the assembly of clathrin coated pits was observed in BS-C-1 cells ${ }^{162}$. The knockdown of Epsin1 significantly inhibited clathrin mediated endocytosis of the influenza virus and the majority of the virus particles entered through a CIEs. Overexpression of the dominant-negative Epsin1 mutant, which lacks the UIMs, almost completely blocked the clathrin mediated entry of the influenza virus. 


\subsection{The ENTH domain}

The organization and composition of the binding motifs vary within the different Epsin proteins, except for the ENTH domain which is always located at the very $\mathrm{N}$-terminus. This 150 -amino acid stretch is the membrane binding module of this protein family. The ENTH domain of Epsin1 has the highest affinity to $\operatorname{Ptd} \operatorname{lns}(4,5) \mathrm{P}_{2}$, but is also recruited to Ptdlns $(3,4,5) \mathrm{P}_{3}$ containing membranes ${ }^{163}$. In the same study, it was demonstrated that the overexpression of a mutant form of Epsin1 (with an ENTH domain defect in phosphoinositide binding) promotes an impairment in the internalization of EGFR in COS-7 cells. It was concluded that the interaction between the membrane and Epsin1 is critical for its role in endocytosis.

\subsubsection{Structural properties of the ENTH domain}

The crystal structure of the ENTH domain was first resolved by Hyman J. et al. (Figure 8A), revealing that it has a globular fold that is composed of seven $\alpha$-helices, and a misaligned eighth one ${ }^{164}$. The seven helices are stacked consecutively with a right-handed twist. Moreover, an additional helix was detected at the very N-terminus of the ENTH domain (Figure $8 \mathrm{C}$ ) through the incubation with inositol-1,4,5-triphosphate (the headgroup of Ptdlns $\left.(4,5) \mathrm{P}_{2}\right)$. This additional helix was designated helix zero $\left(\mathrm{H}_{0}\right)^{116} . \mathrm{H}_{0}$ is amphipathic and was demonstrated to insert into one leaflet of a lipid bilayer. This was determined by measuring the change of surface pressure of a monolayer in presence and absence of the ENTH domain via a computer-controlled tensiometer ${ }^{165}$. The hydrophilic, positively charged amino acids, of $\mathrm{H}_{0}$ contribute to Ptdlns $(4,5) \mathrm{P}_{2}$ headgroup binding. In contrast, the hydrophobic amino acids of this helix are facing the fatty acid region of the membrane (Figure $8 \mathrm{D}$ and $8 \mathrm{E}$ ). This way of binding membranes is termed the hydrophobic insertion mechanism ${ }^{116}$.

The binding of the ENTH domain to soluble inositides depends on the different positions of the phosphate groups within the cyclic alcohol ring. Isothermal titration calometry (ITC) analysis, revealed that the ENTH domain has a high affinity and a one to one stoichiometry for $\operatorname{Ins}(1,4,5) \mathrm{P}_{3}$ and an even higher affinity for the short fatty acid chained $\mathrm{diC}_{8}$ Ptdlns $(4,5) \mathrm{P}_{2}$, which is still soluble in aqueous suspension. In the same study, it was shown that ENTH had a moderate affinity to inositol $(1,3,4,5) \mathrm{P}_{4}$, while the dissociation constant for other inositides tested was high, reflecting low affinity. The phosphates at position one, four and five are critical for ENTH domain binding and coordinate within a binding pocket formed by $\mathrm{H}_{0}, \mathrm{H}_{1}$, the loop $\mathrm{H}_{1}-\mathrm{H}_{2}, \mathrm{H}_{3}$ and $\mathrm{H}_{4}$.

Structurally, the ENTH domain is highly related to the ANTH (AP180 N-terminal homology) domain (Figure 8B), which is the lipid binding module of AP180 (adaptor protein 180 ) and CALM ${ }^{116}$. These proteins also play a role in clathrin mediated endocytosis ${ }^{37,166 .}$ 
The ANTH domain also has a high binding affinity to Ptdlns $(4,5) \mathrm{P}_{2}$, but it binds to membranes upon surface charge interactions and not by the hydrophobic insertion mechanism $^{165}$.

A

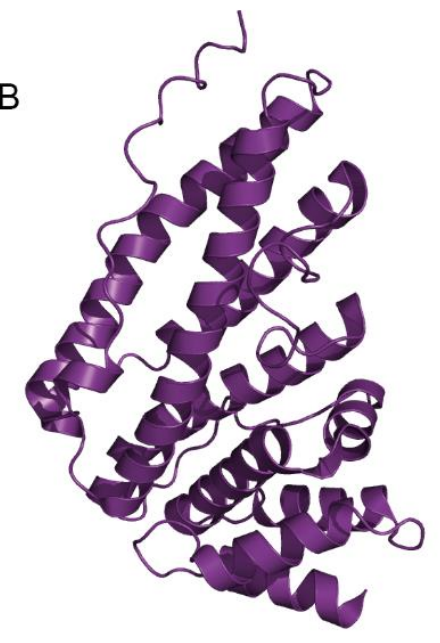

C

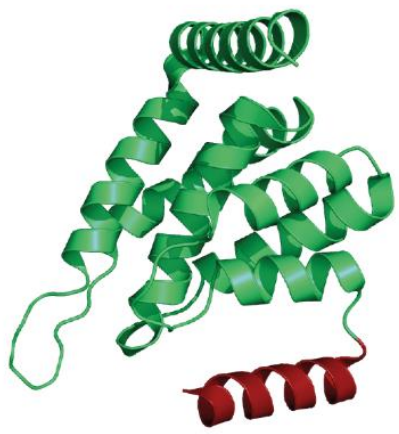

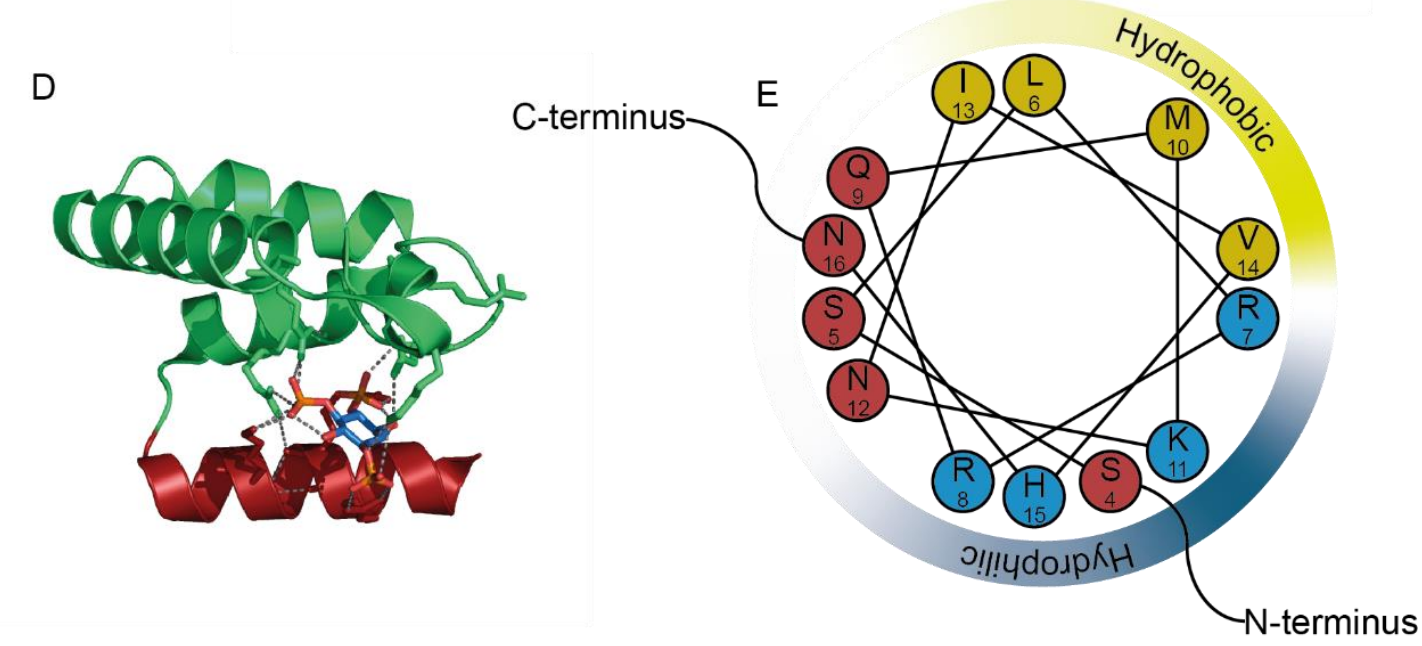

Figure 8: Structural properties of the ENTH domain and related domains. A: The ENTH domain of Epsin1 without structured $\mathrm{H}_{0}$ (Hyman, 2000) in comparison to the ANTH domain of CALM (B, Ford, 2001). C: The ENTH domain of Epsin1 with structured N-terminal $\mathrm{H}_{0}$ (Ford, 2002). D: A close-up of the Ptdlns(4,5)P2 binding pocket with $\operatorname{Ins}(1,4,5) \mathrm{P}_{3}$. E: Radial projection of the amino acids that compose the amphipathic helix.

\subsubsection{Function of the ENTH domain}

The ENTH domain deforms membranes in vitro ${ }^{116}$. The protein was incubated with large unilamellar vesicles (LUVs) composed by a lipid extract (FOLCH lipids), derived from brain, containing $10 \% \operatorname{Ptdlns}(4,5) \mathrm{P}_{2}$. Electron microscopic analysis revealed that the presence of the ENTH domain and full length Epsin1 induced the generation of membrane tubules. This tubulation activity was not observed without Ptdlns $(4,5) \mathrm{P}_{2}$, in absence of the protein or in replacement of the ANTH domain. To find out how the amphipathic helix contributes to membrane deformation, ENTH domain mutants were generated of the lysine 
at the sixth position in the amino acid sequence (L6). Lysine was mutated to glutamic acid $(E)$, glutamine $(\mathrm{Q})$, histidine $(\mathrm{H})$ or tryptophan $(\mathrm{W})$. The ability of these mutants to bind to membranes was determined by liposome co-sedimentation assays. L6E completely failed in binding to membranes and did not show membrane deformation activity. With increasing hydrophobicity of the substituted amino acid, the membrane binding and deformation ability was increasingly restored. L6W showed, in contrast to the wild type, a strong vesiculation activity. Finally, they also showed, in morphological studies of lipid monolayers, that Epsin1 alone is able to recruit clathrin to the membrane as invaginated clathrin lattices ${ }^{116}$.

In order to demonstrate how $\mathrm{H}_{0}$ penetrates the membrane, two groups performed electron paramagnetic resonance (EPR) examination using site-directed spin-labeled ENTH domains bound to LUVs ${ }^{167,168}$. Kweon D. et al. demonstrated that the amphipathic helix was only stably formed in presence of LUVs containing Ptdlns $(4,5) P_{2}$. The immersion depth and the tilt angel of the inserted helix remain controversial. This study determined that the bulk of the helix orients in the depth of the lipid headgroups and the amino acids on position nine and thirteen (glutamine and isoleucine) immerse until $5 \AA$. The amphipathic helix inserts into the membrane with a tilt angle of $11^{\circ}$. Yoon $Y$. et al. determined a tilt angel of the inserted amphipathic helix with $23^{\circ}$ in respect to the membrane normal ${ }^{168}$. The immersion depth was $12 \AA$ A. Both groups used similar lipid compositions for their membranes. Using EPR analysis and by fluorescence microscopy with labeled ENTH domain incubated on GUVs, they detected that the ENTH domain seemed to form clusters. Membrane binding, but not clustering, was still present if they mutated K23E and E42K of the ENTH domain. The data indicates that the amphipathic helix of the ENTH inserts into one leaflet of bilayer in a horizontal, slightly tilted manner. It orientates in the height of the glycerol backbone, the energetic most favorable insertion depth to induce membrane deformation ${ }^{115}$.

As it was mentioned before, BAR domain proteins are endocytic proteins that are able to sense membrane curvature and bind to a preferential degree of curvature ${ }^{50}$. Capraro $\mathrm{B}$. R. et al. investigated if the ENTH domain was also able to sense membrane curvature ${ }^{169}$. Therefore, they used a model membrane system with two degrees of curvature by pulling out membrane tethers from a GUV by optical tweezers. The ENTH domain bound preferentially to the tether and less binding was observed on the GUV.

It remains controversial if the ENTH domain is able to form higher ordered clusters on membranes. EPR spectroscopic experiments demonstrated that ENTH domains dimerize on preformed membrane tubules ${ }^{170}$. Coarse grained molecular dynamics simulation showed that the ENTH domain dimerized in an antiparallel manner and formed a lattice on membrane tubules. ENTH domain bound to vesicles did not order in this way.

In contrast to an older study of the same group, Boucrot E. et al. showed that the presence of ENTH domain induces the generation of $20 \mathrm{~nm}$ vesicles from LUVs in vitro by 
electron microscopy ${ }^{115}$. This effect was enhanced with the L6W mutant and decreased with the L6E mutant. The generation of very small vesicles as the main membrane deformation effect of the ENTH domain was confirmed by using burst analysis spectroscopy (BAS) ${ }^{171}$.

Gleisner M. et al. gave insights into the underlying physics upon membrane insertion of the amphipathic helix ${ }^{172}$. On pore spanning membranes they were able to control membrane curvature by using buffers on both sites of the membrane that were unequal in osmolarity. Addition of the ENTH domain to Ptdlns $(4,5) \mathrm{P}_{2}$ containing membranes induced membrane curvature in buffers with constant osmolarities. They conclude that ENTH domain binding decreased the lateral membrane tension.

Finally, Gleisner M. et al. demonstrated in another study that the ENTH domain membrane deformation activity depends on the tension of the membrane ${ }^{173}$. They were able to control the membrane tension of GUVs by the concentration of $\mathrm{Mg}^{2+}$. The addition of the ENTH domain to GUVs with high tension resulted in collapsing GUVs. In contrast, if they used GUVs with low membrane tension, they observed the formation of membrane tubles.

Single ENTH domain molecules have a complex diffusive behavior even on simple membrane compositions ${ }^{174}$. The trajectories of single ENTH domains bound to membranes composed of phosphatidylcholine and Ptdlns $(4,5) \mathrm{P} 2$ were recorded by TIRFM and used to determine their diffusion behavior. The results revealed that the ETNH domain trajectories are a result of three different diffusion processes that are all distinct from Brownian movement. The authors concluded in this way that the ENTH domain has three different membrane binding states.

Taken together, these results lead to a molecular model of membrane deformation by the ENTH domain. Its amphipathic helix inserts into one leaflet of the membrane with a tilted angle. It inserts until the glycerol backbone, leading to an increase in surface area of one bilayer leaflet and to the generation of positive curvature (Figure 9). 
Introduction: The ENTH domain

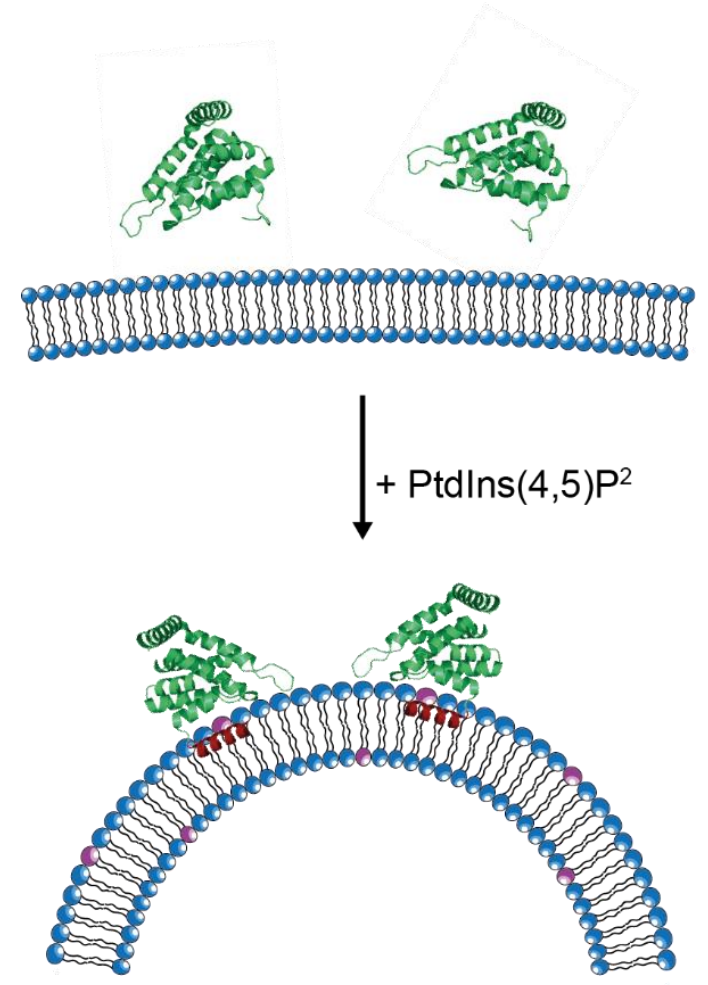

Figure 9: ENTH domain interactions with the membrane: The ENTH does not bind to membranes without Ptdlns $(4,5) \mathrm{P}_{2}$. In presence of Ptdlns $(4,5) \mathrm{P}_{2} \mathrm{H}_{0}$ structures and penetrates the membrane, resulting in membrane curvature.

\subsubsection{The protein crowding model}

In contrast to the amphipathic insertion mechanism, Stachowiak J. C. et al. introduced a distinct molecular model: membrane deformation by protein crowding. They generated regions of high local Ptdlns $(4,5) \mathrm{P}_{2}$ concentration on GUVs and observed only in these regions membrane tubulation by either using ENTH domain or the ANTH domain. They repeated this experiment with an ENTH domain mutant without $\mathrm{H}_{0}$, but containing a hexahistidine, and GUVs with $\mathrm{Ni}^{2+}$ NTA (Nitrilotriacetic acid) lipids. Without the insertion of an amphipathic helix they still observed tubulation. They concluded that tubules are generated by lateral pressure of colliding proteins attached to the membrane ${ }^{118}$. It was shown that Epsin1 and AP180 are able to induce membrane deformation at lower concentrations if compared to their single $\mathrm{N}$-terminal domains ${ }^{175}$, concluding that the unstructured $\mathrm{C}$-termini apply even more local lateral pressure. 
Introduction: The ENTH domain

\subsubsection{ENTH domain protein interactions}

Surprisingly, the yeast ENTH domain and the yeast ANTH domain form heterooligomers. This was observed in addition to membrane tubulation on $\operatorname{Ptdlns}(4,5) \mathrm{P}_{2}$ containing membranes forming a regular coat in vitro ${ }^{176}$. The oligomerization region was determined distinct from the lipid interaction sites of both proteins

ENTH domains seem to play a role in SNARE mediated membrane fusion in yeast. The analyzes of the crystal structure revealed that the ENTH domain of Ent3p has an additional binding pocket for the vesicle transport v-SNARE protein Vti1 which is conserved across all ENTH domains ${ }^{177}$. The physiological impact of inhibiting the complex formation was the mis- localization of Vti1 in yeast.

In another study it was demonstrated that the ENTH domain also has regulatory effects on cell polarity during mitosis in yeast ${ }^{178}$. The ENTH domain of the yeast Ent1 and Ent2 proteins have an additional binding pocket for a GTPase-activating protein specific for Cdc42 (Cell division control protein 42). 


\section{Scope of the thesis}

During clathrin mediated endocytosis cargo molecules are transported across the plasma membrane from the outer cell surface into the cytosol. The plasma membrane undergoes massive local remodeling events. This pathway is mediated and regulated by a complex protein machinery, each component is recruited to the plasma membrane at specific timepoints.

One of these proteins is Epsin1, which is fundamental for CME and highly conserved across eukaryotic evolution. Its N-terminal ENTH domain is the lipid binding motif and specifically binds to phosphatidylinositol-4,5bisphosphate (Ptdlns $\left.(4,5) \mathrm{P}_{2}\right)$. Upon membrane binding, the ENTH domain structures an additional amphipathic helix that inserts into the membrane. The ENTH domain interaction with membranes is associated with the induction of membrane deformation and the predominant generation of small vesicles. Although the ENTH domain induced membrane deformation was extensively studied, little is known about the mechanisms how it generates high degrees of membrane curvature.

So far, membrane deformation analysis were performed with model membranes composed of unspecific lipid extracts, while membranes composed of simple lipid compositions resisted ENTH domain mediated deformation induction. Thus, it is necessary to identify lipid species, beside Ptdlns $(4,5) \mathrm{P}_{2}$, that govern ENTH domain induced membrane deformation to determine if these lipid species directly interact with the ENTH domain or if they influence the physical properties of the membrane.

Therefore, a combined strategy of membrane binding and deformation assays will be used with liposomes of defined lipid compositions to determine the effect of different lipid species. Promising lipid compositions will be then further examined for dynamics of membrane binding and deformation by the GUV assay. Furthermore, regions of interest within the ENTH domain will be mutated and tested for their function. Therefore, lipid binding and formation of homo-oligomers will be examined by FRET assays and identified by mass spectrometry.

Finally, the fucnction of Epsin1 within endocytosis is not completely elucidated. Hence, it potential role in cargo sorting into clathrin coated vesicles will be investigated by co-migration assays and by GUV assays. 


\section{Materials and methods}

\subsection{Materials}

3.1.1 Reagents

\begin{tabular}{|c|c|}
\hline Reagent & Company \\
\hline$\left(\mathrm{NH}_{4}\right)_{2} \mathrm{SO}_{4}$ & $\begin{array}{l}\text { Carl Roth GmbH \& Co. KG, Karlsruhe, } \\
\text { Germany }\end{array}$ \\
\hline 100x MeM vitamin solution & $\begin{array}{l}\text { Thermo Fisher Scientific Inc., Waltham, } \\
\text { USA }\end{array}$ \\
\hline 10X FastDigest Green Buffer & $\begin{array}{l}\text { Thermo Fisher Scientific Inc., Waltham, } \\
\text { USA }\end{array}$ \\
\hline Acetic acid, ROTIPURAN ${ }^{\circledR} 100 \%$ & $\begin{array}{l}\text { Carl Roth GmbH \& Co. KG, Karlsruhe, } \\
\text { Germany }\end{array}$ \\
\hline Acetone, ROTIPURAN ${ }^{\circledR} 99.8 \%$ & $\begin{array}{l}\text { Carl Roth GmbH \& Co. KG, Karlsruhe, } \\
\text { Germany }\end{array}$ \\
\hline Acetonitril, ROTIPURAN ${ }^{\circledR} 99.5 \%$ & $\begin{array}{l}\text { Carl Roth GmbH \& Co. KG, Karlsruhe, } \\
\text { Germany }\end{array}$ \\
\hline Agar-Agar, Kobe & $\begin{array}{l}\text { Carl Roth GmbH \& Co. KG, Karlsruhe, } \\
\text { Germany }\end{array}$ \\
\hline Agarose NEEO ultra quality & $\begin{array}{l}\text { Thermo Fisher Scientific Inc., Waltham, } \\
\text { USA }\end{array}$ \\
\hline Ammonium persulfate & $\begin{array}{l}\text { Carl Roth GmbH \& Co. KG, Karlsruhe, } \\
\text { Germany }\end{array}$ \\
\hline Ammonium- $-{ }^{15} \mathrm{~N}_{2}$ sulfate & Sigma-Aldrich Corp., St. Louis, USA \\
\hline Ampicillin & Sigma-Aldrich Corp., St. Louis, USA \\
\hline Anza $^{\text {TM }} 10$ Dpnl Buffer & Invitrogen AG, Carlsbad, USA \\
\hline Bromophenol blue & Sigma-Aldrich Corp., St. Louis, USA \\
\hline $\mathrm{CaCl}_{2}$ & $\begin{array}{l}\text { Carl Roth GmbH \& Co. KG, Karlsruhe, } \\
\text { Germany }\end{array}$ \\
\hline $\mathrm{CHCl}_{3}, \mathrm{ROTIPURAN}^{\circledR} 99 \%$ & $\begin{array}{l}\text { Carl Roth GmbH \& Co. KG, Karlsruhe, } \\
\text { Germany }\end{array}$ \\
\hline Coomassie Briliant Blue R-250 & $\begin{array}{l}\text { Carl Roth GmbH \& Co. KG, Karlsruhe, } \\
\text { Germany }\end{array}$ \\
\hline
\end{tabular}


Materials and methods: materials

$\mathrm{CuSO}_{4}$

$\mathrm{D}(+)$-sucrose

D-glucose- $1-{ }^{13} \mathrm{C}$

Dimethylformamide (DMF)

Dimethylsulfoxid (DMSO)

Dithiotreitol (DTT)

Ethidium bromide, $0.025 \%$

Ethylenediaminetetraacetic acid (EDTA)

EtOH, ROTIPURAN ${ }^{\circledR} 99.8 \%$

$\mathrm{FeSO}_{4} \cdot 7 \mathrm{H}_{2} \mathrm{O}$

Glycerol

Glycine

$\mathrm{HCl}, 6 \mathrm{~N}$

Hepes

Histodenz $^{\mathrm{TM}}$

Homobifunctional

bis(sulfosuccinimidyl)suberate

Imidazol

lodoacetamide

Isopropyl- $\beta$-D-thiogalactopyranosid (IPTG)

$\mathrm{K}\left(\mathrm{CH}_{3} \mathrm{COO}\right)$

$\mathrm{K}_{2} \mathrm{HPO}_{4}$

Kanamycin sulfate
Sigma-Aldrich Corp., St. Louis, USA

Carl Roth $\mathrm{GmbH}$ \& Co. KG, Karlsruhe, Germany

Sigma-Aldrich Corp., St. Louis, USA

Sigma-Aldrich Corp., St. Louis, USA

Thermo Fisher Scientific Inc., Waltham, USA Germany

Carl Roth GmbH \& Co. KG, Karlsruhe, Germany

Carl Roth GmbH \& Co. KG, Karlsruhe, Germany

Carl Roth $\mathrm{GmbH}$ \& Co. KG, Karlsruhe, Germany

Carl Roth GmbH \& Co. KG, Karlsruhe, Germany

Sigma-Aldrich Corp., St. Louis, USA

Carl Roth $\mathrm{GmbH}$ \& Co. KG, Karlsruhe, Germany

Carl Roth GmbH \& Co. KG, Karlsruhe, Germany

Carl Roth $\mathrm{GmbH}$ \& Co. KG, Karlsruhe, Germany

Carl Roth GmbH \& Co. KG, Karlsruhe, Germany

Sigma-Aldrich Corp., St. Louis, USA

Sigma-Aldrich Corp., St. Louis, USA

Carl Roth $\mathrm{GmbH}$ \& Co. KG, Karlsruhe, Germany

Sigma-Aldrich Corp., St. Louis, USA

Carl Roth $\mathrm{GmbH}$ \& Co. KG, Karlsruhe, Germany

Carl Roth GmbH \& Co. KG, Karlsruhe, Germany

Carl Roth GmbH \& Co. KG, Karlsruhe, Germany

Sigma-Aldrich Corp., St. Louis, USA 


$$
\begin{aligned}
& \mathrm{KC}_{2} \mathrm{H}_{3} \mathrm{O}_{2} \\
& \mathrm{KCl} \\
& \mathrm{KH}_{2} \mathrm{PO}_{4}
\end{aligned}
$$

Lipid-free bovine serum albumin MeOH, ROTIPURAN ${ }^{\circledR} 99.8 \%$

$\mathrm{Mg}\left(\mathrm{CH}_{3} \mathrm{COO}\right)_{2} \cdot 4 \mathrm{H}_{2} \mathrm{O}$

$\mathrm{MgCl}_{2}$

$\mathrm{MgSO}_{4}$

$\mathrm{MnCl}_{2} \cdot 4 \mathrm{H}_{2} \mathrm{O}$

$\mathrm{MnSO}_{4} \cdot \mathrm{H}_{2} \mathrm{O}$

MOPS

$\mathrm{Na}_{2} \mathrm{HPO}_{4} \cdot 2 \mathrm{H}_{2} \mathrm{O}$

$\mathrm{NaCl}$

$\mathrm{NaHCO}_{3}$

$\mathrm{NaOH}$

$\mathrm{NaOH} 50 \%(\mathrm{v} / \mathrm{v})$

$\mathrm{NH}_{4} \mathrm{HCO}_{3}$

$\mathrm{NH}_{4} \mathrm{MoO}_{4}$

Perchloric acid, ROTIPURAN ${ }^{\circledR} 70 \%$

$\mathrm{RbCl}$
Carl Roth GmbH \& Co. KG, Karlsruhe, Germany

Carl Roth $\mathrm{GmbH}$ \& Co. KG, Karlsruhe, Germany

Carl Roth GmbH \& Co. KG, Karlsruhe, Germany

Sigma-Aldrich Crop., St. Louis, USA

Carl Roth $\mathrm{GmbH}$ \& Co. KG, Karlsruhe, Germany

Carl Roth $\mathrm{GmbH}$ \& Co. KG, Karlsruhe, Germany

Carl Roth $\mathrm{GmbH}$ \& Co. KG, Karlsruhe, Germany

Carl Roth $\mathrm{GmbH}$ \& Co. KG, Karlsruhe, Germany

Carl Roth GmbH \& Co. KG, Karlsruhe, Germany

Sigma-Aldrich Corp., St. Louis, USA

Carl Roth $\mathrm{GmbH}$ \& Co. KG, Karlsruhe, Germany

Carl Roth $\mathrm{GmbH}$ \& Co. KG, Karlsruhe, Germany

Carl Roth GmbH \& Co. KG, Karlsruhe, Germany

Carl Roth $\mathrm{GmbH}$ \& Co. KG, Karlsruhe, Germany

Carl Roth GmbH \& Co. KG, Karlsruhe, Germany

Carl Roth $\mathrm{GmbH}$ \& Co. KG, Karlsruhe, Germany

Carl Roth $\mathrm{GmbH}$ \& Co. KG, Karlsruhe, Germany

Sigma-Aldrich Chemie GmbH, Darmstadt, Germany

Carl Roth GmbH \& Co. KG, Karlsruhe, Germany

Sigma-Aldrich Corp., St. Louis, USA 
Reduced Glutathion

Rotiphorese Gel 30, Acrylamide/ Bisacrylamide (37.5:1)

Sodium dodecyl sulfate (SDS)

T4 DNA Ligase

T4 DNA ligase Buffer

Tetramethylethylenediamine (TEMED)

Trichloroacetic acid

Trifluoroacetic acid

Tris

Tryptone

Uranyl acetate $\cdot 2 \mathrm{H}_{2} \mathrm{O}$

Yeast extract

$\mathrm{ZnSO}_{4} \cdot 7 \mathrm{H}_{2} \mathrm{O}$

$\beta$-mercaptoethanol
Sigma-Aldrich Corp., St. Louis, USA

Carl Roth GmbH \& Co. KG, Karlsruhe, Germany

Carl Roth GmbH \& Co. KG, Karlsruhe, Germany

Thermo Fisher Scientific Inc., Waltham, USA

Thermo Fisher Scientific Inc., Waltham, USA

Carl Roth GmbH \& Co. KG, Karlsruhe, Germany

Carl Roth GmbH \& Co. KG, Karlsruhe, Germany

Sigma-Aldrich Corp., St. Louis, USA

Carl Roth GmbH \& Co. KG, Karlsruhe, Germany

Carl Roth GmbH \& Co. KG, Karlsruhe, Germany

SERVA Electrophoresis $\mathrm{GmbH}$, Heidelberg, Germany

Carl Roth GmbH \& Co. KG, Karlsruhe, Germany

Sigma-Aldrich Corp., St. Louis, USA

Sigma-Aldrich Corp., St. Louis, USA

\subsubsection{Consumables}

\begin{tabular}{|c|c|}
\hline Consumable & Company \\
\hline 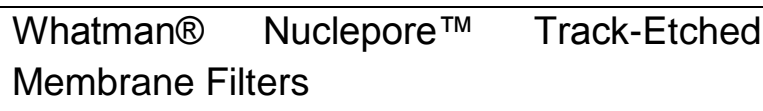 & Whatman plc, Maidstone, England \\
\hline Indium tin oxide-coated glass slides & $\begin{array}{l}\text { Nanion Technologies GmbH, Munich, } \\
\text { Germany }\end{array}$ \\
\hline Nunc $\AA$ Lab-Tek $®$ II chambered coverglass & $\begin{array}{l}\text { Thermo Fisher Scientific Inc., Waltham, } \\
\text { USA }\end{array}$ \\
\hline Spectra/Por Standard RC Tubing 3.5 kD & Spectrum Labs Inc., Broadwick St, USA \\
\hline Amicon® Ultra 4 10,000 NMWL & Merck KGaA, Darmstadt, Germany \\
\hline
\end{tabular}




\subsubsection{Devices}

\begin{tabular}{l} 
Equipment \\
\hline Pneumatic cell disintegrator EmulsiFlex-C3 \\
Isobiotec Cell Homogenizer \\
GUV generation chamber Nanion Vesicle \\
Prep Pro \\
NanoDrop 2000
\end{tabular}

Horizontal electrophoresis system SubCell ${ }^{\circledR}$ GT cell

$\begin{array}{lll}\text { Mini-PROTEAN® } & \text { Tetra } & \text { Vertical } \\ \text { Electrophoresis Cell } & & \end{array}$

PowerPac $^{\mathrm{TM}}$ HC High-Current Power Supply

Biometra power pack model 250 power supply

Intas gel documentation system

UV light source Biometra TI 1

MICCRA D-9 homogenizer

JASCO V-650 Spectrophotometer

Biometra Tpersonal thermocycler

Savant SPD-131DDA SpeedVac Concentrator

Thermomixer comfort

Incubator B-6120

Innova 4200

Innova 44

Eppendorf BioPhotometer

Isobiotec Cell Homogenizer

SONOPLUS HD2200

\section{Company}

Avestin Inc., Ottawa, Canada

Isobiotec, Heidelberg, Germany

Nanion Technologies $\mathrm{GmbH}$, Munich, Germany

Thermo Fisher Scientific Inc., Waltham, USA

Bio-Rad Laboratories Inc., Hercules, USA

Bio-Rad Laboratories Inc., Hercules, USA

Bio-Rad Laboratories Inc., Hercules, USA

Biometra $\mathrm{GmbH}$, Göttingen, Germany

INTAS Science Imaging Instruments $\mathrm{GmbH}$, Göttingen, Germany

Biometra $\mathrm{GmbH}$, Göttingen, Germany

Miccra GmbH, Müllheim, Germany

JASCO Germany GmbH, Gross-Umstadt, Germany

Biometra $\mathrm{GmbH}$, Göttingen, Germany

Thermo Fisher Scientific Inc., Waltham, USA

Eppendorf AG, Hamburg, Germany

Heraeus $\mathrm{GmbH}$, Hanau, Germany

New Brunswick Scientific, Edison, USA

New Brunswick Scientific, Edison, USA

Eppendorf AG, Hamburg, Germany

Isobiotec, Heidelberg, Germany

BANDELIN electronic $\mathrm{GmbH}$ \& Co. KG, 
SONOPLUS UW2070

Mini-extruder

Tpersonal thermocycler

ÄKTAPrime Plus system

ÄKTAPurifier 10

Nikon Eclipse Ti

Electron Multiplying CCD Camera C9100

JEOL JEM 1011

Gatan Orius 1000 CCS detector

Sony DSC-HX60

F-7000 Fluorescence Spectrophotometer

PerkinEImer UltraVIEW VoX system

Spinning disk confocal scan head CSU-X1

Chirascan CD Spectrometer

Orbitrap Fusion Tribrid mass spectrometer

Biometra WR12 tumbling shaker

PEQLAB semi-dry blotting chamber

CAWOMAT 2000 IR developing machine
Berlin, Germany

BANDELIN electronic $\mathrm{GmbH}$ \& Co. KG, Berlin, Germany

Avanti Polar Lipids Inc., Alabaster, USA

Biometra $\mathrm{GmbH}$, Göttingen, Germany

GE Healthcare Life Science, Chalfont St Giles, UK

GE Healthcare Life Science, Chalfont St Giles, UK

Nikon Instruments K.K., Tokyo, Japan

Hamamatsu Photonics K.K., Hamamatsu, Japan

JEOL Ltd., Akishima, Japan

Gatan Inc., Pleasanton, USA

Sony Corp., Tokyo, Japan

Hitachi K. K., Tokio, Japan

Perkin Elmer, Waltham, USA

Yokogawa Denki K. K., Tokyo, Japan

Applied Photophysics Ltd., London, UK

Thermo Fisher Scientific Corp, Waltham, USA

Bioemtra GmbH, Göttingen, Germany

PEQLAB Biotechnologie $\mathrm{GmbH}$, Erlangen, Germany

CAWO Solutions, Schrobenhausen, Germany

\subsubsection{Rotors}

\begin{tabular}{l|l}
\hline Rotor & Company \\
\hline H-12000 BioProcessing & Thermo Scientific, Dreieich, Germany \\
Swing-bucket A-4-62 & Eppendorf AG, Hamburg, Germany \\
Type 70 Ti & Beckman Coulter Inc., Fullerton, California \\
Eppendorf F45-24-11 & Eppendorf AG, Hamburg, Germany
\end{tabular}




\subsubsection{Buffers, mediums and solutions}

\begin{tabular}{|c|c|c|}
\hline Buffer & Composition & \\
\hline LB medium & $\mathrm{NaCl}$ & $10 \mathrm{~g} / \mathrm{L}$ \\
\hline & Yeast extract & $5 \mathrm{~g} / \mathrm{L}$ \\
\hline & Tryptone & $10 \mathrm{~g} / \mathrm{L}$ \\
\hline LB agar & $\mathrm{NaCl}$ & $10 \mathrm{~g} / \mathrm{L}$ \\
\hline & Yeast extract & $5 \mathrm{~g} / \mathrm{L}$ \\
\hline & Tryptone & $10 \mathrm{~g} / \mathrm{L}$ \\
\hline & Agar & $15 \mathrm{~g} / \mathrm{L}$ \\
\hline Hepes-Buffer (pH 7.4) & $\mathrm{NaCl}$ & $200 \mathrm{mM}$ \\
\hline & Hepes/NaOH & $10 \mathrm{mM}$ \\
\hline Lysis Buffer (pH 7.4) & $\mathrm{NaCl}$ & $150 \mathrm{mM}$ \\
\hline & Tris/HCl & $50 \mathrm{mM}$ \\
\hline & DTT & $2 \mathrm{mM}$ \\
\hline & EDTA & $2 \mathrm{mM}$ \\
\hline HKM Buffer (pH 7.4) & Hepes & $25 \mathrm{mM}$ \\
\hline & $\mathrm{C}_{2} \mathrm{H}_{3} \mathrm{KO}_{2}$ & $125 \mathrm{mM}$ \\
\hline & $\mathrm{Mg}\left(\mathrm{CH}_{3} \mathrm{COO}\right)_{2}$ & $5 \mathrm{mM}$ \\
\hline Clathrin disassembly Buffer & Tris & $1 \mathrm{M}$ \\
\hline & DTT & $1 \mathrm{mM}$ \\
\hline GUV salt buffer (pH 7.4) & $\mathrm{NaCl}$ & $192 \mathrm{mM}$ \\
\hline & Hepes/NaOH & $10 \mathrm{mM}$ \\
\hline GUV sucrose buffer ( $\mathrm{pH} 7.4$ ) & $\mathrm{D}(+)$-sucrose & $300 \mathrm{mM}$ \\
\hline & Hepes/NaOH & $10 \mathrm{mM}$ \\
\hline M9 basal medium ( $\mathrm{pH} 7.4)$ & $\mathrm{Na}_{2} \mathrm{HPO}_{4}$ & $42.5 \mathrm{mM}$ \\
\hline & $\mathrm{KH}_{2} \mathrm{PO}_{4}$ & $22 \mathrm{mM}$ \\
\hline & $\mathrm{NaCl}$ & $17.1 \mathrm{mM}$ \\
\hline & $\left(\mathrm{NH}_{4}\right)_{2} \mathrm{SO}_{4}$ & $7.6 \mathrm{mM}$ \\
\hline
\end{tabular}


Materials and methods: materials

Trace elements

Competent cell buffer 1 (pH 5.6)

Competent cell buffer $2(\mathrm{pH} 6.8)$

TAE buffer

4x Loading buffer

SDS-PAGE running buffer

Staining solution

Destaining solution

\begin{tabular}{|c|c|}
\hline $\mathrm{ZnSO}_{4} \cdot 7 \mathrm{H}_{2} \mathrm{O}$ & $0.35 \mathrm{mM}$ \\
\hline $\mathrm{MnSO}_{4} \cdot \mathrm{H}_{2} \mathrm{O}$ & $4.7 \mathrm{mM}$ \\
\hline $\mathrm{FeSO}_{4} \cdot 7 \mathrm{H}_{2} \mathrm{O}$ & $1.8 \mathrm{mM}$ \\
\hline $\mathrm{CuSO}_{4}$ & $0.63 \mathrm{mM}$ \\
\hline $\mathrm{CaCl}_{2}$ & $9.1 \mathrm{mM}$ \\
\hline $\mathrm{K}\left(\mathrm{CH}_{3} \mathrm{COO}\right)$ & $30 \mathrm{mM}$ \\
\hline $\mathrm{RbCl}$ & $100 \mathrm{mM}$ \\
\hline $\mathrm{CaCl}_{2}$ & $10 \mathrm{mM}$ \\
\hline $\mathrm{MnCl}_{2}$ & $50 \mathrm{mM}$ \\
\hline Glycerol & $15 \%(\mathrm{v} / \mathrm{v})$ \\
\hline $\mathrm{MOPS} / \mathrm{HCl}$ & $10 \mathrm{mM}$ \\
\hline $\mathrm{RbCl}$ & $10 \mathrm{mM}$ \\
\hline $\mathrm{CaCl}_{2}$ & $75 \mathrm{mM}$ \\
\hline Glycerol & $15 \%(\mathrm{v} / \mathrm{v})$ \\
\hline Tris $(\mathrm{pH} 7.6)$ & $40 \mathrm{mM}$ \\
\hline Acetic acid & $20 \mathrm{mM}$ \\
\hline EDTA & $1 \mathrm{mM}$ \\
\hline Tris/HCl pH 6.8 & $62.5 \mathrm{mM}$ \\
\hline SDS & $70 \mathrm{mM}$ \\
\hline Glycerol & $50 \%(v / v)$ \\
\hline Bromophenol blue & $0.1 \%(\mathrm{w} / \mathrm{v})$ \\
\hline$\beta$-mercaptoethanol & $5 \%(\mathrm{v} / \mathrm{v})$ \\
\hline Tris/HCl & $25 \mathrm{mM}$ \\
\hline Glycerol & $192 \mathrm{mM}$ \\
\hline SDS & $0.1 \%(\mathrm{w} / \mathrm{v})$ \\
\hline EtOH 96\% & $10 \%(v / v)$ \\
\hline Acetic acid & $5 \%(\mathrm{v} / \mathrm{v})$ \\
\hline $\begin{array}{l}\text { Coomassie Briliant } \\
\text { Blue R-250 }\end{array}$ & $0.1 \%(\mathrm{w} / \mathrm{v})$ \\
\hline $\mathrm{EtOH} 96 \%$ & $10 \%(v / v)$ \\
\hline Acetic acid & $5 \%(v / v)$ \\
\hline
\end{tabular}


Materials and methods: materials

$12.5 \%$ Separation gel $(\mathrm{pH} 8.8)$

$5 \%$ Stacking gel $(\mathrm{pH} 6.8)$

\begin{tabular}{|c|c|}
\hline $\begin{array}{l}\text { Acrylamide/ } \\
\text { Bisacrylamide }\end{array}$ & $\begin{array}{l}12.5 \% / 0.33 \% \\
(v / v)\end{array}$ \\
\hline Tris/HCl & $375 \mathrm{mM}$ \\
\hline SDS & $0.1 \%(w / v)$ \\
\hline $\begin{array}{l}\text { Ammonium } \\
\text { persulfate }\end{array}$ & $0.1 \%(w / v)$ \\
\hline TEMED & $0.08 \%(\mathrm{v} / \mathrm{v})$ \\
\hline $\begin{array}{l}\text { Acrylamide/ } \\
\text { Bisacrylamide }\end{array}$ & $\begin{array}{l}5 \% / 0.16 \% \\
(v / v)\end{array}$ \\
\hline Tris/HCl & $125 \mathrm{mM}$ \\
\hline SDS & $0.1 \%(w / v)$ \\
\hline $\begin{array}{l}\text { Ammonium } \\
\text { persulfate }\end{array}$ & $0.1 \%(w / v)$ \\
\hline TEMED & $0.08 \%(\mathrm{v} / \mathrm{v})$ \\
\hline $\mathrm{NaCl}$ & $136 \mathrm{mM}$ \\
\hline $\mathrm{KCl}$ & $2.7 \mathrm{mM}$ \\
\hline $\mathrm{Na}_{2} \mathrm{HPO}_{4} \cdot 2 \mathrm{H}_{2} \mathrm{O}$ & $8 \mathrm{mM}$ \\
\hline $\mathrm{K}_{2} \mathrm{HPO}_{4}$ & $1.8 \mathrm{mM}$ \\
\hline $\mathrm{NaCl}$ & $150 \mathrm{mM}$ \\
\hline Hepes/NaOH & $50 \mathrm{mM}$ \\
\hline DTT & $2 \mathrm{mM}$ \\
\hline EDTA & $2 \mathrm{mM}$ \\
\hline $\mathrm{NaCl}$ & $100 \mathrm{mM}$ \\
\hline Tris/HCl & $50 \mathrm{mM}$ \\
\hline $\begin{array}{l}\text { Reduced } \\
\text { Glutathion }\end{array}$ & $10 \mathrm{mM}$ \\
\hline $\mathrm{NaCl}$ & $150 \mathrm{mM}$ \\
\hline Hepes/NaOH & $50 \mathrm{mM}$ \\
\hline DTT & $2 \mathrm{mM}$ \\
\hline Imidazol & $20 \mathrm{mM}$ \\
\hline
\end{tabular}


Materials and methods: materials

His elution buffer ( $\mathrm{pH} 7.4)$

Anion exchange binding buffer $(\mathrm{pH} 8)$

Anion exchange elution buffer $(\mathrm{pH} 8)$

TBS-T buffer ( $\mathrm{pH} 7.5)$

\begin{tabular}{|l|l}
\hline $\mathrm{NaCl}$ & $150 \mathrm{mM}$ \\
Hepes/NaOH & $50 \mathrm{mM}$ \\
Imidazol & $1 \mathrm{M}$ \\
\hline $\mathrm{NaCl}$ & $50 \mathrm{mM}$ \\
$\mathrm{Hepes} / \mathrm{NaOH}$ & $50 \mathrm{mM}$ \\
\hline $\mathrm{NaCl}$ & $1 \mathrm{M}$ \\
$\mathrm{Hepes} / \mathrm{NaOH}$ & $50 \mathrm{mM}$ \\
\hline Tris & $20 \mathrm{mM}$ \\
$\mathrm{NaCl}$ & $125 \mathrm{mM}$ \\
Tween 20 & $0.1 \%$ \\
\hline Tris & $20 \mathrm{mM}$ \\
$\mathrm{NaCl}$ & $150 \mathrm{mM}$ \\
SDS & $0.02 \%$ \\
Methanol & $20 \%$ \\
\hline
\end{tabular}

\subsubsection{Chromatography columns}

\begin{tabular}{|c|c|}
\hline Column name & Company \\
\hline GSTrap $^{\mathrm{TM}} \mathrm{FF}, 5 \mathrm{ml}$ & $\begin{array}{l}\text { GE Healthcare Life Science, Chalfont St } \\
\text { Giles, UK }\end{array}$ \\
\hline HiLoad $^{\text {TM }}$ 16/600 Superdex ${ }^{\text {TM }} 75$ pg & $\begin{array}{l}\text { GE Healthcare Life Science, Chalfont St } \\
\text { Giles, UK }\end{array}$ \\
\hline HiTrap ${ }^{\text {TM }} \mathrm{Q} H P, 5 \mathrm{ml}$ & $\begin{array}{l}\text { GE Healthcare Life Science, Chalfont St } \\
\text { Giles, UK }\end{array}$ \\
\hline HiTrap ${ }^{\mathrm{TM}}$ Desalting, $5 \mathrm{ml}$ & $\begin{array}{l}\text { GE Healthcare Life Science, Chalfont St } \\
\text { Giles, UK }\end{array}$ \\
\hline HisTrap ${ }^{\mathrm{TM}} \mathrm{FF}, 5 \mathrm{ml}$ & $\begin{array}{l}\text { GE Healthcare Life Science, Chalfont St } \\
\text { Giles, UK }\end{array}$ \\
\hline HiLoad $^{\text {TM }} 16 / 600$ Superdex $^{\text {TM }} 200$ pg & $\begin{array}{l}\text { GE Healthcare Life Science, Chalfont St } \\
\text { Giles, UK }\end{array}$ \\
\hline Superose $^{\mathrm{TM}} 6,10 / 300 \mathrm{GL}$ & $\begin{array}{l}\text { GE Healthcare Life Science, Chalfont St } \\
\text { Giles, UK }\end{array}$ \\
\hline PD MiniTrap G-25 & $\begin{array}{l}\text { GE Healthcare Life Science, Chalfont St } \\
\text { Giles, UK }\end{array}$ \\
\hline
\end{tabular}




\subsubsection{Fluorophores}

\begin{tabular}{l|l}
\hline Fluorophore & Company \\
\hline Atto 390 NHS ester & ATTO-TEC GmbH (Siegen, Germany) \\
Atto 488 maleimide & ATTO-TEC GmbH (Siegen, Germany) \\
Atto 532 maleimide & ATTO-TEC GmbH (Siegen, Germany) \\
Atto 542 NHS ester & ATTO-TEC GmbH (Siegen, Germany) \\
\hline
\end{tabular}

\subsubsection{Kits}

\begin{tabular}{l|l}
\hline Kit name & Company \\
\hline $\begin{array}{l}\text { Wizard® Plus SV Minipreps DNA } \\
\text { Purification Systems }\end{array}$ & Promega GmbH, Mannheim, Germany \\
$\begin{array}{l}\text { Wizard® SV Gel and PCR Clean-Up } \\
\text { System }\end{array}$ & Promega GmbH, Mannheim, Germany \\
\hline
\end{tabular}

\subsubsection{DNA and Protein standards}

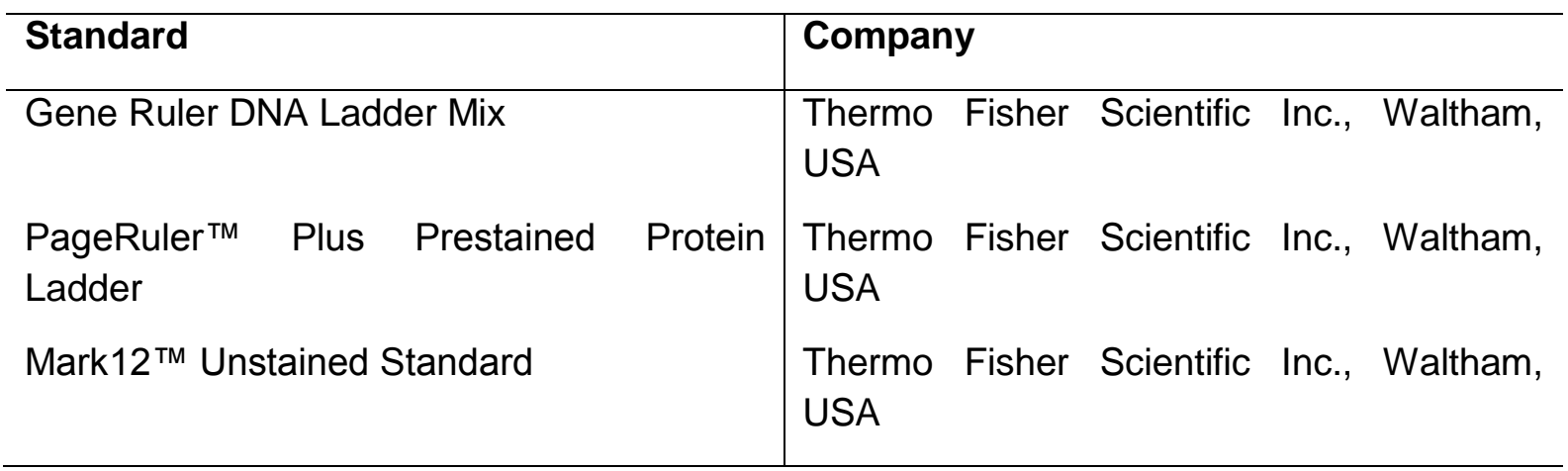

\subsubsection{Designed DNA Oligos}

\begin{tabular}{l|l|l|l}
\hline Primer & Sequence 5' $\mathbf{5}^{\prime} \mathbf{3}^{\prime}$ & $\mathbf{T}_{\mathbf{m}}$ & Purpose \\
\hline MM74F & AACGTATTGAAGCTATCCC & $53^{\circ} \mathrm{C}$ & $\begin{array}{l}\text { Cloning BAR domain } \\
\text { into vector pGEX-6P-2 }\end{array}$ \\
MM75R & TCAAGAATTATACACTCCG & $51^{\circ} \mathrm{C}$ & \\
MM80F & CCAAGGAGAAACTGTGCCAGACTGCCA & $80^{\circ} \mathrm{C}$ & $\begin{array}{l}\text { Mutagenisis of ENTH } \\
\text { domain A155C }\end{array}$ \\
& CGGCTTCC & &
\end{tabular}


Materials and methods: materials

\begin{tabular}{|c|c|c|c|}
\hline MM81R & $\begin{array}{l}\text { GGAAGCCGTGGCAGTCTGGCACAGTTT } \\
\text { CTCCTTGG }\end{array}$ & $80^{\circ} \mathrm{C}$ & \\
\hline $15 \mathrm{~F}$ & TCGGATCCATGTCGGGCCAAAC & $68^{\circ} \mathrm{C}$ & ANTH domain from \\
\hline MM218R & $\begin{array}{l}\text { GCGCGGCCGCCTATTTCTTTCCTTCTAA } \\
\text { G }\end{array}$ & $71^{\circ} \mathrm{C}$ & $\begin{array}{l}\text { AP180 into vector } \\
\text { pGEX-6P-2 }\end{array}$ \\
\hline $24 \mathrm{~F}$ & $\begin{array}{l}\text { GCGTGTATCACAACAGGCCAAAGAGAA } \\
\text { CATGTATGC }\end{array}$ & $75^{\circ} \mathrm{C}$ & $\begin{array}{l}\text { Mutagenisis of Epsin1 } \\
\text { and ENTH domain }\end{array}$ \\
\hline MMP224R & $\begin{array}{l}\text { GCATACATGTTCTCTTTGGCCTGTTGTG } \\
\text { ATACACGC }\end{array}$ & $75^{\circ} \mathrm{C}$ & C96 \\
\hline MP245F & CACCTGCTGTCCCTCCAGCTGCTGATC & $74^{\circ} \mathrm{C}$ & Sequencing Epsin1 \\
\hline MMP248F & $\begin{array}{l}\text { CATACCATGGGGATGCAGATTTTCGTGA } \\
\text { AAAC }\end{array}$ & $74^{\circ} \mathrm{C}$ & $\begin{array}{llr}\text { Clone ubiquitin } & \text { from } \\
\text { pET28a } & (+) & \text { into }\end{array}$ \\
\hline $48 \mathrm{R}$ & $\begin{array}{l}\text { CAACTCGAGCTAACCACGAAGTCTCAAC } \\
\text { ACAAG }\end{array}$ & $74^{\circ} \mathrm{C}$ & Dex-HTc \\
\hline MMP263F & $\begin{array}{l}\text { CAATATGTGGACGCTGATGGCAAGGAC } \\
\text { CAG }\end{array}$ & $73^{\circ} \mathrm{C}$ & $\begin{array}{l}\text { Mutagenisis of ENTH } \\
\text { domain R114A }\end{array}$ \\
\hline MMP263R & $\begin{array}{l}\text { CTGGTCCTTGCCATCAgcGTCCACATAT } \\
\text { TG }\end{array}$ & $73^{\circ} \mathrm{C}$ & \\
\hline MMP264F & CACCTACAATGCTGCGGCCTTCTCCG & $73^{\circ} \mathrm{C}$ & annicic of \\
\hline MP264R & CGGAGAAGGCCGCAGCATTGTAGGTG & $73^{\circ} \mathrm{C}$ & \\
\hline
\end{tabular}

\subsubsection{Commercial DNA Oligos}

\begin{tabular}{|c|c|c|c|}
\hline Primer & Sequence $5^{\prime}-3^{\prime}$ & Target vector & Company \\
\hline pGEX5-FP & AACGTATTGAAGCTATCCC & $\begin{array}{l}\text { Sequencing } \\
\text { pGEX }\end{array}$ & GATC Biotech \\
\hline pGEX3-RP & TCAAGAATTATACACTCCG & $\begin{array}{l}\text { Sequencing } \\
\text { pGEX }\end{array}$ & GATC Biotech \\
\hline pQE-FP & CGGATAACAATTTCACACAG & $\begin{array}{l}\text { Sequencing } \\
\text { pProEX HTc }\end{array}$ & GATC Biotech \\
\hline pTrcHis-RP & CTGATTTAATCTGTATCAGG & $\begin{array}{l}\text { Sequencing } \\
\text { pProEX HTc }\end{array}$ & GATC Biotech \\
\hline T7 & TAATACGACTCACTATAGGG & $\begin{array}{l}\text { Sequencing } \mathrm{pET} \\
\text { vectors }\end{array}$ & GATC Biotech \\
\hline
\end{tabular}




\subsubsection{Antibodies}

\begin{tabular}{l|l|l}
\hline Antibody & Catalog number & Company \\
\hline Epsin 1 & ab75879 & $\begin{array}{l}\text { Abcam AG, Cambridge, UK } \\
\text { Clathrin Heavy Chain }\end{array}$ \\
& 610500 & $\begin{array}{l}\text { Becton Dickinson Corp., } \\
\text { Franklin Lakes, USA }\end{array}$ \\
\hline
\end{tabular}

\subsubsection{Vectors}

\begin{tabular}{l|l}
\hline Vector & Company \\
\hline pGEX-6P-2 & $\begin{array}{l}\text { GE Healthcare Life Science, Chalfont St } \\
\text { Giles, UK } \\
\text { Thermo Fisher Scientific, Carlsbad, USA } \\
\text { pPROEX-HTc } \\
\text { EMD Biosciences Inc., San Diego, USA }\end{array}$ \\
\hline
\end{tabular}

\subsubsection{Constructs}

\begin{tabular}{l|l|l}
\hline Construct & Insert & Vector \\
\hline MM_155 & Rat EndophilinA1 N247 (BAR) & pGEX-6P-2 \\
MM_178 & Rat Epsin1 WT ENTH 1-164 & pGEX-6P-2 \\
MM_202 & Rat Epsin1 WT (full length) - 6His & pPROEX-HTc \\
MM_274 & Rat Epsin1 ENTH C96A A155C & pGEX-6P-2 \\
MM_276 & Rat Epsin1 (full length) C96A & pPROEX-HTc \\
MM_285 & Rat Epsin1 ENTH R114A & pGEX-6P-2 \\
MM_286 & Rat Epsin1 ENTH C96A R114A & pGEX-6P-2 \\
MM_B01 & A155C & pGEX-6P-2 \\
\hline
\end{tabular}

\subsubsection{Enzymes}

\begin{tabular}{l|l}
\hline Enzymes & Company \\
\hline BamHI & Thermo Fisher Scientific Inc., Waltham, USA \\
EcoRI & Thermo Fisher Scientific Inc., Waltham, USA
\end{tabular}


Materials and methods: materials

Sall

Thermo Fisher Scientific Inc., Waltham, USA

Notl

Xhol

Phusion High-Fidelity DNA

Thermo Fisher Scientific Inc., Waltham, USA

Thermo Fisher Scientific Inc., Waltham, USA

Polymerase

T4 DNA Ligase

PreScission protease

TEV protease

Anza $^{\text {TM }} 10 \mathrm{Dpnl}$

Thermo Fisher Scientific Inc., Waltham, USA

Thermo Fisher Scientific Inc., Waltham, USA

GE Healthcare Life Science, Chalfont St Giles, UK

Sigma-Aldrich Chemie GmbH, Darmstadt, Germany

Thermo Fisher Scientific Inc., Waltham, USA

3.1.16 Lipids

\begin{tabular}{|c|c|c|}
\hline Abbreviation & Full name & Company \\
\hline L $\alpha$-PtdCho & L-a-phosphatidylcholine (Egg, Chicken) & $\begin{array}{l}\text { Avanti Polar Lipids Inc., } \\
\text { Alabaster, USA }\end{array}$ \\
\hline L $\alpha$-PtdEtn & $\begin{array}{l}\text { L-a-phosphatidylethanolamine (Egg, } \\
\text { Chicken) }\end{array}$ & $\begin{array}{l}\text { Avanti Polar Lipids Inc., } \\
\text { Alabaster, USA }\end{array}$ \\
\hline L $\alpha$-PtdSer & $\begin{array}{l}\text { L-a-phosphatidylserine (Brain, Porcine) } \\
\text { (sodium salt) }\end{array}$ & $\begin{array}{l}\text { Avanti Polar Lipids Inc., } \\
\text { Alabaster, USA }\end{array}$ \\
\hline Brain Extract Polar & Brain Polar Lipid Extract (Porcine) & $\begin{array}{l}\text { Avanti Polar Lipids Inc., } \\
\text { Alabaster, USA }\end{array}$ \\
\hline La-Ptdlsn & $\begin{array}{l}\text { L-a-phosphatidylinositol (Liver, Bovine) } \\
\text { (sodium salt) }\end{array}$ & $\begin{array}{l}\text { Avanti Polar Lipids Inc., } \\
\text { Alabaster, USA }\end{array}$ \\
\hline La-Ptdlns ( & $\begin{array}{l}\text { L-a-phosphatidylinositol-4,5- } \\
\text { bisphosphate } \quad \text { (Brain, } \quad \text { Porcine) } \\
\text { (ammonium salt) }\end{array}$ & $\begin{array}{l}\text { Avanti Polar Lipids Inc., } \\
\text { Alabaster, USA }\end{array}$ \\
\hline Chol & Cholesterol (ovine wool, >98\%) & $\begin{array}{l}\text { Avanti Polar Lipids Inc., } \\
\text { Alabaster, USA }\end{array}$ \\
\hline Atto647N F & $\begin{array}{l}\text { ATTO } 647 \mathrm{~N} \text { labeled 1,2-dioleoyl-sn- } \\
\text { glycero-3-phosphoethanolamine }\end{array}$ & $\begin{array}{l}\text { ATTO-TEC GmbH (Siegen, } \\
\text { Germany) }\end{array}$ \\
\hline Atto 532 PtdEtn & $\begin{array}{l}\text { ATTO } 532 \text { labeled 1,2-dioleoyl-sn- } \\
\text { glycero-3-phosphoethanolamine }\end{array}$ & $\begin{array}{l}\text { ATTO-TEC GmbH (Siegen, } \\
\text { Germany) }\end{array}$ \\
\hline Atto & $\begin{array}{l}\text { ATTO } 532 \text { labeled 1,2-dioleoyl-sn- } \\
\text { glycero-3-phospho-L-serine }\end{array}$ & $\begin{array}{l}\text { ATTO-TEC GmbH (Siegen, } \\
\text { Germany) }\end{array}$ \\
\hline
\end{tabular}




\subsubsection{Bacteria strains}

\begin{tabular}{l|l|l}
\hline E. coli strains & Genotype & Company \\
\hline BL21(DE3) & F- dcm ompT hsdS(rB-mB-)gal & Stratagene, California, USA \\
XL1-Blue & $\begin{array}{l}\text { recA1 endA1 gyrA96 thi-1 hsdR17 supE44 } \\
\text { relA1 lac [F' proAB laclqZM15 Tn10 (Tetr)] }\end{array}$ & Stratagene, California, USA \\
\hline
\end{tabular}

\subsubsection{Rat strains}

\begin{tabular}{l|l}
\hline Rat strain & Company \\
\hline Lewis rats & $\begin{array}{l}\text { Charles River Laboratories International Inc } \\
\text { (Wilmington, USA) }\end{array}$ \\
\hline
\end{tabular}

\subsubsection{Software}

\begin{tabular}{|c|c|}
\hline Software & Company \\
\hline Double digest calculator & $\begin{array}{l}\text { Thermo Fischer Scientific }{ }^{\mathrm{TM}} \text {, Dreieich, } \\
\text { Germany }\end{array}$ \\
\hline ExPASy ProtParam web tool & $\begin{array}{l}\text { ExPASy, Swiss Institute of Bioinformatics, } \\
\text { Lausanne, Switzerland }\end{array}$ \\
\hline Volocity ${ }^{\circledR} 6.3$ & PerkinEImer Corp., Waltham, USA \\
\hline Proteome Discover 2.1 Software & $\begin{array}{l}\text { Thermo Fisher Scientific Corp, Waltham, } \\
\text { USA }\end{array}$ \\
\hline xiNET & Rappsilber Lab, Edinburgh, UK \\
\hline Digital Micrograph ${ }^{\mathrm{TM}} 1.84 .1177$ & Gatan Inc., Pleasanton, USA \\
\hline Fiji (ImageJ) & $\begin{array}{l}\text { Schindelin, J.; Arganda-Carreras, I. \& } \\
\text { Frise, E. et al. }\end{array}$ \\
\hline GNU Image Manipulation Program (GIMP) & \\
\hline Origin 8.5.1 & OriginLab Corp, Northampton, USA \\
\hline PyMOL 1.8.6.0 & DeLano Scientific LLC, Palo Alto, USA \\
\hline
\end{tabular}




\subsection{Methods}

\subsubsection{Molecular biological methods}

\subsubsection{Determination of DNA concentration}

The concentration of the purified plasmid DNA was determined photometrically using NanoDrop 2000 (Thermo Fisher Scientific Inc., Waltham, USA). The DNA concentration (c) was determined according to the Lambert-Beer equation by measuring the absorbance at $260 \mathrm{~nm}$, with a path length of $\mathrm{d}=1 \mathrm{~cm}$ and an extinction coefficient of $\varepsilon=20\left(\mathrm{ml} / \mathrm{ng}^{*} \mathrm{~cm}^{-1}\right)$.

$$
A_{260}=c \cdot \varepsilon \cdot d
$$

\subsubsection{DNA isolation}

The isolation of plasmid DNA was performed with the Wizard® Plus SV Minipreps DNA Purification Systems according to the manufacturer's manual (Promega $\mathrm{GmbH}$, Mannheim, Germany). For this purpose, E. coli XL-1 Blue competent cells were transformed with the desired plasmid and plated on LB agar as described before. A single colony was transferred into $5 \mathrm{ml}$ LB medium which contained the corresponding antibiotic for selection. The culture was incubated for $8 \mathrm{~h}$ at $37^{\circ} \mathrm{C}$ and $250 \mathrm{rpm}$ until reaching an $\mathrm{OD}_{600}$ of 2.5 to 4 and subsequently centrifuged for 10 minutes at $20^{\circ} \mathrm{C}$ and $3220 \mathrm{xg}(\mathrm{H}-12000$ BioProcessing Rotor, Thermo Fisher Scientific Inc., Waltham, USA).

\subsubsection{Restriction digest}

The key enzyme of this procedure is the restriction endonuclease. It is only found in the domain bacteria and archaea as part of their defensive mechanism against phages to fragmentize foreign DNA. Restriction endonucleases cleave at specific, palindromic recognition sites by hydrolyzing the phosphodiester bond between two nucleotides. The restriction endonucleases, used in this work, were only able to generate overhangs of unpaired nucleotides in the end of the DNA molecule (cohesive ends). This ensures the correct hybridization of DNA molecules (inserts) into target vectors. The DNA constructs in this work were always designed with two different restriction recognition sites at the 5'- end

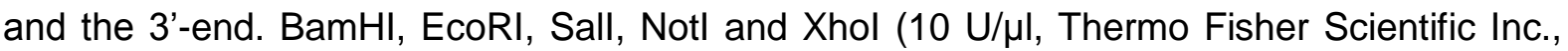
Waltham, USA) were pairwise used as restriction endonucleases. The double digest calculator web tool (Thermo Fisher Scientific Inc., Waltham, USA) was used to determine the 
correct temperature, the appropriate molar ratios of the enzymes and the buffers. The restriction digests were performed at $37^{\circ} \mathrm{C}$ during $1.5 \mathrm{~h}$ during.

Table 1: Restriction digest mix

\begin{tabular}{l|l}
\hline Component & Quantities \\
\hline Template vector / DNA fragment & $1 \mu \mathrm{g}$ \\
Rstriction enzyme buffer & $1 \mathrm{x}$ \\
Restriction endonuclease for 5' recognition site & $10 \mathrm{U}$ \\
Restriction endonuclease for 3' recognition site & $10 \mathrm{U}$ \\
$\mathrm{ddH}_{2} \mathrm{O}$ & Add to $20 \mu \mathrm{l}$ \\
\hline
\end{tabular}

\subsubsection{Ligation of DNA}

The DNA ligase plays an important role in the general DNA replication. It catalyzes the formation of a phosphodiester bond between two DNA chains by linking the free hydroxy group at the 3'-end of a nucleotide to the 5'-phosphate group of a second nucleotide.

These enzymes are used to target DNA with the appropriate position of the multiple cloning site of modified vectors in molecular biological procedures. For the ligation to occur, it is necessary that the vector and insert are digested with the same restriction endonucleases, in order to generate matching cohesive ends. The ligase of the T4 phage is the most commonly used ligase in molecular biological methods because of its versatility. It is able to link blunt ends (no single strand overhang) as well as cohesive ends and even RNA to DNA molecules. In this work, the T4 DNA Ligase $5 \mathrm{U} / \mu$ l (Thermo Fisher Scientific Inc., Waltham, USA) was used together with the 10x T4 DNA ligase Buffer (Thermo Fisher Scientific Inc., Waltham, USA). Two different molar ratios (1:1 and 3:1) of the insert DNA to the vector DNA were prepared in the reaction mixtures in general. The ligations were performed at $16^{\circ} \mathrm{C}$ during $18 \mathrm{~h}$.

Table 2: Ligation reaction mix

\begin{tabular}{l|l}
\hline Component & Quantities \\
\hline Vector & $25 \mathrm{ng}$ \\
Insert DNA & Molar ration of 1 or 3 \\
T4 DNA ligase & $7.5 \mathrm{U}$ \\
10x T4 DNA ligase buffer & $1 \mathrm{x}$ \\
$\mathrm{ddH}_{2} \mathrm{O}$ & Add to $20 \mu \mathrm{l}$ \\
\hline
\end{tabular}




\subsubsection{Agarose gel electrophoresis}

The agarose gel electrophoresis is a method used to separate and further analyze DNA molecules. The phosphate backbone confers the nucleic acids a negative charge that is proportional to their size. Thus, the DNA molecules migrate into the direction of the anode in an electric field. The agarose gel acts as a shive, restraining DNA molecules according to their size. Larger DNA fragments migrate slower than smaller ones.

In order to prepare $1 \%$ agarose gels, $1 \%(\mathrm{w} / \mathrm{v})$ Agarose NEEO ultra quality (Carl Roth $\mathrm{GmbH} \&$ Co KG, Karlsruhe, Germany) was added into TAE buffer and the mixture was heated up until the agarose was solved. To visualize the separated DNA after electrophoresis, $0.1 \%$ (v/v) ethidium bromide solution $250 \mu \mathrm{g} / \mathrm{ml}$ (Carl Roth $\mathrm{GmbH}$ \& Co KG, Karlsruhe, Germany) was added to the solved agarose. The gels were solidified and the electrophoresis was performed in the horizontal electrophoresis system Sub-Cell ${ }^{\circledR}$ GT cell (Bio-Rad Laboratories GmbH, Munich, Germany). The DNA samples were mixed with 10x FastDigest Green Buffer (Thermo Fisher Scientific Inc., Waltham, USA) with a volume ration of $1: 9$ before loading them into the agarose gel. Gene Ruler DNA Ladder Mix $0.5 \mu \mathrm{g} / \mu \mathrm{l}$ (Thermo Fisher Scientific Inc., Waltham, USA) was also loaded in the gel, in order to determine the size of the DNA fragments. After preparing the gel as well as the samples, the electrophoresis was performed at $90 \mathrm{~V}$ during $30 \mathrm{~min}$ with the Biometra power pack model 250 power supply (Biometra $\mathrm{GmbH}$, Göttingen, Germany). The separated DNA was visualized with the Intas gel documentation system (INTAS Science Imaging Instruments GmbH, Göttingen, Germany)

\subsubsection{DNA extraction from agarose gels}

After the separation of DNA molecules by agarose gel electrophoresis, it is possible to extract the identified target DNA fragments from the gel. The isolation was performed with the Wizard® SV Gel and PCR Clean-Up System according to the manufacturer's manual (Promega $\mathrm{GmbH}$, Mannheim, Germany). For this purpose, the DNA fragments were made visible with the UV light source Biometra TI 1 (Biometra GmbH, Göttingen, Germany) and cut out of the gel. The agarose slices were melted at $50^{\circ} \mathrm{C}$ to isolate the DNA with the purification kit.

\subsubsection{Polymerase chain reaction}

The polymerase chain reaction (PCR) is a versatile method to amplify DNA. The key enzyme in the PCR is a thermostable DNA polymerase that retains its enzymatic activity even at the high temperatures used for this method. The DNA polymerase catalyzes the linking of phosphodiester bonds between single nucleotides in dependence of a complementary single stranded DNA template. The enzyme used in this work, was the 
Phusion High-Fidelity DNA Polymerase $2 \mathrm{U} / \mu \mathrm{l}$ (Thermo Fisher Scientific Inc., Waltham, USA). The PCR mix needs in addition short DNA oligonucleotides (self-designed Primers were manufactured at Metabion $\mathrm{GmbH}$, Steinkirchen, Germany) that flank the DNA sequence of interest and deoxyribonucleotide triphosphates to elongate the new synthesized DNA strand.

One PCR cycle consist of three steps:

1. Denaturing: the separation of the DNA molecule into two single strands at $95^{\circ} \mathrm{C}$.

2. Hybridization: the attachment of the DNA primers to the complementary sequence on the template DNA at lower temperature, e.g. $55^{\circ} \mathrm{C}$.

3. Elongation: Synthesis of a new DNA strand mediated by the DNA-polymerase at the catalytic temperature optimum, e.g. $68^{\circ} \mathrm{C}$ )

The three steps were repeated 20 to 40 times. The excess of DNA primers ensured that the new synthesized DNA strands could also be used as templates for the following PCR cycle. Thus, the number of new DNA molecules increased exponentially.

Table 3: PCR reaction mix

\begin{tabular}{l|l}
\hline Component & Quantities \\
\hline DNA template & $100 \mathrm{ng}$ \\
5'-primer & $10 \mathrm{pmol}$ \\
3'-primer & $10 \mathrm{pmol}$ \\
dNTPs (dATP, dGTP, dCTP, dTTP) & $10 \mathrm{nmol}$ \\
$5 x$ HF buffer (Thermo Fisher Scientific Inc., Waltham, USA) & $1 \mathrm{x}$ \\
$\mathrm{DMSO}^{-}$(Sigma-Aldrich Chemie GmbH, Darmstadt, Germany) & $3 \%(\mathrm{v} / \mathrm{v})$ \\
$\mathrm{ddH}_{2} \mathrm{O}$ & Add to $50 \mu \mathrm{l}$ \\
\hline
\end{tabular}

Table 4: PCR program

\begin{tabular}{|c|c|c|c|}
\hline Step & Temperature & Time & Cycles \\
\hline 1. Initial denaturation & $98^{\circ} \mathrm{C}$ & $30 \mathrm{sec}$ & \\
\hline 2. Denaturation & $98^{\circ} \mathrm{C}$ & $50 \mathrm{sec}$ & 7 \\
\hline 3. Hybridization & $\mathrm{X}^{\circ} \mathrm{C}$ & $30 \mathrm{sec}$ & $x 20$ \\
\hline 4. Elongation & $68^{\circ} \mathrm{C}$ & $2 \min$ & ] \\
\hline 5. Final elongation & $68^{\circ} \mathrm{C}$ & $2 \min$ & \\
\hline 6. Storage & $8^{\circ} \mathrm{C}$ & $\infty$ & \\
\hline
\end{tabular}


The hybridization temperature was adjusted $5^{\circ} \mathrm{C}$ lower than the melting temperature of the used DNA primers. The PCRs were performed in the Biometra Tpersonal thermocycler (Biometra $\mathrm{GmbH}$, Göttingen, Germany). Subsequently to the PCR, a Dpnl digest was performed after with every mix to fragmentize the methylated template DNA. Therefore, $10 \mathrm{U}$ of Anza ${ }^{\mathrm{TM}} 10 \mathrm{Dpnl}$ Buffer (Invitrogen AG, Carlsbad, USA) were added directly into the PCR mixes and incubated at $37^{\circ} \mathrm{C}$ for $1 \mathrm{~h}$. The digested PCR mixes were purified with the Wizard® SV Gel and PCR Clean-Up System according to the manufacturer's manual (Promega $\mathrm{GmbH}$, Mannheim, Germany) afterwards. Finally, the DNA concentration was determined and the DNA was stored at $-20^{\circ} \mathrm{C}$.

\subsubsection{Mutagenisis}

In order to mutate a single amino acid in the protein sequence, a mutagenisis PCR was performed. The primers needed for this special kind of PCR were designed with 20 to $30 \mathrm{bp}$ with an alteration in the nucleotide sequence, in respect to the template DNA, in the middle of the primers. Finally, the nucleotide exchange leads to the expression of a mutated protein. The elongation step of the PCR was also increased to $10 \mathrm{~min}$ to ensure that the whole plasmid was amplified.

Table 5: Mutagenisis PCR program

\begin{tabular}{|c|c|c|c|}
\hline Step & Temperature & Time & Cycles \\
\hline 1. Initial denaturation & $98^{\circ} \mathrm{C}$ & $30 \mathrm{sec}$ & \\
\hline 2. Denaturation & $98^{\circ} \mathrm{C}$ & $50 \mathrm{sec}$ & 7 \\
\hline 3. Hybridization & $\mathrm{X}^{\circ} \mathrm{C}$ & $30 \mathrm{sec}$ & $x 20$ \\
\hline 4. Elongation & $68^{\circ} \mathrm{C}$ & $10 \min$ & 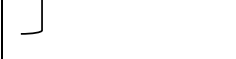 \\
\hline 5. Final elongation & $68^{\circ} \mathrm{C}$ & $10 \mathrm{~min}$ & \\
\hline 6. Storage & $8^{\circ} \mathrm{C}$ & $\infty$ & \\
\hline
\end{tabular}

\subsubsection{General cloning strategy}

In order to insert a target DNA fragment into a vector of choice, suitable restriction sites on the vector sequence were chosen. The DNA fragment and the vector were both cleaved with the same restriction endonucleases. After performing a separation by gel electrophoresis and the extraction of the target DNAs out of the agarose gel, a T4 DNA ligation was performed. Finally, the ligated DNA was used for transformation of E. coli XL1Blue cells for vector amplification and plated out on LB agar plates. 
Materials and methods: methods

\subsubsection{Sequencing of DNA}

All generated plasmid constructs were sequenced by GATC Biotech AG (Konstanz, Germany). 


\subsubsection{Cell biological methods}

\subsubsection{Transformation of chemically competent cells}

In the process of transformation, modified vectors which carry the target genes, are introduced into competent bacterial cells for recombinant expression and vector amplification. For this purpose, 100 to $200 \mathrm{ng}$ of a vector are added to $50 \mu \mathrm{l}$ of a competent bacterial suspension and gently mixed. After incubating the suspension on ice during $5 \mathrm{~min}$, a heat shock is performed within $45 \mathrm{sec}$ at $42^{\circ} \mathrm{C}$ for the uptake of the vector (Thermomixer comfort, Eppendorf AG, Hamburg, Germany). After cooling the suspension on ice for 2 more minutes, $300 \mu \mathrm{l}$ of lysogeny broth (LB) medium is added to the bacteria suspension and incubated for $1 \mathrm{~h}$ at $37^{\circ} \mathrm{C}$ and $450 \mathrm{rpm}$ (Thermomixer comfort, Eppendorf AG, Hamburg, Germany). Depending on transformation efficiency, $50 \mu \mathrm{l}$ up to the whole transformation preparation is transferred onto an LB agar plate, containing the corresponding antibiotics for selection, and streaked out. The prepared agar plates are then incubated for at least $14 \mathrm{~h}$ at $37^{\circ} \mathrm{C}$ in order to obtain visible single colonies (Incubator B-6120, Heraeus $\mathrm{GmbH}$, Hanau, Germany).

In this work, the E. coli strain BL21(DE3) was used as bacterial expression host for all proteins and the E. coli strain XL1-Blue was used for amplification of all vectors.

\subsubsection{Expression of recombinant proteins by IPTG induction}

The modified vectors that were used to transform E. coli expression and amplification hosts have a similar architecture. They contain their own origin of replication and a gene encoding the $\beta$-lactamase, which introduces ampicillin resistance to the bacterial host and acts as a selective marker for bacteria carrying the target vector. The expression is regulated by the lac system. The lac operon upstream of the target gene is under control of the lac repressor. The repressor loses the affinity to the operator in presence of lactose or a lactose analogue (Isopropyl- $\beta$-D-thiogalactopyranosid) and the target gene is accessible for the RNA-polymerase.

In this work the vectors pGEX-6P-2 (GE Healthcare Europe, Freiburg, Germany) and pProEx HTc (Thermo Fisher Scientific, Carlsbad, USA) were used. The transcription of pGEX-6P-2 is regulated by a hybrid promotor (tac promotor) composed by the trp and lac UV5 promotors. The expressed fusion protein contains a $\mathrm{N}$-terminal glutathione $\mathrm{S}$ transferase and a cleavage site for a modified human rhinovirus $3 \mathrm{C}$ protease (PreScission protease). The pProEx HTc vector also contains a hybrid promotor (trc promotor) composed by the trp and lac UV5 promotors. The expressed fusion protein contains a N-terminal hexahistidine, that can be cleaved by a modified tobacco etch virus protease (TEV protease). 
For the recombinant expression E. coli BL21 (DE3) cells were transformed as described before. A single colony was transferred from the LB-agar plate into 50 to $100 \mathrm{ml}$ liquid LB medium containing $100 \mu \mathrm{g} / \mathrm{ml}$ ampicillin (pre-culture) and incubated during 12 to 16 $\mathrm{h}$ at $37^{\circ} \mathrm{C}$ and $250 \mathrm{rpm}$ agitation (Innova 4200, New Brunswick Scientific, Edison, USA). After incubation, the optical density (OD) of the pre-culture was determined (Eppendorf BioPhotometer, Eppendorf AG, Hamburg, Germany) at $600 \mathrm{~nm}$ and used to inoculate 2 to 4 I of LB medium, which contained also $100 \mu \mathrm{g} / \mathrm{ml}$ ampicillin (expression culture). Therefore, the appropriate inoculation volume to reach an $\mathrm{OD}_{600}$ of 0.05 in the expression culture was calculated. The expression culture was incubated afterwards during 2 to $2.5 \mathrm{~h}$ at $37^{\circ} \mathrm{C}$ and $140 \mathrm{rpm}$ agitation until it reached an $\mathrm{OD}_{600}$ of 0.6 to 0.8 . The cell density indicated that the bacterial culture was still in the exponential growth phase. Isopropyl- $\beta-D$ thiogalactopyranosid (IPTG) was added to the expression culture with a final concentration of $1 \mathrm{mM}$ and it was incubated during 3 more hours at $30^{\circ} \mathrm{C}$ and $140 \mathrm{rpm}$ agitation (Innova 44, New Brunswick Scientific, Edison, USA). The expression culture was finally centrifuged for $10 \mathrm{~min}$ at $4^{\circ} \mathrm{C}$ and $5316 \mathrm{xg}$ (Thermo Scientific $\mathrm{H}-12000$ BioProcessing Rotor). The cell pellet was separated from the supernatant and resuspended with $40 \mathrm{ml}$ Hepes-Buffer per 2 I culture on ice. The cell suspension was subsequently centrifuged for 30 min at $4^{\circ} \mathrm{C}$ and 3250 xg (Eppendorf Swing-bucket rotor A-4-62). The supernatant was discarded and the cell pellet was stored at $-20^{\circ} \mathrm{C}$.

In order to express isotope labeled proteins for NMR studies, transformed E. coli BL21 (DE3) cells were cultured and the expression was performed in M9 minimal medium 179. The used minimal medium contained D-glucose- $1-{ }^{13} \mathrm{C}$ (Sigma-Aldrich Corp., St. Louis, USA) as defined carbon source and ammonium- ${ }^{15} \mathrm{~N}_{2}$ sulfate (Sigma-Aldrich Corp., St. Louis, USA) as defined nitrogen source to ensure that the expressed proteins would be isotope labeled. The cultivation and expression was performed in the same way as the expression in LB medium. The M9 minimal medium was freshly mixed together before inoculation and consisted of: 1 I M9 basal medium (containing ammonium- ${ }^{15} \mathrm{~N}_{2}$ sulfate), $2 \mathrm{~g} \mathrm{D}$-glucose- $1-{ }^{13} \mathrm{C}$, $2 \mathrm{mM} \mathrm{MgSO}_{4}, 20 \mathrm{ml}$ trace elements, $10 \mathrm{ml}$ 100x MeM vitamin solution (Thermo Fisher Scientific Inc., Waltham, USA).

\subsubsection{Cell lysis}

E. coli cells were always lysed physically by using the pneumatic cell disintegrator EmulsiFlex-C3 (Avestin Inc., Ottawa, Canada). For this purpose, the E. coli cell pellet was 5fold diluted $(\mathrm{w} / \mathrm{v})$ and resuspended with lysis buffer. The lysis was performed at a pressure of 1000 bar and 3 cycles at $4^{\circ} \mathrm{C}$. The whole cell lysate was centrifuged at $208000 \mathrm{xg}$ and $4^{\circ} \mathrm{C}$ 
during $1 \mathrm{~h}$ (Type 70 Ti Rotor, Beckman Coulter Inc., Fullerton, California) to separate the cell debris from soluble lysate which was used for purification by chromatographic methods.

\subsubsection{Competent cells}

The generation of chemically competent $E$. coli cells was performed according to the procedure described by Hanahan D. et al. ${ }^{180}$. Therefore, untransformed E. coli cells were grown in $1 \mathrm{I} \mathrm{LB}$ medium at $37^{\circ} \mathrm{C}$ and $140 \mathrm{rpm}$ until reaching an $\mathrm{OD}_{600}$ of 0.6 to 0.7 . The culture was subsequently centrifuged for $10 \mathrm{~min}$ at $4^{\circ} \mathrm{C}$ and $2700 \mathrm{xg}$ (Thermo Scientific $\mathrm{H}$ 12000 BioProcessing Rotor) and the supernatant was discarded. The cell pellet was then resuspended with $200 \mathrm{ml}$ of competent cell buffer 1 on ice and centrifuged again for 10 min at $4^{\circ} \mathrm{C}$ and $2700 \mathrm{xg}$ (Thermo Scientific $\mathrm{H}-12000$ BioProcessing Rotor). Finally, the resulting cell pellet was separated from the supernatant and resuspended in $30 \mathrm{ml}$ of competent cell buffer 2 . The cell suspension was then aliquoted, frozen in liquid nitrogen and stored at $80^{\circ} \mathrm{C}$.

\subsubsection{Synaptosomal CCV isolation from rat brains}

Brains were extracted from Lewis rats, deep frozen, and homogenized using a MICCRA D-9 homogenizer (Miccra GmbH, Müllheim, Germany) in HKM buffer, in a ratio of 1:1 (w/v). The homogenized rat brains were 6-fold $(\mathrm{v} / \mathrm{v})$ diluted with HKM buffer and centrifuged at $1000 \mathrm{xg}$ and $4^{\circ} \mathrm{C}$ for $10 \mathrm{~min}(\mathrm{H}-12000$ BioProcessing Rotor, Thermo Fisher Scientific Inc., Waltham, USA). After collecting the supernatant, it was centrifuged at 10200 $\mathrm{xg}$ and $4^{\circ} \mathrm{C}$ for 15 minutes (Type 70 Ti Rotor, Beckman Coulter Inc., Fullerton, California). After separation, the supernatant was collected and homogenized with twenty cycles to 12 $\mu \mathrm{m}$ clearance by the Isobiotec Cell Homogenizer (Isobiotec, Heidelberg, Germany) and subsequently centrifuged at $25000 \mathrm{xg}$ and $4^{\circ} \mathrm{C}$ for 20 minutes (Type 70 Ti Rotor, Beckman Coulter Inc., Fullerton, California) to separate CCVs from the plasma membrane. The supernatant was collected and centrifuged at $100000 \mathrm{xg}$ at $4^{\circ} \mathrm{C}$ for $1 \mathrm{~h}$ to pellet CCVs. Finally, the supernatant was discarded. The pellet was resuspended in $5 \mathrm{ml}$ of clathrin disassembly buffer and incubated at $250 \mathrm{rpm}$ agitation and $4^{\circ} \mathrm{C}$ during $1 \mathrm{~h}$ and then further subjected for purification by chromatographic methods. 
Materials and methods: methods

\subsubsection{Lipid related methods}

\subsubsection{Lipid stocks}

The lipids used in this work were obtained lyophilized from Avanti Polar Lipids Inc. (Alabaster, USA). Lipids were resuspended in a 1:1 (v/v) mixture of $\mathrm{CHCl}_{3}$ ROTIPURAN ${ }^{\circledR}$ (Carl Roth $\mathrm{GmbH} \&$ Co. KG, Karlsruhe, Germany) and MeOH ROTIPURAN ${ }^{\circledR}$ (Carl Roth $\mathrm{GmbH} \&$ Co. KG, Karlsruhe, Germany). The stock concentrations of the membrane matrix lipids La-PtdCho, La-PtdEtn, La-PtdSer, La-Ptdlns, cholesterol and the Brain Polar Lipid Extract (Folch) were adjusted to $25 \mathrm{mg} / \mathrm{ml}$. The lipid La-PtdEtn-Rhod (PtdEnt coupled to the fluorescent molecule lissamine rhodamine B sulfonyl) (Avanti Polar Lipids Inc., Alabaster, USA) was obtained already dissolved in $\mathrm{CHCl}_{3}$ and $\mathrm{MeOH}$ in the ratio $1: 1(\mathrm{v} / \mathrm{v})$ with the concentration of $1 \mathrm{mg} / \mathrm{ml}$. La-Ptdlns(4,5) $\mathrm{P}_{2}$ (Avanti Polar Lipids Inc., Alabaster, USA) was also obtained already dissolved, but in a mixture of $\mathrm{CHCl}_{3}, \mathrm{MeOH}$ and $\mathrm{H}_{2} \mathrm{O}$ with the ratio 20:9:1 (v/v/v) and a concentration of $5 \mathrm{mg} / \mathrm{ml}$.

The fluorescent lipids Atto $647 \mathrm{~N}$ PtdEnt (Atto 647N coupled to 1,2-Dioleoyl-snglycero-3-phosphoethanolamin), Atto 532 PtdEnt (Atto 532 coupled to 1,2-Dioleoyl-snglycero-3-phosphoethanolamin) and Atto 532 PtdSer (Atto 532 coupled to 1,2-dioleoyl-snglycero-3-phospho-L-serine) were obtained from ATTO-TEC GmbH (Siegen, Germany) and were already dissolved in a $1: 1(\mathrm{v} / \mathrm{v})$ mix of $\mathrm{CHCl}_{3}$ and $\mathrm{MeOH}$ with a concentration of 1 $\mathrm{mg} / \mathrm{ml}$ ). All lipid stocks were stored at $-80^{\circ} \mathrm{C}$.

\subsubsection{Preparation of small and large unilamellar vesicles}

Artificial vesicles, of different sizes, are a well-established membranes model and commonly used in a variety of membrane related methods, because of their versatility. LUVs and SUVs are distinguished by their sizes: If the vesicles are larger than $100 \mathrm{~nm}$, they are called LUVs, while vesicles smaller than $50 \mathrm{~nm}$ are called SUVs.

The desired lipid mixtures were prepared directly from the stock solutions. Therefore, the molar ratios of the lipids were calculated and the in solvent solved lipids were transferred into glass tubes. In order to produce a lipid film, the solvents were evaporated initially by flushing with $\mathrm{N}_{2}$ and finally by desiccation with applied vacuum for $2 \mathrm{~h}$. After drying the lipid film, Hepes buffer was added. The final lipid concentrations were between $4 \mathrm{mg} / \mathrm{ml}$ and 10 $\mathrm{mg} / \mathrm{ml}$.

The method to produce unilamellar vesicles by coupling freeze-thaw cycles with extrusion through polycarbonate filters was described by Hope M. J. et al. ${ }^{181}$. The lipid suspensions were frozen in liquid nitrogen, thawed and finally vortexed during $30 \mathrm{sec}$. The cycle was repeated ten times. The lipid suspensions were forced into the right vesicle sizes 
by 41 times extrusion with a mini-extruder (Avanti Polar Lipids Inc., Alabaster, USA) through Whatman ${ }^{\circledR}$ Nuclepore ${ }^{\mathrm{TM}}$ Track-Etched Membranes (Whatman plc, Maidstone, UK) filters with $200 \mathrm{~nm}$ (for LUVs) or $30 \mathrm{~nm}$ (for SUVs). An additional step was included to obtain SUVs after the freeze-thaw cycles. The lipid suspension was treated by sonification with one $1 \mathrm{sec}$ pulse at $20 \mathrm{kHz}$ and $30 \%$ amplitude (SONOPLUS HD2200 \& UW2070, BANDELIN electronic $\mathrm{GmbH} \&$ Co. KG, Berlin, Germany), followed by 15 secs incubation on ice. The cycle was repeated 30 times

\subsubsection{Preparation of giant unilamellar vesicles}

GUVs are an important model membrane system since it is possible to observe them by light microscopy methods. Due to their large size $(>1 \mu \mathrm{m})$ they are accepted as a model membrane system with low curvature. These vesicles are often used to perform protein binding and deformation studies by fluorescence microscopy ${ }^{53,182}$, or to analyze the physical properties of membranes ${ }^{173}$. GUVs were prepared according to Angelova M. I. et al. ${ }^{183}$ in an external alternating $(\mathrm{AC})$ electrical field ${ }^{184} .8 \mu \mathrm{l}$ of the desired lipid mix $(0.2$ $\mathrm{mg} / \mathrm{ml}$ ) in 1:1 (v/v) $\mathrm{CH}_{3}$ and $\mathrm{MeOH}$ (Carl Roth $\mathrm{GmbH} \&$ Co. KG, Karlsruhe, Germany) was spread onto two indium tin oxide-coated glass slides (ITOs, Nanion Technologies $\mathrm{GmbH}$, Munich, Germany) and dried at $50^{\circ} \mathrm{C}$, then by nitrogen flushing and finally by desiccation with applied vacuum for $2 \mathrm{~h}$. After drying, the ITOs were assembled into the GUV generation chamber Nanion Vesicle Prep Pro (Nanion Technologies GmbH, Munich, Germany), separated by $600 \mu \mathrm{l}$ of GUV sucrose buffer in a rubber spacer ring. The GUVs were electroformed by applying an electric field for $3 \mathrm{~h}$ starting at $20 \mathrm{mV}$ and increasing continuously to $1.1 \mathrm{~V}$ at $12 \mathrm{~Hz}$. To detach the GUVs from the ITO slides a final step was included changing the conditions to $2 \mathrm{~V}, 4 \mathrm{~Hz}$ during $30 \mathrm{~min}$.

\subsubsection{Determination of lipid content}

The lipid content of a liposome sample was determined by measuring the phosphate content described by Rouser G. et al. ${ }^{185}$. Therefore, $200 \mu \mathrm{l}$ of perchloric acid (70\%) was added to $30 \mu \mathrm{l}$ of the liposome sample. The mixture was heated up to $220^{\circ} \mathrm{C}$ for $60 \mathrm{~min}$ in order to extract the inorganic phosphate out of the lipids. Subsequently, the sample was cooled down to room temperature and $700 \mu \mathrm{l}$ of molybdenum solution $(0.45 \%(\mathrm{w} / \mathrm{v})$ $\mathrm{NH}_{4} \mathrm{MoO}_{4}$ and $\left.12.6 \%(\mathrm{w} / \mathrm{v}) \mathrm{HClO}_{4}\right)$ and $700 \mu \mathrm{l}$ of a $1.7 \%(\mathrm{w} / \mathrm{v})$ ascorbic acid solution were added. The sample was incubated at $80^{\circ} \mathrm{C}$ for 10 minutes and finally, the absorption at 820 $\mathrm{nm}$ was measured for the samples by a JASCO V-650 Spectrophotometer (JASCO Germany $\mathrm{GmbH}$, Gross-Umstadt, Germany). The phosphate content was determined by using a standard ranging from $0 \mu \mathrm{g}$ to $2 \mu \mathrm{g}$ phosphate produced from a $\mathrm{NaH}_{2} \mathrm{PO}_{2}$ solution. 


\subsubsection{Protein biochemistry}

\subsubsection{Sodium dodecyl sulfate polyacrylamide gel electrophoresis (SDS-PAGE)}

The SDS-PAGE is a method to separate proteins according to their molecular size. The negatively charged detergent SDS assembles into complex with proteins in a constant mass to charge proportion. The proteins denature due to the formation of the detergentprotein complexes, thus the intrinsic structure and charge of the proteins are irrelevant. The polyacrylamide matrix acts as a molecular shive, decelerating the migration of larger proteins.

SDS-gels for this work were prepared according to Lämmli U. K. ${ }^{186}$. The gels were casted with two SDS matrices, a separation gel overlaid by a stacking gel. The coarse-pored stacking gel had a pH of 6.8 and the fine-pored separation gel had a pH of 8.8. Due to the $\mathrm{pH}$ differences within the gel, glycine ions show two different migration behaviors in comparison to the chloride ions. In the stacking gel glycine migrates slow because of the zwitterionic character, while it migrates faster in the separation gel. This effect is used to focus the protein samples within the interlayer between the two gel matrices.

The electrophoretic separation was performed in a Mini-PROTEAN® Tetra Vertical Electrophoresis Cell (Bio-Rad Laboratories Inc., Hercules, USA) with the PowerPac ${ }^{\mathrm{TM}} \mathrm{HC}$ High-Current Power Supply (Bio-Rad Laboratories Inc., Hercules, USA). 4x loading buffer was added to the samples and loaded into the wells of the SDS gel. PageRuler TM Plus Prestained Protein Ladder (Thermo Fisher Scientific Inc., Waltham, USA) was loaded into one well in addition, in order to determine the sizes of the proteins. The chamber was filled with SDS-PAGE running buffer and the run was performed at initially $70 \mathrm{~V}$ until the samples were focused and then at $180 \mathrm{~V}$ until the running front reached the end of the gel. The gels were then used for Coomassie staining, or for Western blotting.

\subsubsection{Visualization of proteins by Coomassie Brilliant Blue}

In order to visualize the separated proteins after gel electrophoresis the SDS gels were stained with a solution containing Coomassie Brilliant Blue R-250. The staining solution contains in addition acetic acid to fix the proteins on the gel.

The gels were placed into the staining solution, shortly heated up and incubated under gentle agitation for $30 \mathrm{~min}$. After that, the staining solution was discarded and the gels were washed with water. Finally, the gels were put into destaining solution to remove the unspecific residuals of the Coomassie Brilliant Blue R-250. 
In order to visualize also lipids, in addition to proteins on a gel, a staining solution without $\mathrm{EtOH}$ was used and the destaining procedure was performed just with $\mathrm{ddH}_{2} \mathrm{O}$.

\subsubsection{Protease digest}

Proteases are enzymes, that catalyze the hydrolyses of a peptide bond between two amino acids. The protease digests in this work were performed to cleave the expressed fusion proteins into affinity tag and target protein. The PreScission-Protease was used for fusion proteins expressed from pGEX-6P vectors. It is a modified cysteine protease from the human rhinovirus $3 \mathrm{C}$ and recognizes the sequence Leu - Glu - Val - Leu - Phe - Gln - Gly Pro. The TEV (tabacho etch virus) protease was used if proteins were expressed from the pProEx HTc. The TEV protease is also a cysteine protease and recognizes the sequence Glu - Asn - Leu - Tyr - Phe - Gln - Gly.

The proteases were added to the fusion protein with a molar ratio of 1:100. The digest reaction was performed at $4^{\circ} \mathrm{C}$ with gentle agitation during $16 \mathrm{~h}$.

\subsubsection{Concentration of proteins}

Proteins in aqueous solution were concentrated by centrifugation. Therefore, concentrators that possess a membrane with defined pore sizes (Amicon®) Ultra 4 and 15 mL Centrifugal Filters 10,000 NMWL, Merck KGaA, Darmstadt, Germany) were used. The proteins are concentrated in the solution above the membrane, while the flow through is collected into vile. The size of the target proteins correlates with the pore size thus the proteins can be retained above the membrane. The centrifugation was performed at $5316 \mathrm{xg}$ ( $\mathrm{H}-12000$ BioProcessing Rotor, Thermo Fisher Scientific Inc., Waltham, USA) and $4^{\circ} \mathrm{C}$ during $5 \mathrm{~min}$. The procedure was repeated several times and the proteins suspension was mixed by pipetting after each centrifugation.

\subsubsection{Protein determination}

Protein concentrations were determined spectrophotometrically either by NanoDrop ${ }^{\text {TM }} 2000$ (Thermo Fisher Scientific Inc., Waltham, USA), or by the JASCO V-650 Spectrophotometer (JASCO Germany GmbH, Gross-Umstadt, Grmany). The protein concentrations (c) were calculated according to the Lambert-Beer equation by measuring the absorbance at $280 \mathrm{~nm}$, with a path length of $d=1 \mathrm{~cm}$. The individual extinction coefficients $(\varepsilon)$ and the exact molar masses of the proteins were determined by the EXPASY ProtParam web tool ${ }^{187}$.

$$
A_{280}=c \cdot \varepsilon \cdot d
$$




\subsubsection{Fluorescent label of proteins}

In order to perform fluorescence microscopy with GUVs and also FRET experiments, several proteins were fluorescently labeled during this work. Two different reactive groups, coupled to the fluorophore, are commonly used to label proteins:

1. N-Hydroxysuccinimide (NHS-ester) reacts with primary amines of the amino acid chains. Thus, the first amino acid of the sequence as well as accessible lysines are labeled. The substitution reaction takes preferentially place in a $\mathrm{pH}$ of 8.0 to 9.0. Fluorophores attached to NHS-ester were dissolved in dimethyl sulfoxide (DMSO) with a concentration of $8 \mathrm{mg} / \mathrm{ml}$.

2. Maleimides react with accessible cysteines of the protein and the preferred $\mathrm{pH}$ for the reaction is between 7.0 and 7.5. Fluorophores attached to maleimides were dissolved in dimethylformamide (DMF) with a concentration of $8 \mathrm{mg} / \mathrm{ml}$.

The ENTH WT (C96A A155C) domain, the ENTH R114A (C96A A155C) and Epsin1 WT (C96A) were labeled with Atto488 maleimide (ATTO-TEC GmbH, Siegen, Germany), and for FRET experiments with Atto532 maleimide in addition, by cysteine modification. The substitution reaction took place in PBS buffer $(\mathrm{pH} 7.4)$ with a molar access of the fluorophore of 1.4 in respect to the protein. The substitution was performed at $4^{\circ} \mathrm{C}$ with gentle agitation on a tumbling shaker (Biometra WR12 Taumelschüttler, Bioemtra GmbH, Göttingen, Germany) during $16 \mathrm{~h}$.

Clathrin was labeled with Atto542 NHS-ester and Ubiquitin chains were labeled with Atto390 NHS-ester (ATTO-TEC GmbH, Siegen, Germany) by primary amine modification. The substitution was performed in PBS buffer, in which the $\mathrm{pH}$ was increased by the addition of $200 \mathrm{mM} \mathrm{NaHCO}_{3}(\mathrm{pH}$ 9) with a ratio of 20:1 (v/v). The molar access of both fluorophores was 3 in respect to the proteins. The substitution was performed at $4^{\circ} \mathrm{C}$ with gentle agitation on a tumbling shaker (Biometra WR12 Taumelschüttler, Bioemtra GmbH, Göttingen, Germany) during $16 \mathrm{~h}$.

When the reaction was finished, the proteins were separated from the free fluorophores by size exclusion chromatography with PD MiniTrap G-25 prepacked columns (GE Healthcare Life Science, Chalfont St Giles, UK). Finally, the degree of labeling (DoL) of the proteins was determined spectrophotometrically by measuring the UV-Vis (NanoDrop 2000, Thermo Fisher Scientific Inc., Waltham, USA). For this purpose, the following equation was used:

$$
\mathrm{DoL}=\mathrm{A}_{\max } \cdot \varepsilon_{\text {prot }} \cdot\left(\mathrm{A}_{280}-\left(\mathrm{A}_{\max } \cdot \mathrm{CF}_{280}\right)^{-1} \cdot \varepsilon_{\max }^{-1}\right.
$$


$A_{\max }$ is the absorption at the characteristic wavelength of the fluorophore, $\varepsilon_{\max }$ is the molar extinction coefficient of the fluorophore, $A_{280}$ is the absorption of the protein at $280 \mathrm{~nm}, \varepsilon_{\text {prot }}$ is the molar extinction coefficient of the labeled protein and $\mathrm{CF}_{280}$ is the correction factor of the fluorophore.

\subsubsection{TCA precipitation}

Protein precipitation by trichloroacetic acid (TCA) (Carl Roth GmbH \& Co. KG, Karlsruhe, Germany) is a commonly used method to denature proteins and to reduce the volume of a protein sample for SDS-PAGE. TCA denatures proteins by promoting hydrophobic aggregation in two assumed ways: it dehydrates the hydration shell around proteins and it presumably disrupts electrostatic interactions within the proteins, due to its strong anionic character. Therefore, $10 \%(\mathrm{w} / \mathrm{v})$ of ice-cold TCA was added to the protein samples and incubated on ice during $30 \mathrm{~min}$. The samples were then centrifuged at 16000 $\mathrm{xg}$ at $4{ }^{\circ} \mathrm{C}$ for 30 min (Eppendorf rotor F45-24-11, Eppendorf AG, Hamburg, Germany). The supernatant was discarded after centrifugation and the pellet was resuspended with $500 \mu \mathrm{l}$ ice-cold acetone. The samples were centrifuged a second time with the same conditions and the pellets were dried for $2 \mathrm{~h}$ with a Savant SPD-131DDA SpeedVac Concentrator (Thermo Fisher Scientific Inc., Waltham, USA), after separating them from the supernatants. Finally, the dried samples were resuspended with $30 \mu \mathrm{l} 2 \mathrm{x}$ SDS-loading buffer and analyzed by SDS-PAGE.

\subsubsection{Western Blot and immuno staining}

In order to detect specific proteins after SDS-PAGE, proteins were transferred from SDS Gels by western blotting and visualized by immuno staining. Therefore, the SDS gels was placed on a methanol-activated PVDF membrane, soaked with blotting buffer and transferred into a semi-dry blotting chamber (PEQLAB Biotechnologie GmbH, Erlangen, Germany). The western blot was performed for $1 \mathrm{~h}$ at125 $\mathrm{mA}$ and $13 \mathrm{~V}$.

After blotting, the membrane was blocked in TBS-T buffer containing 5\% skim milk and the appropriate concentration of antibodies for $1 \mathrm{~h}$ at room temerpature. Subsequently to this, the membrane was washed 3 times for $15 \mathrm{~min}$ in TBS-T buffer and incubated with the appropritate concentration of secondary antibody in TBS-T buffer for $1 \mathrm{~h}$ at room temperature. Finally, the membrane was washed again 3 times for $15 \mathrm{~min}$ in TBS-T buffer. The ECL or Luminata solutions were added to the membrane and signals were detected on $\mathrm{x}$-ray films by developing in the CAWOMAT 2000 IR developing machine (CAWO Solutions, Schrobenhausen, Germany). 
Materials and methods: methods

\subsubsection{Chromatographic methods}

\subsubsection{Affinity chromatography of GST fusion proteins}

The purification by Glutathion S-transferase (GST) affinity chromatography is a highly specific and selective isolation method of target proteins. Target proteins are expressed from pGEX vectors as GST fusion proteins. The $26 \mathrm{kDa}$ GST protein has a high affinity to the tripeptide glutathione (GSH), which is embedded into the sepharose matrix of GST affinity chromatography columns (GSTrapFF TM 5 ml, GE Healthcare Life Science, Chalfont St Giles, UK). The elution of the GST fusion proteins is achieved by the addition of reduced GSH in the liquid phase which binds to GST with a higher affinity than the GSH sepahrose and GST proteins are mobilized again.

GSTrapFF ${ }^{\text {TM }} 5 \mathrm{ml}$ columns were used together with the ÄKTAPrime Plus system (GE Healthcare Life Science, Chalfont St Giles, UK) in this work. The column was equilibrated with GST binding buffer in the initial step with a flow of $5 \mathrm{ml} / \mathrm{min}$ for 5 column volumes (25 $\mathrm{ml}$ ), followed by the injection of the soluble cell lysate or the protein sample with a flow of 0.4 $\mathrm{ml} / \mathrm{min}$. The column was then washed with GST binding buffer until the absorbance at 280 $\mathrm{nm}$ decreased to 0 with a flow of $5 \mathrm{ml} / \mathrm{min}$. In the final step, the elution of GST or GST fusion proteins was promoted by GST elution buffer with a flow of $1 \mathrm{ml} / \mathrm{min}$. All purifications were performed at $4^{\circ} \mathrm{C}$.

\subsubsection{Affinity chromatography of polyhistidine fusion proteins}

Fusion proteins that were expressed with a polyhistidine (polyhis) affinity sequence from pProEx vectors, were purified by HisTrapFFTM $5 \mathrm{ml}$ (GE Healthcare Life Science, Chalfont St Giles, UK). The principle of this method is that metal chelate complexes embedded into the column matrix by sepharose. HisTrapFF ${ }^{\mathrm{TM}} 5 \mathrm{ml}$ columns possess $\mathrm{Ni}^{2+}$ as metal ions which are immobilized by nitrilotriacetic acid (Ni-NTA). The elution of the fusion proteins is promoted by high concentrations of imidazole that binds with higher affinity to the column material.

The method is less specific and selective than the GST affinity chromatography since proteins with histidines in relative proximity on the molecular surface of the proteins also bind the column material. Thus, the elution was always promoted by an imidazole gradient with increasing concentration.

HisTrapFF ${ }^{\text {TM }} 5 \mathrm{ml}$ columns were always used with the ÄKTAPrime Plus system (GE Healthcare Life Science, Chalfont St Giles, UK) in this work. In the initial step, the column was equilibrated with five times the column volume $(25 \mathrm{ml})$ and a flow of $5 \mathrm{ml} / \mathrm{min}$ of His binding buffer. After equilibration, the sample was injected onto the column with a flow of 0.5 
$\mathrm{ml} / \mathrm{min}$, followed by a wash step with a flow of $5 \mathrm{ml} / \mathrm{min}$ until the absorbance at $280 \mathrm{~nm}$ decreased to 0 . The elution was promoted with a gradient of $20 \mathrm{mM}$ imidazole to $1 \mathrm{M}$ imidazole (His binding buffer to His elution buffer) for $75 \mathrm{ml}$ and a flow of $2 \mathrm{ml} / \mathrm{min}$. Finally, the column was washed with $30 \mathrm{ml}$ with His elution buffer and a flow of $5 \mathrm{ml} / \mathrm{min}$. All purifications were performed at $4^{\circ} \mathrm{C}$.

\subsubsection{Buffer exchange of protein solutions with the ÄKTAPrime Plus}

Small scale buffer exchanges of protein solutions were performed with HiTrap ${ }^{\mathrm{TM}}$ Desalting $5 \mathrm{ml}$ columns (GE Healthcare Life Science, Chalfont St Giles, UK) coupled with ÄKTAPrime Plus system (GE Healthcare Life Science, Chalfont St Giles, UK). The column matrix of the desalting columns consists of Sephadex G-25 Superfine, a porous material which decelerates the migration speed of molecules anti-proportional to their size.

The buffer exchanges were initiated by washing with five times the column volume, using the buffer of choice and a flow of $5 \mathrm{ml} / \mathrm{min}$. The protein sample was injected with 1 $\mathrm{ml} / \mathrm{min}$ and a maximum volume of $2 \mathrm{ml}$ of sample. Finally, the sample was eluted with 2 $\mathrm{ml} / \mathrm{min}$. All purifications were performed at $4^{\circ} \mathrm{C}$.

\subsubsection{Anion exchange chromatography}

The principle of ion exchange chromatographies is based on the net surface charge of the proteins. The matrix of anion exchange column consists of sepharose coupled to a quaternary ammonium that is positively charged. The net charge of a protein depends on the $\mathrm{pH}$ of the buffer. Proteins with a negative net charge interact with the column material and are separated from positively charged or non-charged proteins. The elution is promoted by using high salt buffers.

Anion exchange chromatography was predominantly used to separate the ENTH domain (and mutants) from cleaved GST. The computed theoretical isoelectric point ( $\mathrm{pl}$ ) of the ENTH domain was 9.14, and pl of the GST tag was 5.20 (computation of the pl was performed with the EXPASY ProtParam web tool). Thus, the $\mathrm{pH}$ of the buffers was adjusted to 8.0 in which the ENTH domain is positively charged and the GST tag is negatively charged. So, the ENTH domain was expected to pass through column and the GST was expected to be retained.

In this work, HiTrap ${ }^{\mathrm{TM}}$ Q HP, $5 \mathrm{ml}$ (GE Healthcare Life Science, Chalfont St Giles, UK) coupled with ÄKTAPrime Plus system (GE Healthcare Life Science, Chalfont St Giles, UK) were used for anion exchange chromatography. All steps were performed at $4^{\circ} \mathrm{C}$. In the initial step, the column was equilibrated with 5 column volumes of the anion exchange binding buffer with a flow of $5 \mathrm{ml} / \mathrm{min}$, followed by the injection of the protein sample with a 
flow of $1 \mathrm{ml} / \mathrm{min}$ and a washing step with a flow of $3 \mathrm{ml} / \mathrm{min}$ until the absorption at $280 \mathrm{~nm}$ decreased to zero. The ENTH domain was expected to elute in these steps. Finally, the elution of GST was promoted by running a short gradient from the anion exchange binding buffer to the anion exchange elution buffer for $50 \mathrm{ml}$ and a flow of $3 \mathrm{ml} / \mathrm{min}$, followed by 30 $\mathrm{ml}$ of $100 \%$ anion exchange elution buffer with a flow of $3 \mathrm{ml} / \mathrm{min}$.

\subsubsection{PD 25 buffer exchange chromatography}

The principle of separation by PD MiniTrap G-25 (GE Healthcare Life Science, Chalfont St Giles, UK) is the size exclusion chromatography. In this work, it was predominately used to separate free fluorophores from labeled proteins after the fluorophore conjugation reaction by gravity flow. The columns were equilibrated with 5 times the bed volume of the buffer of choice. $0.5 \mathrm{ml}$ of the protein sample was transferred onto the bed and finally eluted by adding the buffer of choice. Two visible bands were observed during the chromatography: the band with the faster migration speed representing the conjugated proteins, the slower band corresponded to the free fluorophores. All steps were performed at $4^{\circ} \mathrm{C}$.

\subsubsection{Size exclusion chromatography}

Molecules are separated due to their hydrodynamic voluminal by size exclusion chromatography (gel filtration). The molecules do not bind to the column material like in the affinity chromatographic methods. The matrix of the columns consists of a composite crosslinked agarose and dextran in the case of superdex columns, or of cross linked agarose in the case of superpose columns. The column materials form a matrix with defined pore sizes that decrease the migration speed of passing molecules due to their molecular mass and shape.

For the purification of smaller proteins $\left(<30 \mathrm{kDa}\right.$ ) the HiLoad ${ }^{\text {TM }} 16 / 600$ Superdex $^{\text {TM }} 75$ pg (GE Healthcare Life Science, Chalfont St Giles, UK) was used and bigger proteins like Epsin1 and AP180 were purified with the HiLoad ${ }^{\mathrm{TM}}$ 16/600 Superdex ${ }^{\mathrm{TM}} 200$ pg pg (GE Healthcare Life Science, Chalfont St Giles, UK). Clathrin triskelia were separated with Superose $^{\text {TM }}$ 6, 10/300 GL pg (GE Healthcare Life Science, Chalfont St Giles, UK).

The columns were equilibrated with the buffer of choice, 1.5 times of the column volume and a flow rate of $1 \mathrm{ml} / \mathrm{min}$. The protein sample was injected with a flow of $1 \mathrm{ml} / \mathrm{min}$ and a sample size that did not exceed $2 \mathrm{ml}$ for superdex columns and $0.5 \mathrm{ml}$ for the superpose column. The elution was performed with $1 \mathrm{ml} / \mathrm{min}$ until 1 column volume of the buffer of choice passed through the column. All chromatographies were performed at $4^{\circ} \mathrm{C}$ using the ÄKTAPrime Plus system, or the ÄKTAPurifier 10 system. 
Materials and methods: methods

\subsubsection{Dialysis}

The principle of dialysis is based on the endeavor of particles for entropy and osmosis. The dialysis was used to perform buffer exchanges, in this work. A dialysis bag with a defined pore size of $3.5 \mathrm{kD}$ (Spectra/Por Standard RC Tubing, Spectrum Labs Inc., Broadwick St, USA) was filled with a protein sample (5 to $30 \mathrm{ml}$ ) and closed. The bag was then transferred into 3 to $5 \mathrm{I}$ of a buffer of choice and incubated for $12 \mathrm{~h}$ at $4^{\circ} \mathrm{C}$ with gentle magnetic stirring. Smaller particles are able to defund through the pores of the dialysis bag, whereas molecules of a bigger size, like proteins, are retained. The buffer molecules defund until reaching equilibrium. Thus, the concentration of the components of the previous buffer is strongly diluted and the proteins are transferred into the dialysis buffer. The dialysis was coupled with the protease digest for the cleavage of the BAR domain and the ANTH domain fusion proteins. 
Materials and methods: methods

\subsubsection{Analytical methods}

\subsubsection{DLS}

Dynamic light scattering (DLS) is a method to determine the hydrodynamic radius of spherical particles in solution. Coherent and monochromatic laser beams are scattered if they encounter particles in solution that cause interferences. The particles in solution are under constant motion, due to the Brownian movement and the scatter intensities fluctuate. The fluctuations give information about the motion speed of the particles which is used to determine the hydrodynamic radii of these particles. DLS determinations were used for two purposes in this work, they gave information about the quality of a whole liposome population after extrusion, and they were used to determine if liposomes were deformed. The motion of spherical liposomes differs from the motion of membrane tubules causing great error bars in the measurement.

The liposome suspension was diluted to $0.2 \mathrm{mg} / \mathrm{ml}$ and set into the measurement chamber of a Zetasizer Nano-S (Malvern Instruments Ltd., Worcestershire, UK). The data was acquired by three independent measurements, each one consisting of 21 repetitions at $25^{\circ} \mathrm{C}$, and using the Zetasizer Software 7.01 (Malvern Instruments Ltd., Worcestershire, UK).

\subsubsection{Co-sedimentation assay}

The co-sedimentation assay (spin assay) was used for two detections. Liposomes in aqueous samples sediment if they are ultracentrifuged, while soluble proteins remain in the supernatant. Thus, the detection of protein binding to liposomes was determined via the spin assay. This assay was also used to detect if small vesicles were generated due to membrane deformation. The sedimentation of spherical particles in aqueous solution is described by Stokes's law:

$$
F_{g}=\left(\rho_{p}-\rho_{f}\right) \cdot g \cdot 4 / 3 \cdot \pi \cdot R^{3}
$$

The excess force $F_{g}$ is dependent on the difference of the densities of the spherical object and the surrounding fluid $\left(\rho_{p}-\rho_{\mathrm{f}}\right)$, the gravity $(\mathrm{g})$ and the cubed radius of the spherical object $\left(R^{3}\right)$. The sedimentation behavior of a liposome is more dependent on the size than on the density and it is possible to separate SUVs from LUVs by centrifugation.

The liposomes were prepared as described before, diluted to 2 to $3 \mathrm{mg} / \mathrm{ml}$ and mixed with 7.5 to $20 \mu \mathrm{M}$ purified proteins. After incubating the sample for $3 \mathrm{~h}$ at $30^{\circ} \mathrm{C}, 150 \mu \mathrm{l}$ of the sample was ultracentrifuged at $22^{\circ} \mathrm{C}$ and $205000 \mathrm{xg}$ for 19 min (TLA 100.3, Beckman 
Coulter Inc., Fullerton, California). Finally, the supernatant was separated from the pellet and analyzed by SDS-PAGE.

\subsubsection{Co-migration}

The co-migration assay (flotation assay) was used in order to detect protein binding to liposomes and the potential membrane deformation ability of these proteins. Liposomes migrate through a density gradient until reaching a layer that corresponds to their own density. Deformed liposomes have another migration behavior through the gradient, thus their migration stops at a different layer. If proteins bind to liposomes, they migrate through the layers together.

Liposome $(4 \mathrm{mg} / \mathrm{ml})$, or liposome protein $(20 \mu \mathrm{M})$ samples were incubated at $30^{\circ} \mathrm{C}$ for $3 \mathrm{~h}$ and overlaid with a discontinuous Histodenz ${ }^{\text {TM }}$ (Sigma-Aldrich Corp., St. Louis, USA) gradient of $40 \%, 20 \%, 10 \%, 5 \%$ and $0 \%$. Histodenz ${ }^{\mathrm{TM}}$ was previously dissolved in Hepes buffer. Each density layer of the discontinuous gradient had a volume of $800 \mu$ l. The density gradient was centrifuged at $150000 \mathrm{xg}$ and $20^{\circ} \mathrm{C}$ for $1 \mathrm{~h}(\mathrm{SW} 60 \mathrm{Ti}$, Beckman Coulter Inc., Fullerton, California). After centrifugation, pictures were taken from the floated liposomes in the gradient (Sony DSC-HX60, Sony Corp., Tokyo, Japan). Finally, the layers were separated into $500 \mu$ l fractions, precipitated with TCA and analyzed by SDS-PAGE.

\subsubsection{Electron microscopy}

LUVs were used for electron microscopy to visualize membrane deformation. Therefore, liposomes $(0.2 \mathrm{mg} / \mathrm{ml})$ were incubated with proteins $(15 \mu \mathrm{M})$ at $30^{\circ} \mathrm{C}$ during $3 \mathrm{~h}$. The samples were subsequently diluted to $0.2 \mathrm{mg} / \mathrm{ml}$ of liposomes with Hepes buffer and 5 $\mu \mathrm{l}$ of the suspension was then transferred onto a formvar carbon coated copper grid (Agar Scientific Ltd., Essex, UK) and incubated for $1 \mathrm{~min}$ at room temperature. The suspension was removed and the grid was set onto a droplet $(50 \mu \mathrm{l})$ of $3 \%$ uranyl acetate for negative staining. The residual solution was directly removed.

Electron microscopic visualization was performed with a JEOL JEM 1011 transmission electron microscope (JEOL Ltd., Akishima, Japan) and a Gatan Orius 1000 CCS detector (Gatan Inc., Pleasanton, USA).

\subsubsection{Binding and membrane deformation dynamics on GUVs}

GUVs were used for fluorescence microscopy in order to examine the dynamics of protein membrane binding and membrane deformation. Therefore, GUVs were prepared as previously described in addition with $0.5 \%$ of the fluorescently labeled lipid Atto647N PtdEnt (ATTO-TEC GmbH, Siegen, Germany). $50 \mu \mathrm{l}$ of the GUV suspension was carefully 
transferred into the microscopy chamber Nunc® Lab-Tek® II chambered coverglass (Thermo Fisher Scientific Inc., Waltham, USA), that was coated with lipid-free bovine serum albumin (Sigma-Aldrich Crop., St. Louis, USA) and filled with $250 \mu \mathrm{l}$ of GUV salt buffer.

The fluorescence spinning disc confocal microscopy was performed at $25^{\circ} \mathrm{C}$ with a Nikon Eclipse Ti microscope (Nikon Instruments K.K., Tokyo, Japan), a PerkinElmer UltraVIEW VoX system (Perkin Elmer, Waltham, USA) with a spinning disk confocal scan head CSU-X1 (Yokogawa Denki K. K., Tokyo, Japan) and an Electron Multiplying CCD Camera C9100 (Hamamatsu Photonics K.K., Hamamatsu, Japan). The data was acquired with the software Volocity ${ }^{\circledR} 6.3$ (PerkinElmer Corp., Waltham, USA). Proteins that were labeled with Atto488 maleimide, Atto390 NHS ester, or Atto542 NHS (ATTO-TEC GmbH, Siegen, Germany) were titrated into the GUV suspension in $10 \mu \mathrm{M}$ steps and mixed by gentle stirring. The fluorophores were excited at the optimal wavelength and detected at the optimal emission wavelength according to the manufacturer (ATTO-TEC GmbH, Siegen, Germany). All fluorophores were excited at low laser powers (5\% to $8 \%$ ) and at fast exposure times (50 msec to $120 \mathrm{msec}$ ). The pictures were taken with speed 30 frames per minute for $30 \mathrm{~min}$.

\subsubsection{FRET assays}

Förster resonance energy transfer (FRET) measurments are used to detect interaction between molecules. The principle this effect is based upon the radiation-free energy transfer between two fluorophores. These fluorophores are called a FRET pair, if the emission of the donor fluorophore overlaps with the excitation of the acceptor fluorophore. The FRET effect appears, if the distance between the donor and acceptor fluorophores does not exceed is between 0.5 to $10 \mathrm{~nm}$.

In this work, FRET measurements were performed to detect the oligomerization of ENTH domains and the interaction between these proteins and specific lipids. Atto 488 coupled to the ENTH domain was used as donor and Atto 532 coupled to DOPS, DOPE, or ENTH domain was used as acceptor. The donor was excited at $493 \mathrm{~nm}$ and the acceptor emission maximum is at $552 \mathrm{~nm}$. For the measurments, a total concentration of 5 and $15 \mu \mathrm{M}$ labeled ENTH domain added into a $2 \mathrm{mg} / \mathrm{ml}$ lipid suspension. The FRET experiments were performed in a F-7000 Fluorescence Spectrophotometer (Hitachi K. K., Tokio, Japan) and the emission spectra were recorded between $500 \mathrm{~nm}$ and $700 \mathrm{~nm}$. All FRET analysis were carried out by Niels Denkert of the Michael Meinecke group (Biochemistry 2, Humboldallee 23, Göttingen, Germany). 


\subsubsection{Secondary structure analysis by CD spectroscopy}

Circular dichroism (CD) spectroscopy is a powerful method to analyze secondary structures within biological macromolecules. Linear polarized is converted by a quarter-wave plate to left-handed and right-handed circular polarized light that are absorbed by chiral molecules, like proteins, to different extends. The CD spectrum results upon of the percentages of $\beta$-sheets and $\alpha$-helices within the protein.

CD spectroscopy was used to compare the folding of the wildtype ENTH domain and the ENTH domain mutant R114A by using a Chirascan CD Spectrometer (Applied Photophysics Ltd., London, UK). Proteins were transferred into a $10 \mathrm{mM}$ sodium potassium phosphate buffer $\mathrm{pH} 7.4$ with a concentration of $0.1 \mathrm{mg} / \mathrm{ml}$. The measurements were carried out at $25^{\circ} \mathrm{C}$ between $180 \mathrm{~nm}$ and $260 \mathrm{~nm}$ with $1 \mathrm{~nm}$ step sizes and an accumulation time of $5 \mathrm{sec}$. The mean residue weight ellipticity was calculated according to Kelly S. M. et al. ${ }^{188}$ with the following formula:

$$
[\Theta]_{\mathrm{MRW}}=(\Theta \cdot \mathrm{MRW}) /(10 \cdot \mathrm{c} \cdot \mathrm{d})
$$

The molar ellipticity $(\Theta)$ and the mean residue weight (MRW) are dependent on the optical path length (d) and the protein concentration (c).

\subsubsection{Chemical cross-linking and In-Gel digest}

Protein-liposome samples were chemically cross linked, in order to visualize the oligomerization of the ENTH. Therefore, protein samples were prepared with, or without liposomes in Hepes buffer, as described before. The proteins were chemically cross-linked by the addition of the amine-reactive, water-soluble and homobifunctional bis(sulfosuccinimidyl)suberate (BS3, Thermo Fisher Scientific Inc., Waltham, USA) with a molar excess of 50 to 300 . After addition of BS3, the samples were mixed and incubated at RT for $40 \mathrm{~min}$. The reaction was finally quenched by the addition of $4 \mathrm{x}$ sample buffer (final concentration: $100 \mathrm{mM}$ DTT, $50 \mathrm{mM}$ Tris- $\mathrm{HCl}, 2 \% \mathrm{SDS}$ ) and incubated during $10 \mathrm{~min}$ at $70^{\circ} \mathrm{C}$. The cross-linked protein was visualized by SDS-PAGE and Coomassie staining.

The cross-linked samples were further subjected for an In-Gel digest. Therefore, the bands that corresponded to cross-linked proteins were extracted from the gel and incubated with $150 \mu \mathrm{l}$ acetonitrile (ACN) for $15 \mathrm{~min}$ at $26^{\circ} \mathrm{C}$ and $1050 \mathrm{rpm}$ agitation (Thermomixer comfort, Eppendorf AG, Hamburg, Germany). To reduce disulfide bonds, the pieces were incubated in $100 \mu \mathrm{l} 10 \mathrm{mM}$ dithiothreitol (DTT) for $50 \mathrm{~min}$ at $56^{\circ} \mathrm{C}$ and washed again with ACN afterwards. In order to alkylate reduced cysteine residues, $100 \mu \mathrm{l}$ of $55 \mathrm{mM}$ iodoacetamide was added to samples, incubated for $20 \mathrm{~min}$ at $26^{\circ} \mathrm{C}$ and $1050 \mathrm{rpm}$ and 
washed again with ACN afterwards. The gel pieces were additionally treated with $150 \mu \mathrm{l}$ of $100 \mathrm{mM} \mathrm{NH}_{4} \mathrm{HCO}_{3}$ and incubate for $15 \mathrm{~min}$ at $26^{\circ} \mathrm{C}$ and $1050 \mathrm{rpm}$, washed again with ACN and finally dried by SpeedVac (Savant SPD-131DDA SpeedVac Concentrator, Thermo Fisher Scientific Inc., Waltham, USA). The digest was performed by rehydrating the gel pieces with In-Gel digest buffer $1\left(0.0125 \mu \mathrm{g} / \mu \mathrm{l}\right.$ Trypsin, $\left.4 \mathrm{mM} \mathrm{CaCl}_{2}, 40 \mathrm{mM} \mathrm{ABC}\right)$ for 30 to $45 \mathrm{~min}$ at $4^{\circ} \mathrm{C}$. 10 to $20 \mu \mathrm{ln}$-Gel digest buffer 2 was added to the gel pieces and the digest was performed at $37^{\circ} \mathrm{C}$ overnight.

The digested peptides were extracted from the SDS gel by the addition of $5 \%(\mathrm{v} / \mathrm{v})$ formic acid and incubation for $15 \mathrm{~min}$ at $37^{\circ} \mathrm{C}$ and $1050 \mathrm{rpm}$ agitation. The chemical crosslinking, as well as the In-Gel digest was performed by Iwan Parfentev of the Henning Urlaub group (MPIBPC, research group: Mass Spectrometry, Am Fassberg 11, Göttingen, Germany).

\subsubsection{MS/MS analysis}

Mass spectrometry (MS) was employed to analyze the cross-linked ENTH domain monomers and oligomers. Therefore, the digested and extracted peptides were separated by reverse-phase high performance liquid chromatography (RP-HPLC) on a Dionex Ultimate 3000 chromatography system (Thermo Fisher Scientific Corp., Waltham, USA): The injection was performed with $5 \%(\mathrm{v} / \mathrm{v}) \mathrm{ACN}$ as the liquid phase and $0.1 \%(\mathrm{v} / \mathrm{v})$ trifluoroacetic acid (TFA) as the proton donor onto a $0.3 \times 5 \mathrm{~mm} \mu$-Precolumn (C18 PepMap100, $5 \mu \mathrm{m}, 100 \AA$, Thermo Fisher Scientific Corp., Waltham, USA). The separation was performed with a linear gradient of $10 \%$ to $46 \%(\mathrm{v} / \mathrm{v}) \mathrm{ACN}$ for $36 \mathrm{~min}$ with $300 \mathrm{nl} / \mathrm{min}$ flow rate on a $30 \mathrm{~cm} \mathrm{C18}$ analytical column (packed in-house with Reprosil-Pur 120 C18-AQ, $1.9 \mu \mathrm{m}$, Dr. Maisch, Ammerbuch-Entringen, Germany).

The analysis of the ionized peptides was performed by Orbitrap Fusion Tribrid mass spectrometer (Thermo Fisher Scientific Corp, Waltham, USA). The tandem MS analysis was performed in three technical replicates with the method called "Top Speed". Briefly, after a survey scan (MS1), the most intense precursors with the charge states of 3 to 8 (380 - 1500 $(\mathrm{m} / \mathrm{z})$ scan range) were isolated in the quadrupole mass filter (MS2) and fragmented by higher-energy collisional dissociation (HCD) (the 3 technical replicates were analysed with $28 \%, 30 \%$ and $33 \%$ normalized collision energy, respectively). A dynamic exclusion time of $2 \mathrm{sec}$ was set. MS1 was performed with an Orbitrap resolution of 120,000, automatic gain control (AGC) target of $4 \cdot 10^{5}$ and a maximum injection time of $50 \mathrm{msec}$. MS2 was performed with an Orbitrap resolution of 30000 . The AGC targets were set to $5 \cdot 10^{4}$ and a maximum injection time of $120 \mathrm{msec}$. 
Finally, the raw files were converted into the mgf format by the Proteome Discover 2.1 Software (Thermo Fisher Scientific Corp, Waltham, USA). The converted files were used for a database search, containing the sequence of rat Epsin1, by pLink 1.23. The search parameters included a maximum of three trypsin miss-cleavages, a mass filter of $\pm 10 \mathrm{ppm}$, carbamidomethylation of cysteines as a fixed modification and oxidation of methionines as variable modification. The results were obtained with a false discovery rate of $1 \%$ and the cross-links were visualized by xiNET (Rappsilber Lab, Edinburgh, UK). The tandem MS, as well as the data analysis was performed by Iwan Parfentev of the Henning Urlaub group (MPIBPC, research group: Mass Spectrometry, Am Fassberg 11, Göttingen, Germany). 


\section{Results}

\subsection{Protein purifications}

\subsubsection{Purification of ENTH domain proteins}

The ENTH domain consists of the first 164 amino acids of Epsin1. In order to express and purify the protein the first 492 bp of Rattus norvegicus Epsin1 were cloned into the vector pGEX-6p-2. This construct was further used to generate the mutants used in this work: ENTH C96A A155C, ENTH R114A, ENTH C96A R114A A155C and ENTH V50,51A.

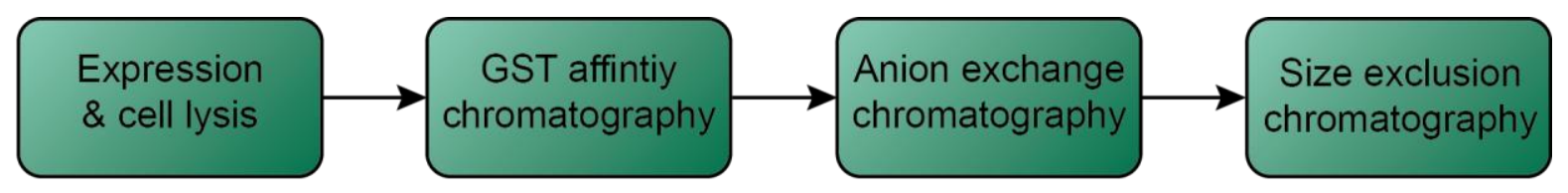

Figure 10: Schematic illustration of the purification strategy of ENTH domain constructs.

The ENTH domain was expressed as the fusion protein GST.ENTH in E. coli BL21 (DE3) as described before (3.2.2.2 Expression of recombinant proteins by IPTG induction). After pelleting the cells and cell lysis, the soluble lysate was separated from cell debris and used for GST affinity chromatography. The GST.ENTH fusion protein was successfully separated from the soluble lysate and eluted after changing the buffer to GST elution buffer. $150 \mathrm{mg}$ of fusion protein was purified in the first chromatography step. In order to cleave the GST affinity tag from the ENTH domain, a PreScission-Protease digest was performed. To ensure a clear separation of the ENTH domain from cleaved GST, anion exchange chromatography was employed as the subsequent purification step. Therefore, the isoelectric points of the ENTH domain (9.14) and the GST affinity tag (5.73) were computationally determined by the EXPASY ProtParam web tool. The $\mathrm{pH}$ of the purification buffers was adjusted to 8 . In these conditions, the GST tag is negatively charged, while the ENTH domain has a cationic character. The separation was successfully performed and ENTH domain didn't bind to column in anion exchange washing buffer, while the GST tag bound to the column material. Size exclusion chromatography with a HiLoad ${ }^{\mathrm{TM}}$ 16/600 Superdex $^{\mathrm{TM}} 75 \mathrm{pg}$ (GE Healthcare Life Science, Chalfont St Giles, UK) was performed as the last purification step to set the target protein into Hepes buffer and to receive single band purity (Figure 10). In this way, $46 \mathrm{mg}$ of the highly pure and soluble monomeric ENTH domain was purified out of 1 I expression culture (Figure 10). 
Results: Protein purification

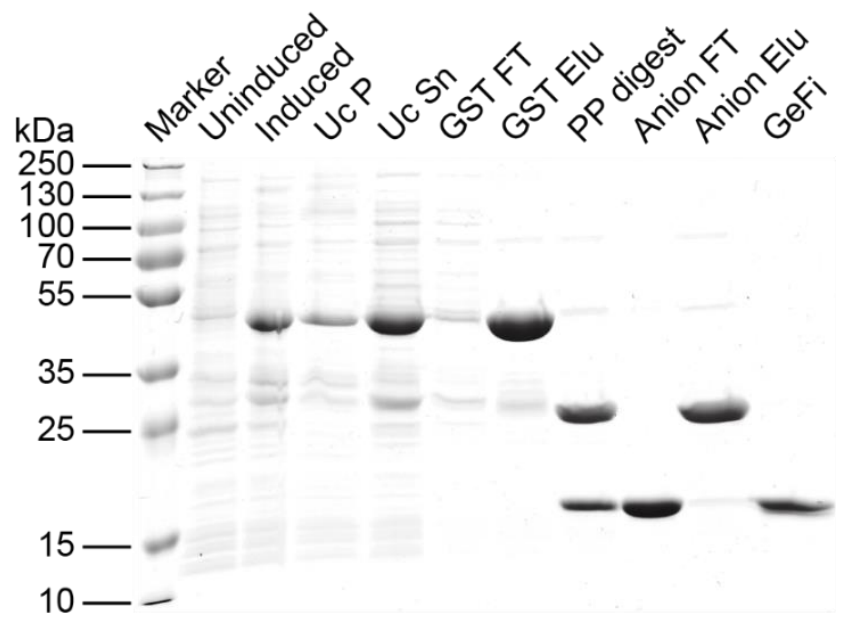

Figure 11: Recombinant expression and purification of rat ENTH domain. BL21 cells were induced by addition of $1 \mathrm{mM} \mathrm{IPTG}$ at $30^{\circ} \mathrm{C}$ for $3 \mathrm{~h}$ (uninduced, induced). The soluble cell lysate was separated from the insoluble cell debris by ultracentrifugation (Uc P, Uc Sn). The GST.ENTH fusion protein was isolated by GST affinity chromatography (GST FT, GST Elu), the tag was cleaved (PP digest) and the ENTH domain was isolated from the tag by anion exchange chromatography (Anion FT, Anion Elu). The ENTH domain was finally purified by size exclusion chromatography (GeFi). PageRulerTM Plus Prestained Protein Ladder (Thermo Fisher Scientific Inc., Waltham, USA) was used as protein standard.

The mutant proteins that were generated from the ENTH domain WT construct were expressed and purified in the same way (Figure 11). The purification of ENTH R114A was similar successful as the WT protein. A small amount of fusion protein did not remain in the supernatant und pellet with the cell debris and a small amount of fusion protein was not retained during GST affinity chromatography. In the end, $52 \mathrm{mg}$ of the highly pure and soluble monomeric ENTH R114A was purified out of 1 I expression culture. 
Results: Protein purification

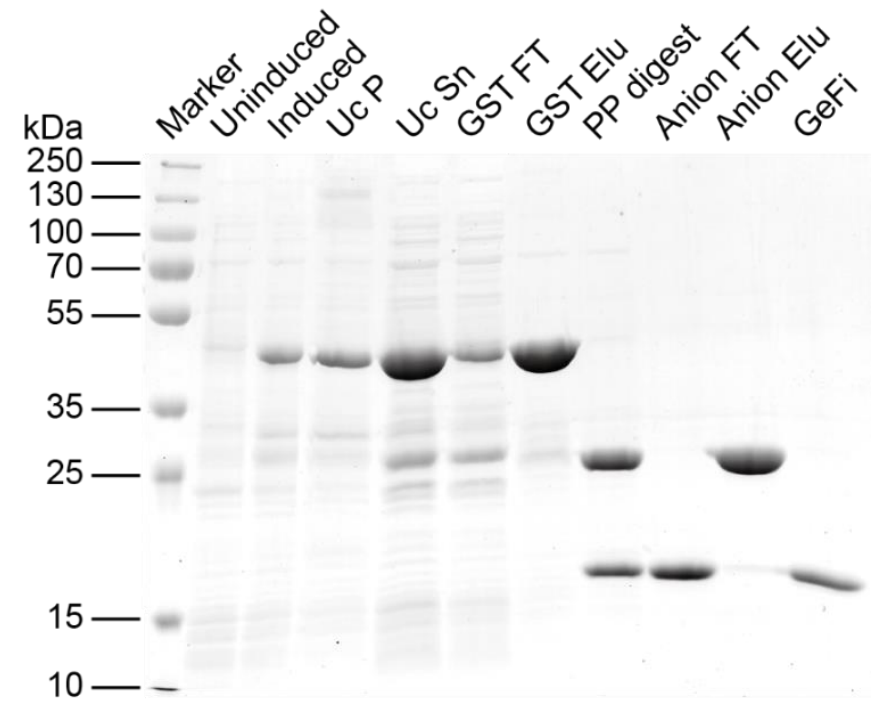

Figure 12: Recombinant expression and purification of ENTH R114A. ENTH R114A was purified in the same as the ENTH domain (Fig. 8). The protein was expressed in BL21 cells by $1 \mathrm{mM} \mathrm{IPTG}$ induction (uninduced, induced). The soluble cell lysate was separated from the insoluble cell debris by ultracentrifugation (Uc $P, U_{c}$ Sn). The fusion protein was isolated by GST affinity chromatography (GST FT, GST Elu), the tag was cleaved (PP digest) and ENTH R114A was isolated from the tag by anion exchange chromatography (Anion FT, Anion Elu). Size exclusion chromatography was used as last purification step (GeFi). PageRuler ${ }^{\mathrm{TM}}$ Plus Prestained Protein Ladder (Thermo Fisher Scientific Inc., Waltham, USA) was used as protein standard

The purification of ENTH V50,51A was less efficient (Figure 13). Less fusion protein was expressed and thus, purified during GST affinity chromatography and just $98 \mathrm{mg}$ of fusion protein was determined. It was also not possible to purify ENTH V50,51A to single band purity by this strategy and several higher order kDa bands were observed beside a prominent target protein band after size exclusion chromatography. $31 \mathrm{mg}$ of the soluble protein was purified. 


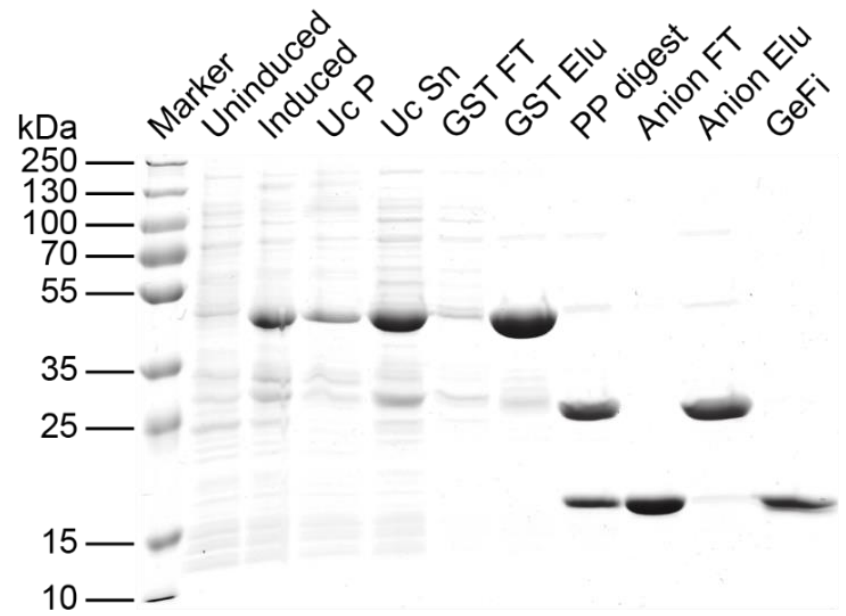

Figure 13: Recombinant expression and purification of ENTH V50,51A. ENTH V50,51A was purified in the same as the ENTH domain (Fig. 8). The protein expression was performed in BL21 cells (uninduced, induced) and the lysate was separated by ultrcentrifugation (Uc P, Uc Sn). The fusion protein was isolated by GST affinity chromatography (GST FT, GST Elu), the tag was cleaved (PP digest) and ENTH V50,51A was isolated from the tag by anion exchange chromatography (Anion FT, Anion Elu). Size exclusion chromatography was used as last purification step (GeFi). PageRuler ${ }^{\mathrm{TM}}$ Plus Prestained Protein Ladder (Thermo Fisher Scientific Inc., Waltham, USA) was used as protein standard.

\subsubsection{Purification of the BAR domain and ANTH domain}

The BAR domain and the ANTH domain are well described endocytic proteins and used in this work as controls. The BAR domain encoding gene was designed from the first $741 \mathrm{bp}$ of endophilinA1 of Rattus norvegicus. The ANTH domain encoding gene was obtained from the $795 \mathrm{bp}$ of Rattus norvegicus AP180. Both genes were cloned into the vector pGEX-6P-2. Both proteins were expressed and purified in the same way.

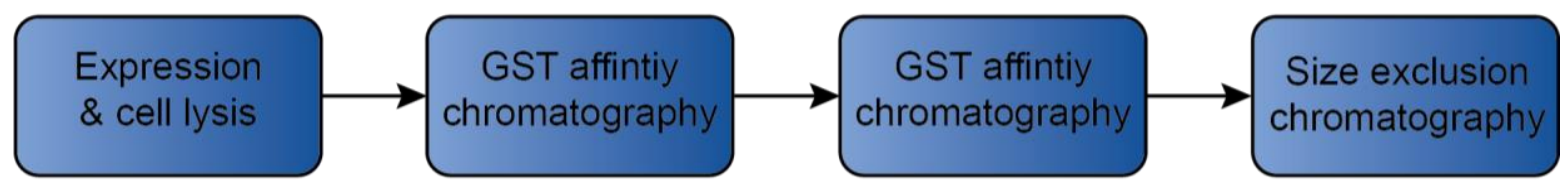

Figure 14: Schematic illustration of the purification strategy of BAR domain and ANTH domain constructs.

The BAR domain and ANTH domain were expressed as GST fusion proteins in $E$. coli BL21 (DE3) as described before. The soluble cell lysate was used for GST affinity chromatography to isolate the GST fusion proteins, after cell lysis and separation by ultracentrifugation. Because anion exchange chromatography was not suitable to separate the cleaved GST tag from the target proteins, a second GST affinity chromatography was included into the purification strategy. Therefore, the PreScission-Protease digest was 
coupled to rebuffering by dialysis. $1 \%(\mathrm{~mol} / \mathrm{mol})$ PreScission-Protease was added to the fusion proteins and the protein suspension was dialysed against GST binding buffer at $4^{\circ} \mathrm{C}$ with gentle agitation over night. The suspension was used for the second GST affinity chromatography subsequently and the target proteins eluted into the flow through, while the GST tag was retained. The ANTH and the BAR domain were both finally purified by size exclusion chromatography (Figure 14).

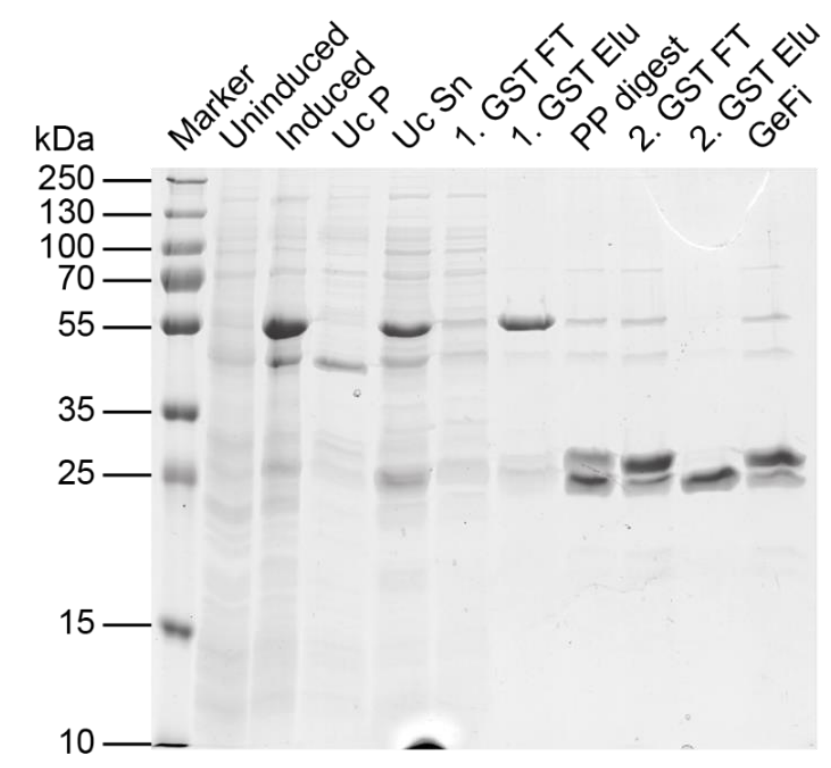

Figure 15: Recombinant expression and purification of the BAR domain. The BAR domain was expressed in BL21 cells by $1 \mathrm{mM}$ IPTG induction (uninduced, induced). The soluble cell lysate was separated from the insoluble cell debris by ultracentrifugation (Uc P, Uc Sn). The fusion protein was isolated by GST affinity chromatography (1. GST FT, 1. GST Elu), the tag was cleaved (PP digest) and the BAR domain was isolated from the tag by a second GST affinity chromatography (2. GST FT, 2. GST Elu). Size exclusion chromatography was used as last purification step (GeFi). PageRuler ${ }^{\text {TM }}$ Plus Prestained Protein Ladder (Thermo Fisher Scientific Inc., Waltham, USA) was used as protein standard.

The purification of the BAR domain led to $31 \mathrm{mg}$ soluble protein from 1 I expression culture (Figure 15). The purified protein was not highly pure because a second prominent protein signal appeared on the SDS gel (approx. $23 \mathrm{kDa}$ ) beneath the expected BAR domain signal $(29 \mathrm{kDa})$. In addition, higher order bands were observed that might have been uncleaved protein, impurity or homo-oligomers after size exclusion chromatography. 


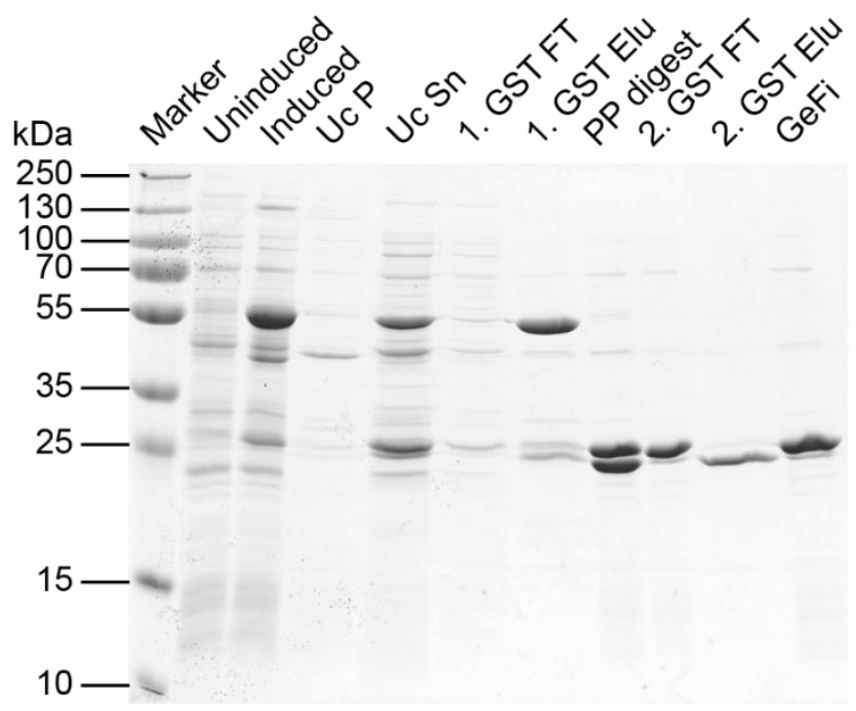

Figure 16: Recombinant expression and purification of the ANTH domain. The ANTH domain was purified in the same way as the BAR domain starting with the expression in BL21 cells by $1 \mathrm{mM}$ IPTG induction (uninduced, induced), the separation of the soluble cell lysate from the insoluble cell debris by ultracentrifugation (Uc $P$, Uc $\mathrm{Sn}$ ) and the isolation of the fusion by GST affinity chromatography (1. GST FT, 1. GST Elu). After tag cleavage (PP digest), the ANTH domain was isolated from the tag by a second GST affinity chromatography (2. GST FT, 2. GST Elu). Size exclusion chromatography was used as last purification step (GeFi). PageRuler TM Plus Prestained Protein Ladder (Thermo Fisher Scientific Inc., Waltham, USA) was used as protein standard.

The purification of the ANTH domain was more successful and $29 \mathrm{mg}$ of the soluble protein were purified from a 1 I expression culture (Figure 16). The ANTH domain protein band appeared very pronounced on the SDS gel, although it migrated to approx. $27 \mathrm{kDa}$ instead to $23 \mathrm{kDa}$, as expected. The purified protein was also not completely pure, since a faint protein signal appeared beneath and above the ANTH domain band after size exclusion chromatography.

\subsubsection{Purification of Epsin1}

In order to recombinantly express and purify the full-length protein Epsin1, the coding sequence of Rattus norvegicus Epsin1 was cloned into the vector pProEx HTc. The resulting construct was further used to generate the mutant for this work: Epsin1 C96A.

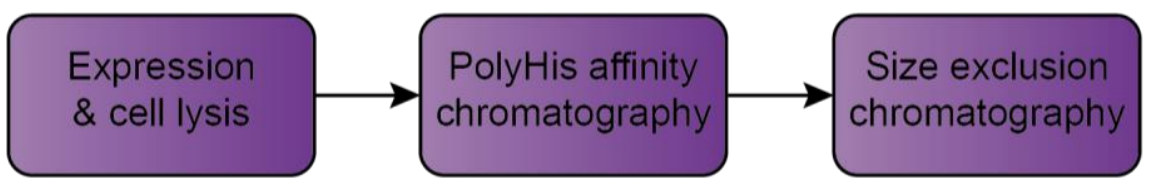

Figure 17: Schematic illustration of the purification strategy of Epsin1 constructs. 
Epsin1 was recombinantly expressed with an N-terminal hexaHis-tag in in E. coli BL21 (DE3) as described before. The soluble cell lysate was used for polyHis affinity chromatography after cell lysis and isolation by ultracentrifugation and Epsin1 was successfully separated from the rest of the lysate. In order to cleave the hexaHis tag from the target protein, the fusion protein was incubated with 1:100 (mol:mol) TEV protease and incubated at $4^{\circ} \mathrm{C}$ with gentle agitation over night. Finally, Epsin 1 was separated from residual impurity by size exclusion chromatography.

A

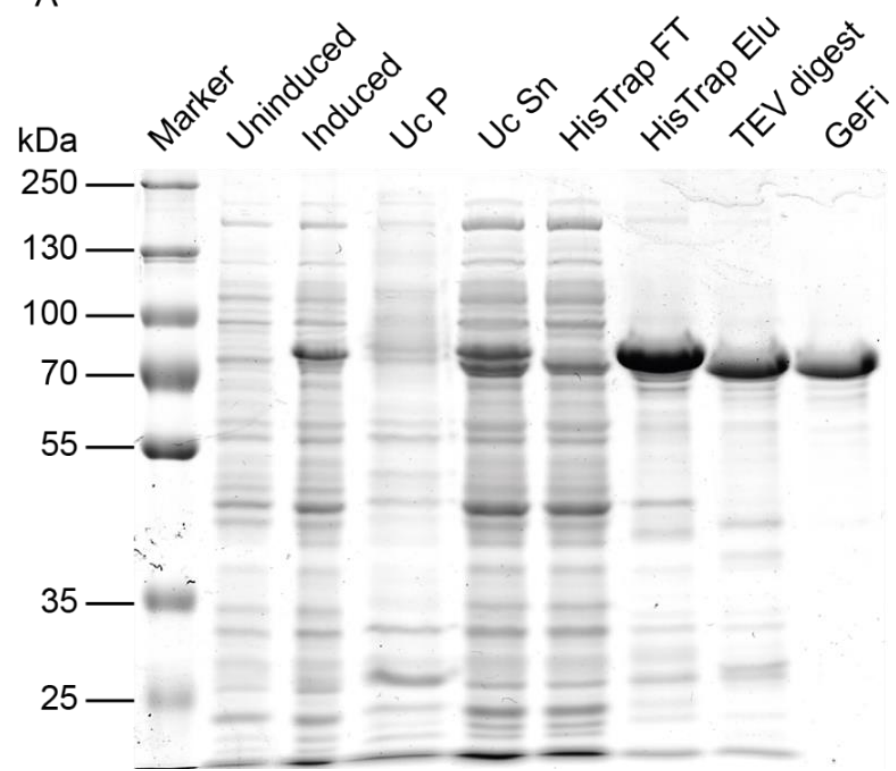

B

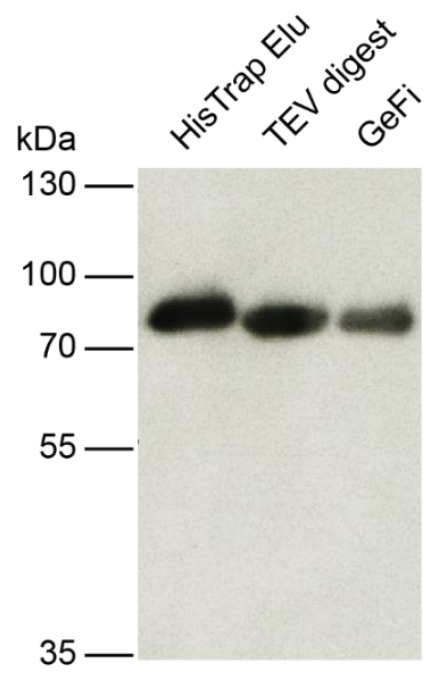

Figure 18: Recombinant expression and purification of the rat Epsin1. Epsin1 was recombinantly expressed in BL21 cells by $1 \mathrm{mM}$ IPTG induction (uninduced, induced). The soluble cell lysate was separated from the insoluble cell debris by ultracentrifugation (Uc $\mathrm{P}, \mathrm{Uc} \mathrm{Sn}$ ) and the isolation the hexaHis-tagged Epsin1 was by size exclusion chromatography (GeFi). PageRuler ${ }^{\mathrm{TM}}$ Plus Prestained Protein Ladder (Thermo Fisher Scientific Inc., Waltham, USA) was used as protein standard. A. SDS-PAGE of all purification steps. B. Visualization of Epsin1 by western blot and immuno staining of the His trap elution, the tag cleavage and the size exclusion chromatography.

The soluble, highly pure Epsin1 was successfully purified and $27 \mathrm{mg}$ of the target protein were isolated from 1 I expression culture (Figure 18). The SDS gel shows a pronounced protein signal at approx. $80 \mathrm{kDa}$ with faint degradation bands beneath. It is obvious that the target protein underwent a slight size shift after it was digested with TEV protease. To ensure that Epsin1 was really purified, samples before the TEV protease digest, after the TEV protease digest and after size exclusion chromatography were used for western blot and immune detection with the Epsin1 antibody. 


\subsubsection{Purification of clathrin triskelia from native tissue}

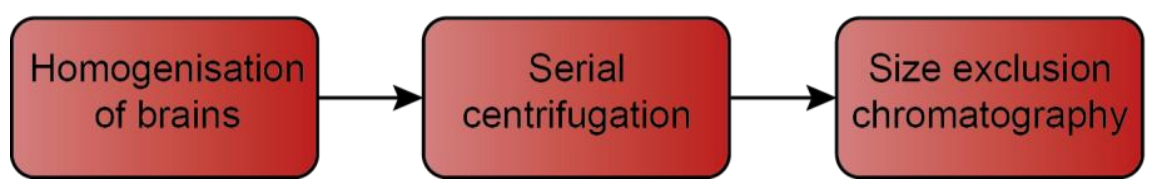

Figure 19: Schematic illustration of the purification strategy of clathrin triskelia from rat brains..

Clathrin triskelia were isolated from brains of Lewis rats, since it is not possible to recombinantly express them. Therefore, the brains were homogenized, clathrin coated vesicles were isolated by serial centrifugation and clathrin disassembly was induced by incubation in clathrin disassembly buffer, as described before (3.2.2.5 Synaptosomal CCV isolation from rat brains) and incubated. Clathrin triskelia were finally isolated by size exclusion chromatography with a Superose ${ }^{\mathrm{TM}}$ 6, 10/300 GL (GE Healthcare Life Science, Chalfont St Giles, UK) (Figure 19).

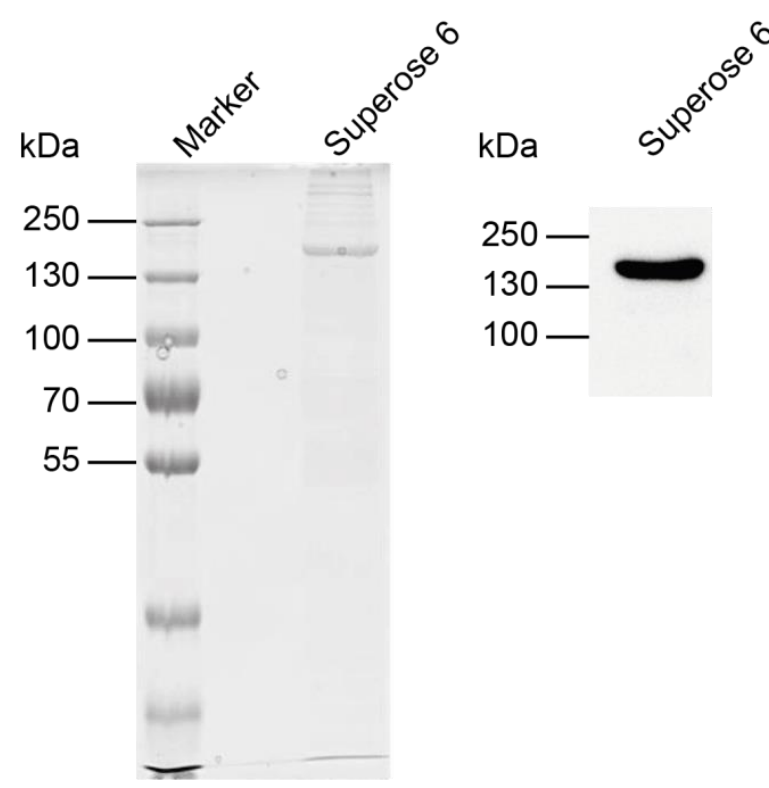

Figure 20: Purification of clathrin triskelia from rat brains. CCVs were purified and disassembled into clathrin triskelia. Finally, clathrin triskelia were purified by size exclusion chromatography (Superose 6). Right side: SDSPAGE and Coomassie staining, left side: Western blot and immuno staining.

Clathrin was successfully purified in this way (Figure 20). The SDS gel shows a pronounced protein band at approx. $180 \mathrm{kDa}$ which is the size of the clathrin heavy chain. In addition, several protein bands were observed above the heavy chain, but none beneath, indicating that native adaptor proteins were successfully separated. To ensure that clathrin was purified, the sample was used for western blot and immune detection with the Clathrin 
Results: Protein purification

Heavy Chain antibody (Becton Dickinson Corp., Franklin Lakes, USA). Just one pronounced protein signal was detected at the same height as in the SDS gel. $6 \mathrm{mg}$ of soluble clathrin triskelia were purified from 20 brains. The soluble protein was stored in the clathrin disassembly buffer and rebuffered by dialysis shortly before usage. 
Results: PtdSer promotes ENTH domain dependent membrane deformation

\subsection{PtdSer promotes ENTH domain dependent membrane deformation}

The ENTH domain of Epsin1 was shown in many different studies to bind to Ptdlns $(4,5) \mathrm{P}_{2}$ containing liposomes, as well as to deform those liposomes ${ }^{116,171,115}$. But so far, liposomes used in these experiments to demonstrate the membrane deformation activity of the ENTH domain were prepared with an not complete defined brain lipid extract (Folch) in addition with Ptdlns $(4,5) \mathrm{P}_{2}$.

In the beginning, we wanted to find out, if we can observe ENTH domain induced membrane deformation on liposomes with a defined lipid composition. By this we addressed the question, if other lipid species are involved in the ENTH domain induced membrane deformation processes.

As a starting point, we analyzed the binding and membrane deformation of the ENTH domain on liposomes with different lipid compositions. Therefore we prepared liposomes of $100 \%$ Folch lipids, 95\% Folch and 5\% La-PtdIns(4,5) $\mathrm{P}_{2}$ and 65\% L $\alpha$-PtdCho, 30\% L $\alpha-$ PtdEtn and $5 \% \operatorname{L} \alpha$-Ptdlns $(4,5) \mathrm{P}_{2}$. These liposomes were incubated with $12 \mu \mathrm{M}$ purified ENTH domain for $3 \mathrm{~h}$ at $30^{\circ} \mathrm{C}$. Membrane binding was analyzed by a co-sedimentation assay and the morphological changes as the result of membrane deformation were analyzed by electron microscopy and by DLS.

As expected ENTH domain binding was only dependent on the presence of Ptdlns $(4,5) \mathrm{P}_{2}$ and it co-sedimented with liposomes composed of Folch La-Ptdlns $(4,5) \mathrm{P}_{2}$ and 65\% L $\alpha$-PtdCho, 30\% L $\alpha$-PtdEtn and 5\% L $\alpha$-Ptdlns(4,5) $\mathrm{P}_{2}$ (Figure 21A). The assay was adjusted to detect possible vesiculation as a consequence of ENTH domain induced membrane deformation and if vesiculation would appear, the lipid signal would have shifted from the pellet into the supernatant as published before ${ }^{115}$. Intrestingly, no vesiculation appeared in all tested conditions. Noteworthy, the ENTH domain incubated with liposomes composed of Folch La-Ptdlns $(4,5) \mathrm{P}_{2}$ led to a prominent protein signal at about $35 \mathrm{kDa}$.

The ENTH domain was only able to induce membrane deformation on liposomes composed of Folch La-Ptdlns $(4,5) \mathrm{P}_{2}$ whereas all the other liposome compositions remained unaffected (Figure 21B). The analyzes by EM showed, that ENTH domain induced membrane deformation resulted in the generation of membrane tubles. The scatter profile of DLS analysis showed a similar results (Figure 21C): liposomes composed of Folch and LaPtdlns $(4,5) \mathrm{P}_{2}$ and 65\% L $\alpha$-PtdCho, 30\% L $\alpha$-PtdEtn and 5\% L $\alpha$-Ptdlns $(4,5) \mathrm{P}_{2}$ had a similar profile like the control liposomes, indicating that no deformation was induced. The scatter profile of Folch La-Ptdlns $(4,5) \mathrm{P}_{2}$ was more diverse with long error bars, indicating that the liposomes did not behave like spherical particles anymore. 
Results: PtdSer promotes ENTH domain dependent membrane deformation

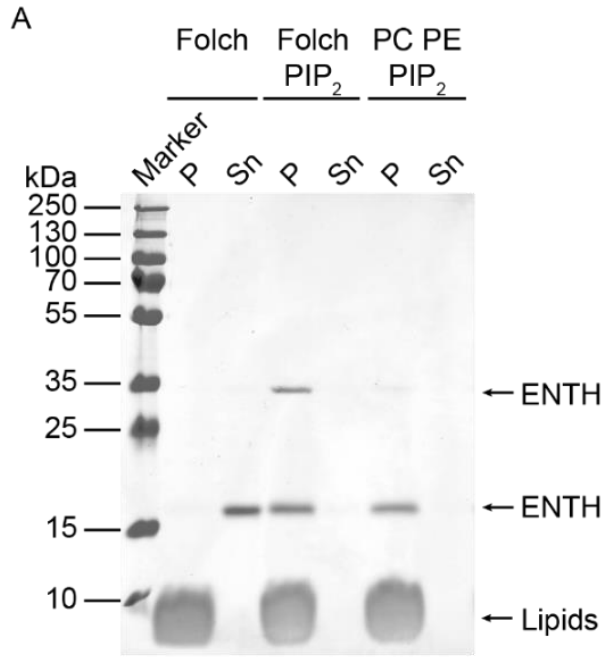

B
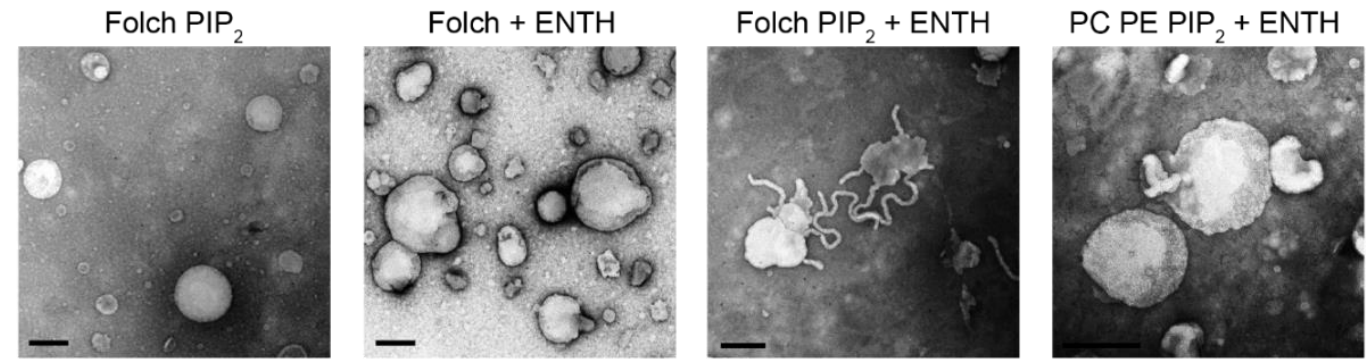

C
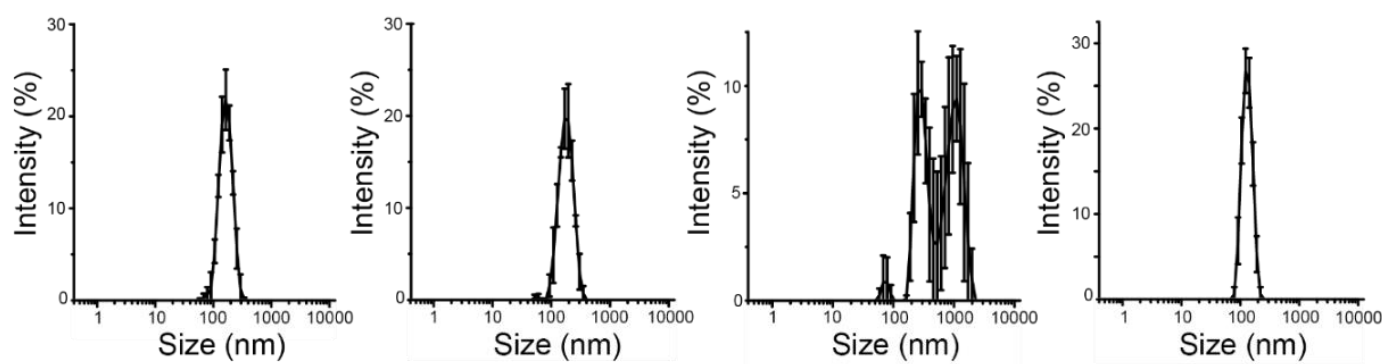

Figure 21: The ENTH domain deforms LUVs composed of brain lipid extract in Ptdlns $(4,5) \mathrm{P}_{2}$ dependency. LUVs were composed of brain lipid extract (Folch), brain lipid extract + Ptdlns $(4,5) \mathrm{P}_{2}\left(\right.$ Folch $\left.\mathrm{PIP}_{2}\right)$ and $\mathrm{PtdCho}$, PtdEtn and Ptdlns (4,5) $\mathrm{P}_{2}\left(\mathrm{PC} P E \mathrm{PIP}_{2}\right)$. A. Co-sedimentation of the ENTH domain with LUVs $(\mathrm{P}=$ pellet, $\mathrm{Sn}=$ supernatant), B. Membrane deformation analysis of LUVs by electron microscopy. LUVs composed of Folch + Ptdlns $(4,5) \mathrm{P}_{2}$ incubated without ENTH domain were used as control. Scale bars correspond to $200 \mathrm{~nm}$. C. Membrane deformation analysis of LUV populations by DLS.

The first results confirmed that ENTH domain binding to liposomes is only dependent on the presence of Ptdlns $(4,5) \mathrm{P}_{2}$. The protein was not able to deform liposomes prepared from a simple lipid composition while it deformed efficiently liposomes composed of a brain lipid extract (FOLCH). Together, these results indicate that membrane deformation additionally depends on the lipid composition.

As control experiment, we performed co-sedimentation assays and detection of protein dependent liposome deformation with the ENTH domain in comparison to the BAR 
Results: PtdSer promotes ENTH domain dependent membrane deformation

domain of rat endophiliA1 and the ANTH domain of rat AP180 (Figure 22A). These protein domains are well studied and derive from endocytic proteins. The ANTH domain was shown to bind to Ptdlns $(4,5) \mathrm{P}_{2}$ containing liposomes but does not deform them. The BAR domain in contrast would be a positive control since it binds liposomes and induces tubulation. Liposomes composed of $2 \mathrm{mg} / \mathrm{ml}$ 95\% Folch and 5\% La-Ptdlns $(4,5) \mathrm{P}_{2}$ were incubated with $12 \mu \mathrm{M}$ protein for $3 \mathrm{~h}$ at $30^{\circ} \mathrm{C}$. All three protein domains co-sedimented with the liposomes and the proteins alone remained in the supernatant. We observed again the appearance of a band at about $35 \mathrm{kDa}$ of lipid bound ENTH domain, while the unbound ENTH domain remained monomeric.

The ENTH domain and the BAR domain both deformed liposomes (Figure 22B). The tubules that were generated by the BAR domain appeared more straight and rigid, while ENTH domain induced tubles showed kinks. The ANTH domain did not deform liposomes as expected. The results were confirmed by the corresponding DLS scattering profiles (Figure 22C). The scattering profile indicated membrane deformation only if liposomes were incubated with the ENTH domain or the BAR domain, while incubation with the ANTH domain showed a similar profile to the control. 
Results: PtdSer promotes ENTH domain dependent membrane deformation

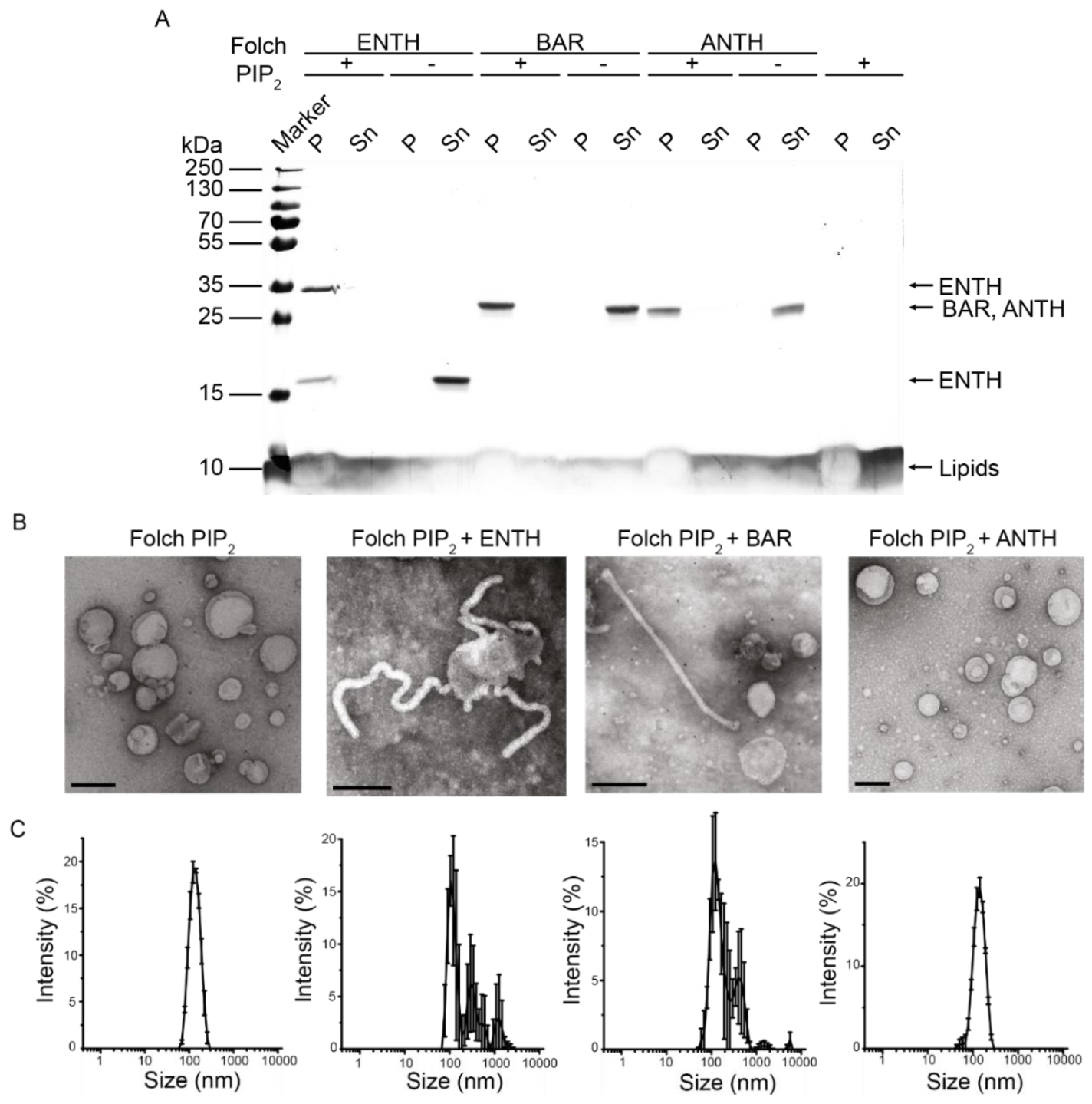

Figure 22: Comparison of endocytic, membrane interacting domains. LUVs, composed of brain lipid extract + Ptdlns $(4,5) \mathrm{P}_{2}$ (Folch PIP 2 ), were incubated either with the ENTH domain of Epsin1 (ENTH), the BAR domain of endophilinA1 (BAR) and the ANTH domain of AP180 (ANTH). A. Co-sedimentation of the ENTH domain, BAR domain and ANTH domain with LUVs ( $P=$ pellet, $S n=$ supernatant). Proteins without LUVs and LUVs without proteins were used as control. B. Membrane deformation analysis of LUVs by electron microscopy. LUVs composed of Folch + Ptdlns $(4,5) \mathrm{P}_{2}$ incubated without proteins were used as control. Scale bars correspond to $200 \mathrm{~nm}$. C. Membrane deformation analysis of LUV populations by DLS.

Next, we started to screen for phospholipids to include in our liposome compositions that would promote membrane deformation. Although information about the total lipid content of the Floch lipids is not available, Avanti Polar Lipid homepage provides information about the most abundant lipid species inside their extract (Table 6). 
Results: PtdSer promotes ENTH domain dependent membrane deformation

Table 6: Phospholipid profile of the Avanti polar brain lipid extract. From the Avanit Polar Lipids webpage.

\begin{tabular}{c|c}
\hline Component & \% (wt/wt) \\
\hline PtdCho & 12.6 \\
PtdEtn & 33.1 \\
Ptdlns & 4.1 \\
PtdSer & 18.5 \\
PA & 0.8 \\
Unkonwn & 30.9 \\
\hline
\end{tabular}

The table shows first of all the diversity within this lipid extract. Beside PtdCho and PtdEtn, PtdSer is the most abundant phospholipid. The mammalian plasma membrane contains high amounts of PtdSer ${ }^{4}$. The distribution of PtdSer in the plasma membrane is asymmetrical and only present in the inner leaflet ${ }^{189}$, where endocytic proteins are located.

To test if the addition of PtdSer to our liposome composition is able to promote ENTH domain induced membrane deformation we used three compositions with decreasing molar percentages of PtdSer: La-PtdCho, La-PtdEtn, La-PtdSer, La-Ptdlns(4,5)P $\mathrm{P}_{2}$ (45: $\left.30: 20: 5\right)$, $(60: 30: 5: 5)$ and $(65: 30: 0: 5)$. To distinguish if occurrent effects are related to the additional negative charge, introduced by PtdSer or by headgroup specificity, we additionally used the lipid composition La-PtdCho, La-PtdEtn, La-Ptdlns, La-Ptdlns (4,5) $\mathrm{P}_{2}$ (45: $30: 20$ : 5). Ptdlns introduces equal negative charges to liposomes, but has a different packing parameter due to its bulky headgroup. As additional controls we used a liposome composition without Ptdlns $(4,5) \mathrm{P}_{2}$ in which we did not expect recruitment of the ENTH domain to the membrane, liposomes with ENTH domain (La-PtdCho, La-PtdEtn, La-PtdSer, La-Ptdlns (4,5) $\left.\mathrm{P}_{2}(45: 30: 20: 5)\right)$ and ENTH domain without liposomes. We incubated 12 $\mu \mathrm{M}$ of ENTH domain together with the differently composed liposomes at $30^{\circ} \mathrm{C}$ for $3 \mathrm{~h}$ and analyzed the membrane binding and membrane deformation.

The co-sedimentation assay showed that the ENTH domain was only recruited to liposomes in presence of Ptdlns $(4,5) \mathrm{P}_{2}$ (Figure 23A). Without Ptdlns $(4,5) \mathrm{P}_{2}$ the ENTH domain remained in the supernatant similar to protein incubated without liposomes Surprisingly, the presence of $20 \%$ PtdSer induced the formation of ENTH homo-oligomers and protein bands appeared at approx. $35 \mathrm{kDa}, 60 \mathrm{kDa}$ and above $70 \mathrm{kDa}$ that remained still stable during SDS-PAGE. In the liposome composition with 5\% PtdSer these bands became fainter but were still visible. In all the other conditions used the ENTH domain behaved monomeric, independent from liposome binding. 
Results: PtdSer promotes ENTH domain dependent membrane deformation

When the same samples were analyzed for membrane curvature induction we found the ENTH domain induced membrane deformation only in the presence of PtdSer (Figure 23B, 22C). With 20\% PtdSer nearly all liposomes showed tubles and DLS analysis confirmed that the liposome population did not behave like spherical particles anymore. Liposomes with 5\% PtdSer showed still moderate membrane deformation but many liposomes did not have tubles. The DLS confirmed that membrane deformation occurred, but to a lesser extent than with $20 \%$ PtdSer. The ENTH domain was not able to deform liposomes in lipid compositions without PtdSer and with $20 \%$ Ptdlns. The controls, ENTH domain incubated with liposomes without Ptdlns $(4,5) \mathrm{P}_{2}$, liposomes alone and ENTH domain alone behaved like expected in the co-sedimentation assay and in the analysis of membrane deformation. Based on electron microscopy pictures, a quantitative evaluation of deformed membrane structures and tubule length was performed. For this purpose, we counted at least 150 membranous structures at every condition. In the liposome samples containing $20 \%$ PtdSer more than $80 \%$ of the counted structures were tubulated (Figure $24 \mathrm{~A}$ ). With $5 \%$ PtdSer the percentage of tubulated structures decreased to approx. 45\%. Without PtdSer, with $20 \%$ Ptdlns and in liposomes without Ptdlns $(4,5) \mathrm{P}_{2}$ nearly no deformation occurred similar to the control liposomes. Most of the tubules had a length between $125 \mathrm{~nm}$ and 250 $\mathrm{nm}$ (Figure 24B).

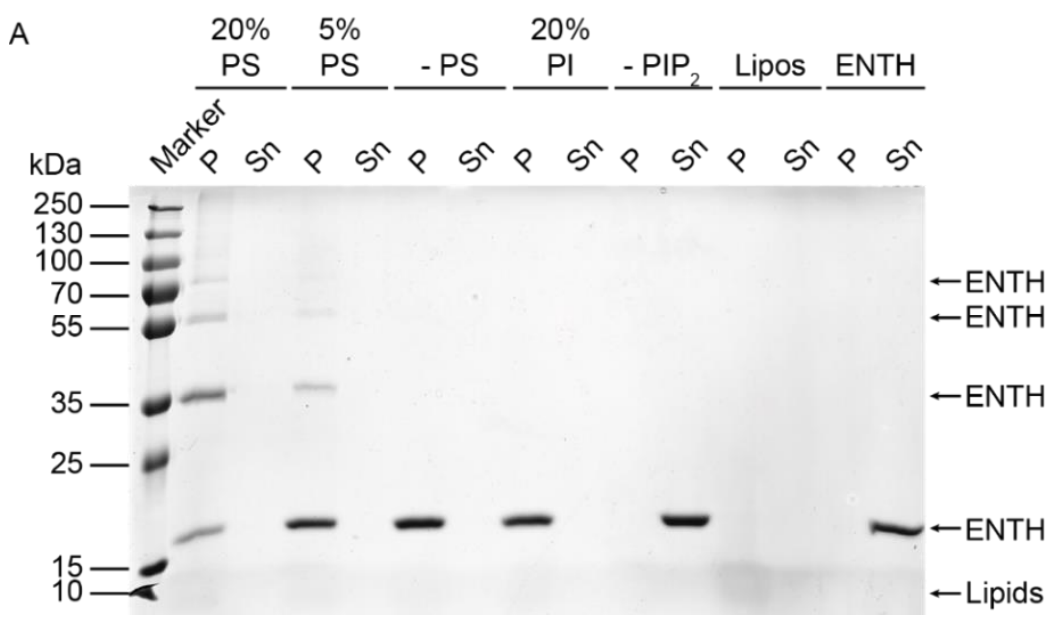


B

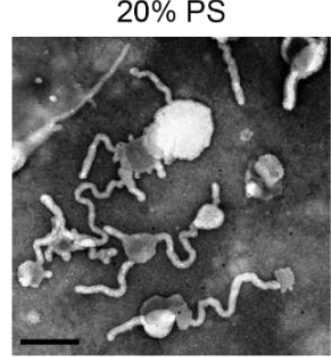

C

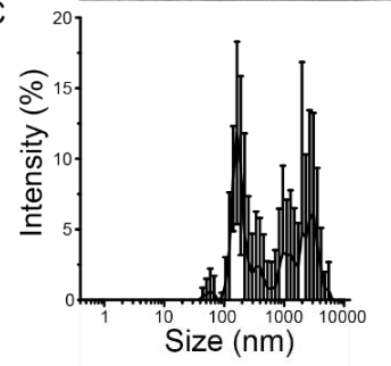

$20 \% \mathrm{Pl}$
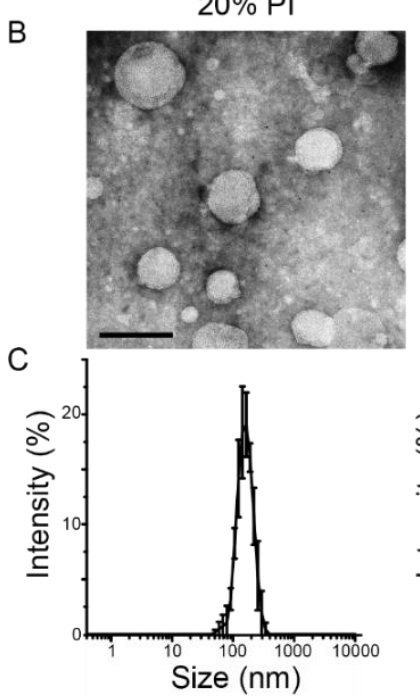

$5 \%$ PS
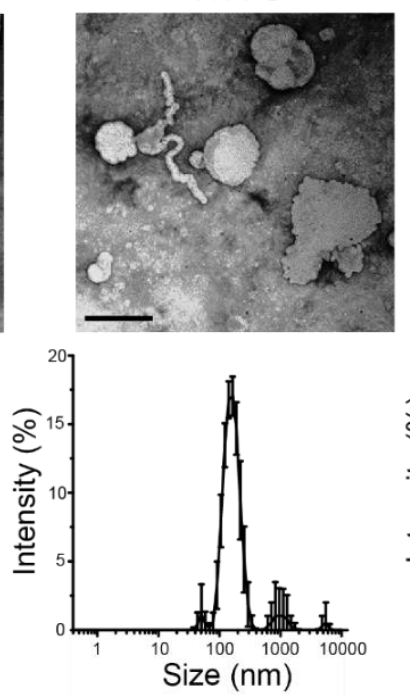

$-\mathrm{PIP}_{2}$
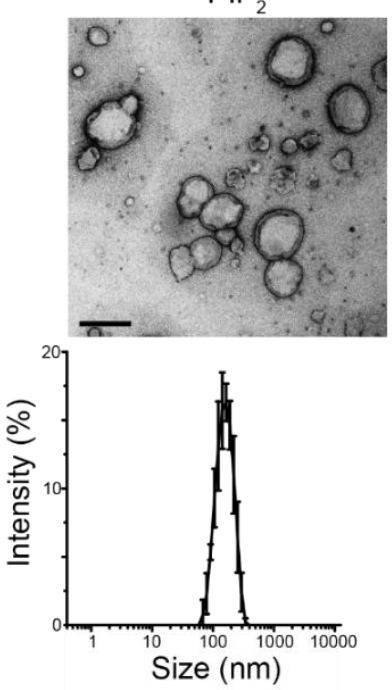

- PS
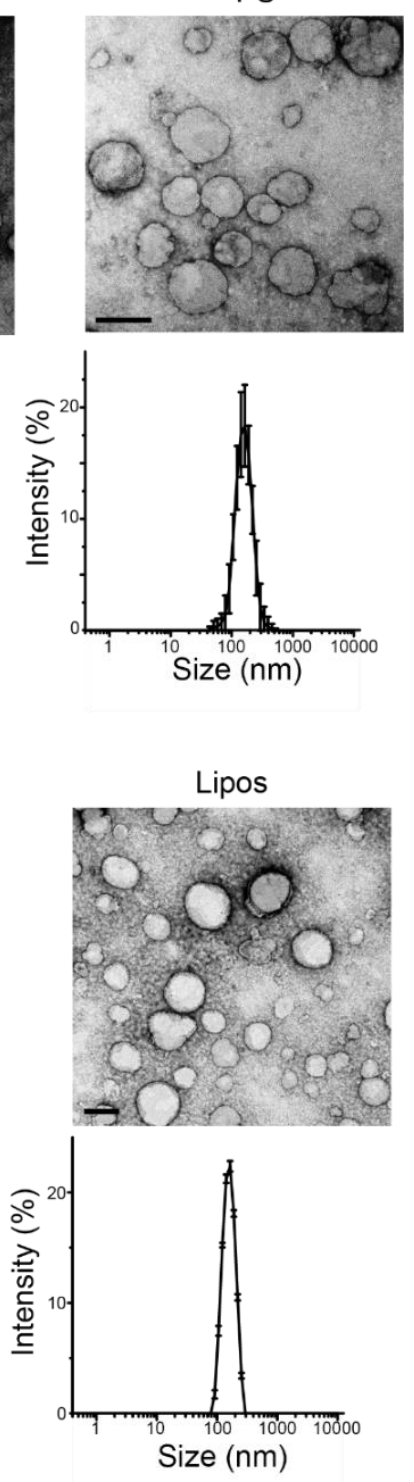

Figure 23: PtdSer promotes ENTH domain induced membrane deformation and the formation of ENTH domain homo-oligomers. LUVs were composed of PtdCho, PtdEtn, PtdSer, Ptdlns $(4,5) \mathrm{P}_{2}(20 \%$ PS - $45: 30$ : $20: 5)$. (5\% PS - $60: 30: 5: 5)$, (0\% PS - $65: 30: 5)$ and were incubated with the ENTH domain. In addition, LUVs composed of PtdCho, PtdEtn, Ptdlns, Ptdlns(4,5)P 2 (20\% PI - $45: 30: 20: 5)$ and PtdCho, PtdEtn, PtdSer (- PIP $-50: 30: 20$ ) were also incubated with the ENTH domain. A. Co-sedimentation of the ENTH domain with LUVs $(P=$ pellet, $S n=$ supernatant). ENTH domain without LUVs and LUVs without ENTH domain were used as control. B. Membrane deformation analysis of LUVs by electron microscopy. LUVs incubated without proteins were used as control. Scale bars correspond to $200 \mathrm{~nm}$. C. Membrane deformation analysis of LUV populations by DLS. 
A

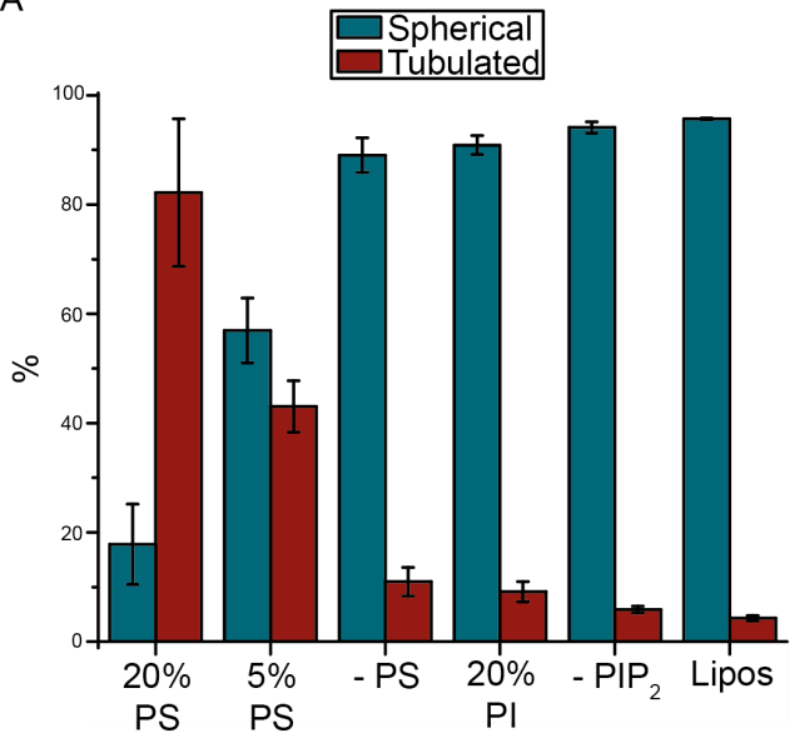

B

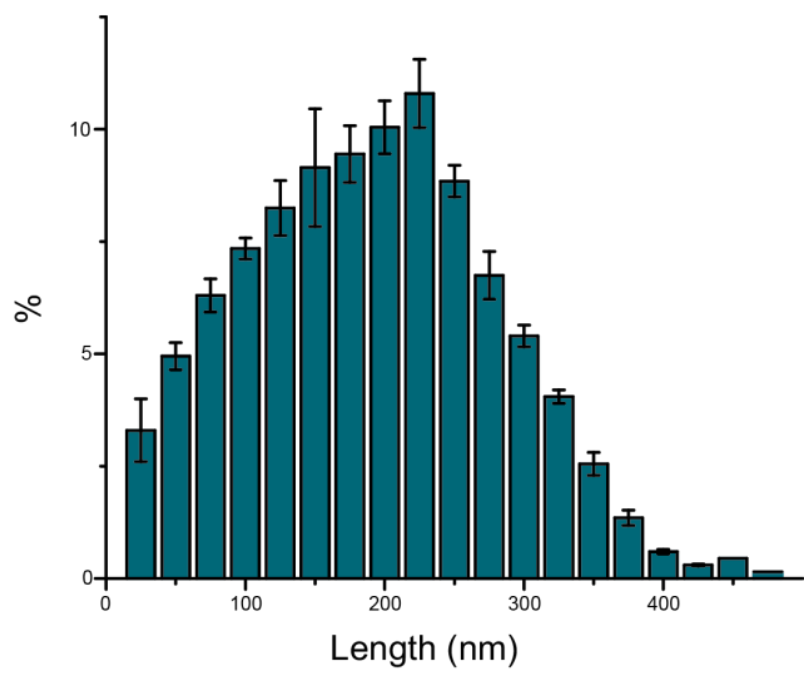

Figure 24: Quantitative evaluation of PtdSer dependent membrane deformation by the ENTH domain. At least 150 membranous structures were evaluated per condition. LUVs were composed as in figure 23. A. Percentage of spherical and tubulated membranous structures per condition. B. Percentage of tubule length generated by the ENTH domain on LUVs composed of PtdCho, PtdEtn, PtdSer, Ptdlns(4,5)P 2 (45: $30: 20: 5)$.

Together, these results show that ENTH domain dependent membrane deformation and formation of homo-oligomers is dependent on the presence of PtdSer. This effect is not only dependent on the negative charges introduced by PtdSer since it was not possible to get similar results by replacing PtdSer with Ptdlns.

Next, we asked if ENTH domain induced membrane deformation is dependent on the lipid species PtdSer itself, or if PtdSer changes the physical properties of the membrane so it becomes easier to deform? PtdSer has an inverse conical shape with a small headgroup in comparison to the rest of the lipid similar to PtdEtn which is not charged. We replaced the additional molar percentage of PtdSer with PtdEtn to get the lipid composition: La-PtdCho, La-PtdEtn, La-Ptdlns(4,5) $\mathrm{P}_{2}(45: 50: 5) .2 \mathrm{mg} / \mathrm{ml}$ liposomes of this composition were incubated with and without $12 \mu \mathrm{M}$ ENTH domain and tested again for membrane binding and membrane deformation.

The ENTH domain was still recruited to these liposomes but the formation of homooligomers did not occur (Figure 25A). We also did not see any tubulation and the liposomes behaved like spherical particles in DLS analysis (Figure 25B, 25C). The intrinsic controls of this experiment behaved like expected: liposomes without ENTH pelleted and ENTH domain without the liposomes remained in the supernatant. The control liposomes were not deformed as well. 
Results: PtdSer promotes ENTH domain dependent membrane deformation
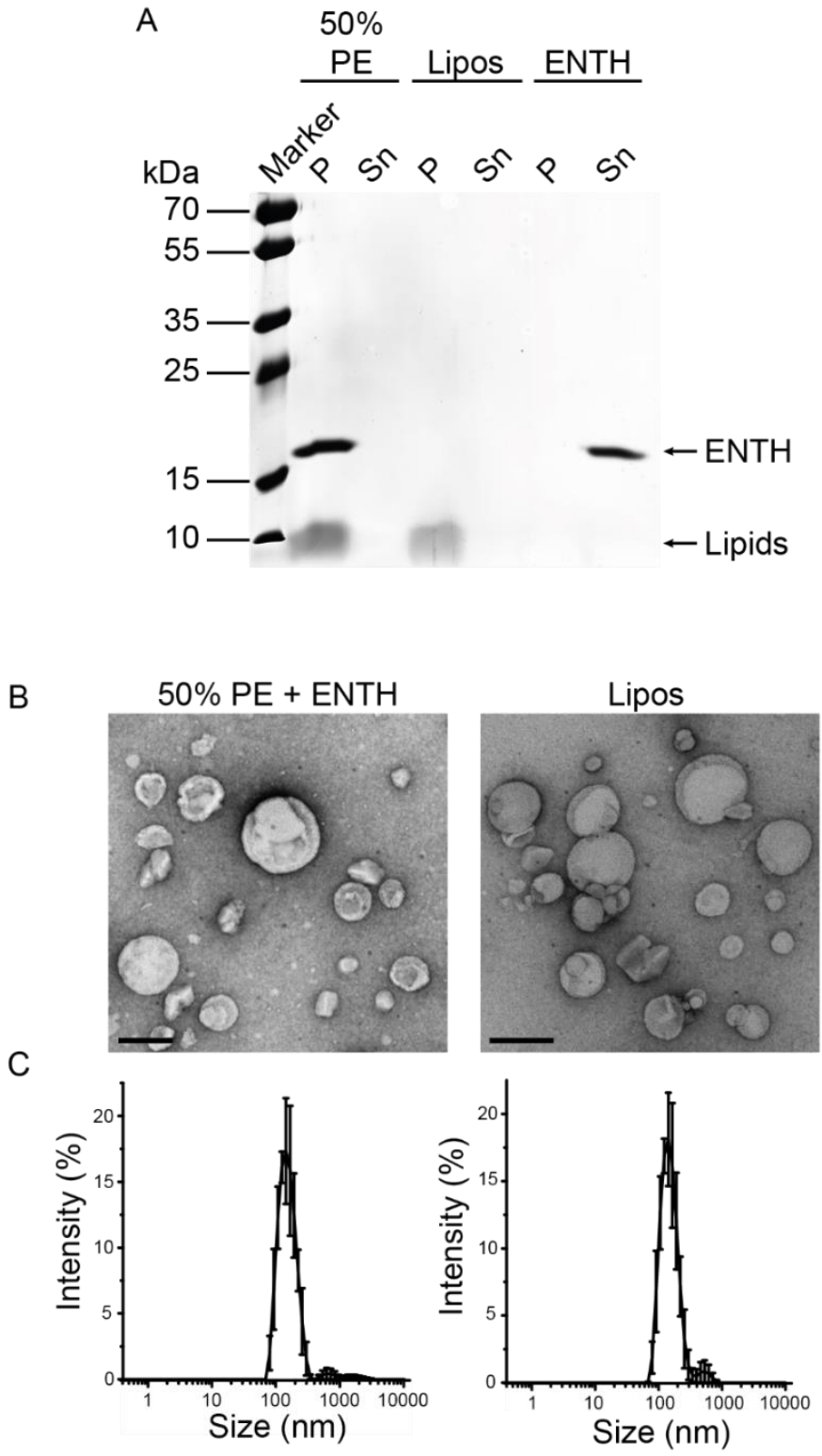

Figure 25: PtdEtn is not able to promote ENTH domain induced membrane deformation and the formation of ENTH domain homo-oligomers. LUVs were composed of PtdCho, PtdEtn Ptdlns (4,5) $\mathrm{P}_{2}(50 \% \mathrm{PE}-45$ : 50 : 5) and were incubated with the ENTH domain. A. Co-sedimentation of the ENTH domain with LUVs ( $P=$ pellet, $\mathrm{Sn}=$ supernatant). ENTH domain without LUVs (ENTH) and LUVs without ENTH domain (Lipos) were used as control. B. Membrane deformation analysis of LUVs by electron microscopy. LUVs incubated without protein were used as control. Scale bars correspond to $200 \mathrm{~nm}$. C. Membrane deformation analysis of LUV populations by DLS.

So far, the results indicated that the ENTH domain is able to induce membrane deformation on liposomes containing PtdSer. To observe membrane binding and deformation in real time we employed fluorescence microscopy together with GUVs. We chose Atto 488 maleimide to label the ENTH domain and Atto 647N DO-PtdEtn for the 
Results: PtdSer promotes ENTH domain dependent membrane deformation

GUVs to avoid the FRET effect. The emission of Atto 488 does not overlap with the absorption of Atto 647N (Figure 26A). The ENTH domain possesses one cysteine at position 96 within helix 5 that might have been a target for maleimide modification. To avoid helix breaks and disrupt the structural integrity of the protein we mutated this cysteine to an alanine and mutated the alanine on position 155 in the end of the ENTH domain to a cysteine (Figure 26B). The mutant ENTH C96A A155C was efficiently labeled and still bound to membranes. We subsequently tested the stability of Atto $647 \mathrm{~N}$ over $157 \mathrm{~min}$ (Figure 26C). Therefore, we generated GUVs by using a lipid composition with La-PtdCho, La- PtdEtn, Atto $647 \mathrm{~N}$ DO-PtdEtn (69.5 : 30 : 0.5). The GUVs were recorded with $5 \%$ laser intensity, an exposure time of $100 \mathrm{msec}$ and a recording frequency of 30 pictures per min. The fluorophore remained stable over this time and no cross-talk into the emission wavelength of Atto 488 occurred.

A

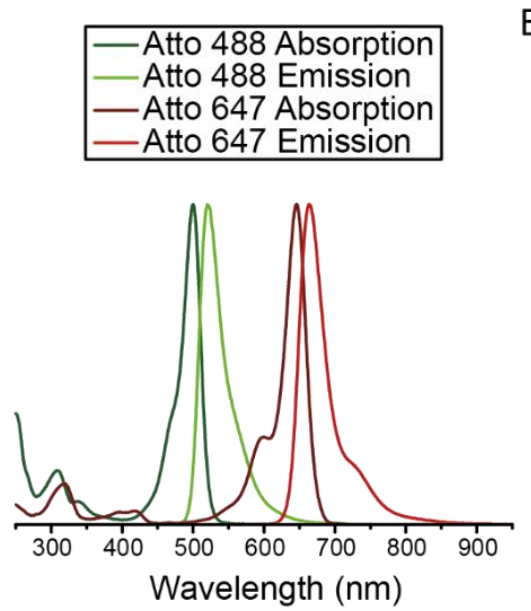

C
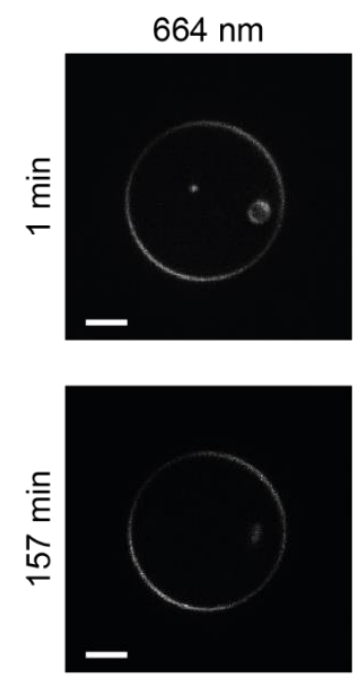

B

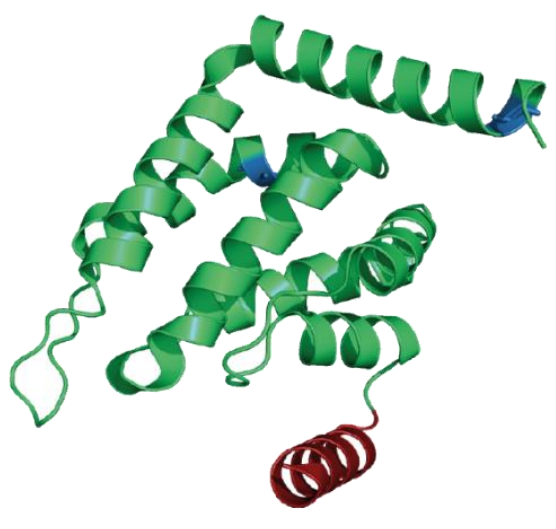

$520 \mathrm{~nm}$
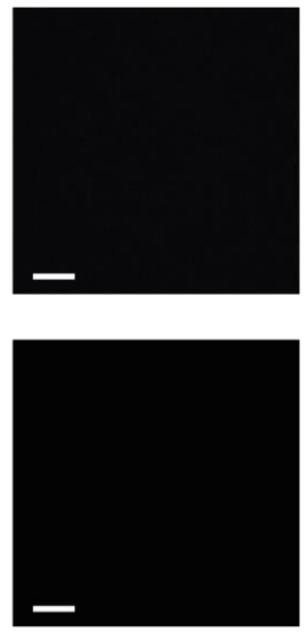

Figure 26: The GUV assay. A. Spectra of Atto 488 and Atto 647N. B. ENTH domain C96A A155C used as labeling mutant. Mutated residues are indicated in blue. C. Atto $647 \mathrm{~N}$ did not show cross-talk into emission of Atto 488 and was photo stabile Scale bars correspond to $8 \mu \mathrm{m}$. 
Results: PtdSer promotes ENTH domain dependent membrane deformation

$2 \mu \mathrm{M}$ of the labeled ENTH domain was incubated with GUVs composed of LaPtdCho, La-PtdEtn, La-PtdSer, La-Ptdlns(4,5)P $\mathrm{P}_{2}$ and Atto 647N DO-PtdEtn (44.5 : 30 : 20 : $5: 0.5)$ at $25^{\circ} \mathrm{C}$. Since it is not possible to mix the GUV suspension without disturbing the integrity of the vesicles, we waited until the ENTH domain diffused to the target GUV. After reaching the membrane, the ENTH domain started to bind (Figure 27A). Shortly, after saturation of the ENTH signal at the membrane, we observed the generation of long membrane tubles originating from the GUV accompanied with the shrinking of the GUV and final collapse of the GUV (Figure 27B).

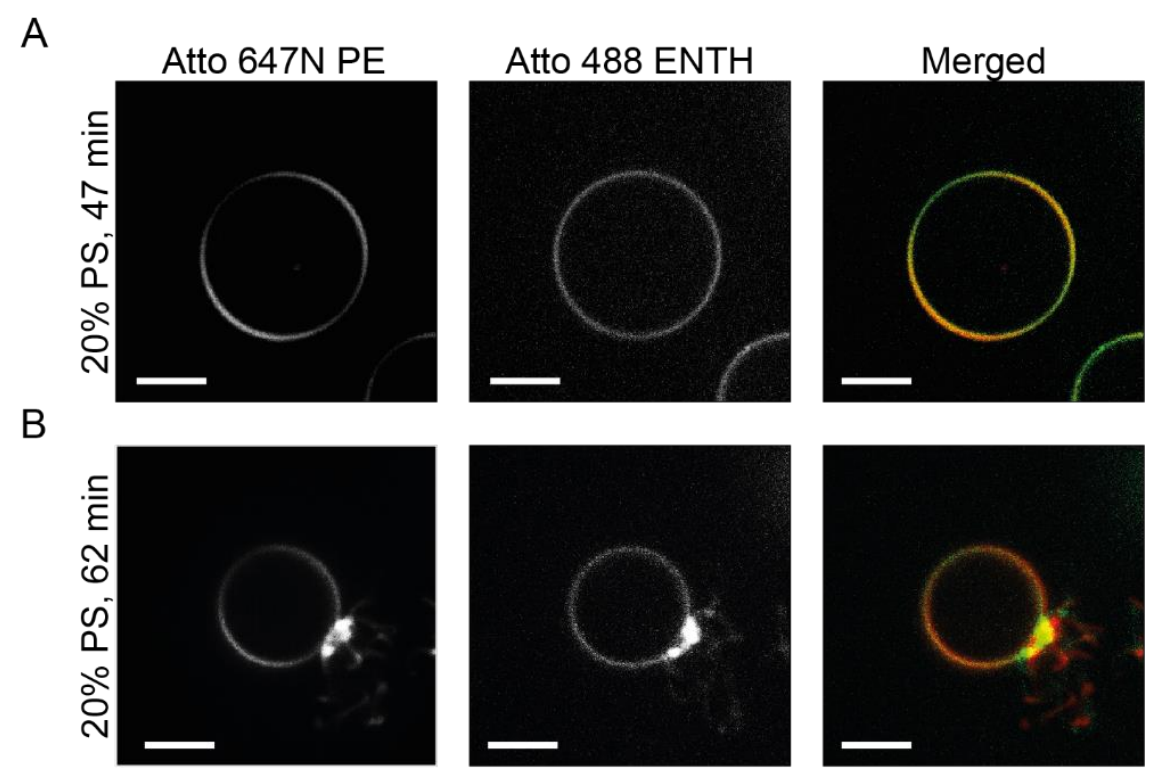

Figure 27: The ENTH domain binds to and deforms PtdSer containing GUVs. Atto 488 ENTH (520 nm) and the GUV membrane Atto647N PE (664 nm) were recorded. A. Full membrane coverage of the ENTH domain was observed after $47 \mathrm{~min}$. B. The membrane tubulation started after $62 \mathrm{~min}$. Scale bars correspond to $5 \mu \mathrm{m}$.

In comparison, we incubated labeled ENTH domain with GUVs composed of LaPtdCho, La- PtdEtn, La- PtdIns(4,5) $\mathrm{P}_{2}$ and Atto 647N DO-PtdEtn (64.5: $\left.30: 5: 0.5\right)$ under the same conditions. The recruitment of the protein to the GUVs was still observed but no signs of the generation of membrane tubules occured and the GUVs remained stable during the recording time (Figure 28). 
Results: PtdSer promotes ENTH domain dependent membrane deformation
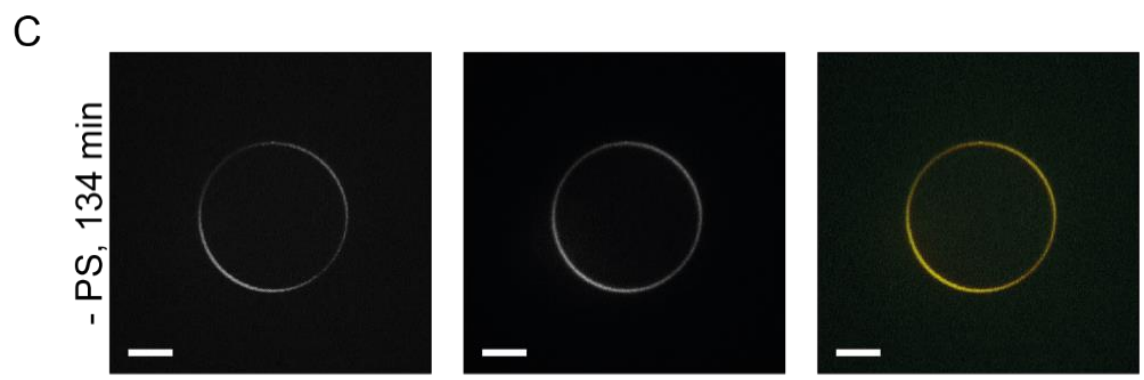

Figure 28: The ENTH domain does not deform GUVs without PtdSer. Atto 488 ENTH ( $520 \mathrm{~nm}$ ) and the GUV membrane Atto647N PE (664 nm) were recorded. Full membrane coverage of the ENTH domain was observed after $40 \mathrm{~min}$. But no membrane deformation occurred until the end of recording (134 $\mathrm{min})$. Scale bars correspond to $8 \mu \mathrm{m}$.

The whole tubulation event was very fast and took just $22 \mathrm{sec}$ until the GUV collapsed (Figure 29). In the beginning, nucleation spots were observed on the GUV in which the intensity of the membrane signal and the protein signal increased. Membrane tubules originated from these spots on which the protein still co-localized. The GUV shrunk and more membrane material was put into the growing tubules until the GUV was not in focus anymore.

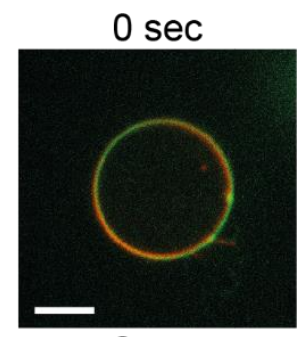

$8 \mathrm{sec}$

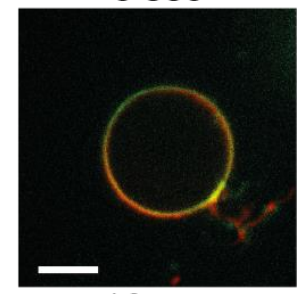

$16 \mathrm{sec}$

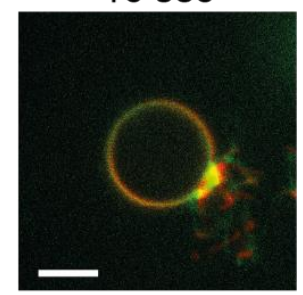

$2 \mathrm{sec}$

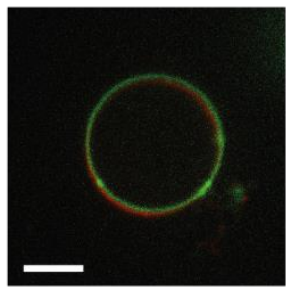

$10 \mathrm{sec}$

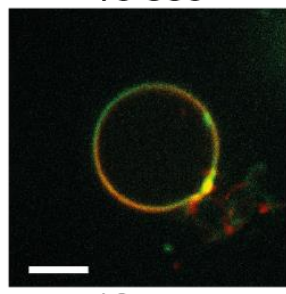

$18 \mathrm{sec}$

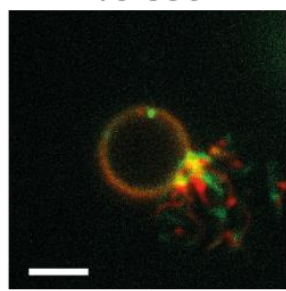

$4 \mathrm{sec}$

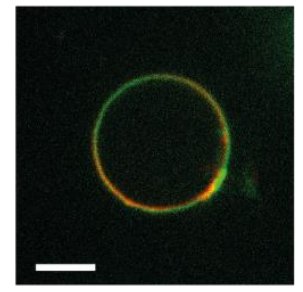

$12 \mathrm{sec}$

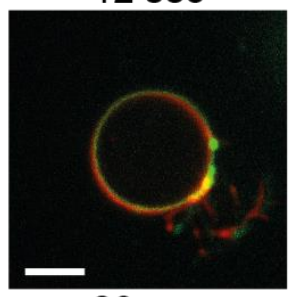

$20 \mathrm{sec}$

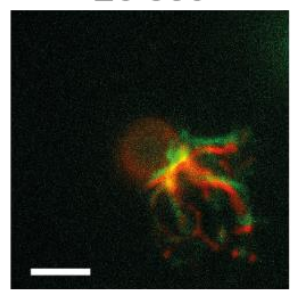

$6 \mathrm{sec}$

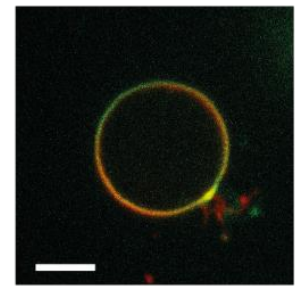

$14 \mathrm{sec}$

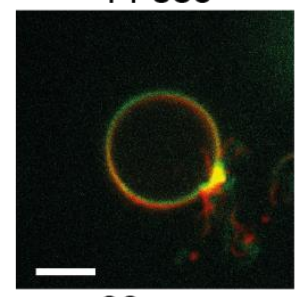

$22 \mathrm{sec}$

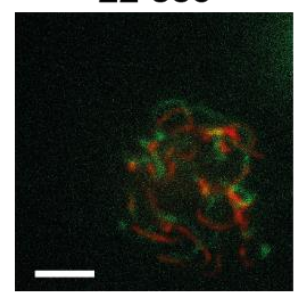

Figure 29: The ENTH domain does not deform GUVs without PtdSer. Atto 488 ENTH ( $520 \mathrm{~nm}$ ) and the GUV membrane Atto647N PE (664 nm) were recorded. Full membrane coverage of the ENTH domain was observed after $40 \mathrm{~min}$. But no membrane deformation occurred until the end of recording (134 min). Scale bars correspond to $8 \mu \mathrm{m}$. 
Results: PtdSer promotes ENTH domain dependent membrane deformation

Finally, we examined, if the soluble PtdSer headgroup is sufficient to induce similar effects as the lipid embedded inside the membranes. Therefore, we prepared LUVs composed of La-PtdCho, La-PtdEtn and La-Ptdlns (4,5) $\mathrm{P}_{2}(65: 30: 5)$ and incubated them with and without $12 \mu \mathrm{M}$ ENTH domain, $48 \mu \mathrm{M}$ O-phosphoserine, or both together for $3 \mathrm{~h}$ at $30^{\circ} \mathrm{C}$. The ENTH domain was also incubated with O-phosphoserine alone as control. The analysis of the co-sedimentation assay showed, that the ENTH domain was recruited to the membranes in presence and absence of O-phosphoserine, while it remains in the supernatant without LUVs (Figure 30A). But only in presence of the PtdSer headgroup and the membrane the ENTH domain formed homo-oligomers again and protein signal was visible at $35 \mathrm{kDa}$, above $55 \mathrm{kDa}$ and above $70 \mathrm{kDa}$.

The analysis by electron microscopy reveled that membrane deformation occurred, if LUVs were incubated with ENTH domain and O-Phosphoserine together, although it was not as drastic as if the PtdSer was part of the membrane in electron microscopy confirmed by DLS (Figure 30B, 30C). Liposomes alone or with O-phosphoserine or with ENTH domain did not show tubulation in the electron microscopy, as well as no deformation measured by DLS.

We counted again over 150 membrane structures per condition, taken from electron microscopy pictures, for the statistical analysis (Figure 30D). Here, the results indicate, that the membrane deformation activity of the ENTH domain was partially recovered by the presence of PtdSer headgroup in comparison to the other conditions. In the presence of the headgroup, about $50 \%$ of the counted structures were tubulated, while nearly no deformation occurred only with O-phosphoserine, or only with ENTH domain.

All results together strongly indicate that PtdSer affects the ENTH domain induced membrane deformation. PtdSer does not seem to change the physical properties of the used model membranes, since protein induced membrane deformation was not observed in the control conditions containing the negatively charged Ptdlns, or the inverse conical shaped PtdEtn. In addition, the presence of PtdSer induced the formation of ENTH domain homooligomers, if the ENTH domain was recruited to model membranes indicating that ENTH domain induced membrane deformation and homo-oligomerization are associated. 
Results: PtdSer promotes ENTH domain dependent membrane deformation
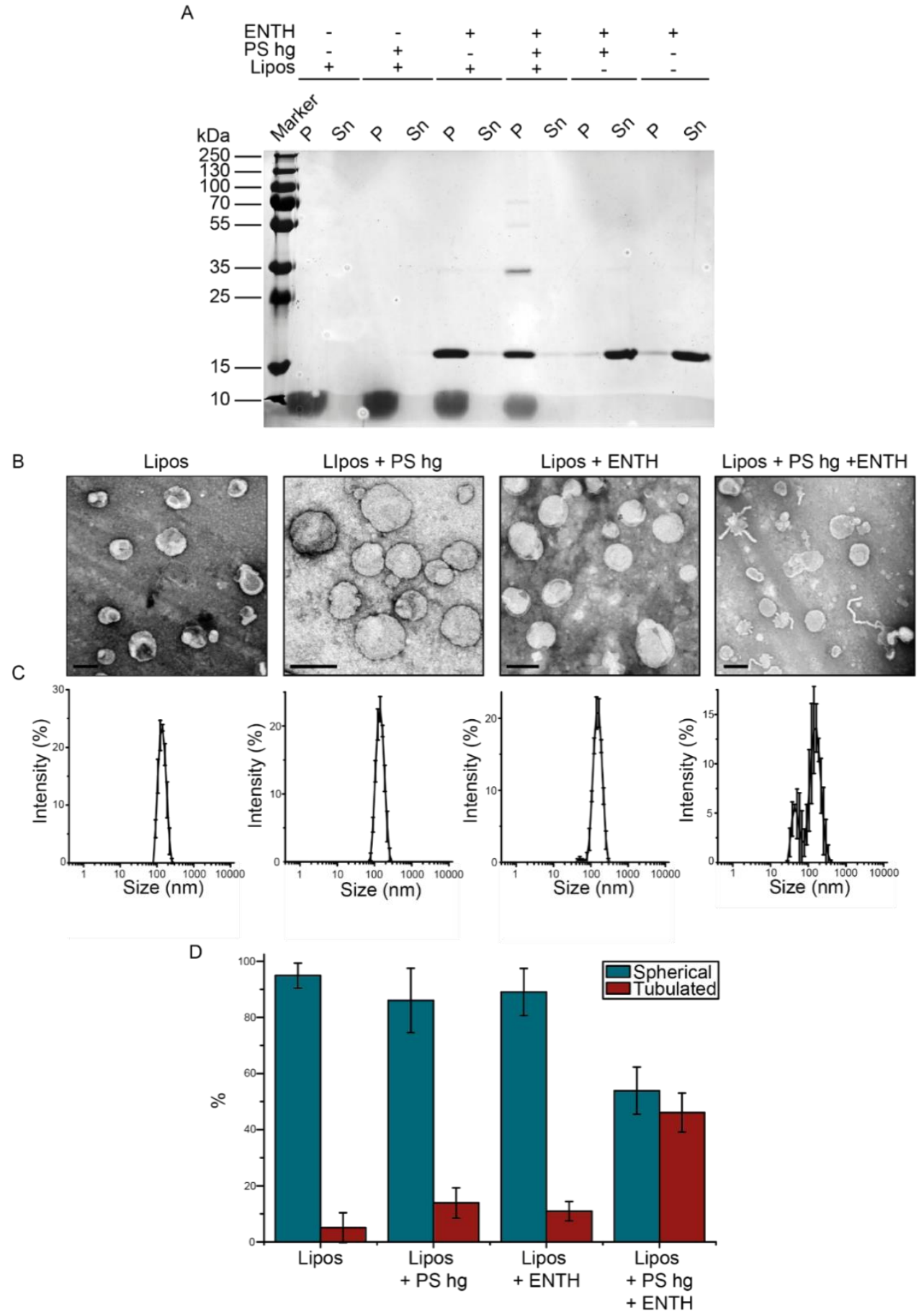

Figure 30: 0-phosphoserine is partially able to rescue ENTH domain induced membrane deformation and homo-oligomer formation. LUVs were composed of PtdCho, PtdEtn, Ptdlns $(4,5) \mathrm{P}_{2}$ (Lipos - $65: 30: 5$ ) and were incubated with the ENTH domain with or without O-phosphoserine (PS hg). A. Co-sedimentation of the ENTH domain with LUVs ( $P$ = pellet, $S n=$ supernatant). ENTH domain without LUVs $(E N T H)$ and LUVs without ENTH domain and with, or without O-phosphoserine (Lipos) were used as control. B. Membrane deformation analysis of LUVs by electron microscopy. LUVs incubated without protein were used as control. Scale bars correspond to $200 \mathrm{~nm}$. C. Membrane deformation analysis of LUV populations by DLS. D. Quantitative evaluation of electron micrographs. 
Results: PtdSer promotes ENTH domain dependent membrane deformation

All results together strongly indicate that PtdSer interacts with the ENTH domain. PtdSer does not seem to change the physical properties of the model membranes so that ENTH domain induced membrane deformation becomes more favorable, since tubulation was not observed with the negatively charged Ptdlns or the inverse conical shaped PtdEtn. In addition, the presence of PtdSer induced the formation of ENTH domain homo-oligomers, if the ENTH domain was recruited to the used model membranes. This indicates, that ENTH domain induced membrane deformation and homo-oligomerization are associated.

We started to cooperate with the Zweckstetter group (Markus Zweckstetter, Max Planck Institute for Biochemistry, Göttingen, Germany) to perform solid state NMR studies of ${ }^{13} \mathrm{C}$ and ${ }^{15} \mathrm{~N}$ labeled ENTH domain bound to LUVs composed of PtdCho, PtdEtn, Ptdlns (4,5) $\mathrm{P}_{2}(65: 30: 5)$ and PtdCho, PtdEtn, PtdSer, Ptdlns $(4,5) \mathrm{P}_{2}(45: 30: 20: 5)$. The data indicates that the ENTH domain bound to PtdSer underwent structural changes and appeared to be more "rigid" in comparison to ENTH domain bound to LUVs without PtdSer (data not shown).

Finally, we started to examine the effect of cholesterol on ENTH domain dependent membrane deformation (Figure 31). For preliminary studies, we used LUVs composed of PtdCho, PtdSer, chol, Ptdlns(4,5) $\mathrm{P}_{2}$ (45: $\left.30: 20: 5\right)$. Those LUVs (2 mg/ml lipid content) were incubated with $12 \mu \mathrm{M}$ ENTH domain the same way as described before. The analysis of membrane deformation revealed a new phenotype for membrane deformation. The ENTH domain still induced the generation of tubles, but these membrane tubles were segmented. We designated this phenotype beads-on-a-sting. The single segments were approx. $25 \mathrm{~nm}$ in diameter.

All these results taken together indicate that the ability of the ENTH domain strongly depended on the lipid composition as well as the phenotype of resulting membrane deformation. 
Results: PtdSer promotes ENTH domain dependent membrane deformation

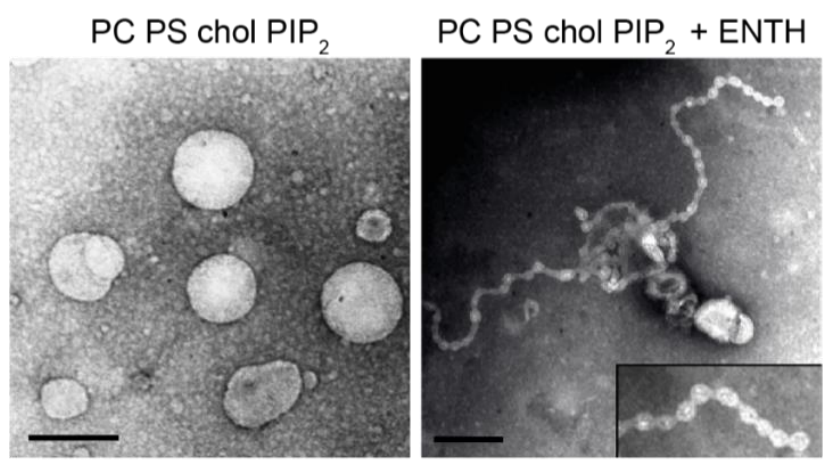

Figure 31: The presence of cholesterol within LUVs promotes the ENTH domain dependent generation of segmented membrane tubules. LUVs were composed of PtdCho, PtdSer, chol, Ptdlns(4,5)P2 (45: $30: 20: 5)$ and were incubated with and without the ENTH domain. Membrane deformation analysis of LUVs were performed by electron microscopy. Scale bars correspond to $200 \mathrm{~nm}$. 
Results: ENTH domain oligomerization is dependent on PtdSer and the arginine 114

\subsection{ENTH domain oligomerization is dependent on PtdSer and the arginine 114}

PtdSer had two effects on the ENTH domain: we observed that the ENTH domain induced the generation of membrane tubules in dependency of PtdSer. In addition, we observed at least dimerization of membrane bound ENTH domains, also only in the presence of PtdSer. The effects we observed on the ENTH domain were lipid headgroup specific since it was not possible to obtain similar effects if we exchanged PtdSer with lipids that had similar physical characteristics. But so far, we were not able to identify the molecular background of this effect.

In 2012 Lai C. et al performed coarse-grained molecular dynamics (CG MD) simulation of the ENTH domain bound to liposomes and to membrane tubules. Beside the Ptdlns $(4,5) \mathrm{P}_{2}$ binding pocket, they identified two regions of interest: The ENTH domain possesses two valines (V50,51) in the N-terminal end of helix 3 (Figure 32). The CG MD simulations showed that these two residues are surface exposed and the authors proposed that these residues might have a role as protein-protein interaction sites to form ENTH domain homo-dimers in an antiparallel orientation ${ }^{170}$. The second region of interest was identified within the loop between helix 6 and helix 7. Based upon EPR studies and structural analysis the authors claimed that this loop touches the surface of the membrane ${ }^{170}$. Especially, an arginine (R114) within this region had a significant role in their considerations (Figure 32) and they proposed that this basic amino acid might interact with acidic lipid headgroups and determines the orientation of the ENTH domain on the membrane. The ENTH domain would form at least dimers to stabilize membrane tubules and act as a scaffold. Since these ideas are lacking experimental evidence we adopted them to test if our observations about PtdSer dependent membrane tubulation and homo-oligomerization are in context with these two regions.

ENTH V50,51

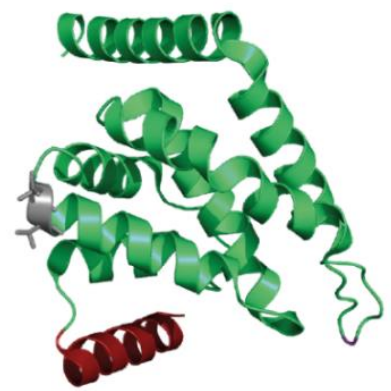

ENTH R144A

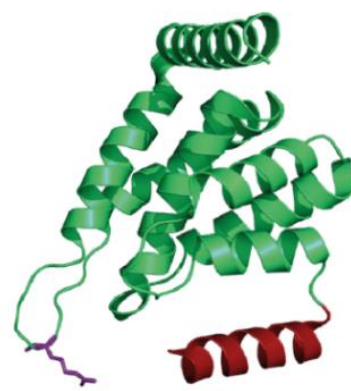

Figure 32: Positions of amino acids V50,51 and R114 within the crystal structure of the ENTH domain. 
Results: ENTH domain oligomerization is dependent on PtdSer and the arginine 114

First, we generated an ENTH domain construct in which we mutated the two valines on the positions 50 and 51 of the amino acid sequence to alanines (ENTH V50,51A). By doing this we intended to make this region less hydrophobic and inhibit the oligomerization of the protein. We tested ENTH V50,51A for membrane binding by co-sedimentation assays and analyzed the ability to deform membrane by electron microscopy. In order to do so we used three different lipid compositions to generate LUVs which we used already to characterize membrane binding and membrane deformation by the ENTH domain WT:

1. La-PtdCho, La-PtdEtn, La-PtdSer, La-PtdIns(4,5) $\mathrm{P}_{2}(45: 30: 20: 5)$

2. La-PtdCho, La-PtdEtn, La-Ptdlns $(4,5) \mathrm{P}_{2}(65: 30: 5)$

3. La-PtdCho, La-PtdEtn, La-PtdSer (50:30:20)

We incubated $12 \mu \mathrm{M}$ of ENTH V50,51A with LUVs ( $2 \mathrm{mg} / \mathrm{ml}$ lipid content) of each liposome composition and used liposomes (La-PtdCho, La-PtdEtn, La-PtdSer, LaPtdlns $\left.(4,5) \mathrm{P}_{2}\right)$ and ENTH V50,51A alone as control. The samples were incubated for $3 \mathrm{~h}$ at $30^{\circ} \mathrm{C}$.

Analysis of the co-sedimentation revealed an unexpected behavior of ENTH V50,51A (Figure 33A). Unlike the ENTH domain WT which co-sedimented only in dependency of Ptdlns $(4,5) \mathrm{P}_{2}$ containing LUVs ENTH V50,51A pelleted along with any used LUV population. Interestingly, ENTH V50,51A still behaved like a soluble protein in the control that did not contain liposomes. The mutant formed homo-oligomers (or agglomerates) independently from the membrane and protein bands were observed at about $35 \mathrm{kDa}$ and $70 \mathrm{kDa}$.

The analysis of the electron micrographs revealed that ENTH V50,51A was unable to deform membranes, also if we used a lipid composition containing PtdSer and Ptdlns $(4,5) \mathrm{P}_{2}$ together (Figure 33B). The results together indicate that ENTH V50,51A is a loss of function mutant, which we did not investigate further. 
Results: ENTH domain oligomerization is dependent on PtdSer and the arginine 114

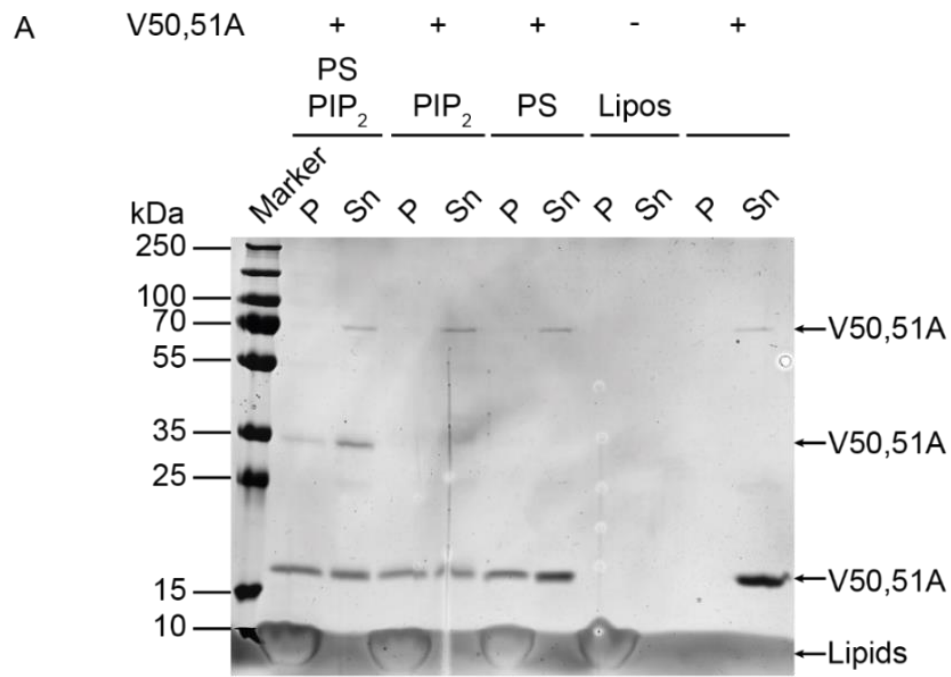

B
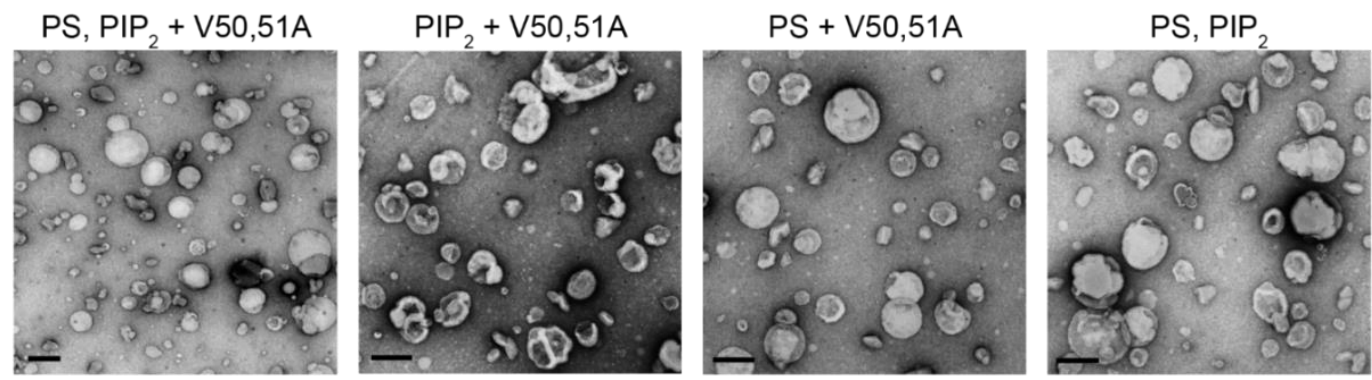

Figure 33: ENTH V50,51A is a loss of function mutant. LUVs were composed of PtdCho, PtdEtn, PtdSer Ptdlns(4,5) $\mathrm{P}_{2}$ (PS PIP $-45: 30: 20: 5$ ), PtdCho, PtdEtn, Ptdlns(4,5) $\mathrm{P}_{2}\left(\mathrm{PIP}_{2}-65: 30: 5\right)$ and PtdCho, PtdEtn, PtdSer (PS - $50: 30: 20$ ). Those LUVs were incubated with ENTH V50,51A. A. Co-sedimentation of ENTH V50,51A with LUVs $(P=$ pellet, $S n=$ supernatant). ENTH V50,51A without LUVs and LUVs without protein (Lipos) were used as control. B. Membrane deformation analysis of LUVs by electron microscopy. LUVs incubated without protein were used as control. Scale bars correspond to $200 \mathrm{~nm}$.

Next, we mutated the positively charged arginine at the amino acid sequence position 114 of the ENTH domain WT to a non-charged alanine (ENTH R114A). This region might play a central role in interaction with negatively charged lipids within the membrane.

To test the ability of ENTH R114A to bind and deform membranes we used again the cosedimentation assay and electron microscopy and compared the results directly with the ENTH domain WT. Therefore, we used our established lipid compositions to generate LUVs in which we expect binding and deformation, only binding and no binding:

1. La-PtdCho, La-PtdEtn, La-PtdSer, La-PtdIns $(4,5) \mathrm{P}_{2}(45: 30: 20: 5)$

2. La-PtdCho, La-PtdEtn, La-Ptdlns $(4,5) \mathrm{P}_{2}(65: 30: 5)$

3. La-PtdCho, La-PtdEtn, La-PtdSer (50:30:20)

ENTH R114A and ENTH domain WT $(12 \mu \mathrm{M})$ were incubated with LUVs of each lipid composition ( $2 \mathrm{mg} / \mathrm{ml}$ lipid content) for $3 \mathrm{~h}$ at $30^{\circ} \mathrm{C}$. The membrane recruitment of ENTH 
R114A was similar to the ENTH domain WT (Figure 34A and 34B). It co-sedimented with LUVs that contained Ptdlns $(4,5) \mathrm{P}_{2}$, did not bind to LUVs that were only composed of PtdCho, PtdEtn and PtdSer and behaved like a soluble protein without membranes. But it was remarkable that ENTH R114A did not show any signs of higher molecular weight band pattern on the SDS gel, showing that the mutant lost the ability to form homo-oligomers.

A

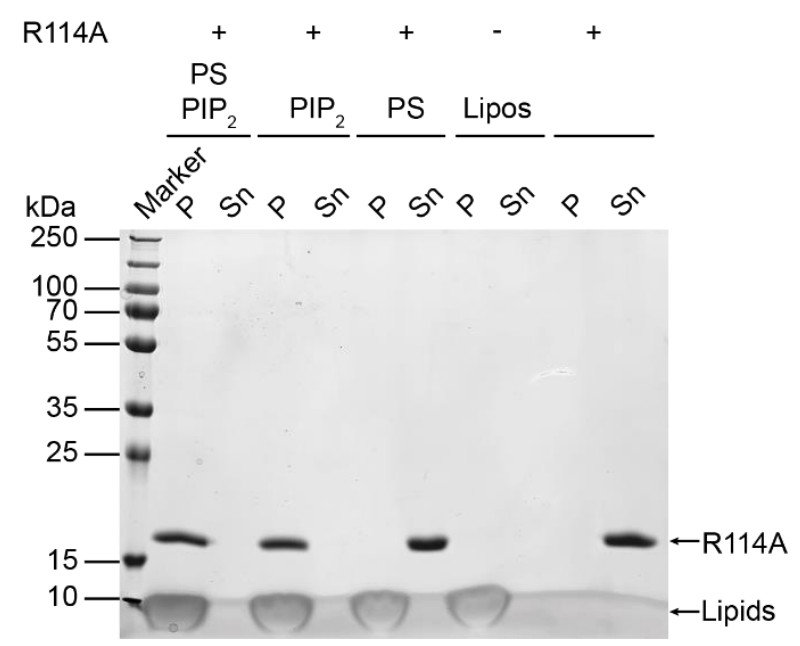

B

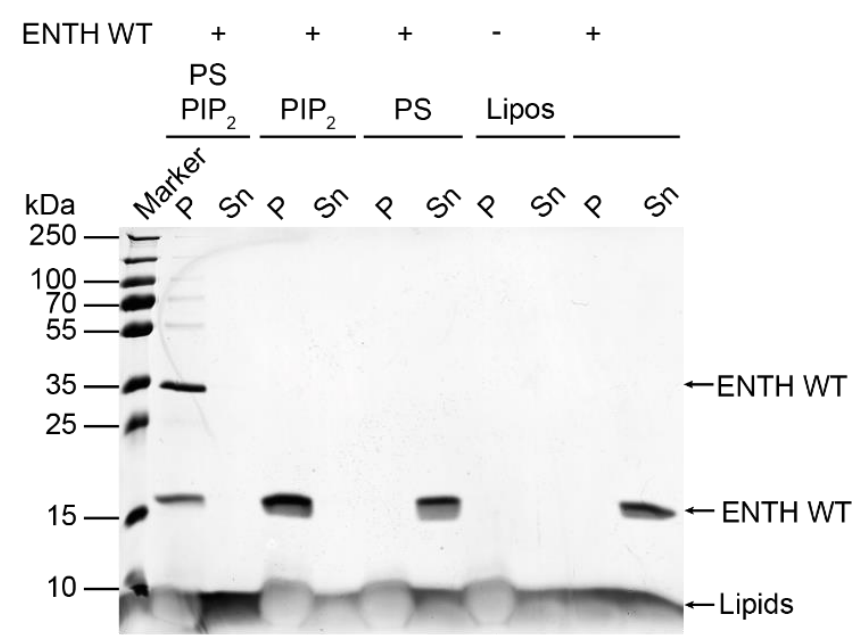

Figure 34: Co-sedimentation of ENTH R114A in comparison to the ENTH domain WT. LUVs were composed of PtdCho, PtdEtn, PtdSer Ptdlns(4,5) $\mathrm{P}_{2}$ (PS PIP 2 - $\left.45: 30: 20: 5\right)$, PtdCho, PtdEtn, Ptdlns $(4,5) \mathrm{P}_{2}$ $\left(P_{P}-65: 30: 5\right)$ and PtdCho, PtdEtn, PtdSer (PS - $\left.50: 30: 20\right)$. Those LUVs were incubated with ENTH R114A and the ENTH domain WT. A. Co-sedimentation of ENTH R114A with LUVs $(P=$ pellet, $S n=$ supernatant). ENTH R114A without LUVs and LUVs without protein (Lipos) were used as control. B Cosedimentation of the ENTH domain WT with LUVs ( $P=$ pellet, $S n=$ supernatant). ENTH domain WT without LUVs and LUVs without protein (Lipos) were used as control.

Analysis of the ability to deform membranes revealed that R144A was not able to induce the formation of membrane tubules in any lipid composition (Figure 35A, 33C) while the ENTH domain WT tubulated LUVs containing both PtdSer and Ptdlns $(4,5) \mathrm{P}_{2}$ as shown before (Figure 23B). This was confirmed by DLS analysis where all liposome populations incubated with ENTH R114A behaved like spherical particles. In comparison, LUVs containing PtdSer and Ptdlns $(4,5) \mathrm{P}_{2}$ showed a characteristic profile for deformed membranes in the DLS experiments if incubated with the ENTH domain WT (Figure 35B and 35D). 
A
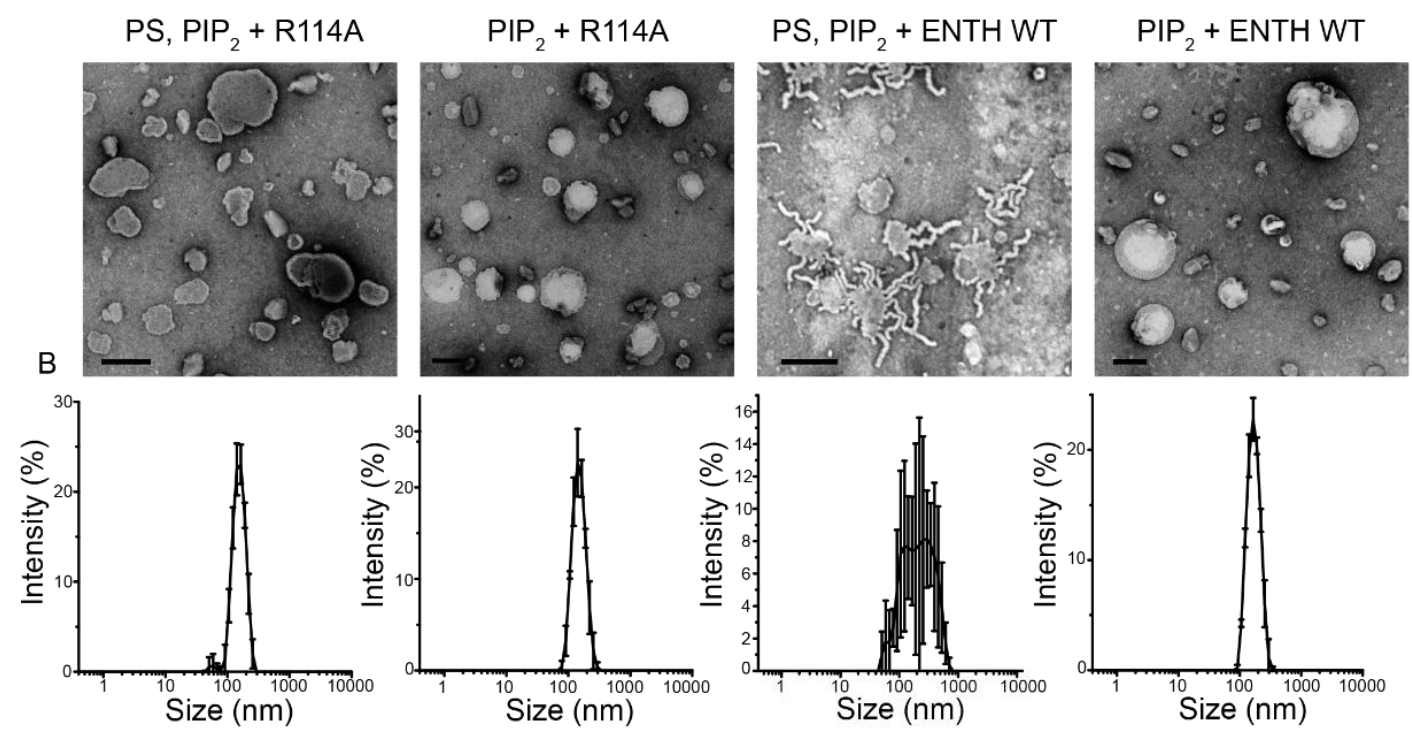

C
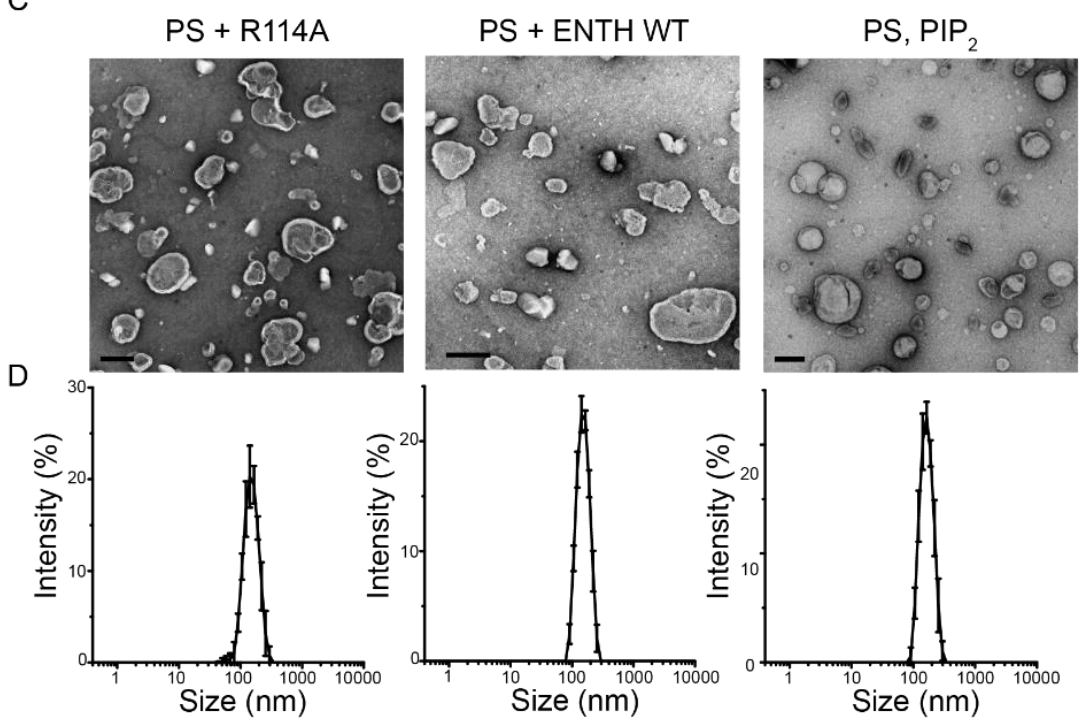

Figure 35: Analysis of membrane deformation by ENTH R114A in comparison to the ENTH domain WT. LUVs were composed of PtdCho, PtdEtn, PtdSer Ptdlns(4,5)P $\mathrm{P}_{2}$ (PS PIP $-45: 30: 20: 5$ ), PtdCho, PtdEtn, Ptdlns (4,5) $\mathrm{P}_{2}\left(\mathrm{PIP}_{2}-65: 30: 5\right)$ and PtdCho, PtdEtn, PtdSer (PS - $\left.50: 30: 20\right)$. Those LUVs were incubated with ENTH R114A and the ENTH domain WT. A. Electron micrographs of ENTH R114A and the ENTH domain WT incubated with PS $\mathrm{PIP}_{2}$ and $\mathrm{PIP}_{2}$ LUVs. Scale bars correspond to $200 \mathrm{~nm}$. B. Corresponding DLS analysis profiles to A. C. Electron micrographs of control experiments with ENTH R114A and the ENTH domain WT incubated with PS LUVs and liposomes without protein. Scale bars correspond to $200 \mathrm{~nm}$. D. Corresponding DLS analysis profiles to $\mathbf{C}$.

We evaluated the electron microscopy pictures and counted tubulated membrane structures and spherical membrane structures (Figure 36). At least 200 membrane structures were counted for each used condition. The resulting statistics revealed only the ENTH domain WT deformed membranes if the LUVs contained PtdSer and Ptdlns $(4,5) \mathrm{P}_{2}$ 
and approx. $90 \%$ of the counted membranous structures were tubulated. In comparison, LUVs without PtdSer, or without Ptdlns $(4,5) \mathrm{P}_{2}$ did not show a significant increase in tubulation. ENTH R114A failed in deforming the membranes. We just detected approx. 15\% of tubulated membranous structures if it was incubated with LUVs containing PtdSer and Ptdlns $(4,5) \mathrm{P}_{2}$ and even less in the other LUV compositions.

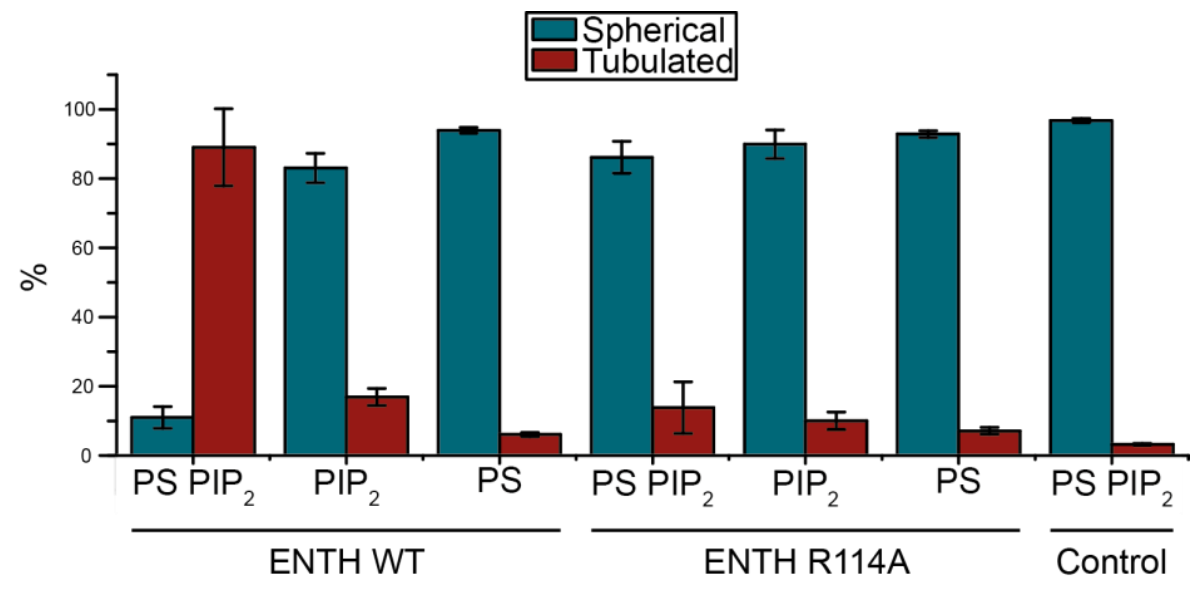

Figure 36: Statistical analysis of membrane deformation by ENTH R114A in comparison to the ENTH domain WT. Electron micrographs of figure 32 were used for evaluation.

In order to resolve membrane deformation and binding of the wildtype and mutant at the same time we employed the flotation assay (co-migration assay). $18 \mu \mathrm{M}$ of ENTH R114A, or ENTH domain WT was incubated with LUVs of the same lipid compositions as before $\left(3 \mathrm{mg} / \mathrm{ml}\right.$ ) for $3 \mathrm{~h}$ at $30^{\circ} \mathrm{C}$ and finally used for the flotation assay (Figure 37 and 38 ). The ENTH domain WT did not affected the flotation pattern of LUVs composed either of PtdCho, PtdEtn and Ptdlns $(4,5) \mathrm{P}_{2}$, or PtdCho, PtdEtn and PtdSer and the liposomes migrated between the $0 \%(\mathrm{w} / \mathrm{v})$ histodenz layer and the $5 \%(\mathrm{w} / \mathrm{v})$ layer as the undeformed control LUVs without protein. If the LUVs were composed of PtdCho, PtdEtn, PtdSer and Ptdlns $(4,5) \mathrm{P}_{2}$ membrane signals were visible between all layers indicating that the ENTH domain WT induced membrane deformation. In comparison, LUVs of any lipid composition incubated ENTH R114A were not deformed and migrated only between the $0 \%$ layer and the $5 \%$ layer. The layers of each flotation sample were separated and used for SDS-PAGE to analyze if the proteins co-migrated with the LUVs. The ENTH domain WT co-migrated with LUVs containing Ptdlns $(4,5) \mathrm{P}_{2}$, while it did not migrate along LUVs composed of PtdCho, PtdEtn and PtdSer or without any LUVs. The protein was found between the $0 \%$ layer and the $5 \%$ layer if incubated with LUVs composed of PtdCho, PtdEtn and Ptdlns $(4,5) \mathrm{P}_{2}$ and in all interlayers if incubated with LUVs composed of PtdCho, PtdEtn, PtdSer and Ptdlns (4,5) $\mathrm{P}_{2}$. In addition, we saw the formation of at least homo-dimers. In comparison ENTH R114A migrated only between the interlayer between $0 \%$ and $5 \%$ histodenz if 
Results: ENTH domain oligomerization is dependent on PtdSer and the arginine 114

incubated with LUVs containing Ptdlns $(4,5) \mathrm{P}_{2}$ or did not migrate without LUVs, or with LUVs composed of PtdCho, PtdEtn and PtdSer. We did not observe any formation of homo-dimers with ENTH R114A.

A
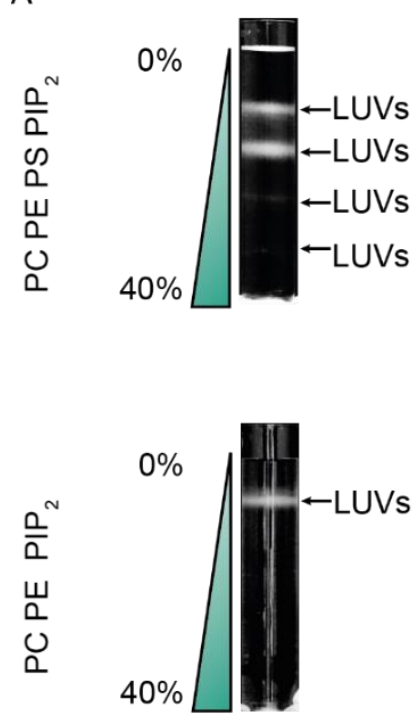

B
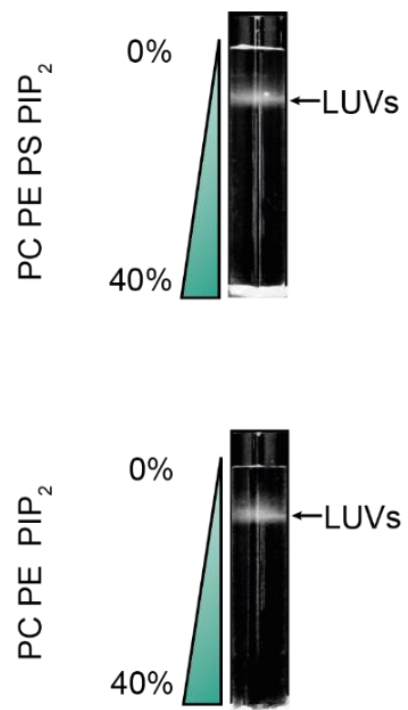
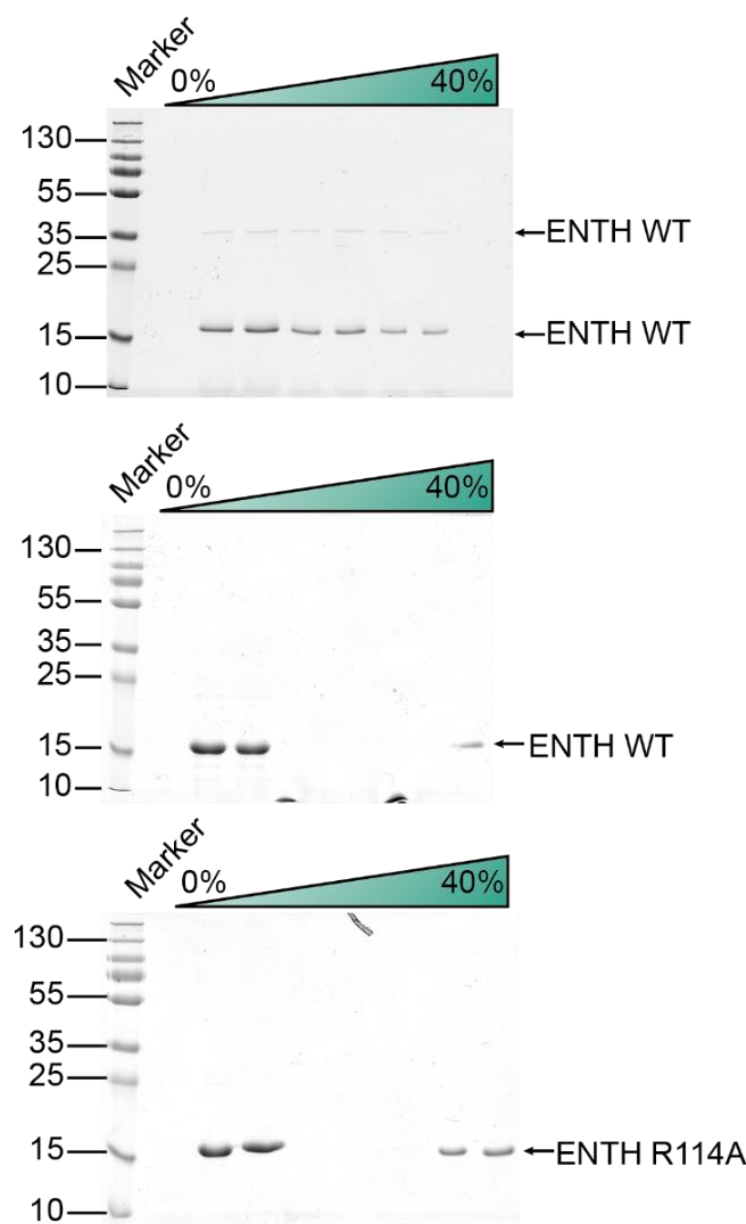

$40^{x+2}$

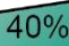

130

$55-$

35

25

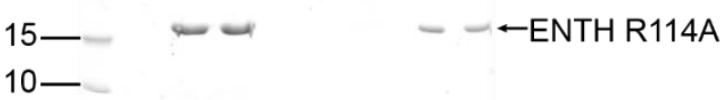

Figure 37: Co-migration assay of ENTHR114A in comparison to the ENTH domain WT. LUVs were composed of PtdCho, PtdEtn, PtdSer Ptdlns(4,5)P 2 (PC PE PS PIP 2 - 45: $30: 20: 5$ ), PtdCho, PtdEtn, Ptdlns $(4,5) \mathrm{P}_{2}\left(\mathrm{PC} P E \mathrm{PIP}_{2}-65: 30: 5\right)$ A. Flotation pattern and co-migration of the ENTH domain WT with PC PE PS PIP 2 and PC PE PIP 2 LUVs. B. Flotation pattern and co-migration of ENTH R114A with PC PE PS PIP 2 and PC PE PIP 2 LUVs. 
Results: ENTH domain oligomerization is dependent on PtdSer and the arginine 114

A
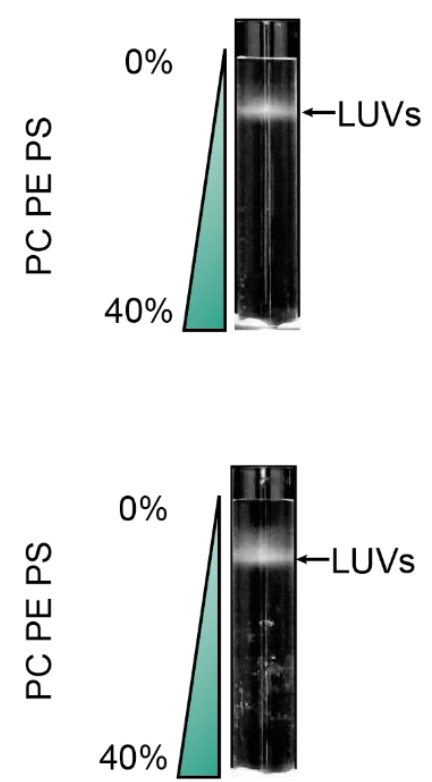

B

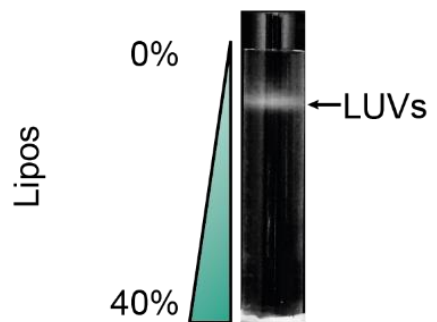

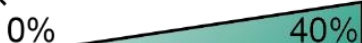

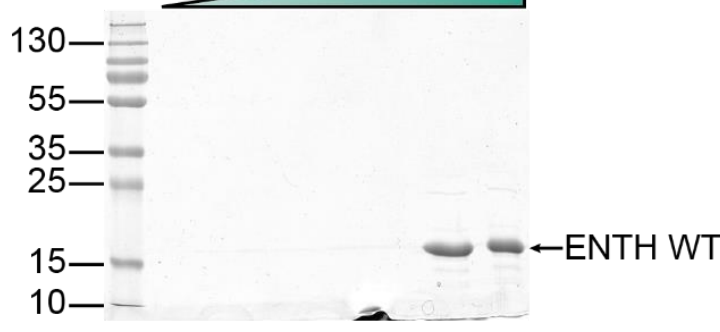

$0 \% \quad 40 \%$

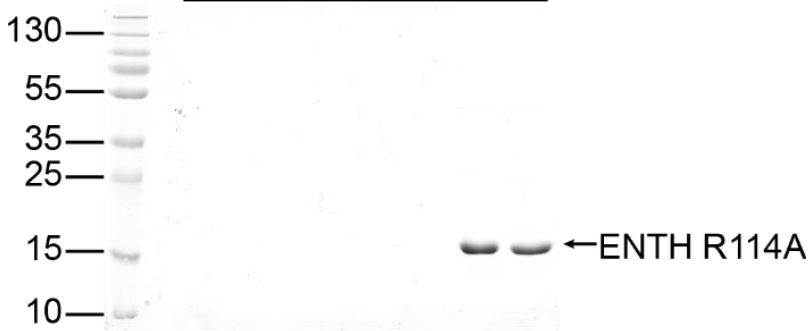

C

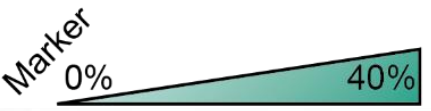

$$
130-
$$

\begin{tabular}{ll} 
은 & $55-$ \\
$\stackrel{0}{3}$ & $35-$ \\
\hline & $25-$
\end{tabular}

15-

10 -

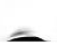

$40 \%$

$$
\begin{array}{ll} 
& 130- \\
& 55- \\
\stackrel{0}{\circ} & 35- \\
\hline \multirow{1}{*}{} & 25- \\
& 15- \\
& 10-
\end{array}
$$

Figure 38: Controls of the co-migration assay of ENTHR114A in comparison to the ENTH domain WT. LUVs were composed of PtdCho, PtdEtn, PtdSer (PC PE PS - $50: 30: 20$ ) A. Flotation pattern and comigration of ENTH domain WT and ENTH R114A incubated with LUVs. B. Flotation pattern of liposomes without protein (Lipos). C. Migration of the ENTH domain WT and ENTH R114A without liposomes.

In sum, the results show that the characterized mutant ENTH R114A, which still binds to membranes containing Ptdlns $(4,5) \mathrm{P}_{2}$, fails completely to generate membrane tubules and to form homo-oligomers. This indicates that the observed ability of ENTH 
Results: ENTH domain oligomerization is dependent on PtdSer and the arginine 114

domain to deform membranes and to form homo-oligomers are somehow connected and dependent on the loop region between helix 6 and helix 7 , especially on the function of R114.

Before we went on with analyzing the connection of oligomerization, membrane deformation and the loop region, we wanted to find out, if the mutation of the ENTH domain induced changes within structure and thus impaired the function of the ENTH domain. Therefore, we employed CD spectroscopy to compare the secondary structures of ENTH R114A and the ENTH domain WT (Figure 39).

Purified ENTH domain WT and ENTH R114A were transferred into $10 \mathrm{mM}$ potassium phosphate buffer ( $\mathrm{pH} \mathrm{7.4)}$ and the protein concentrations were adjusted to $0.1 \mathrm{mg} / \mathrm{ml}$. The CD spectroscopy analysis of the ENTH domain WT displayed a typical profile of a protein consisting of a-helices, indicating correct folding. In comparison, the CD profile of ENTH R114A displayed a nearly perfect overlay over the profile of the ENTH domain WT. We also measured the absorbance of the potassium phosphate buffer to show that it did not interfere the CD spectroscopy in the range of $190 \mathrm{~nm}$ to $260 \mathrm{~nm}$. The CD data indicated that the mutation did not induce helix brakes or misfoldings within the structure of ENTH R114A.

A
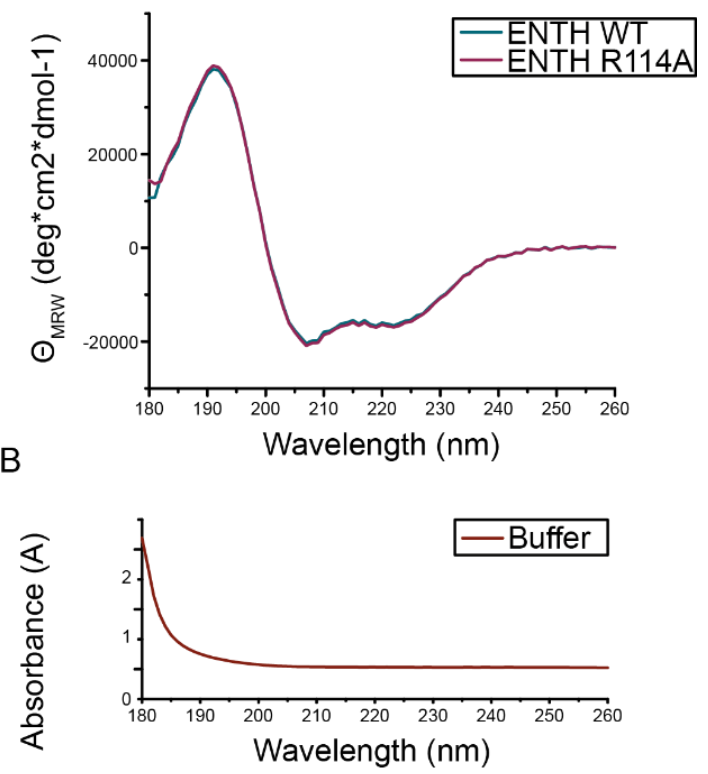

Figure 39: CD spectroscopic analysis of ENTHR114A in comparison to the ENTH domain WT. Proteins were rebuffered into $10 \mathrm{mM}$ potassium phosphate buffer with a concentration of $0.1 \mathrm{mg} / \mathrm{ml}$. A. CD spectroscopic profiles of ENTH R114A (purple) and the ENTH domain WT (cyan). B. Absorbance of the potassium phosphate buffer. 
Results: ENTH domain oligomerization is dependent on PtdSer and the arginine 114

We already showed that the ENTH domain forms homo-oligomers in presence of PtdSer if the protein is recruited to the membrane and that ENTH 114A failed in forming similar oligomers under the same conditions. In order to resolve the formation of oligomers in a comparable quantitative manner, we employed the Förster resonance energy transfer (FRET) assay. The FRET assay enables us to analyze the ability of the proteins to form homo-oligomers, or at least of proteins close enough to each other, even at low protein concentrations. Therefore, we used the labeling mutants of the ENTH domain WT (ENTH C96A A155C) and of ENTH R114A (ENTH C96A R114A A155C) and generated two populations of labeled proteins: one population was labeled with Atto 488 maleimide and the other one was labeled with Atto 532 maleimide (Figure 40). To avoid a false FRET signal by protein crowding effects but still ensure full binding of the proteins, we used only $5 \mu \mathrm{M}$ of total protein concentration and $2 \mathrm{mg} / \mathrm{ml}$ lipid concentration of LUVs as reaction mix. We prepared two LUV populations to compare just protein binding to formation of oligomers on the membrane:

1. La-PtdCho, La-PtdEtn, La-PtdSer, La-PtdIns $(4,5) \mathrm{P}_{2}(45: 30: 20: 5)$

2. La-PtdCho, La-PtdEtn, La-Ptdlns (4,5) $\mathrm{P}_{2}(65: 30: 5)$

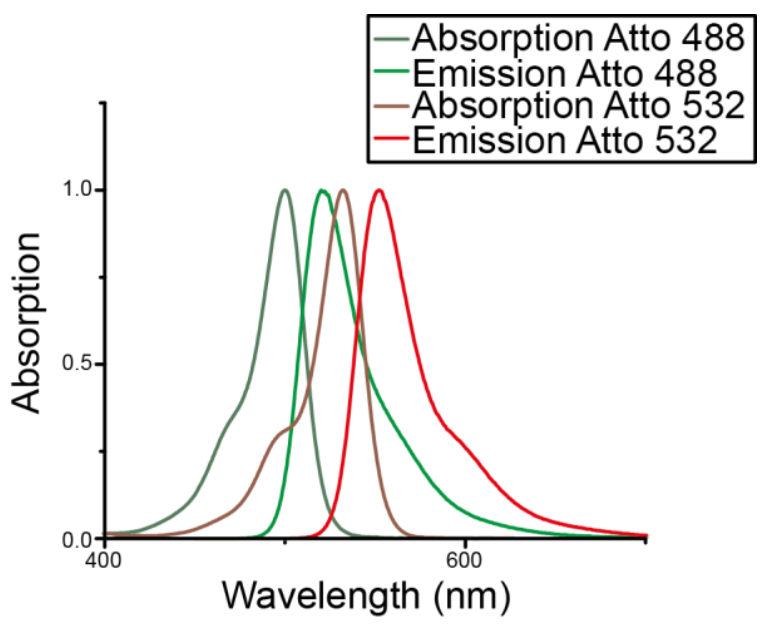

Figure 40: Choice of fluorophores for the FRET assay. Absorption and emission profile of Atto 488 and Atto 532 in comparison.

The normalized spectra show that the ENTH domain WT indeed showed a FRET effect if LUVs with PtdSer were used and we observed an increase of acceptor emission at $552 \mathrm{~nm}$ (Figure 41). In comparison, we observed strongly decreased acceptor emission if we used LUVs without PtdSer. If we used ENTH R114A instead we did not observe strong acceptor emission independent from the presence of PtdSer within the LUVs. With other words, the mutant also failed in this assay to form homo-oligomers. 


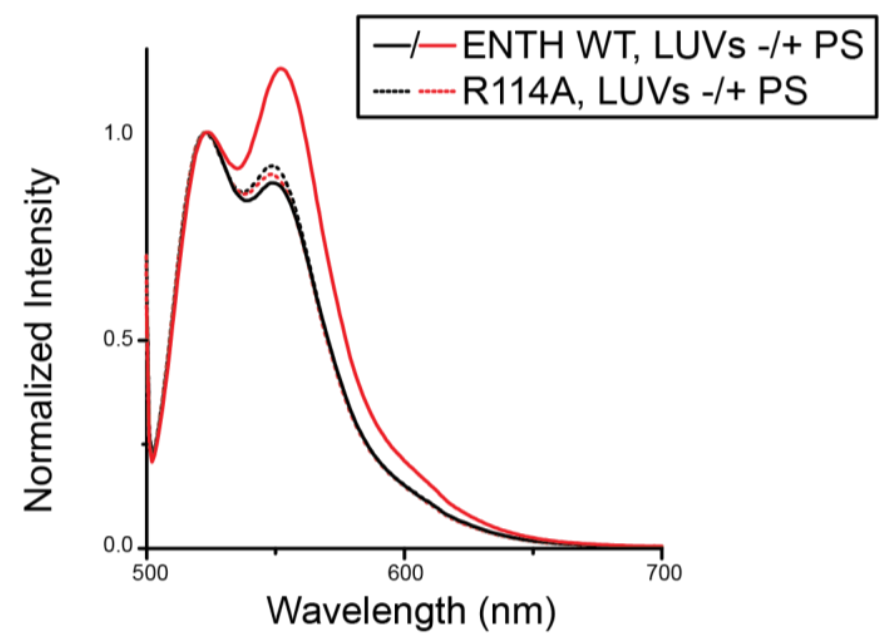

Figure 41: Protein-protein FRET assay of ENTH R114A in comparison to the ENTH domain WT. Two differently labeled protein populations were generated of both proteins, one labeled with Atto 532 mal, the other one labeled with Atto 488 mal. Proteins were incubated with LUVs composed of PtdCho, PtdEtn, PtdSer Ptdlns (4,5) $\mathrm{P}_{2}$ (+ PS - $45: 30: 20: 5$ ) and PtdCho, PtdEtn, Ptdlns(4,5) $\mathrm{P}_{2}$ (- PS - $65: 30: 5$ ).

The protein FRET experiment shows that the formation of ENTH domain homooligomers is concentration independent and dependent on the presence of PtdSer within the membrane. Furthermore, the loop between helix 6 and 7 and especially the arginine plays a central role in oligomerization. But still we did not know if this arginine directly interacts with PtdSer or if it has a distinct role from specific lipid interaction. Therefore, we designed a second FRET experiment in which we analyzed the lipid binding of the ENTH domain to PtdSer (Figure 42). Therefore, we used the ENTH domain C96A A155C and ENTH C96A R114A A155C (5 $\mu \mathrm{M}$ end concentration), only labeled with Atto488 maleimide as FRET donor. We used Atto 532 labeled PtdSer as FRET acceptor for our LUVs to determine the lipid binding. Atto 532 labeled PtdEtn was used as a control to the lipid binding specificity of the ENTH domain. Therefore, we used two LUV $(2 \mathrm{mg} / \mathrm{ml})$ compositions:

1. La-PtdCho, La-PtdEtn, La-PtdSer, La-Ptdlns(4,5)P $\mathrm{P}_{2}$, Atto 532 PtdSer (55 : 20 : 19.5 : 5: 0.5$)$

2. La-PtdCho, La-PtdEtn, La-PtdSer, La-Ptdlns(4,5) $\mathrm{P}_{2}$, Atto 532 PtdEtn (55 : 20 : 19.5 : 5: 0.5)

The FRET spectra show that the ENTH domain specifically binds to PtdSer, since we observed an increase of acceptor emission if we used Atto 532 PtdSer, but no increase if we used Atto 532 PtdEtn in our membranes. Surprisingly, we observed the same effect if we used labeled ENTH R114A indicating that PtdSer binding is independent from the arginine at position 114. The loop region seems to have an important role in oligomerization of the 
Results: ENTH domain oligomerization is dependent on PtdSer and the arginine 114

ENTH domain, but not in selective binding of PtdSer. Still, oligomerization and PtdSer binding seem to be intertwined effects.

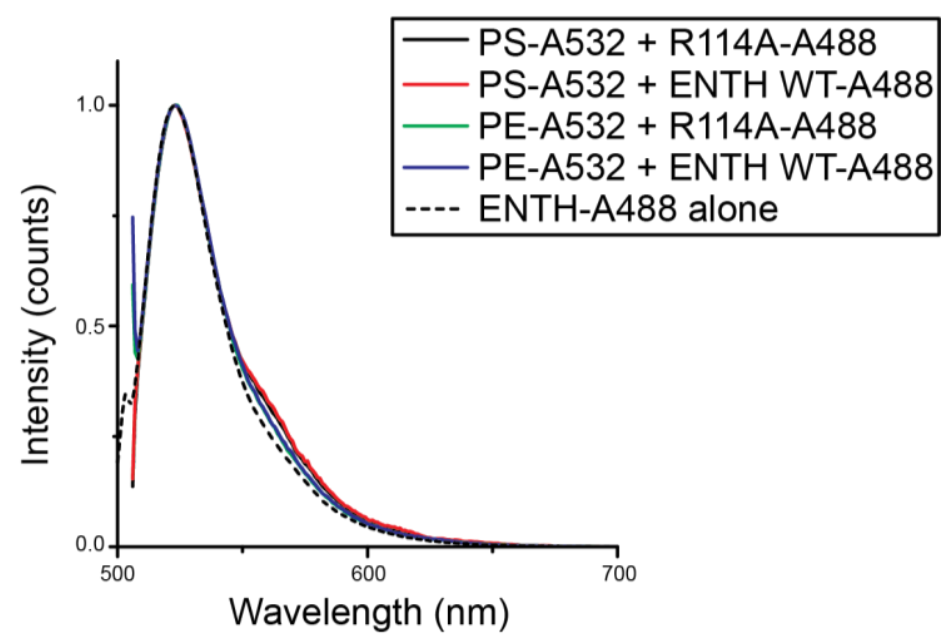

Figure 42: Lipid-protein FRET assay of ENTH R114A in comparison to the ENTH domain WT. Proteins were labeled with Atto $488 \mathrm{mal}$ and membranes contained Atto $532 \mathrm{PE}$ or Atto $532 \mathrm{PS}$. Proteins were incubated on LUVs composed of La-PtdCho, La-PtdEtn, La-PtdSer, La-Ptdlns(4,5)P2, Atto 532 PtdSer (55 : 20 : 19.5 : 5 : 0.5), or La-PtdCho, La-PtdEtn, La-PtdSer, La-Ptdlns(4,5)P 2 , Atto 532 PtdEtn (55: 20 : 19.5 : 5: 0.5).

Since we observed the formation of ENTH domain homo-oligomers in dependency of the arginine 114, we wanted to find the localization of oligomerization. Thus, we employed an analysis strategy including chemical cross-linking, trypsin digest and MS/MS. ENTH domain WT and ENTH R114A (15 $\mu \mathrm{M})$ were incubated with three populations of LUVs (2.5 $\mathrm{mg} / \mathrm{ml}$ lipid concentration):

1. La-PtdCho, La-PtdEtn, La-PtdSer, La-PtdIns $(4,5) \mathrm{P}_{2}(45: 30: 20: 5)$

2. La-PtdCho, La-PtdEtn, La-Ptdlns $(4,5) \mathrm{P}_{2}(65: 30: 5)$

3. La-PtdCho, La-PtdEtn, La-PtdSer (50: $30: 20)$

The incubation was performed, as described before, for $3 \mathrm{~h}$ at $30^{\circ} \mathrm{C}$ and subsequently cross-linked by using BS3 (Figure 43A). The analysis of the cross-linked proteins revealed that in all samples containing ENTH domain WT and ENTH R114A oligomerization occurred if the proteins were incubated with LUVs. The ENTH domain WT formed dimers, trimers and even higher order oligomers if incubated with LUVs containing PtdSer and Ptdlns $(4,5) \mathrm{P}_{2}$, or Ptdlns $(4,5) \mathrm{P}_{2}$ alone. The ENTH domain WT oligomer bands were fainter, if it was incubated with LUVs that did not contain Ptdlns $(4,5) \mathrm{P}_{2}$. ENTH R114A formed oligomers with the same LUV compositions as ENTH domain WT, but they were fainter in comparison. Monomers, dimers and trimers were cut out of the gel und used for trypsin digest and MS/MS analysis (Figure 43B and Figure 43C). Proteins that were incubated with LUVs composed of PtdCho, PtdEtn, PtdSer showed weak signs oligomerization and the monomer bands remained more 
Results: ENTH domain oligomerization is dependent on PtdSer and the arginine 114

pronounced. If the ENTH domain WT was incubated with LUVs containing Ptdlns $(4,5) \mathrm{P}_{2}$ with or without PtdSer three positions on the amino acid sequence were cross-linked: the most abundant cross linking position was K117, but also position K149 was cross-linked. Notably, if ENTH R114 was used less inter-protein cross-links were observed in general. Cross-links only occurred abundantly at position $\mathrm{K} 149$ and no cross-links were detected at position $\mathrm{K} 117$, next to the mutated arginine. The data indicate that the ENTH domain oligomerizes at, or close to position $\mathrm{K} 117$ and that the single replacement of the arginine on position 114 to an alanine inhibits the formation of ENTH domain homo-oligomers.

Table 7: Relative peptide fragment abundancy of inter-protein cross-links between K117. The ENTH domain WT and ENTH R114A were incubated with LUVs composed of PtdCho, PtdEtn, PtdSer Ptdlns $(4,5) \mathrm{P}_{2}$ (PC PE PS PIP2 - $45: 30: 20: 5$ ) and PtdCho, PtdEtn, Ptdlns(4,5)P2 (PC PE PIP2 - $65: 30: 5$ ). Only dimers and trimers were used for analysis.

\begin{tabular}{|c|c|c|c|c|c|c|}
\hline Protein & \multicolumn{3}{|c|}{ ENTH WT } & \multicolumn{3}{|c|}{ ENTH R114A } \\
\hline LUVs & $\mathrm{PC} \mathrm{PE} \mathrm{PIP} 2$ & $P C$ & $\mathrm{PIP}_{2}$ & $\mathrm{PC} P E \mathrm{PIP}_{2}$ & $P C$ & $\mathrm{PIP}_{2}$ \\
\hline Oligomer & 2 mer & $2 \mathrm{mer}$ & 3 mer & $2 \mathrm{mer}$ & $2 m e r$ & $3 m e r$ \\
\hline 117-117 & $10 \%$ & $18 \%$ & $10 \%$ & 0 & 0 & 0 \\
\hline
\end{tabular}


Results: ENTH domain oligomerization is dependent on PtdSer and the arginine 114

A

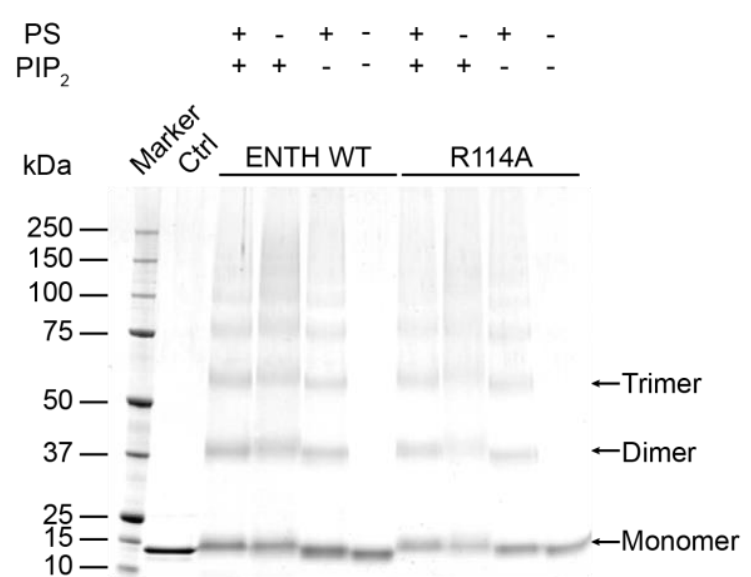

B

ENTH WT
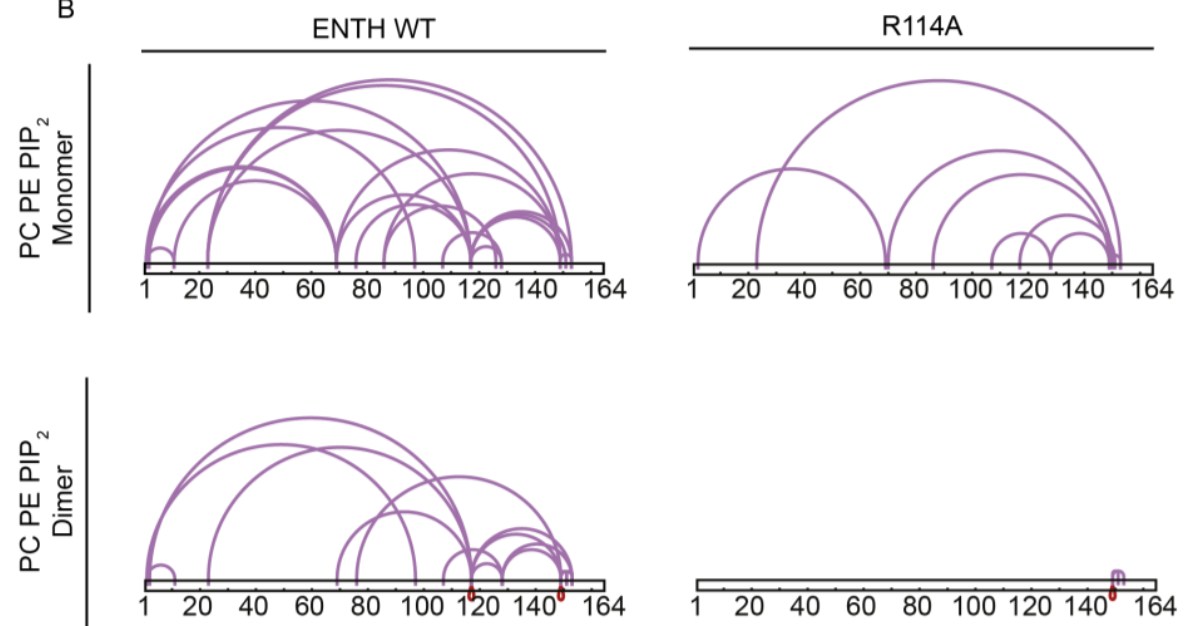

$120 \quad 406080100120140^{\circ} 164$

Image caption on following page. 
Results: ENTH domain oligomerization is dependent on PtdSer and the arginine 114
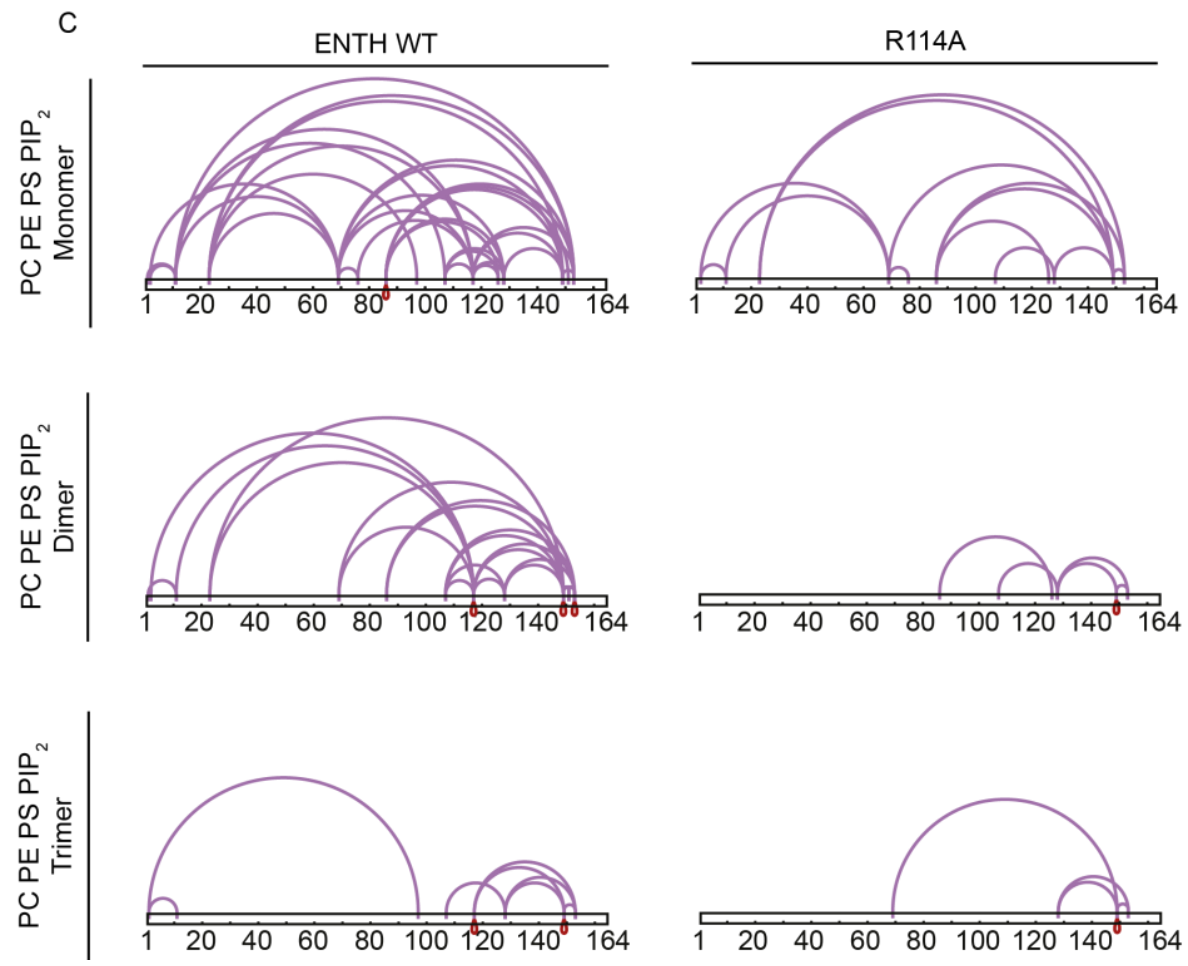

Figure 43: Cross-linking and MS/MS analysis of ENTH domain oligomerization in comparison to ENTH R114A. LUVs were composed of La-PtdCho, La-PtdEtn, La-PtdSer, La-Ptdlns(4,5)P2 (45: $30: 20: 5$ ), LaPtdCho, La-PtdEtn, La-Ptdlns(4,5)P2 (65:30:5) and La-PtdCho, La-PtdEtn, La-PtdSer (50:30:20). These LUVs were incubated with ENTH domain WT and ENTHR114A. A. SDS-PAGE of the cross-linking experiment by BS3. B. MS/MS analyzes of trypsin digest ENTH domain WT and ENTH R114A incubated with LUVs composed of La-PtdCho, La-PtdEtn, La-PtdIns(4,5)P2 (65:30:5). C. MS/MS analyzes of trypsin digest ENTH domain WT and ENTH R114A incubated with LUVs composed of La-PtdCho, La-PtdEtn, La-PtdSer, La-PtdIns(4,5)P2 (45 : $30: 20: 5)$. 
Results: Epsin1 is able to recruit clathrin and tetraubiquitin to the membrane

\subsection{Epsin1 recruits clathrin and tetraubiquitin to the membrane}

Epsin1 is described as an adaptor protein in endocytosis. It directly interacts with the main endocytic proteins clathrin and AP-2, and with the plasma membrane. Additionally, it interacts with endocytic nucleation proteins like intersectin and Eps15. Since the membrane deforming ability of the ENTH domain was characterized ${ }^{116}$, the question arose if Epsins have more roles in endocytosis, apart from their adaptor functions. Epsins also have ubiquitin interaction motifs within their unstructured C-terminus indicating their possible function in cargo selection ${ }^{122}$. CME is a highly regulated process and many functions are redundant in different proteins, like membrane deformation. But these abilities of membrane deformation coupled to clathrin recruitment and cargo selection display the potential of Epsin1 to drive endocytosis in a minimal system.

We started to optimize our assays for the use of the full length Epsin1. Therefore, the membrane binding and the ability to deform vesicles was tested with three already established LUV compositions:

4. La-PtdCho, La-PtdEtn, La-PtdSer, La-Ptdlns $(4,5) \mathrm{P}_{2}(45: 30: 20: 5)$

5. La-PtdCho, La-PtdEtn, La-PtdIns $(4,5) \mathrm{P}_{2}(65: 30: 5)$

6. La-PtdCho, La-PtdEtn, La-PtdSer $(50: 30: 20)$

Epsin1 $(8 \mu \mathrm{M})$ was incubated together with these three LUV populations $(2 \mathrm{mg} / \mathrm{ml}$ lipid concentration) for $3 \mathrm{~h}$ at $30^{\circ} \mathrm{C}$. Membrane binding was determined by the cosedimentation assay and membrane deformation was analyzed by EM and DLS.

As expected, Epsin1 displayed the same binding phenotype as the ENTH domain (Figure 44A). The protein co-sedimented with liposomes containing Ptdlns $(4,5) \mathrm{P}_{2}$, while it remained in the supernatant if incubated with LUVs without Ptdlns $(4,5) \mathrm{P}_{2}$ or if it was incubated without any LUVs. Epsin1 also deformed the membranes only if $\operatorname{Ptdlns}(4,5) \mathrm{P}_{2}$ and PtdSer were present in the membrane and LUVs without one of these lipids remained spherical (Figure 44B). The DLS profiles also pronounced this results and liposomes containing Ptdlns $(4,5) \mathrm{P}_{2}$ and PtdSer displayed the characteristic profile of membrane deformation, while LUVs containing just one of these lipid species remained spherical (Figure 44C). 
Results: Epsin1 is able to recruit clathrin and tetraubiquitin to the membrane

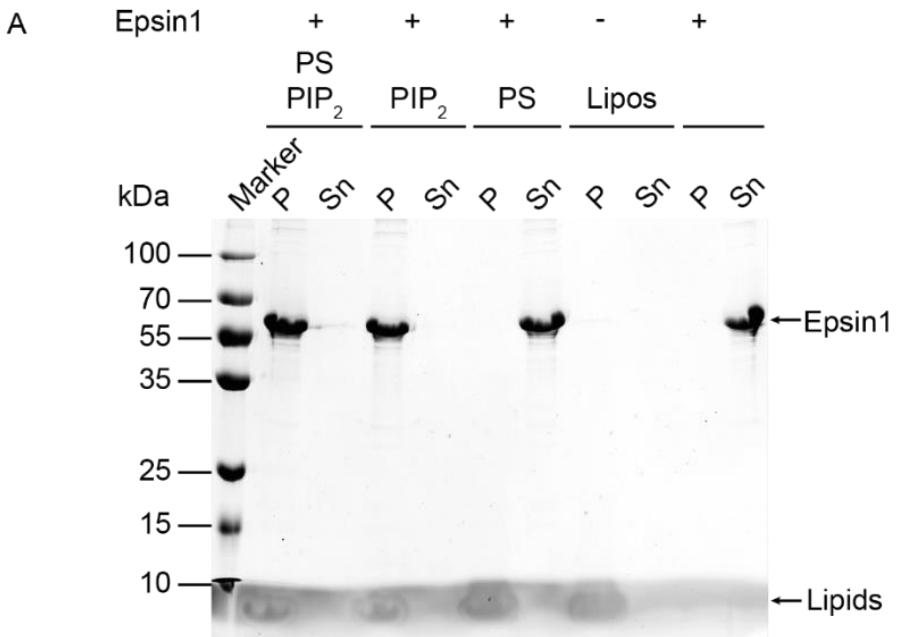

B

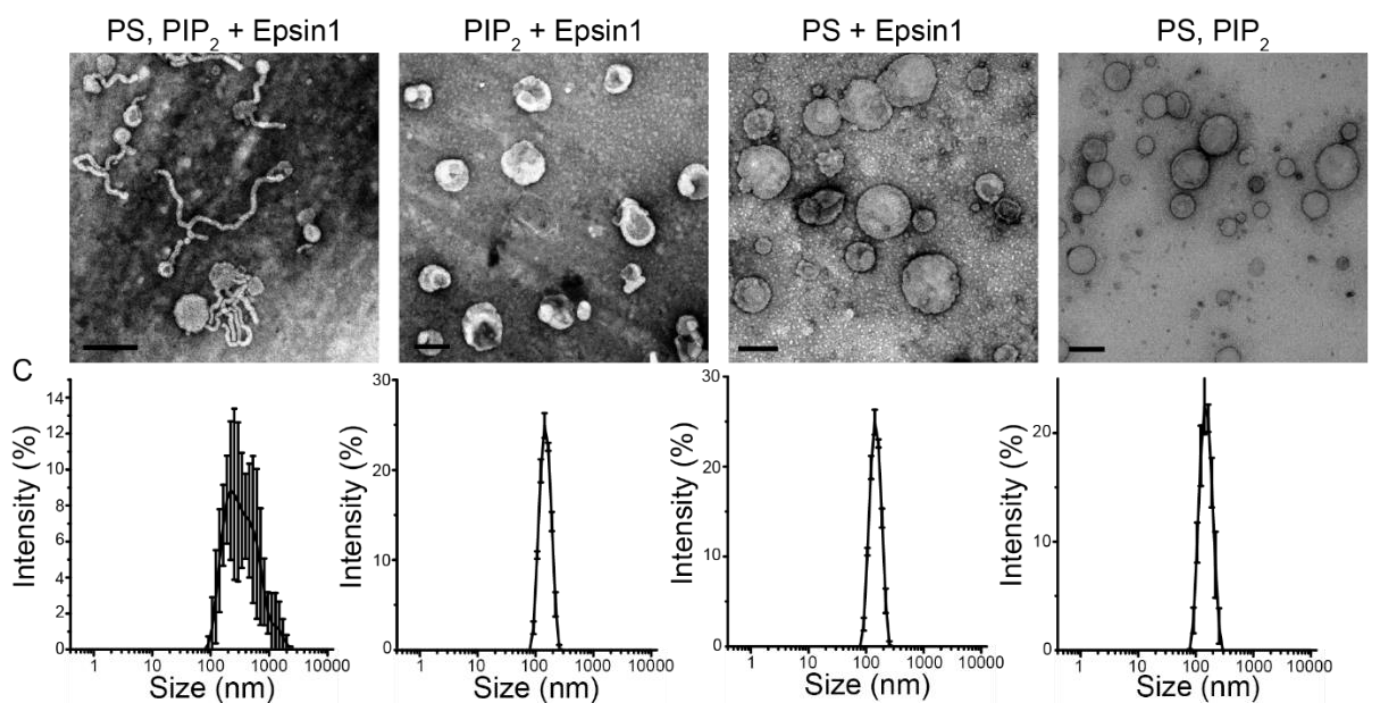

Figure 44: Epsin1 displays the same phenotype as the ENTH domain in membrane binding and deformation. LUVs were composed of PtdCho, PtdEtn, PtdSer Ptdlns(4,5)P $\mathrm{P}_{2}\left(\mathrm{PS} \mathrm{PIP}_{2}-45: 30: 20: 5\right)$, PtdCho, PtdEtn, Ptdlns(4,5) $P_{2}$ (PIP $-65: 30: 5$ ) and PtdCho, PtdEtn, PtdSer (PS - $50: 30: 20$ ). Those LUVs were incubated with Epsin1. A. Co-sedimentation of Epsin1 with LUVs ( $P=$ pellet, $S n=$ supernatant). Epsin1 without LUVs and LUVs without protein (Lipos) were used as control. B. Electron micrographs of Epsin1 incubated with LUVs. Scale bars correspond to $200 \mathrm{~nm}$ C. Corresponding DLS analysis profiles to B.

In the next step, we analyzed membrane binding as well as deformation by Epsin1 employing the GUV assay (Figure 45). We used GUVs composed of La-PtdCho, La-PtdEtn, La-PtdSer, La-Ptdlns(4,5)P2, Atto 647N PtdSer (44.5: $30: 20: 5: 0.5)$ and incubated them with Atto 488 maleimide labeled Epsin1 C96A (5 $\mu \mathrm{M})$ and incubated at $25^{\circ} \mathrm{C}$. Shortly after addition, Epsin1 co-localized at the membrane and started to deform the GUVs until the GUV collapsed. Epsin1 also seemed to form clusters on the membrane. 
Results: Epsin1 is able to recruit clathrin and tetraubiquitin to the membrane
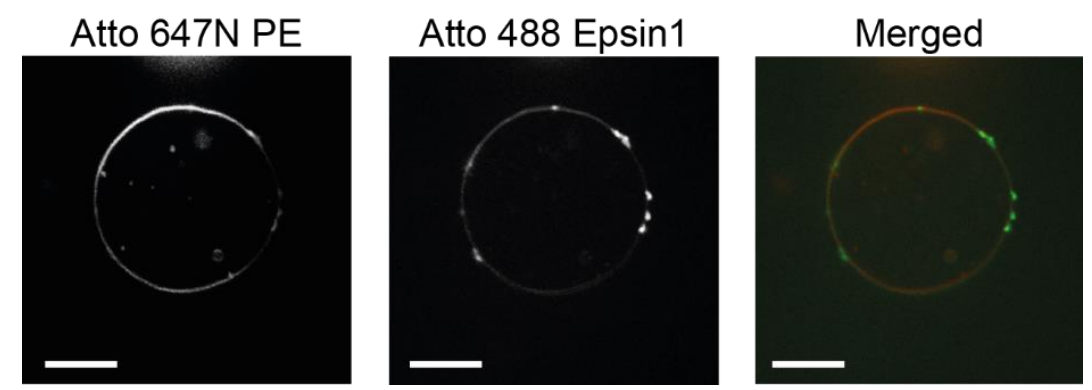

Figure 45: Epsin1 binds to Ptdlns(4,5) $P_{2}$ containing membranes in the GUV assay. GUVs were composed of La-PtdCho, La-PtdEtn, La-PtdSer, La-Ptdlns(4,5)P2, Atto 647N PtdSer (44.5: $30: 20: 5: 0.5)$ and incubated with Epsin1. The signal of the membrane (Atto 647N) and the emission of Epsin1 (Atto 488) were recorded. Scale bars correspond to $8 \mu \mathrm{m}$.

Next, we addressed if Epsin1 is able to recruit clathrin to LUVs using the liposome co-sedimentation assay. We modified the assay with a second protein incubation step: LUVs (2 $\mathrm{mg} / \mathrm{ml}$ lipid concentration) composed of La-PtdCho, La-PtdEtn, La-PtdSer, LaPtdlns(4,5)P2 (45: $30: 20: 5)$ were at first incubated with $8 \mu \mathrm{M}$ Epsin1 on ice for $1 \mathrm{~h}$. Subsequently, purified and rebuffered clathrin triskelia $(5 \mathrm{mg} / \mathrm{ml})$ were added and the mix was incubated for 2 more $\mathrm{h}$ at room temperature. The analysis of membrane binding in the co-sedimentation assay was carried out by SDS-PAGE and also by western blot and immune staining (Figure $46 \mathrm{~A}$ and $46 \mathrm{~B}$ ). The results displayed that Epsin1 alone was recruited to the membrane while clathrin alone remained in the supernatant. Both proteins were incubated together with LUVs clathrin indeed co-sedimented completely. The proteins remained in the supernatant if they were incubated without LUVs. Thereby, we established the co-recruitment of clathrin in our assay and showed that clathrin only bound to membranes if Epsin1 was present. Interestingly, Epsin1 also formed homo-oligomers, which were more pronounced if the protein was incubated with LUVs. 
Results: Epsin1 is able to recruit clathrin and tetraubiquitin to the membrane

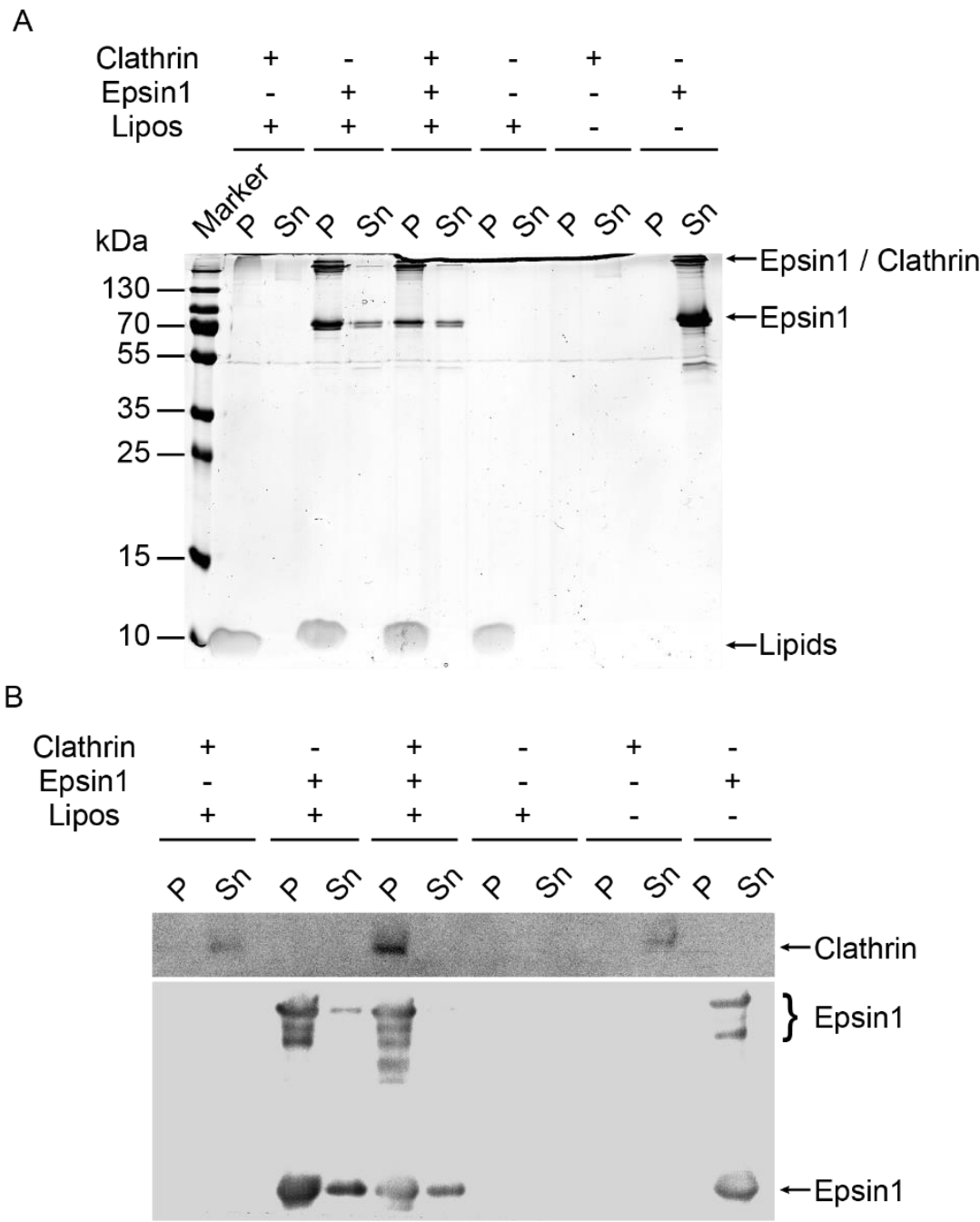

Figure 46: Epsin1 is able to recruit clathrin to LUVs. LUVs were composed of PtdCho, PtdEtn, PtdSer Ptdlns $(4,5) \mathrm{P}_{2}(45: 30: 20: 5)$, incubated with Epsin1 and subsequently with clathrin. The co-sedimentation was performed with Epsin1 and clathrin together with LUVs ( $P=$ pellet, $S n=$ supernatant). Epsin1 and clathrin without LUVs and LUVs without protein were used as control. The co-sedimentation was resolved by Coomassie staining (A) and by western blotting (B).

To show clathrin recruitment to GUVs, we prepared GUVs composed of La-PtdCho, La-PtdEtn, La-PtdSer, La-Ptdlns(4,5)P2, Atto 647N PtdSer (44.5: $30: 20: 5:$ 0.5) (Figure 47). First Atto 488 maleimide labeled Epsin1 C96A (2.5 $\mu \mathrm{M})$ was added to the GUVs and incubated for $1 \mathrm{~h}$ at $10^{\circ} \mathrm{C}$. Subsequently, Atto $390 \mathrm{NHS}$ labeled clathrin triskelia $(1 \mu \mathrm{M})$ were added and incubated at $25^{\circ} \mathrm{C}$ for $1 \mathrm{~h}$. Clathrin indeed co-localized with membrane bound Epsin1. It is remarkable that a lot of clathrin agglomerated independently displaying the sensitivity of clathrin triskelia to crush out. 
Results: Epsin1 is able to recruit clathrin and tetraubiquitin to the membrane

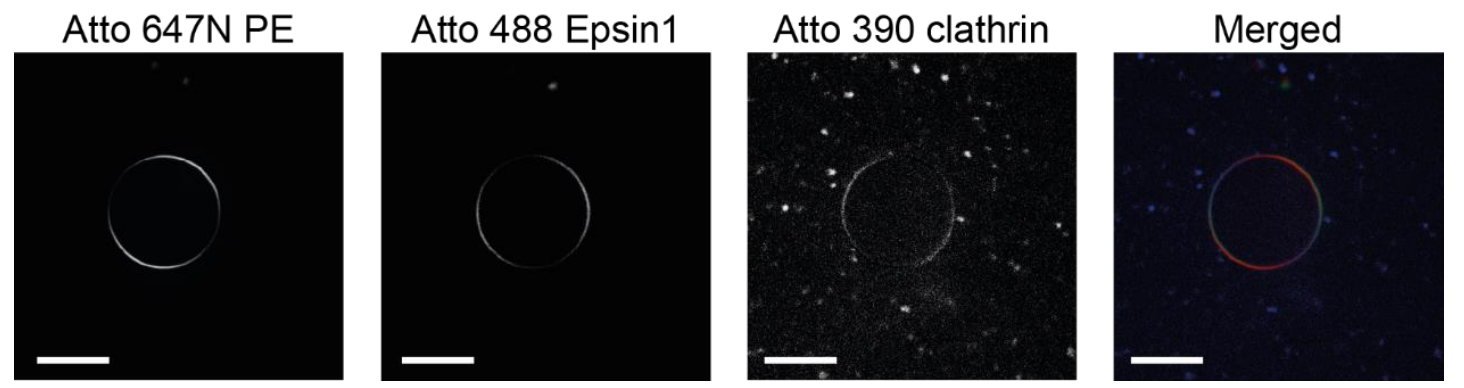

Figure 47: Clathrin co-localizes with Epsin1 on GUVs. GUVs were composed of La-PtdCho, La-PtdEtn, LaPtdSer, La-Ptdlns(4,5)P2, Atto 647N PtdSer (44.5: $30: 20: 5: 0.5)$ and incubated with Epsin1 and clathrin. The signal of the membrane (Atto $647 \mathrm{~N}$ ), the emission of clathrin (Atto 390) and the emission of Epsin1 (Atto 488) were recorded. Scale bars correspond to $5 \mu \mathrm{m}$.

Next, we wanted to find out if we can visualize the recruitment of ubiquitin by Epsin1 in our GUV assay (Figure 48). Therefore, we used a linear tetraubiquitin construct connected by lysine 63 and labeled with Atto 390 NHS. We used the same GUVs as before and incubated them with Atto 488 maleimide labeled Epsin1 C96A $(2.5 \mu \mathrm{M})$ at $10^{\circ} \mathrm{C}$ for $1 \mathrm{~h}$ to establish high membrane coverage without deformation. Next, tetraubiquitin was added and incubated at $25^{\circ} \mathrm{C}$. Shortly after addition the tetraubiquitin construct co-localized at the membrane together with Epsin1. Epsin1 was able to recruit ubiquitin to the membrane.
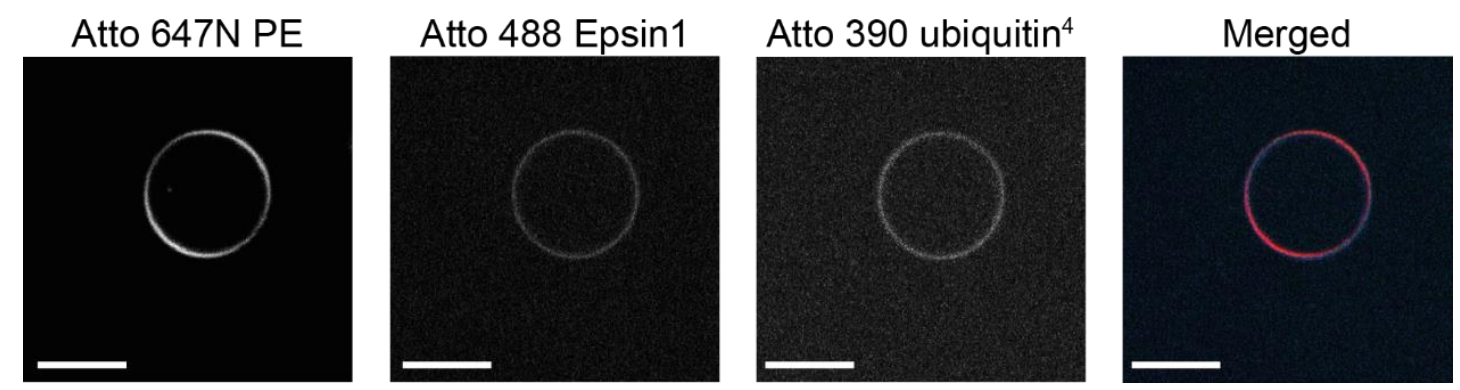

Figure 48: Tetraubiquitin is recuitied by Epsin1 to GUVs. GUVs were composed of La-PtdCho, La-PtdEtn, La-PtdSer, La-Ptdlns(4,5)P2, Atto 647N PtdSer (44.5: $30: 20: 5: 0.5)$ and incubated with Epsin1 and tetraubiquitin (ubiquitin ${ }^{4}$ ). The signal of the membrane (Atto $647 \mathrm{~N}$ ), the emission of tetraubiquitin (Atto 390) and the emission of Epsin1 (Atto 488) were recorded. Scale bars correspond to $4 \mu \mathrm{m}$. 


\section{Discussion}

Clathrin mediated endocytosis is an essential process for cell homeostasis in eukaryotes. During CME cargo molecules are transported across the plasma membrane from the outer cell surface into the cytosol. This pathway is mediated and regulated by numerous proteins that are recruited to the plasma membrane at specific timepoints. One of these proteins is Epsin1 which is highly conserved in eukaryotic evolution. The ENTH domain is the lipid interaction module of this protein and specifically binds to $\operatorname{Ptd} \operatorname{lns}(4,5) \mathrm{P}_{2}$. Lipid binding is associated with the formation of an amphipathic helix at the $\mathrm{N}$-terminal end of the protein which inserts into one leaflet of the membrane ${ }^{45}$.

\subsection{PtdSer promotes ENTH domain induced membrane tubulation}

The ENTH domain membrane binding and amphipathic helix insertion is associated with the generation of local membrane curvature ${ }^{45}$ which was extensively studied with different approaches. Experiments demonstrating the ENTH domain induced membrane deformation were classically performed with model membranes composed of a not completely defined lipid extract (Folch) enriched with Ptdlns $(4,5) \mathrm{P}_{2}{ }^{45,115}$, while the ENTH domain failed to deform model membranes composed of simple lipid composition like PtdCho, PtdEtn and Ptdlns $(4,5) \mathrm{P}_{2}$, indicating that the generation of membrane curvature induced by the ENTH domain is dependent on additional lipid species.

We addressed the questions which lipid species beside Ptdlns $(4,5) \mathrm{P}_{2}$ play a role in ENTH domain mediated membrane deformation and how they affect this process. In the beginning we demonstrated that the ENTH domain binding to LUVs is only dependent on Ptdlns(4,5) $\mathrm{P}_{2}$ (Figure 21A), while membrane deformation only occurred on LUVs composed of the brain lipid extract enriched with Ptdlns $(4,5) \mathrm{P}_{2}$. LUVs composed of PtdCho, PtdEtn and Ptdlns (4,5) $\mathrm{P}_{2}$ did not show any membrane deformation (Figure $21 \mathrm{~B}$ and $21 \mathrm{C}$ ). The dependency of ENTH domain membrane binding on the presence of Ptdlns $(4,5) \mathrm{P}_{2}$ within the used model membrane systems was demonstrated by liposome co-sedimentation by Ford, M. G. J. et al $^{45}$. We observed the predominant generation of membranous tubules from LUVs as the ENTH domain phenotype of membrane deformation which is consistent with the

observations of Ford, M. G. J. et al ${ }^{45}$, but distant from the findings of Boucrot, E. et al, who determined the generation of SUVs with a diameter of approx. $25 \mathrm{~nm}$ as the predominant membrane deforming effect. Remarkably, two distinct brain lipid extract mixtures were used 
in these two studies: Ford M. G. J. et al used $90 \%$ bovine brain lipid extract Type I, Folch Fraction I (Sigma-Aldrich Corp., St. Louis, USA) enriched with $10 \% \operatorname{Ptdlns}(4,5) \mathrm{P}_{2}$, while Boucrot, E. et al used a mixture of $47,5 \%$ bovine brain lipid extract Type I, Folch Fraction I (Sigma-Aldrich Corp., St. Louis, USA) and $47.5 \%$ porcine total brain lipid extract (Avanti Polar Lipids Inc., Alabaster, USA) enriched with $5 \% \operatorname{Ptdlns}(4,5) \mathrm{P}_{2}$. The lipid compositions within the extracts are distinct from each other and the bovine brain lipid extract Type $I$ is enriched in Ptdlns and PtdSer, while the porcine total brain lipid extract is enriched in PtdEtn, PtdCho and PtdSer, but $58.7 \%$ of its lipid species are unknown. This might explain the distinct phenotypes for ENTH dependent membrane deformation in the two studies. Only phospholipids were determined in these lipid mixtures, but not other lipid species like sphingolipids and sterols that were demonstrated to have an effect on membrane rigidity and membrane shaping 190, 191, 192. The lipid composition of those extracts strongly depends on the species and the tissue they were derived from and can differ a lot ${ }^{193}$. We used $95 \%$ Brain Polar Lipid Extract Porcine (Avanti Polar Lipids Inc., Alabaster, USA) enriched with 5\% Ptdlns $(4,5) \mathrm{P}_{2}$ that is also distinct in lipid composition from the two used extracts in the studies, but this seems to be more consistent with the findings of Ford M. G. J et al. We never observed the generation of SUVs from LUVs in our experiments, but by using the lipid composition PtdCho, PtdSer, Chol, Ptdlns(4,5) $\mathrm{P}_{2}(45: 30: 20: 5)$ we demonstrated the generation of segmented tubules by the ENTH domain, designated "beads-on-a-string" phenotype. Each segment was approx. $25 \mathrm{~nm}$, consistent with the diameter of the SUVS characterized by Boucrot, E. et al. The addition of cholesterol to lipid compositions might govern the formation of small vesicles as main membrane deformation phenotype of the ENTH domain. We only used $20 \%$ cholesterol in our artificial model membranes, but mammalian cell membranes can contain up to $50 \%$ cholesterol. To determine if cholesterol has an effect on vesiculation it is necessary to repeat the deformation analysis by EM and DLS experiments with increasing cholesterol content in the lipid compositions of the model membranes and incubate them with the ENTH domain.

Beside Epsin1, several proteins that are involved in CME contain characteristic membrane modules mediating their membrane binding and membrane deformation ability. The ANTH domain that can be found in CALM and AP180 for example is associated with membrane binding due to surface charge interactions, but not with membrane deformation 194, 165. In contrast, N-BAR domains that are the membrane interaction modules of amphiphysin and endophilin for example, also bind membranes due to surface charge interactions, but induce and stabilize membrane curvature due to the scaffold mechanism 195. The interaction of these domains with model membranes is well characterized. Thus, we used them in our membrane binding and deformation assays in comparison to the ENTH domain (Figure 22). As expected, all modules were recruited to LUVs, but only the BAR 
domain and the ENTH domain induced membrane deformation. The tubules generated by the BAR domain appeared to be straight and rigid without kinks which is consistent to the BAR domain associated deformation mechanism; the scaffold mechanism. The BAR domain forms oligomers upon membrane binding, inducing and stabilizing high degrees of membrane curvature ${ }^{114,48}$. The ENTH domain generated membranous tubules appeared to be flexible with kinks. The mechanism of membrane deformation mediated by the ENTH domain is the hydrophobic insertion mechanism, in which the surface of one leaflet of the membrane is increased upon the insertion of the amphipathic helix, inducing membrane packing defects ${ }^{45}$. However, Boucrot, E. et al demonstrated that the two mechanisms can be synergetically in one protein ${ }^{115}$. For example, amphiphysin and endophilin possess amphipathic helices inside their BAR domains.

Since ENTH domain induced membrane deformation was observed in LUVs composed of brain lipid extracts, but not of a simple lipid composition we started to screen for lipid species to include into our model membranes. The phospholipid profile of the Brain Polar Lipid Extract Porcine (Avanti Polar Lipids Inc., Alabaster, USA) shows that, beside PtdCho and PtdEtn, PtdSer is the most abundant lipid species (Table 6). Van Meer, G. et al also reviewed that PtdSer is enriched at the inner leaflet of the mammalian plasma membrane ${ }^{4}$, where CME proteins bind. We demonstrated that PtdSer does not have any effect on ENTH domain recruitment to the LUVs and membrane binding is indeed only dependent on Ptdlns $(4,5) \mathrm{P}_{2}{ }^{45}$. However, the presence of PtdSer governed the generation of membrane tubules mediated by the ENTH domain as the formation of tubules decreased with the decrease of the PtdSer content and in absence of this lipid species, no tubulation was observed (Figure 23 and 24). We also observed the same effect by changing the model membrane system from LUVs to GUVs and ENTH domain mediated membrane tubulation only occurred if PtdSer was present in the membrane (Figure 27, 28 and 29). Remarkably, the GUV assay showed that the ENTH domain is not equally distributed on the GUV membrane and small ENTH domain clustering spots appeared before membrane tubulation started (Figure 29). Stachowiak, J. C. et al showed that membrane deformation of GUVs induced by the ENTH domain is dependent on protein surface coverage, or in other words: the ENTH domain induces membrane deformation by a crowding effect on the membrane inducing lateral pressure by molecule collision ${ }^{118}$. Our observations are distinct, since we did not see any membrane deformation on GUVs without PtdSer (Figure 28), but PtdSer tubulated after ENTH domain binding (Figure 27). Although we are not able to quantify the membrane bound protein so far, we assume that the ENTH domain membrane coverage of both GUV populations were similar, since we used the same conditions.

Since PtdSer is negatively charged, we replaced it with Ptdlns and tested if we can rescue ENTH domain induced membrane deformation (Figure 23 and 24). The co- 
sedimentation assay displayed that Ptdlns had no effect on membrane binding, but no deformation was observed on LUVs by EM and DLS analysis. Ptdlns is an abundant phospholipid in the membrane ${ }^{4}$, but seemingly does not promote ENTH domain mediated membrane deformation.

PtdSer is inversely conical shaped with a small headgroup compared to the area of the fatty acid chains ${ }^{100}$. This shape might induce lipid packing defects, making the model membranes more favorable for deformation events. We tested this hypothesis by replacing PtdSer by additional PtdEtn which has a similar inverse conical shape, but is uncharged (Figure 25), so that LUVs were composed of PtdCho, PtdEtn and Ptdlns $(4,5) \mathrm{P}_{2}$ (45: $\left.50: 5\right)$. The ENTH domain was recruited to those LUVs, but failed to induce membrane deformation. The tests we performed indicate that ENTH domain induced membrane deformation depends specifically on the presence of PtdSer. Since we observed no tubulation by replacing PtdSer with a positively charged lipid (PtdIns) and an inverse conical shaped lipid (PtdEtn) we excluded that membrane deformation occurred only because PtdSer alters the physical properties of the membrane. As our assays just gave indications, it is necessary to determine physical properties of model membrane systems prepared of the lipid compositions we used. Gleisner, M. et al demonstrated that the membrane tension of GUVs with a defined lipid composition is altered by the addition of the ENTH domain ${ }^{173}$. This experiment would be suitable to compare membrane tensions of GUVs prepared of lipid compositions containing PtdSer, or Ptdlns, or an increased PtdEtn content and how the addition of ENTH domain would affect these GUVs.

By solid state NMR experiments, we were able to demonstrate that the ENTH domain undergoes structural changes upon binding to PtdSer containing LUVs in comparison to LUVs composed of PtdCho, PtdEtn and Ptdlns $(4,5) \mathrm{P}_{2}$. The data indicates that the ENTH domain becomes more rigid due to the interaction with PtdSer containing membranes. Since we observed that the ENTH also induces the generation of membranous tubuli it might be necessary to distinguish if these structural changes occur because of interaction to PtdSer, or due its localization on membrane tubules that have a high membrane curvature compared to LUVs. Goldstein, A. S. et al were able to prepare preformed membranous nanotubes by using the ceramide galactocerebroside, in their lipid composition ${ }^{196}$. By repeating solid state NMR experiments with Ptdlns $(4,5) \mathrm{P}_{2}$ containing membrane nanotubes without PtdSer we could determine if bound ENTH domain is affected in the same way as in NMR experiments with LUVs.

Finally, we were able to partially rescue ENTH domain induced membrane tubulation by using the PtdSer headgroup O-phosphoserine together with LUVs composed without PtdSer (Figure 30) indicating that the ENTH domain interacts with PtdSer directly. To further examine the interactions of the ENTH we started to establish isothermal titration calometry 
(ITC) experiments with liposomes composed with and without PtdSer. In further steps, we also want to titrate O-phosphoserine into LUVs composed of PtdCho, PtdEtn and Ptdlns $(4,5) \mathrm{P}_{2}$ and saturated with ENTH domain so that we can examine energy changes by PtdSer headgroup binding to the ENTH domain. Busse, R. A. et al already characterized the membrane binding of PROPPIN, the peripheral membrane binding domain of Atg18, Atg21 and Hsv2, successfully by using ITC establishing the feasibility of the method ${ }^{197}$. Finally, Pérez-Lara, A. et al performed an interesting EPR experiment to determine the orientation and the membrane binding of synaptotagmin-1 on membranes containing Ptdlns $(4,5) \mathrm{P}_{2}$ in absence and presence of PtdSer. They spin-labeled synaptotagmin-1 at the Ptdlns $(4,5) \mathrm{P}_{2}$ binding motif and also at amino acids that were supposed to touch the membrane surface. By doing so they demonstrated that synaptotagmin-1 orientates differently on PtdSer and Ptdlns $(4,5) \mathrm{P}_{2}$ containing membranes than on membranes containing just one of these lipid species. EPR measurements were already performed with the ENTH domain to determine the insertion depth and orientation of the amphipathic helix within membranes ${ }^{167,}{ }^{168}$. We would like to find out by this approach if the orientation of the ENTH domain on the membrane changes in presence of PtdSer.

Altogether, the results indicate that ENTH domain induced membrane deformation is dependent on the lipid composition. In addition to the presence of $\operatorname{Ptd} \operatorname{lns}(4,5) \mathrm{P}_{2}$. We demonstrated that PtdSer promotes the generation of membrane tubules and that the presence of cholesterol changes the morphology of those tubules from a smooth surface to segmentations (beads-on-a-string). We were not able to find a defined lipid composition that governs the formation of SUVs from LUVs. 


\subsection{The ENTH domain induced membrane deformation is associated with the formation of homo-oligomers}

In addition the interaction of the ENTH domain with PtdSer we could observe formation of ENTH domain homo-oligomers whenever ENTH domain induced membrane deformation occured. Lai, C. et al performed CG MD simulations and identified two regions of the ENTH domain that might be involved in PtdSer binding (R114) and in ENTH domain inter-protein interactions (V50,51).

ENTH V50,51A seemed to be a loss of function mutant. It sedimented together with any LUV population independently from the presence of Ptdlns $(4,5) \mathrm{P}_{2}$ (Figure 32A), but not if it was incubated without liposomes. Although the concentrations of ENTH V50,51A were similar in each sample and control the LUVs occupy space within the samples. This may decrease the space between each protein molecule, leading to crowding and agglomeration effects. Agglomeration effects would also explain why the SDS-PAGE of ENTH V50,51A cosedimentation assays displayed higher order kDa bands in the supernatant. We also did not observe any membrane deformation induced by V50,51A. The exchange of the two valines in helix 3 to two alanines might induce helix breaks and influence the structural integrity of the protein.

Next, we used the mutant ENTH R114A in which an arginine within the loop between helix 6 and 7 was mutated to alanine. Lia, C. et al claim, that this arginine comes in close proximity to the membrane and might interact with negatively charged lipids ${ }^{170}$. The interaction of peripheral membrane proteins to more than one distinct lipid species at the same time was shown with synaptotagmin-1 by Pérez-Lara, A. et al ${ }^{198}$. This is consistent with the data we obtained, since we observed that the ENTH domain seems to interact with PtdSer. However, the mutant ENTH R114A had a distinct phenotype: although it was recruited to LUVs in a similar way as the ENTH domain WT it was not able to form homooligomers on the membrane anymore (Figure 33) and it also failed to induce tubulation on LUVs containing Ptdlns $(4,5) \mathrm{P}_{2}$ and PtdSer analyzed by EM, DLS experiments and flotation assays (Figure 34A, 34B, 35 and 36). In comparison to ENTH R114A the ENTH domain WT deformed LUVs which were produced of the same lipid composition. The flotation assay is a well- established technique to resolve membrane binding and deformation in the same assay. Barbot, M. et al demonstrated that LUVs incubated with the BAR domain of endophilinA1 and Mic10, both membrane deforming proteins, show a characteristic ladder because deformed liposomes migrate into all the interphases between the discontinuous density gradient ${ }^{106}$. We only observed this characteristic deformation ladder with ENTH domain WT deformed LUVs containing Ptdlns $(4,5) \mathrm{P}_{2}$ and PtdSer. The corresponding SDS 
gel displays that the ENTH domain WT floated along these liposomes (Figure 36A) accompanied by the formation of homo-dimers. ENTH R114A bound to LUVs of the same composition, but did not deform them and both, LUVs and the protein migrated only into the interphase between $0 \%$ and $5 \%$ histodenz similar to LUVs composed without PtdSer (Figure 36B). ENTH R114A failed to form homo-oligomers here.

Protein induced membrane deformation is often accompanied by the formation of homo-oligomers. For example, BAR domain containing proteins like endophilins and amphiphysins form homo-oligomer-scaffolds surrounding membranous tubules in a helical way ${ }^{195,52}$. Barbot, M. et al demonstrated that Mic10, an integral membrane protein involved in the formation of cristae junctions, forms homo-oligomers and that Mic10 induced membrane deformation is dependent on this process ${ }^{106}$.

Different studies also suggested that the ENTH domain forms homo-oligomers. Yoon, Y. et al proposed that ENTH domains interact with each other by lysine 23 (K23) and glutamic acid 42 (E42) ${ }^{168}$. Lai, C. et al performed CG MD simulation and suggested that ENTH domains interact via V50,51 ${ }^{170}$. However, Boucrot et al demonstrated that ENTH domains act as monomers and induce membrane deformation independently from each other ${ }^{115}$. However, we found evidence that ENTH domain induced membrane deformation is at least accompanied by the formation of homo-oligomers and that R114 plays a crucial role in both processes.

Since ENTH R114A did not show the same phenotype as the ENTH domain WT we wanted to ensure that the mutant protein did not contain helix breaks. The CD spectrum of the ENTH domain WT and ENTH R114A displayed a nearly perfect overlay indicating that the mutation did not affected the secondary structures.

Next, we used the FRET assay to determine if the ENTH domain WT, and ENTH R114A come in close proximity to PtdSer and to each other, indicating self-assembly. The ENTH domain self-assembles on LUVs only if Ptdlns $(4,5) \mathrm{P}_{2}$ and PtdSer are present in the membrane (Figure 41) while ENTH R114A failed in all used conditions to induce a FRET effect. We also observed a FRET signal if we used labeled PtdSer together with ENTH domain WT and also ENTH R114A (Firgure 40). No FRET signal appeared if we used labeled PtdEtn.

To identify at which position of the amino acid sequence the ENTH domain oligomerizes we used a cross-linking approach coupled to trypsin digest and MS/MS analysis of the tryptic peptides (Figure 43). A similar approach was used to identify the binding motif of synaptobrevin to the complex of syntaxin1, SNAP25 and Munc18-1 to form a functional SNARE complex ${ }^{199}$. In general, more inter-protein cross-links were identified with the ENTH domain WT than with ENTH R114A. K117-K117 was the most abundant crosslink on LUVs composed with Ptdlns $(4,5) \mathrm{P}_{2}$ and in presence and absence of PtdSer, beside 
K149-K149 and K153-K149 (Table 7). The K117-K117 cross-link was not detected if ENTH R114 was used. Here, the most abundant crosslink was K149-K149. K117 is located within the loop between helix 6 and helix 7, while K149 and K153 are located within the unaligned helix 8 . We claim that the loop between helix 6 and helix 7 might be the location of ENTH domain dimerization.

The K117-K117 fragment was not identified at all by MS/MS analysis, if we used ENTH R114A. To receive a clearer picture about oligomerization of the ENTH domain in further analysis, we want to use ${ }^{15} \mathrm{~N}$-labeled ENTH domain populations and incubate it together with unlabeled ENTH domain on LUVs as composed before. The nitrogen isotope would induce distinct mass shifts within the MS/MS profile and we would receive cross-link spectra for ${ }^{15} \mathrm{~N}$-ENTH domain dimers, ${ }^{15} \mathrm{~N}$-ENTH domain - ENTH domain and unlabeled ENTH domain dimers. This approach was shown before by Melchior, J. T. et al ${ }^{200}$.

The results so far indicate that membrane deformation is dependent on ENTH domain oligomerization. We identified that ENTH domain homo-dimerize by the loop between helix 6 and helix 7 . Nevertheless, beside the occurrence of dimers we observed the formation of higher order homo-oligomers indicating that the ENTH domain has at least another inter-protein interaction site. However, the formation of higher order oligomers also depended on R114. Recent studies demonstrated that the ENTH domain can interact with distinct proteins and has many different interaction sites. The ENTH domain of yeast Ent1 interacts with the ANTH domain of Sla2 forming a regular, hetero-oligomeric coat ${ }^{176}$. The interaction was inhibited by using the mutant ENTH T104A. Wang, J. et al demonstrated that ENTH domains of yeast Ent3 bind to the SNARE protein Vit1 due to an interface formed by the loop between helix 2 and helix 3, the loop between helix 4 and helix 5 and helix 8 itself 177. Finally, the ENTH domain of yeast Ent1 and Ent2 interacts with the cell division protein Cdc42 ${ }^{201}$. We demonstrated that the loop between helix 6 and helix 7 is involved in the formation of ENTH domain dimers.

To address the cellular endocytic consequence of ENTH domain oligomerization we want to start experiments with HeLa cells. Boucrot, E. et al used siRNAs to silence all three copies of Epsin inside such cells impairing endocytosis ${ }^{115}$. By introducing their own Epsin1 construct into silenced HeLa cells they could rescue CME. We want to use this system and follow the endocytic uptake of EGFR, which is an Epsin1 specific cargo. By using an Epsin1 WT construct we aim to rescue the EGFR uptake. Furthermore, we want to visualize if the formation of ENTH domain homo-oligomers has an effect on CME by introducing an ENTH R114A construct. 


\subsection{Epsin1 interacts with clathrin and tetraubiquitin on the membrane}

The role of Epsin1 in CME is controversially discussed. It was discovered as an interaction partner for Eps15, and described as an adaptor protein interacting with clathrin, AP-2 and the membrane itself ${ }^{120}$. It is still debated if Epsin1 is crucial for CME and if it is involved in cargo selection. Several studies demonstrate that Epsin1 is crucial for CCV maturation and its release from the plasma membrane 132, 115, while other studies demonstrate that CCVs do even form if only the unstructured part of Epsin1 was used ${ }^{202}$.

We addressed the potential of Epsin1 to drive clathrin mediated endocytosis in a minimal component system. Therefore, we examined the membrane binding and deformation behavior of Epsin1 with the same membrane systems, as we used for the ENTH domain. Epsin1 had the same binding and membrane deformation phenotype (Figure 44) as the ENTH domain (Figure 23) and was recruited to LUVs only in the presence of Ptdlns $(4,5) \mathrm{P}_{2}$ and generated membrane tubules only in the additional presence of PtdSer. In comparison to the ENTH domain ( $12 \mu \mathrm{M}$ for the assays) only $8 \mu \mathrm{M}$ Epsin1 was necessary to observe similar results. Epsin1 was demonstrated to be more efficient in membrane deformation than its ENTH domain alone on LUVs and GUVs ${ }^{175}$. The authors claim that Epsin1 is more efficient, due to its bigger hydrodynamic radius than the isolated ENTH domain in their molecular crowding model. The ENTH domain covers approx. 15 to $20 \mathrm{~nm}^{2}$ on the membrane after binding, while Epsin1 covers approx. 70 to $100 \mathrm{~nm}$ due to its large disordered C-terminus. The larger hydrodynamic radius of the full-length protein might induce more lateral pressure due to collisions between the proteins than the small globular ENTH domain does. Interestingly, if we incubated GUVs with Epsin1, we observed the formation of small clusters on the membrane indicating that Epsin1 forms oligomers more efficient than the sole ENTH domain, although we did not observe this occurrence on SDSPAGEs after co-sedimentation assays (Figure 45). The reason might have been that Epsin1 forms so large homo-oligomers that they don't migrate through the separation gel during SDS-PAGE. The protein FRET assay might give more conclusive results if Epsin1 forms homo-oligomers on the membrane.

To observe if Epsin1 is able to recruit clathrin to membranes we modified the cosedimentation assay with a second incubation cycle. The idea was to obtain a high membrane coverage of Epsin1 without membrane deformation and then start the incubation with clathrin ${ }^{45}$. The analysis of the SDS gel and detection by Coomassie staining was inconclusive (Figure 46A). Here, we observed Epsin1 oligomers, but also in the control of the soluble protein without LUVs. In contrast, purified Epsin1 did not show higher order oligomers after size exclusion chromatography (Figure 18). We were also not able to detect 
clathrin by this staining method. However, the detection by immunostaining showed a clearer result (Figure 45B). First, we detected that Epsin1 forms homo-oligomers and more pronounced if it is recruited to LUVs. Especially, if it was incubated with clathrin the Epsin1 oligomer signal appeared to be more pronounced than the monomer signal. The second observation was that clathrin is indeed only recruited to the membrane if Epsin1 is present. This is consistent with several findings ${ }^{45,145}$. Nonetheless, we expected a stronger immune staining signal for clathrin. The reason for the weak signal might be the way clathrin was isolated and prepared for the assays. Clathrin triskelia are purified into a buffer that inhibits the self-assembly and transferred shortly before usage into HEPES buffer by dialysis and centrifuged to pellet agglomerated protein. The triskelia already start to agglomerate during the whole procedure and thus it is hard to determine the functional triskelia concentration efficiently. We were also able to label clathrin triskelia with Atto $390 \mathrm{NHS}$ and use it in the GUV assay together with Epsin1. Although we detected clathrin recruitment to the membrane in dependency of Epsin1, we observed a lot of clathrin agglomerates, indicating that the additional labeling prodcedure had an adverse effect on on the stability of clathrin (Figure 47). Thus, we need to modify the preparations by decreasing the time between clathrin triskelia storage and usage for the assays. A solution might be to use desalting columns instead of dialysis and perform the labeling at room temperature for a shorter period instead of labeling at $4^{\circ} \mathrm{C}$ for $12 \mathrm{~h}$. Nevertheless, the data we obtained are consistent with the general findings that clathrin is co-recruited by Epsin 1 to membranous tubuli ${ }^{145}$ and to LUVs ${ }^{45}$. Still we did not answer the question if Epsin1 together with clathrin alone is able to form clathrin coated vesicles in our in vitro systems. Therefore, we need to modify the preparation of EM grids. It is possible to coat EM grids with a membrane monolayer and incubate it first with Epsin1 and clathrin and by this induce the formation of clathrin coated vesicles ${ }^{45}$. Together with immune gold staining it might be a powerful technique to first observe the formation of CCVs and to analyze the localization of Epsin1 and clathrin in those vesicles.

Besides the recruitment of clathrin we wanted to show that Epsin1 can bind to conjugated ubiquitin. It was demonstrated that the ubiquitinated EGFR is a specific cargo for Epsin1 since its internalization depends on the function of Epsin $1{ }^{149}$. It was also shown, that the UIMs of Epsin1 bind to higher order conjugated ubiquitins (at least tetraubiquitin) and ubiquitinated proteins derived from cytosolic fractions ${ }^{122}$. Based on these reports we started to analyze the interaction of Epsin1 and an artificial cargo composed of tetraubiquitin labeled with Atto 390 NHS Using GUV assay as initial test, we clearly observed the recruitment of this cargo to the membrane in presence of Epsin1 (Figure 48). To further analyze the corecruitment of tetraubiquitin we want to employ the co-sedimentation assay and the flotation assay to resolve if ubiquitin also binds to Epsin1 in the deformation pattern. As before, EM 
coupled with immunogold staining will be a powerful technique to resolve the co-localization of tetratubiquitin on Epsin1 generated membrane tubuli. Here we can also use Ni-NTA containing lipids (Ni-NTA DOGS) to first recruit hexa-his-tetraubiquitin to the LUVs and then incubate it with Epsin1 to induce deformation and analyze the localization of the ubiquitin cargo by immunogold staining.

Our final goal is to detect ubiquitin sorting into clathrin baskets by Epsin1 as the only adaptor protein (Figure 49). Therefore, we must modify the assays we use with an additional incubation step. The co-sedimentation assay might resolve the co-recruitment of tetraubiquitin and clathrin to the membrane while EM coupled to immunogold staining will resolve if all proteins co-localize into CCVs. Furthermore, our GUV assay must be modified for the use of a fourth fluorophore. Atto 565 NHS seems to be the most suitable fluorophore because it has the least cross- Interaction to the fluorophores already in use.

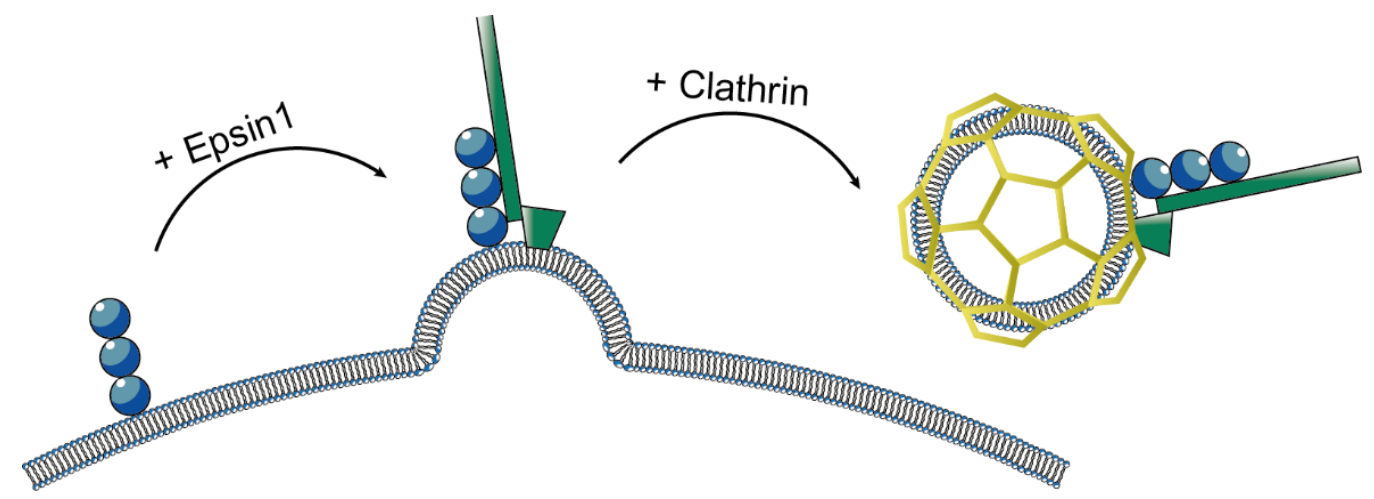

Figure 49: Schematic illustration of the in vitro cargo sorting of ubiquitin into clathrin baskets by Epsin1 


\section{Conclusion}

In clathrin mediated endocytosis (CME), cargo molecules are transported across the plasma membrane from the outer cell surface into the cytosol. During this process, the plasma membrane undergoes massive local remodeling events which are mediated and regulated by a numerous number of proteins. One of these proteins is Epsin1 which is highly conserved across eukaryotic evolution. Epsin1 is composed of a tightly folded ENTH domain and an unstructured C-terminus containing several short interaction motifs for CME proteins. The ENTH domain is the lipid binding module of Epsin1 and binds specifically to phosphatidylinositol 4,5-bisphosphate. Membrane binding of the ENTH domain is associated with the folding of an additional, amphipathic helix, which inserts into one leaflet of the membrane. Helix insertion was demonstrated to be associated with membrane deformation but little is known about the mechanisms that drive the deformation process by the ENTH domain.

In this thesis, molecular details of membrane deformation induced by the ENTH domain of Epsin1 were investigated. By using model membrane systems with defined lipid compositions we were able to identify the lipid species beside Ptdlns $(4,5) \mathrm{P}_{2}$ playing a role in membrane deformation. Phosphatidylserine (PtdSer) promoted the generation of membrane tubles from model membranes, induced by the ENTH domain. This effect appeared lipid species specific since it was not possible to rescue ENTH domain induced membrane deformation by replacing PtdSer by lipid species with similar physical abilities, or by using the soluble headgroup O-phophoserine. By solid-state NMR we found that the presence of PtdSer within LUVs induced conformational changes and that the ENTH domain became more rigid than on membranes without PtdSer.

By using LUVs containing Ptdlns $(4,5) \mathrm{P}_{2}$, PtdSer and cholesterol we were able to identify an additional phenotype of membrane deformation which appeared as segmented membrane tubuli which might be an intermediate between tubulation and vesiculation.

In addition, we demonstrated that ENTH domain induced membrane deformation is accompanied by the formation of homo-oligomers and that the mutant ENTH R114A failed in both, although it was recruited to LUVs in the same way as the ENTH domain WT in liposome co-sedimentation assays. FRET data indicate that the ENTH domain formation of homo-oligomers is dependent on Ptdlns $(4,5) \mathrm{P}_{2}$ and PtdSer within the membrane and that ENTH 
Conclusion

R114A was not able to form oligomers on those membranes. However, both the ENTH domain WT and R114A interacted with PtdSer in lipid-protein FRET assays and no FRET effect appeared if PtdSer was replaced by PtdEtn. Using a strategy combining cross-linking, trypsin digestion and MS/MS analysis we could identify the location of oligomerization within the loop between helix 6 and helix 7 which comes in close proximity to the membrane due to ENTH domain membrane recruitment.

Finally, we established the recruitment of clathrin to model membrane systems by Epsin1 in liposome co-sedimentation assays, as well as in GUV assays and demonstrated the interaction of tetraubiquitin with Epsin1 by GUV assays. 


\section{References}

1. Calderón, R. O. \& DeVries, G. H. Lipid composition and phospholipid asymmetry of membranes from a Schwann cell line. J. Neurosci. Res. 49, 372-380 (1997).

2. Pankov, R., Markovska, T., Antonov, P., Ivanova, L. \& Momchilova, A. The plasma membrane lipid composition affects fusion between cells and model membranes. Chem. Biol. Interact. 164, 167-173 (2006).

3. Subra, C., Laulagnier, K., Perret, B. \& Record, M. Exosome lipidomics unravels lipid sorting at the level of multivesicular bodies. Biochimie 89, 205-212 (2007).

4. van Meer, G., Voelker, D. R. \& Feigenson, G. W. Membrane lipids: where they are and how they behave. Nat. Rev. Mol. Cell Biol. 9, 112-124 (2008).

5. Zachowski, A. Phospholipids in Animal Eukaryotic Membranes: Transverse Asymmetry and Movement. Biochem. J. 294, 1-14 (1993).

6. Mukherjee, S., Ghosh, R. N. \& Maxfield, F. R. Endocytosis. Physiol. Rev. 77, 759 LP803 (1997).

7. Doherty, G. J. \& McMahon, H. T. Mechanisms of endocytosis. Annu. Rev. Biochem. 78, 857-902 (2009).

8. Wang, E. et al. Apical and Basolateral Endocytic Pathways of MDCK Cells Meet in Acidic Common Endosomes Distinct from a Nearly-Neutral Apical Recycling Endosome. Traffic 1, 480-493 (2000).

9. Gruenberg, J. The endocytic pathway: a mosaic of domains. Nat Rev Mol Cell Biol 2, 721-730 (2001).

10. Presley, J. F. et al. Bafilomycin A 1 Treatment Retards Transferrin Receptor Recycling More than Bafilomycin A 1 Treatment Retards Transferrin Receptor Recycling More than Bulk Membrane Recycling *. 272, 13929-13936 (1997).

11. Johnson, L. S., Dunn, K. W., Pytowski, B. \& McGraw, T. E. Endosome acidification and receptor trafficking: bafilomycin $A 1$ slows receptor externalization by $a$ mechanism involving the receptor's internalization motif. Mol. Biol. Cell 4, 1251-66 (1993).

12. Maxfield, F. R. \& McGraw, T. E. Endocytic recycling. Nat. Rev. Mol. Cell Biol. 5, 121132 (2004).

13. Mousavi, S. A., Malerød, L., Berg, T. \& Kjeken, R. Clathrin-dependent endocytosis. Biochem. J. 377, 1-16 (2004).

14. Traub, L. M. Common principles in clathrin-mediated sorting at the Golgi and the plasma membrane. Biochim. Biophys. Acta - Mol. Cell Res. 1744, 415-437 (2005). 
References

15. Marsh, M. \& Helenius, A. Virus entry: Open sesame. Cell 124, 729-740 (2006).

16. Mayor, S. \& Pagano, R. E. Pathways of clathrin-independent endocytosis. Nat Rev Mol Cell Biol 8, 603-612 (2007).

17. Richter, T. et al. High-resolution 3D quantitative analysis of caveolar ultrastructure and caveola-cytoskeleton interactions. Traffic 9, 893-909 (2008).

18. Cheng, Z.-J., Deep Singh, R., Marks, D. L. \& Pagano, R. E. Membrane microdomains, caveolae, and caveolar endocytosis of sphingolipids (Review). Mol. Membr. Biol. 23, 101-110 (2006).

19. Fu, Y. et al. Expression of Caveolin-1 Enhances Cholesterol Efflux in Hepatic Cells. J. Biol. Chem. 279, 14140-14146 (2004).

20. Kozera, L., White, E. \& Calaghan, S. Caveolae act as membrane reserves which limit mechanosensitive $\mathrm{ICl}$,swell channel activation during swelling in the rat ventricular myocyte. PLoS One 4, (2009).

21. Drab, M. Loss of Caveolae, Vascular Dysfunction, and Pulmonary Defects in Caveolin-1 Gene-Disrupted Mice. Science (80-. ). 293, 2449-2452 (2001).

22. Le Lay, S. \& Kurzchalia, T. V. Getting rid of caveolins: Phenotypes of caveolindeficient animals. Biochim. Biophys. Acta - Mol. Cell Res. 1746, 322-333 (2005).

23. Örtegren, U. et al. Lipids and glycosphingolipids in caveolae and surrounding plasma membrane of primary rat adipocytes. Eur. J. Biochem. 271, 2028-2036 (2004).

24. Bastiani, M. \& Parton, R. G. Caveolae at a glance. J. Cell Sci. 123, 3831-3836 (2010).

25. Hoop, C. L., Sivanandam, V. N., Kodali, R., Srnec, M. N. \& Van Der Wel, P. C. A. Structural characterization of the caveolin scaffolding domain in association with cholesterol-rich membranes. Biochemistry 51, 90-99 (2012).

26. Sabharanjak, S., Sharma, P., Parton, R. G. \& Mayor, S. GPI-Anchored Proteins Are Delivered to Recycling Endosomes via a Distinct cdc42-Regulated, ClathrinIndependent Pinocytic Pathway. Dev. Cell 2, 411-423 (2017).

27. Sabharanjak, S., Sharma, P., Parton, R. G. \& Mayor, S. GPI-anchored proteins are delivered to recycling endosomes via a distinct cdc42-regulated clathrin-independent pinocytic pathway. Dev. Cell 2, 411-423 (2002).

28. Parton, R. G., Joggerst, B. \& Simons, K. Regulated internalization of caveolae. J. Cell Biol. 127, 1199-1215 (1994).

29. Mayor, S., Rothberg, K. G. \& Maxfield, F. R. Sequestration of GPI-anchored proteins in caveolae triggered by cross-linking. Science (80-. ). 264, 1948-1951 (1994).

30. Pearse, B. M. Clathrin: a unique protein associated with intracellular transfer of membrane by coated vesicles. Proc. Natl. Acad. Sci. U. S. A. 73, 1255-1259 (1976).

31. Mcmahon, H. T. \& Boucrot, E. Molecular mechanism and physiological functions of 
References

clathrin-mediated endocytosis. Nat. Publ. Gr. 12, 517-533 (2011).

32. Stimpson, H. E. M., Toret, C. P., Cheng, A. T., Pauly, B. S. \& Drubin, D. G. EarlyArriving Syp1p and Ede1p Function in Endocytic Site Placement and Formation in Budding Yeast. Mol. Biol. Cell 20, 4640-4651 (209AD).

33. Henne, W. M. et al. FCHo proteins are nucleators of clathrin-mediated endocytosis. Science 328, 1281-1284 (2010).

34. Kirchhausen, T., Owen, D. \& Harrison, S. C. Molecular Structure, Function, and Dynamics of Clathrin-Mediated Membrane Traffic. Cold Spring Harb. Perspect. Biol. (2014).

35. Gaidarov, I., Chen, Q., Falck, J. R., Reddy, K. K. \& Keen, J. H. A Functional Phosphatidylinositol 3 , 4 , 5-Trisphosphate / Phosphoinositide Binding Domain in the Clathrin Adaptor AP-2 „ Subunit. Biochemistry 271, 20922-20929 (1996).

36. Gaidarov, I. \& Keen, J. H. Phosphoinositide-Ap-2 Interactions Required for Targeting to Plasma Membrane Clathrin-Coated Pits. J. Cell Biol. 146, 755 LP-764 (1999).

37. Ford, M. G. et al. Simultaneous binding of Ptdlns(4,5)P2 and clathrin by AP180 in the nucleation of clathrin lattices on membranes. Science 291, 1051-1055 (2001).

38. Brett, T. J., Traub, L. M. \& Fremont, D. H. Accessory protein recruitment motifs in clathrin-mediated endocytosis. Structure 10, 797-809 (2002).

39. Cocucci, E., Aguet, F., Boulant, S. \& Kirchhausen, T. The first five seconds in the life of a clathrin-coated pit. Cell 150, 495-507 (2012).

40. Haucke, V. \& Camilli, P. De. AP-2 Recruitment to Synaptotagmin Stimulated by Tyrosine-Based Endocytic Motifs. Science (80-. ). 285, 1268 LP-1271 (1999).

41. Boucrot, E., Saffarian, S., Zhang, R. \& Kirchhausen, T. Roles of AP-2 in clathrinmediated endocytosis. PLoS One 5, (2010).

42. Motley, A., Bright, N. A., Seaman, M. N. J. \& Robinson, M. S. Clathrin-mediated endocytosis in AP-2-depleted cells. J. Cell Biol. 162, 909 LP-918 (2003).

43. Henne, W. M. et al. FCHo Proteins Are Nucleators of Clathrin-Mediated Endocytosis. Science (80-. ). 328, 1281 LP-1284 (2010).

44. Dannhauser, P. N. \& Ungewickell, E. J. Reconstitution of clathrin-coated bud and vesicle formation with minimal components. Nat. Cell Biol. 14, 634-639 (2012).

45. Ford, M. G. J. et al. Curvature of clathrin-coated pits driven by epsin. Nature 419, 361-366 (2002).

46. Tebar, F., Sorkina, T., Sorkin, A., Ericsson, M. \& Kirchhausen, T. Eps15 is a component of clathrin-coated pits and vesicles and is located at the rim of coated pits. J. Biol. Chem. 271, 28727-28730 (1996).

47. Saffarian, S., Cocucci, E. \& Kirchhausen, T. Distinct dynamics of endocytic clathrin- 
References

coated pits and coated plaques. PLoS Biol. 7, (2009).

48. Masuda, M. et al. Endophilin BAR domain drives membrane curvature by two newly identified structure-based mechanisms. EMBO J. 25, 2889-2897 (2006).

49. Peter, B. J. et al. BAR domains as sensors of membrane curvature: the amphiphysin BAR structure. Science 303, 495-499 (2004).

50. Sorre, B. et al. Nature of curvature coupling of amphiphysin with membranes depends on its bound density. Proc. Natl. Acad. Sci. 109, 173-178 (2012).

51. Taylor, M. J., Perrais, D. \& Merrifield, C. J. A high precision survey of the molecular dynamics of mammalian clathrin-mediated endocytosis. PLoS Biol. 9, (2011).

52. Mim, C. et al. Structural basis of membrane bending by the N-BAR protein endophilin. Cell 149, 137-145 (2012).

53. Meinecke, M. et al. Cooperative recruitment of dynamin and BIN/Amphiphysin/Rvs (BAR) domain-containing proteins leads to GTP-dependent membrane scission. J. Biol. Chem. 288, 6651-6661 (2013).

54. Grabs, D. et al. The SH3 domain of amphiphysin binds the proline-rich domain of dynamin at a single site that defines a new SH3 binding consensus sequence. J. Biol. Chem. 272, 13419-13425 (1997).

55. Hinshaw, J. E. \& Schmid, S. L. Dynamin self-assembles into rings suggesting a mechanism for coated vesicle budding. Nature 374, 190-192 (1995).

56. Sweitzer, S. M. \& Hinshaw, J. E. Dynamin Undergoes a GTP-Dependent Conformational Change Causing Vesiculation. Cell 93, 1021-1029 (2017).

57. Stowell, M. H., Marks, B., Wigge, P. \& McMahon, H. T. Nucleotide-dependent conformational changes in dynamin: evidence for a mechanochemical molecular spring. Nat. Cell Biol. 1, 27-32 (1999).

58. Roux, A., Uyhazi, K., Frost, A. \& De Camilli, P. GTP-dependent twisting of dynamin implicates constriction and tension in membrane fission. Nature 441, 528-531 (2006).

59. Macia, E. et al. Dynasore, a Cell-Permeable Inhibitor of Dynamin. Dev. Cell 10, 839850 (2017).

60. Van der Bliek, A. M. et al. Mutations in human dynamin block an intermediate stage in coated vesicle formation. J. Cell Biol. 122, 553-563 (1993).

61. Schlossman, D. M., Schmid, S. L., Braell, W. A. \& Rothman, J. E. An enzyme that removes clathrin coats: purification of an uncoating ATPase. J. Cell Biol. 99, 723 LP733 (1984).

62. Ungewickell, E. et al. Role of auxilin in uncoating clathrin-coated vesicles. Nature 378, 632-635 (1995).

63. Anderson, R. G. W., Brown, M. S. \& Goldstein, J. L. Role of the coated endocytic vesicle in the uptake of receptor-bound low density lipoprotein in human fibroblasts. 
References

Cell 10, 351-364 (1977).

64. lacopetta, B. J. \& Morgan, E. H. The kinetics of transferrin endocytosis and iron uptake from transferrin in rabbit reticulocytes. J. Biol. Chem. 258, 9108-9115 (1983).

65. Jing, S. Q., Spencer, T., Miller, K., Hopkins, C. \& Trowbridge, I. S. Role of the human transferrin receptor cytoplasmic domain in endocytosis: localization of a specific signal sequence for internalization. J. Cell Biol. 110, 283 LP-294 (1990).

66. Traub, L. M., Bonifacino, J. S., Kirchhausen, T., Owen, D. \& Stephen, C. Cargo Recognition in Clathrin-Mediated Endocytosis. 1-24 (2014). doi:10.1101/cshperspect.a016790

67. Brown, M. S. \& Goldstein, J. L. Receptor-mediated endocytosis: insights from the lipoprotein receptor system. Proc. Natl. Acad. Sci. U. S. A. 76, 3330-7 (1979).

68. Claing, A. et al. $\beta$-Arrestin-mediated ADP-ribosylation Factor 6 Activation and $\beta 2$ Adrenergic Receptor Endocytosis. J. Biol. Chem. 276, 42509-42513 (2001).

69. Trischitta, V. et al. Endocytosis, recycling, and degradation of the insulin receptor. Studies with monoclonal antireceptor antibodies that do not activate receptor kinase. J. Biol. Chem. 264, 5041-5046 (1989).

70. Sousa, L. P. et al. Suppression of EGFR endocytosis by dynamin depletion reveals that EGFR signaling occurs primarily at the plasma membrane. Proc. Natl. Acad. Sci. 109, 4419-4424 (2012).

71. Herbst, R. S. Review of epidermal growth factor receptor biology. Int. J. Radiat. Oncol. Biol. • Phys. 59, S21-S26 (2017).

72. Tomas, A., Futter, C. E. \& Eden, E. R. EGF receptor trafficking: consequences for signaling and cancer. Trends Cell Biol. 24, 26-34 (2017).

73. Bejsovec, A. Wingless/Wnt signaling in Drosophila: The pattern and the pathway. Mol. Reprod. Dev. 80, 882-894 (2013).

74. Yu, A. et al. Association of Dishevelled with the Clathrin AP-2 Adaptor Is Required for Frizzled Endocytosis and Planar Cell Polarity Signaling. Dev. Cell 12, 129-141 (2007).

75. Sorkin, A. \& von Zastrow, M. Endocytosis and signalling: intertwining molecular networks. Nat Rev Mol Cell Biol 10, 609-622 (2009).

76. Maycox, P. R., Link, E., Reetz, A., Morris, S. A. \& Jahn, R. Clathrin-coated vesicles in nervous tissue are involved primarily in synaptic vesicle recycling. J. Cell Biol. 118, 1379-1387 (1992).

77. Adams, A. E. \& Pringle, J. R. Relationship of actin and tubulin distribution to bud growth in wild-type and morphogenetic-mutant Saccharomyces cerevisiae. J. Cell Biol. 98, 934 LP-945 (1984).

78. Kilmartin, J. V \& Adams, A. E. Structural rearrangements of tubulin and actin during 
References

the cell cycle of the yeast Saccharomyces. J. Cell Biol. 98, 922 LP-933 (1984).

79. Reider, A. et al. Syp1 is a conserved endocytic adaptor that contains domains involved in cargo selection and membrane tubulation. EMBO J. 28, 3103-3116 (2009).

80. Claudio Aguilar, R., Watson, H. A. \& Wendland, B. The yeast epsin Ent1 is recruited to membranes through multiple independent interactions. J. Biol. Chem. 278, 1073710743 (2003).

81. Sun, Y. Interaction of Sla2p's ANTH Domain with Ptdlns $(4,5) P 2$ Is Important for Actindependent Endocytic Internalization. Mol. Biol. Cell 16, 717-730 (2004).

82. Robertson, A. S. et al. The WASP homologue Las17 activates the novel actinregulatory activity of Ysc84 to promote endocytosis in yeast. Mol. Biol. Cell 20, 16181628 (2009).

83. Toret, C. P., Lee, L., Sekiya-Kawasaki, M. \& Drubin, D. G. Multiple pathways regulate endocytic coat disassembly in Saccharomyces cerevisiae for optimal downstream trafficking. Traffic 9, 848-859 (2008).

84. Israelachvili, J. N., Mitchell, D. J. \& Ninham, B. W. Theory of self-assembly of lipid bilayers and vesicles. BBA - Biomembr. 470, 185-201 (1977).

85. Pomorski, T. G., Nylander, T. \& Cárdenas, M. Model cell membranes: Discerning lipid and protein contributions in shaping the cell. Adv. Colloid Interface Sci. 205, 207-220 (2014).

86. Kranenburg, M. \& Smit, B. Phase behavior of model lipid bilayers. J. Phys. Chem. B 109, 6553-6563 (2005).

87. Koynova, R. \& Caffrey, M. Phases and phase transitions of the phosphatidylcholines. Biochim. Biophys. Acta - Rev. Biomembr. 1376, 91-145 (1998).

88. Rawicz, W., Olbrich, K. C., McIntosh, T., Needham, D. \& Evans, E. Effect of chain length and unsaturation on elasticity of lipid bilayers. Biophys. J. 79, 328-339 (2000).

89. Singer, S. J. \& Nicolson, G. L. The Fluid Mosaic Model of the Structure of Cell Membranes. Sience 175, 720-731 (1972).

90. Nicolson, G. L. The Fluid - Mosaic Model of Membrane Structure: Still relevant to understanding the structure, function and dynamics of biological membranes after more than 40 years. Biochim. Biophys. Acta - Biomembr. 1838, 1451-1466 (2014).

91. Pike, L. J. Lipid rafts. J. Lipid Res. 44, 655-667 (2003).

92. Kirkham, M. \& Parton, R. G. Clathrin-independent endocytosis: new insights into caveolae and non-caveolar lipid raft carriers. Biochim. Biophys. Acta 1746, 350-363 (2005).

93. Simons, K. \& Sampaio, J. Membrane organization and lipid rafts. Cold Spring Harb. Perspect. Biol. 3, 1-18 (2011). 
References

94. Stachowiak, J. C., Brodsky, F. M. \& Miller, E. a. A cost-benefit analysis of the physical mechanisms of membrane curvature. Nat. Cell Biol. 15, 1019-27 (2013).

95. Canham, P. B. The minimum energy of bending as a possible explanation of the biconcave shape of the human red blood cell. J. Theor. Biol. 26, 61-81 (1970).

96. Helfrich, W. Elastic Properties of Lipid Bilayers: Theory and Possible Experiments. Zeitschrift fur Naturforsch. - Sect. C J. Biosci. 28, 693-703 (1973).

97. Evans, E. \& Rawicz, W. Entropy-driven tension and bending elasticity in condensedfluid membranes. Phys. Rev. Lett. 64, 2094-2097 (1990).

98. McMahon, H. T. \& Gallop, J. L. Membrane curvature and mechanisms of dynamic cell membrane remodelling. Nature 438, 590-596 (2005).

99. McMahon, H. T. et al. Membrane curvature at a glance. J. Cell Sci. 128, 1065-70 (2015).

100. Bigay, J. \& Antonny, B. Curvature, Lipid Packing, and Electrostatics of Membrane Organelles: Defining Cellular Territories in Determining Specificity. Dev. Cell 23, 886895 (2012).

101. Kooijman, E. E. et al. Spontaneous Curvature of Phosphatidic Acid and Lysophosphatidic Acid. Biochemistry 44, 2097-2102 (2005).

102. Brown, W. J., Chambers, K. \& Doody, A. Phospholipase A2 (PLA2) enzymes in membrane trafficking: mediators of membrane shape and function. Traffic 4, 214-221 (2003).

103. Goñi, F. M. \& Alonso, A. Biophysics of sphingolipids I. Membrane properties of sphingosine, ceramides and other simple sphingolipids. Biochim. Biophys. Acta Biomembr. 1758, 1902-1921 (2006).

104. Thomas, P. D. \& Poznansky, M. J. Curvature and composition-dependent lipid asymmetry in phosphatidylcholine vesicles containing phosphatidylethanolamine and gangliosides. Biochim. Biophys. Acta - Biomembr. 978, 85-90 (1989).

105. Jarsch, I. K., Daste, F. \& Gallop, J. L. Membrane curvature in cell biology: An integration of molecular mechanisms. J. Cell Biol. 214, 375-387 (2016).

106. Barbot, M. et al. Mic10 Oligomerizes to Bend Mitochondrial Inner Membranes at Cristae Junctions. Cell Metabolism 21, 756-763 (2015).

107. Puthenveedu, M. A. et al. Sequence-dependent sorting of recycling proteins by actinstabilized endosomal microdomains. Cell 143, 761-773 (2010).

108. Saarikangas, J. et al. ABBA regulates plasma-membrane and actin dynamics to promote radial glia extension. J. Cell Sci. 121, 1444-1454 (2008).

109. Waterman-Storer, C. M. \& Salmon, E. D. Endoplasmic reticulum membrane tubules are distributed by microtubules in living cells using three distinct mechanisms. Curr. Biol. 8, 798-806 (1998). 
References

110. Estrada, P. et al. Myo4p and She3p are required for cortical ER inheritance in Saccharomyces cerevisiae. J. Cell Biol. 163, 1255-1266 (2003).

111. Capraro, B. R. et al. Kinetics of endophilin N-BAR domain dimerization and membrane interactions. J. Biol. Chem. 288, 12533-12543 (2013).

112. Casal, E. et al. NIH Public Access. Small 45, 12917-12928 (2008).

113. Rao, Y. \& Haucke, V. Membrane shaping by the Bin/amphiphysin/Rvs (BAR) domain protein superfamily. Cell. Mol. Life Sci. 68, 3983-3993 (2011).

114. Farsad, K. et al. Generation of high curvature membranes mediated by direct endophilin bilayer interactions. J. Cell Biol. 155, 193-200 (2001).

115. Boucrot, E. et al. Membrane fission is promoted by insertion of amphipathic helices and is restricted by crescent BAR domains. Cell 149, 124-136 (2012).

116. Ford, M. G. J. et al. Curvature of clathrin-coated pits driven by epsin. Nature 419, 361-366 (2002).

117. Scheve, C. S., Gonzales, P. a., Momin, N. \& Stachowiak, J. C. Steric Pressure between Proteins Opposes Membrane Phase Separation. Biophys. J. 104, 43a (2013).

118. Stachowiak, J. C. et al. Membrane bending by protein-protein crowding. Nat. Cell Biol. 14, 944-949 (2012).

119. Snead, W. T. et al. Membrane fission by protein crowding. Proc. Natl. Acad. Sci. 201616199 (2017). doi:10.1073/pnas.1616199114

120. Chen, $\mathrm{H}$. et al. Epsin is an EH-domain-binding protein implicated in clathrin-mediated endocytosis. Nature 394, 793-797 (1998).

121. Hofmann, K. \& Falquet, L. A ubiquitin-interacting motif conserved in components of the proteasomal and lysosomal protein degradation systems. Trends Biochem. Sci. 26, 347-350 (2001).

122. Hawryluk, M. J. et al. Epsin 1 is a polyubiquitin-selective clathrin-associated sorting protein. Traffic 7, 262-281 (2006).

123. Drake, M. T., Downs, M. a. \& Traub, L. M. Epsin Binds to Clathrin by Associating Directly with the Clathrin-terminal Domain. J. Biol. Chem. 275, 6479-6489 (2000).

124. Morinaka, K. et al. Epsin binds to the EH domain of POB1 and regulates receptormediated endocytosis. Oncogene 18, 5915-5922 (1999).

125. Adams, A. Intersectin, an adaptor protein involved in clathrin-mediated endocytosis, activates mitogenic signaling pathways. J. Biol. Chem. 275, 27414-27420 (2000).

126. Wendland, B., Steece, K. E. \& Emr, S. D. Yeast epsins contain an essential Nterminal ENTH domain, bind clathrin and are required for endocytosis. EMBO J.18, 4383-4393 (1999).

127. Rosenthal, J. a. et al. The epsins define a family of proteins that interact with 
References

components of the clathrin coat and contain a new protein module. J. Biol. Chem. 274, 33959-33965 (1999).

128. Spradling, K. D., McDaniel, A. E., Lohi, J. \& Pilcher, B. K. Epsin 3 Is a Novel Extracellular Matrix-induced Transcript Specific to Wounded Epithelia. J. Biol. Chem. 276, 29257-29267 (2001).

129. Kalthoff, C., Groos, S., Kohl, R., Mahrhold, S. \& Ungewickell, E. J. Clint: A Novel Clathrin-binding ENTH-Domain Protein at the Golgi. Mol. Biol. Cell 13, 4060-4073 (2002).

130. Mills, I. G. et al. Epsinr: An AP1/clathrin interacting protein involved in vesicle trafficking. J. Cell Biol. 160, 213-222 (2003).

131. Wasiak, S. et al. Enthoprotin: A novel clathrin-associated protein identified through subcellular proteomics. J. Cell Biol. 158, 855-862 (2002).

132. Messa, M. et al. Epsin deficiency impairs endocytosis by stalling the actin-dependent invagination of endocytic clathrin-coated pits. Elife e03311 (2014). doi:10.7554/eLife.03311

133. Horvath, C. A. J., Vanden Broeck, D., Boulet, G. A. V, Bogers, J. \& De Wolf, M. J. S. Epsin: Inducing membrane curvature. Int. J. Biochem. Cell Biol. 39, 1765-1770 (2007).

134. De Camilli, P. et al. The ENTH domain. FEBS Lett. 513, 11-18 (2002).

135. Duncan, M. C., Costaguta, G. \& Payne, G. S. Yeast epsin-related proteins required for Golgi-endosome traffic define a y-adaptin ear-binding motif. Nat. Cell Biol. 5, 7781 (2002).

136. Deng, Y. et al. Gga2 mediates sequential ubiquitin-independent and ubiquitindependent steps in the trafficking of ARN1 from the trans-Golgi network to the vacuole. J. Biol. Chem. 284, 23830-23841 (2009).

137. Cadavid, A. L. M., Ginzel, A. \& Fischer, J. A. The function of the Drosophila Fat facets deubiquitinating enzyme in limiting photoreceptor cell number is intimately associated with endocytosis. Development 127, 1727-1736 (2000).

138. Tian, X. Epsin potentiates Notch pathway activity in Drosophila and C. elegans. Development 131, 5807-5815 (2004).

139. Bao, H., Reist, N. E. \& Zhang, B. The Drosophila epsin 1 is required for ubiquitindependent synaptic growth and function but not for synaptic vesicle recycling. Traffic 9, 2190-2205 (2008).

140. Xie, X., Cho, B. \& Fischer, J. A. Drosophila Epsin's role in Notch ligand cells requires three Epsin protein functions: The lipid binding function of the ENTH domain, a single Ubiquitin interaction motif, and a subset of the C-terminal protein binding modules. Dev. Biol. 363, 399-412 (2012). 
References

141. Meloty-Kapella, L., Shergill, B., Kuon, J., Botvinick, E. \& Weinmaster, G. Notch Ligand Endocytosis Generates Mechanical Pulling Force Dependent on Dynamin, Epsins, and Actin. Dev. Cell 22, 1299-1312 (2012).

142. Manna, P. T., Gadelha, C., Puttick, A. E. \& Field, M. C. ENTH and ANTH domain proteins participate in AP2-independent clathrin-mediated endocytosis. J. Cell Sci. 128, 2130-2142 (2015).

143. Gabernet-Castello, C., Dacks, J. B. \& Field, M. C. The single ENTH-domain protein of trypanosomes; endocytic functions and evolutionary relationship with epsin. Traffic 10, 894-911 (2009).

144. Kyung, J. W., Bae, J. R., Kim, D.-H., Song, W. K. \& Kim, S. H. Epsin1 modulates synaptic vesicle retrieval capacity at CNS synapses. Sci. Rep. 6, 31997 (2016).

145. Holkar, S. S., Kamerkar, S. C. \& Pucadyil, T. J. Spatial control of epsin-induced clathrin assembly by membrane curvature. J. Biol. Chem. jbc.M115.653394 (2015). doi:10.1074/jbc.M115.653394

146. Hanukoglu, I. \& Hanukoglu, A. Epithelial sodium channel (ENaC) family: Phylogeny, structure-function, tissue distribution, and associated inherited diseases. Gene 579, 95-132 (2016).

147. Wang, $\mathrm{H}$. et al. Clathrin-mediated endocytosis of the epithelial sodium channel: Role of epsin. J. Biol. Chem. 281, 14129-14135 (2006).

148. Dikic, I. Mechanisms controlling EGF receptor endocytosis and degradation. Biochem. Soc. Trans. 31, 1178-81 (2003).

149. Kazazic, M. et al. Epsin 1 is involved in recruitment of ubiquitinated EGF receptors into clathrin-coated pits. Traffic 10, 235-245 (2009).

150. Coon, B. G., Burgner, J., Camonis, J. H. \& Aguilar, R. C. The Epsin family of endocytic adaptors promotes fibrosarcoma migration and invasion. J. Biol. Chem. 285, 33073-33081 (2010).

151. Mukherjee, D. et al. The yeast endocytic protein Epsin 2 functions in a cell-division signaling pathway. J. Cell Sci. 122, 2782-2782 (2009).

152. Pawlowski, K. M. et al. Comparison of cellular and tissue transcriptional profiles in canine mammary tumor. J. Physiol. Pharmacol. 60, 85-94 (2009).

153. Mori, J. et al. EPSIN 3, A Novel p53 Target, Regulates the Apoptotic Pathway and Gastric Carcinogenesis. Neoplasia (United States) 19, 185-195 (2017).

154. Pasula, S. et al. Endothelial epsin deficiency decreases tumor growth by enhancing VEGF signaling. J. Clin. Invest. 122, 4424-4438 (2012).

155. Tessneer, K. L. et al. Endocytic Adaptor Protein Epsin Is Elevated in Prostate Cancer and Required for Cancer Progression. ISRN Oncol. 2013, 1-8 (2013).

156. Hyman, S. E. The NIMH perspective: Next steps in schizophrenia research. Biol. 
Psychiatry 47, 1-7 (2000).

157. Pimm, J. et al. The Epsin 4 gene on chromosome 5q, which encodes the clathrinassociated protein enthoprotin, is involved in the genetic susceptibility to schizophrenia. Am. J. Hum. Genet. 76, 902-907 (2005).

158. Tang, R. Q. et al. Family-based association study of Epsin 4 and Schizophrenia. Mol. Psychiatry 11, 395-9 (2006).

159. Liou, Y.-J. et al. Genetic analysis of the human ENTH (Epsin 4) gene and schizophrenia. Schizophr. Res. 84, 236-43 (2006).

160. Lin, A. E., Benmerah, A. \& Guttman, J. A. Eps15 and Epsin1 are crucial for enteropathogenic Escherichia coli pedestal formation despite the absence of adaptor protein 2. J. Infect. Dis. 204, 695-703 (2011).

161. Lakadamyali, M., Rust, M. J. \& Zhuang, X. Ligands for clathrin-mediated endocytosis are differentially sorted into distinct populations of early endosomes. Cell 124, 9971009 (2006).

162. Chen, C. \& Zhuang, X. Epsin 1 is a cargo-specific adaptor for the clathrin-mediated endocytosis of the influenza virus. Proc. Natl. Acad. Sci. U. S. A. 105, 11790-11795 (2008).

163. Itoh, T. et al. Role of the ENTH domain in phosphatidylinositol-4,5-bisphosphate binding and endocytosis. Science 291, 1047-1051 (2001).

164. Hyman, J., Chen, H., Di Fiore, P. P., De Camilli, P. \& Brunger, A. T. Epsin 1 undergoes nucleocytosolic shuttling and its Eps15 interactor NH2-terminal homology (ENTH) domain, structurally similar to Armadillo and HEAT repeats, interacts with the transcription factor promyelocytic leukemia Zn2+ finger protein (PLZF). J. Cell Biol. 149, 537-546 (2000).

165. Stahelin, R. V. et al. Contrasting membrane interaction mechanisms of AP180 Nterminal homology (ANTH) and epsin N-terminal homology (ENTH) domains. J. Biol. Chem. 278, 28993-28999 (2003).

166. Tebar, F., Bohlander, S. K. \& Sorkin, A. Clathrin assembly lymphoid myeloid leukemia (CALM) protein: localization in endocytic-coated pits, interactions with clathrin, and the impact of overexpression on clathrin-mediated traffic. Mol. Biol. Cell 10, 2687-702 (1999).

167. Kweon, D.-H. et al. Membrane topology of helix 0 of the Epsin N-terminal homology domain. Mol. Cells 21, 428-435 (2006).

168. Yoon, Y. et al. Molecular basis of the potent membrane-remodeling activity of the epsin 1 N-terminal homology domain. J. Biol. Chem. 285, 531-540 (2010).

169. Capraro, B. R., Yoon, Y., Cho, W. \& Baumgart, T. Curvature sensing by the epsin Nterminal homology domain measured on cylindrical lipid membrane tethers. J. Am. 
References

Chem. Soc. 132, 1200-1201 (2010).

170. Lai, C. L. et al. Membrane Binding and Self-Association of the Epsin N-Terminal Homology Domain. J. Mol. Biol. 423, 800-817 (2012).

171. Brooks, A. et al. Single particle fluorescence burst analysis of epsin induced membrane fission. PLoS One 10, 1-14 (2015).

172. Gleisner, M. et al. Driving a planar model system into the 3(rd) dimension: generation and control of curved pore-spanning membrane arrays. Soft Matter 10, 6228-6236 (2014).

173. Gleisner, M. et al. Epsin N-terminal homology domain (ENTH) activity as a function of membrane tension. J. Biol. Chem. jbc.M116.731612 (2016). doi:10.1074/jbc.M116.731612

174. Rozovsky, S., Forstner, M. B., Sondermann, H. \& Groves, J. T. Single molecule kinetics of ENTH binding to lipid membranes. J. Phys. Chem. B 116, 5122-5131 (2012).

175. Busch, D. J. et al. Intrinsically disordered proteins drive membrane curvature. Nat. Commun. 6, 7875 (2015).

176. Skruzny, M. et al. An Organized Co-assembly of Clathrin Adaptors Is Essential for Endocytosis Article An Organized Co-assembly of Clathrin Adaptors Is Essential for Endocytosis. Dev. Cell 33, 150-162 (2015).

177. Wang, J. et al. Epsin N-terminal homology domains bind on opposite sides of two SNAREs. Proc. Natl. Acad. Sci. U. S. A. 108, 12277-12282 (2011).

178. Aguilar, R. C. et al. Epsin N-terminal homology domains perform an essential function regulating Cdc42 through binding Cdc42 GTPase-activating proteins. Proc. Natl. Acad. Sci. 103, 4116-4121 (2006).

179. Harwood, C. R. \& Cutting, S. M. Molecular biological methods for Bacillus. (Wiley, 1990).

180. Hanahan, D. Studies on transformation of Escherichia coli with plasmids. J. Mol. Biol. $166,557-580$ (1983).

181. Hope, M. J., Bally, M. B., Webb, G. \& Cullis, P. R. Production of large unilamellar vesicles by a rapid extrusion procedure. Characterization of size distribution, trapped volume and ability to maintain a membrane potential. Biochim. Biophys. Acta Biomembr. 812, 55-65 (1985).

182. Simunovic, M. et al. How curvature-generating proteins build scaffolds on membrane nanotubes. Proc. Natl. Acad. Sci. U. S. A. 113, (2016).

183. Angelova, M. I. \& Dimitrov, D. S. Liposome electroformation. Faraday Discuss. Chem. Soc. 81, 303-311 (1986).

184. Angelova, M. I., Soléau, S., Méléard, P., Faucon, F. \& Bothorel, P. in Trends in 
References

Colloid and Interface Science VI (eds. Helm, C., Lösche, M. \& Möhwald, H.) 127-131 (Steinkopff, 1992). doi:10.1007/BFb0116295

185. Rouser, G., Fleischer, S. \& Yamamoto, A. Two dimensional thin layer chromatographic separation of polar lipids and determination of phospholipids by phosphorus analysis of spots. Lipids 5, 494-496 (1970).

186. Lämmli, U. K. Cleavage of Structural Proteins during the Assembly of the Head of Bacteriophage T4. Nature 227, 680-685 (1970).

187. Gasteiger, E. et al. ExPASy: The proteomics server for in-depth protein knowledge and analysis. Nucleic Acids Res. 31, 3784-3788 (2003).

188. Kelly, S. M., Jess, T. J. \& Price, N. C. How to study proteins by circular dichroism. Biochim. Biophys. Acta - Proteins Proteomics 1751, 119-139 (2005).

189. Koldsø, H., Shorthouse, D., Hélie, J. \& Sansom, M. S. P. Lipid Clustering Correlates with Membrane Curvature as Revealed by Molecular Simulations of Complex Lipid Bilayers. PLoS Comput. Biol. 10, (2014).

190. Samsonov, A. V., Mihalyov, I. \& Cohen, F. S. Characterization of CholesterolSphingomyelin Domains and Their Dynamics in Bilayer Membranes. Biophys. J. 81, 1486-1500 (2001).

191. Shi, Z. \& Baumgart, T. Membrane tension and peripheral protein density mediate membrane shape transitions. Nat. Commun. 6, 5974 (2015).

192. Ivankin, A., Kuzmenko, I. \& Gidalevitz, D. Cholesterol mediates membrane curvature during fusion events. Physical Review Letters 108, (2012).

193. Folch, J., Lees, M. \& Solane Stanley, G. H. A Simple Method for the Isolation and Purification of Total Lipides from Animal Tissues. J. Biol. Chem. 226, 497-509 (1957).

194. Ford, M. G. et al. Simultaneous binding of Ptdlns(4,5)P2 and clathrin by AP180 in the nucleation of clathrin lattices on membranes. Science 291, 1051-1055 (2001).

195. Daumke, O., Roux, A. \& Haucke, V. BAR domain scaffolds in dynamin-mediated membrane fission. Cell 156, 882-892 (2014).

196. Goldstein, A. S., Lukyanov, A. N., Carlson, P. A., Paul Yager \& Gelb, M. H. Formation of high-axial-ratio-microstructures from natural and synthetic sphingolipids. Chem. Phys. Lipids 88, 21-36 (1997).

197. Busse, R. A. et al. Characterization of PROPPIN-Phosphoinositide Binding and Role of Loop 6CD in PROPPIN-Membrane Binding. Biophys. J. 108, 2223-2234 (2015).

198. Pérez-Lara, Á. et al. PtdlnsP2 and PtdSer cooperate to trap synaptotagmin-1 to the plasma membrane in the presence of calcium. Elife 5, 1-22 (2016).

199. Jakhanwal, S., Lee, C., Urlaub, H. \& Jahn, R. An activated Q-SNARE/SM protein complex as a possible intermediate in SNARE assembly. EMBO J. 36, 1788-1802 (2017). 
References

200. Melchior, J. T. et al. An evaluation of the crystal structure of c-terminal truncated apolipoprotein A-I in solution reveals structural dynamics related to lipid binding. $J$. Biol. Chem. 291, 5439-5451 (2016).

201. Ritter, B. \& McPherson, P. S. There's a GAP in the ENTH domain. Proc. Natl. Acad. Sci. U. S. A. 103, 3953-4 (2006).

202. Dannhauser, P. N. \& Ungewickell, E. J. Reconstitution of clathrin-coated bud and vesicle formation with minimal components. Nat. Cell Biol. 14, 634-639 (2012). 


\section{Acknowledgments}

First of all, I would like to thank Prof. Michael Meinecke to give me the opportunity for my PhD thesis. Thank you, a lot, for letting me grow into this project, for the support even in many rough times, the discussions and especially for trusting my decisions.

I would also like to thank Dr. Achim Dickmanns who was part of my thesis committee. Thank you, a lot, for professional advices since the end of my bachelor thesis, but also for supporting me during personal issues.

Also, I would like to thank Prof. Dr. Andreas Janshoff for being part of my thesis committee, for nice discussions, advices and for always having an open door for questions.

There are several people I would like to thank -

- Prof. Dr. Kai Tittmann, Prof. Dr. Silvio Rizzoli and Prof. Dr. Markus Bohnsack for being part as the extended thesis committee.

- Daryna Tarasenko and Niels Denkert for a nice lab atmosphere and stimulating discussions. Especially Niels for performing the FRET experiments.

- The whole Steinem group, especially Dr. Martin Gleisner, Markus Schön, Jonas Schäfer, Jeremias Sibold, Nelli Teske and Stefan Krüger for having a nice time in their social room and for helping me with lipid determinations.

- Klaus Neifer for helping me with some protein purifications as well as helping me to maintain our ÄKTAPrime. And for helping me to disassemble a Superdex pg200 column.

- Olaf Bernhard for performing MS to identify my proteins and for having no-work conversations.

- Iwan Parfentev from the Urlaub group for performing MS/MS studies and being a very nice cooperation partner and bouldering partner 
- Sören Rindfleisch from the Tittmann group for teaching me to use the ITC and Dr. Viktor Sautner for teaching me how to use the CD spectrometer.

- Dr. Garima Jaipuria from the Zweckstetter group for performing the solid-state NMR experiments.

- Dr. Fabian Rabe von Pappenheim for reading some parts of the thesis even on the day of submission and for remaining a friend after all these years.

- Dr. Ira Milosevic for introducing me to the spinning disc and offering a helping hand in my project.

- Dr. Michael Hoppert for introducing me to the electron microscope and for helping me out with EM issues even on a Sunday.

- The GGNB Biomolecules program. Especially Lukas Schulte and Sven Johannsson, who were quite good representatives.

- Dawid Lbik who extracted about 50 rat brains for me. And for being a friend from the beginning of my studies.

- Manu Kriehn for having a nice time and all his support.

- David Bürkner and Tino Mark who always kept in touch, even after night time writing.

- $\quad$ Lisa-Marie Funk for being a very good friend, sharing a nice time with me and for all the support she gave me. Especially for listening to me and giving trust in me and my work even if it was hard for me.

- My parents Nina and Fritz and my sister Sabrina who always supported me and believed in me.

- My grandmother Kuldip Bedi, who passed away before I submitted. 


\section{Curriculum vitae}

\begin{tabular}{l|l} 
Personal data & \\
Name & Benjamin Kroppen \\
Date of birth & $26^{\text {th }}$ February 1984 \\
Place of birth & Bad Arolsen \\
Citizenship & German
\end{tabular}

\section{Education}

$2014-2017$

$2011-2013$

Ph.D thesis at the Georg-August University, Göttingen (Prof. Dr. Michael Meinecke). Title of thesis: Molecular details membrane deformation by ENTH domains.

M.Sc. Microbiology at Friedrich-Schiller University at Jena. Title of master thesis: Reductive dehalogenation of aliphatic and aromatic organohalides by Desulfomonile tie-dye and Desulfitobacterium hafnocene strain PCE-S.

2007 - 2011 B.Sc. Biology at Georg-August-Universität Göttingen. Title of bachelor thesis: Aufreinigung, Fluoreszenz-Markierung und biophysikalische Studien über elF1A, elF5B, RPS17A und ihre Interaktionen mit der kleinen ribosomalen Untereinheit.

2005 - 2006 Dipl. Sociologies at Phillips-Universität Marburg.

$2004-2005$ Civilian Service at DKV Residenz am Tibusplatz (Münster).

1994 - $2004 \quad$ School Education at Alte Landesschule in Korbach 


\section{Scientific contribution}

Peer-reviewed publications

2017

Tarasenko, Daryna, Mariam Barbot, Daniel C Jans, Benjamin Kroppen,

Boguslawa Sadowski, Gudrun Heim, Wiebke Möbius, Stefan Jakobs, and Michael Meinecke. 2017. "The MICOS Component Mic60 Displays a Conserved Membrane-Bending Activity That Is Necessary for Normal Cristae Morphology." The Journal of Cell Biology 216 (4)

Gleisner, Martin, Benjamin Kroppen, Christian Fricke, Nelli Teske, Torben-Tobias Kliesch, Andreas Janshoff, Michael Meinecke, and Claudia Steinem. 2016. "Epsin N-Terminal Homology Domain (ENTH) Activity as a Function of Membrane Tension." Journal of Biological Chemistry, no. 5 Barbot, Mariam, Daniel C. Jans, Christian Schulz, Niels Denkert, Benjamin Kroppen, Michael Hoppert, Stefan Jakobs, and Michael Meinecke. 2015. "Mic10 Oligomerizes to Bend Mitochondrial Inner Membranes at Cristae Junctions." Cell Metabolism.

Selected poster presentations

International Symposium "Biological Dynamics from Microscopic to Mesoscopic Scales": Molecular Characterization of Membrane Deformation by ENTH Domains.

Evaluation of Collaborative Research Center 803 "Functionally controlled by organization in and between membranes" by the DFG. Project B09: Functional analysis of membrane remodeling by epsin 1 . 4th GGNB Science Day. Molecular Details of Membrane Deformation by ENTH Domains 